\title{
DESIGN FOUNDATIONS: TOWARDS A MODEL OF STYLE GRAMMAR IN CREATIVE DRAWING
}

BY

\section{JENNIE SWEO}

\author{
A thesis \\ Submitted to the Victoria University of Wellington \\ In fulfillment of the requirements for the degree of \\ Doctor of Philosophy
}

Victoria University of Wellington

(2017) 


\section{Abstract}

A style grammar is a principled rule set that governs the organization of very complex ideas. It allows for the examination of underlying structures which are often times obscured. Style grammars have been developed for many fields such as writing, fashion and architecture but to date there is no style grammar for creative drawing. The research identifies the necessary visual features and core traits associated with each feature towards developing such a model for creative drawings. Then operational measures are defined using the computer to extract and measure the core traits of those features towards developing a model of style grammar in drawing. These visual features include line, tone, and depth. Core traits include line length, line width, line expressiveness, local tone, global tone, texture, pattern, outline, shape, and position.

A multidimensional scaling (MDS) using input from 27 subjects, 10 art experts and 17 novices, supported the overall list of visual features and added the dimension of smudge to the list. A second MDS sort discusses issues with images and large art categorical sorts from the standpoint of both human perception and machine measures that were obtained using feature extraction. It was concluded from the results of the second MDS that large art categories were too broad to be useful in evaluating measures to develop the model.

Further analysis was run using only drawings from three artists, two impressionists to compare similarity and one expressionist for dissimilarity to determine if the machine measures of the core traits of the visual features were able to differentiate smaller groupings of consistent drawing styles. Using the computer allowed for systematic and objective procedures to be used to obtain measures. The multinomial logistic regression showed high significance for all the traits except marginal significance for line length and no significance for depth. Binomial logistic regressions run on each pair of artists showed high significance for all the traits except depth. 
The combined positive results of the first MDS card sort and the binomial and multinomial regression analysis provide proof of concept and offer strong support towards the development of a model of style grammar for creative drawings. Implications for teaching drawing using the identified visual features and core traits are offered. The outcomes and analysis provided in this research currently support a general practice rule in design reuse and intelligent borrowing that suggests first smudge, then depth, then tone, and then line quality are the most significant elements to use for style comparison. Discussions for future research including improved measures and other types of perception testing are provided towards further development of the model. 


\section{Acknowledgements}

There is an African proverb that states "It takes a village to raise a child.” I think it takes a village to raise a Ph.D., and I would like to take a moment to acknowledge my village. I am grateful to my committee Dr. Sydney Shep, Reader in Book History, Waiteata Press and Head of School of Design, Douglas Easterly for their support in helping me overcome the numerous obstacles I faced through my research.

I would like to thank the Design School Administration-Mailyn Webb, Bronwyn Knight, and Eli Feth for all their help in making sure I always had all my paperwork turned in on time, scheduling meetings, and most of all their friendship. I want to say thank you to Dr. Rhazes Spell and John Lewis for helping with my first steps on my research path.

I would like to say thank you to the people at Bridgeman Education for their assistance in supplying the images used in my research.

I would like to thank my friends, especially Dr. Sandy Pate and Dr. Shelley Gordon for their belief in me.

I would like to thank my mom, Fannie Mitchell-Villani whose memory I keep with me.

And finally, I want to thank my best-friend and husband for his limitless patience, kindness, support and sense of humor, Dr. Robert Sweo.

Here's to my village_ — past, present, and future! 


\section{Table of Contents}

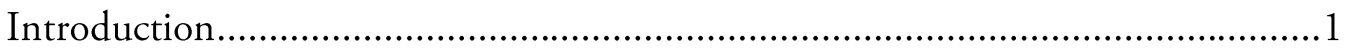

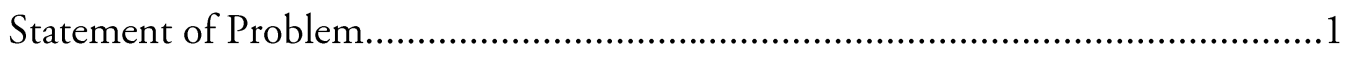

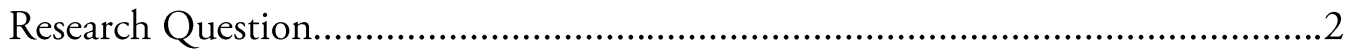

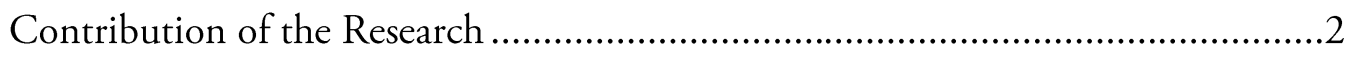

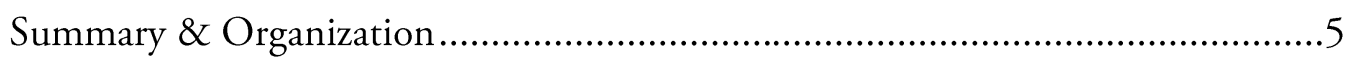

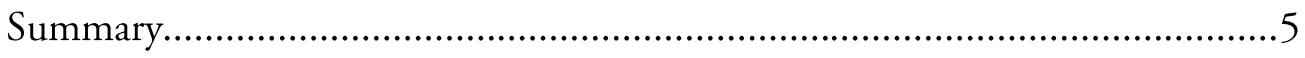

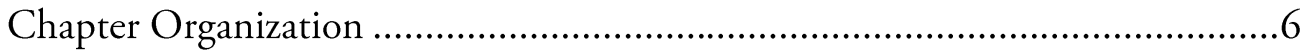

Chapter 2: Background ...........................................................................

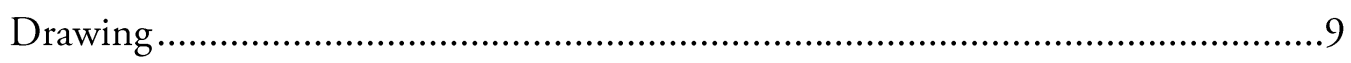

Drawing Types: Task-oriented \& Creative..................................................10

Drawing Technique vs. Art Style...............................................................16

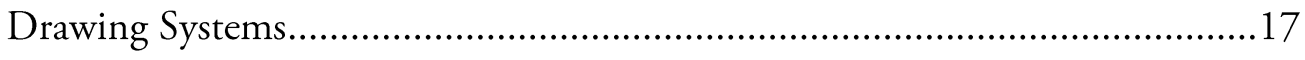

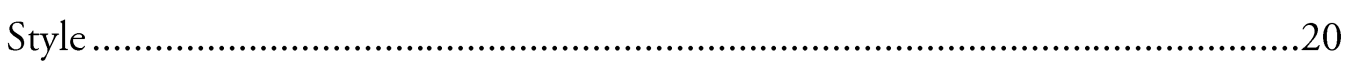

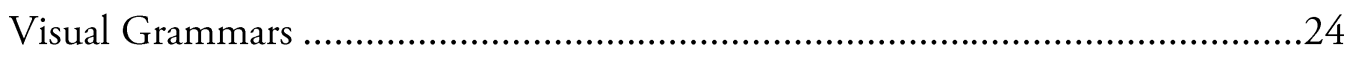

Chapter 3: Model Development....................................................................

Establishing a Set of Visual Features \& Core Traits........................................... 31

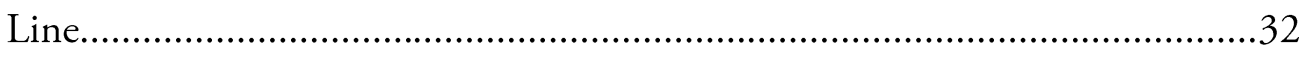

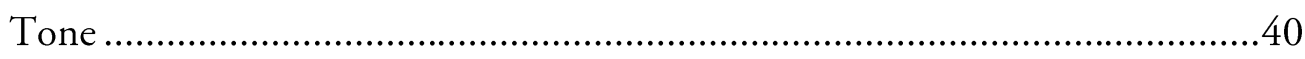

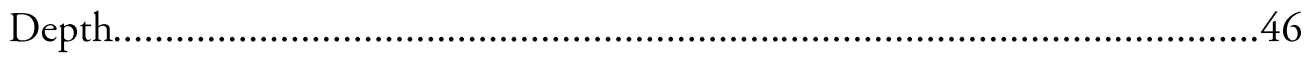

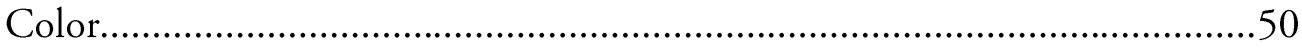

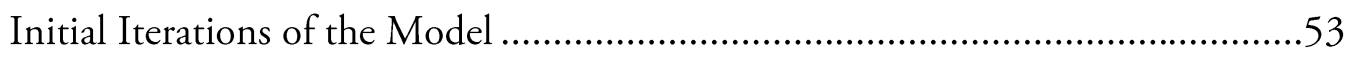

Implications of the Model on Teaching Drawing ...........................................56

Chapter 4: Testing the Model Phase 1..........................................................61 
Overview: Testing the Model

Ancillary Activities - Image Selection.......................................................61

Testing Human Perception of Visual Features...................................................64

The Identification of Test Subjects \& Protocols ....................................................66

Multidimensional Scaling Procedure Protocols..................................................70

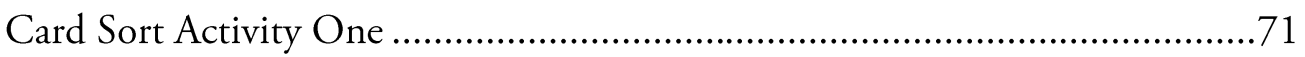

Data Analysis of the Card Sorts .................................................................. 72

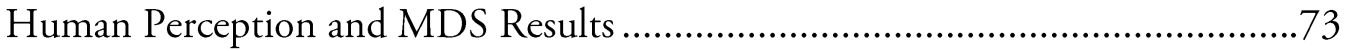

The Discovery of Smudge …........................................................................

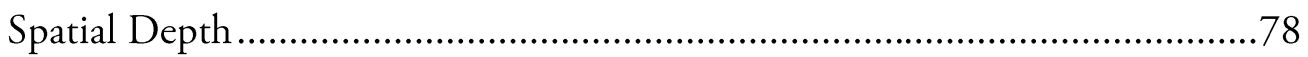

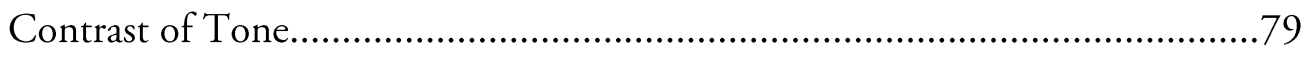

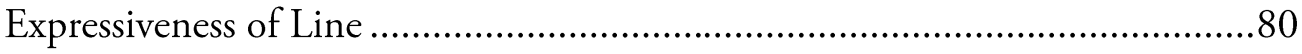

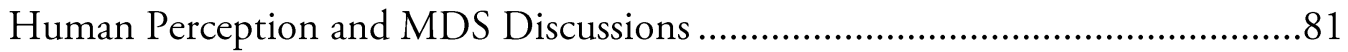

Chapter 5: Testing the Model Phase Two ........................................................83

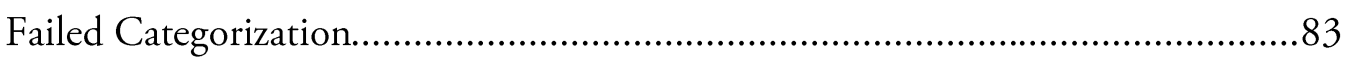

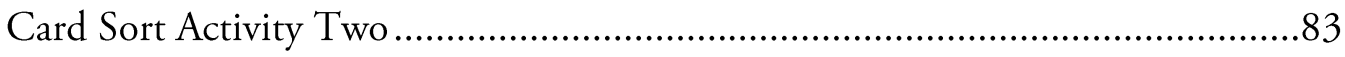

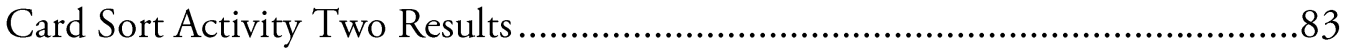

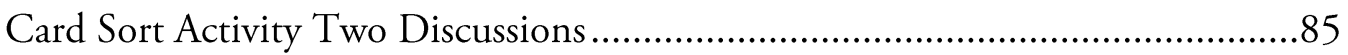

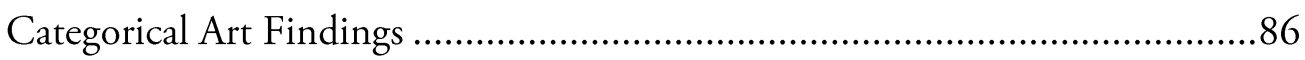

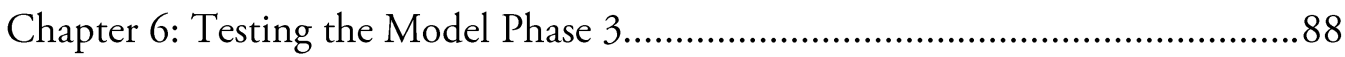

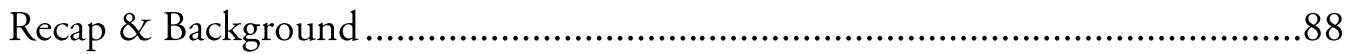

Devices, Tools \& Operators: An Historical Perspective ...................................89

The Computer, Tools \& Operators: A Modern Perspective ............................93

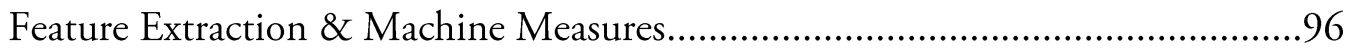




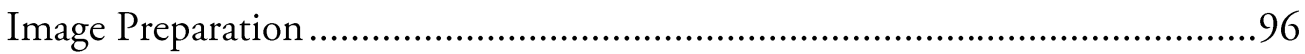

Initial Testing of Operational Measures …………………………………......97

Feature Extractions for Line ..................................................................98

Feature Extractions for Tone.....................................................................104

Feature Extraction for Depth ......................................................................107

Feature Extraction for Smudge ....................................................................108

Improved Image Categories...........................................................................110

Phase 3 Machine Measures Results.........................................................................111

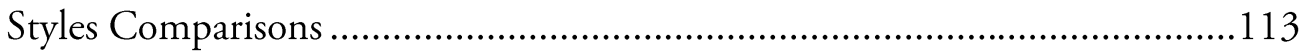

Phase 3 Machine Measures Discussions..............................................................118

Multinomial Logistic Regression Main Effects .................................................120

Predicted Classification of Images ................................................................121

Bivariate Logistic Regression Findings...........................................................122

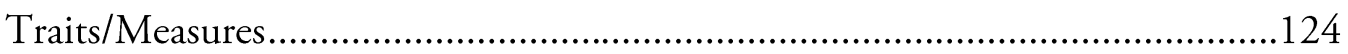

Smudge

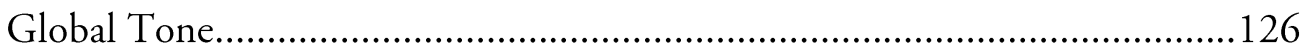

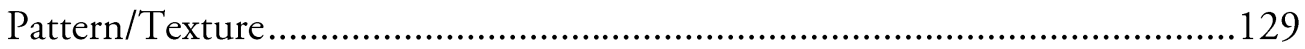

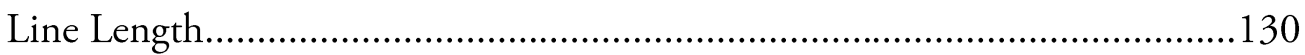

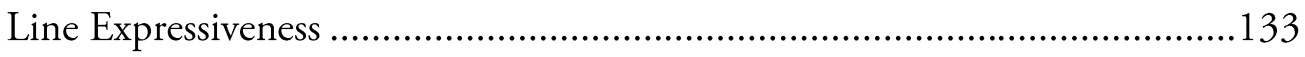

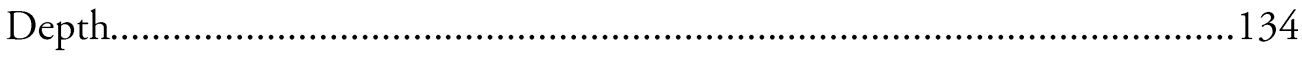

Chapter 7: The Overall Model.......................................................................135

Discussion of Combined Outcomes ...............................................................135

Visual Feature Analysis...........................................................................136

Understanding and Creating Styles ............................................................137 
The Interaction of Line

Chapter 8: Future Research

Visual Features \& Feature Extraction

Pattern/Texture.

Line Width

Color

Depth.

The Human Perception of Line \& Other Marks

A “Pleasantness" Test

Exciting Marks vs. Calming Marks.

Can Various Combinations of Line Affect Appetite?

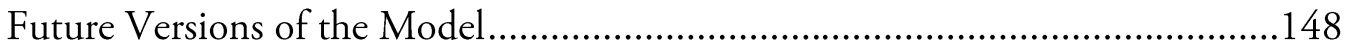

Culture \& Art Tradition Influences on the Model ........................................148

Other Uses of the Model in Teaching .........................................................149

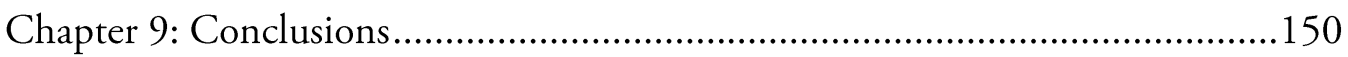

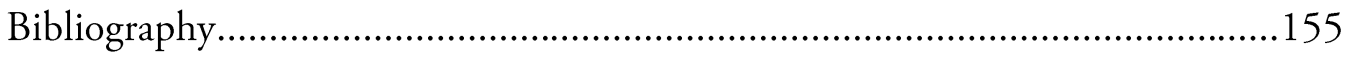

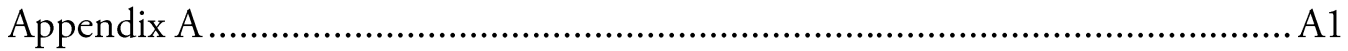

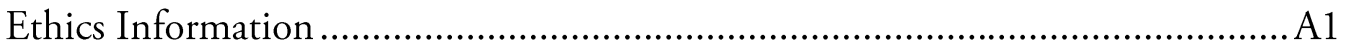

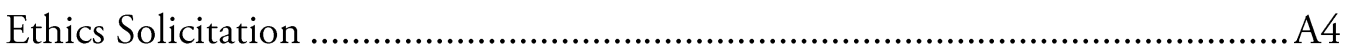

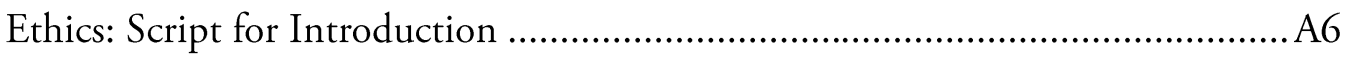

Ethics Participant Consent Form …............................................................ A9

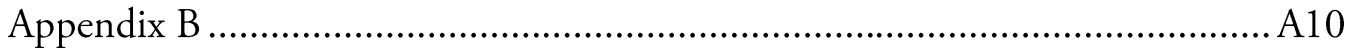

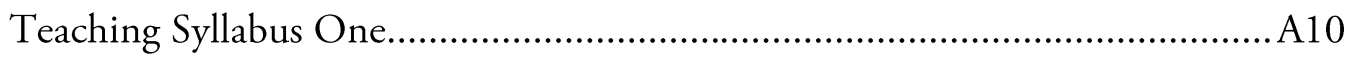

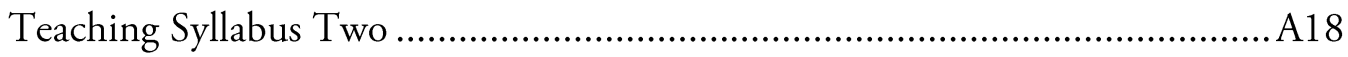


Teaching Syllabus Three

Appendix C

Developing a Multi-Modular Design Exercise Based on the Identification of

Visual Features

Module One: Line \& Word Pairings.

Module Two: Line \& Word Pairings ....

Module Three: The Creation of 30 Analogs.

Module Four: The Selection of Characters

Module Five: The Storyboard A58

Module Six Analysis and Evaluation. A61

Learning Outcomes of the Storyboard Project. A62

Appendix D A63

Correspondence Bridgeman Images A63

Appendix E A64

Additional MDS Plots Card Sort One. A64

Appendix F A66

MDS Card Sort One Results \& Dimensions A66

Appendix G. A73

Image Usage Logistic Regressions A73 


\section{List of Figures}

FIgURE 1: A VISUAL COMPARISON OF TWO DRAWING TYPES: A. TASK-ORIENTED AND

B. CREATIVE DRAWINGS. .4

Figure 2: A VISUAL OF APPROPRIATE LINE TYPES IN THE BOOK: “ARCHITECTURAL

GRAPHICS” BY FRANCIS CHING, 2015, P. 15.

FIGURE 3: A VISUAL COMPARISON OF THE INFLUENCE OF STANDARDS SET WITHIN TASK-ORIENTED DRAWINGS.

FIGURE 4: A VISUAL COMPARISON OF THE POSITION OF AN OBJECT BASED ON THE DRAWING SYSTEM USED.

FIGURE 5: A VISUAL THE USE OF LINEAR PERSPECTIVE IN WESTERN EUROPEAN ART TRADITION

FIgURE 6: A VISUAL COMPARISON OF A WORK BY PIET MONDRIAN SHOWING TRANSFORMATIONS OF A LINEAR PERSPECTIVE DRAWING SYSTEM AND A TYPICAL CHINESE SILK PAINTING USING ORTHOGRAPHIC PROJECTION.

FIgURE 7: A VISUAL DESCRIBING A PARTICULAR ORGANIZATION OF SPACE AND A SIMPLE SHAPE GRAMMAR USING TWO RULES, (BASED ON A GRAMMAR EXAMPLE

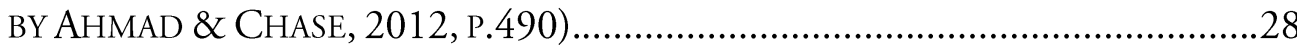

FIGURE 8: A VISUAL DEFINITION FOR LINE. LINE SAMPLE SEGMENTS. 34

FIGURE 9: A DETAIL VISUALIZATION OF A SECTION OF A DRAWING ILLUSTRATING HARD-EDGES AND THE PROBLEMATIC DETERMINATION OF LINE LENGTH........36

FigURE 10: A VISUALIZATION ILLUSTRATING ISSUES OF BLENDING AND THE PERCEPTION OF LINE-LENGTH.

FIGURE 11: A VISUALIZATION ILLUSTRATING THE CONCEPT OF LOST AND FOUND AND IMPLIED LINE IN AN ILLUSTRATED PIECE OF WORK. .38

FIGURE 12: A VISUALIZATION ILLUSTRATING THE CONCEPT OF LINE LENGTHWIDTH. WHEN DOES LINE STOP BEING LINE AND BECOMES A SHAPE? 39

FIGURE 13: A VISUAL DESCRIBING VARIOUS TYPES OF RHYTHM AND THEIR VISUAL EFFECT ON PATTERN. FROM LEFT TO RIGHT REGULAR RHYTHM, ALTERNATING 
RHYTHM, AND RANDOMNESS—THE LACK OF PATTERN. BASED ON DESIGN DISCUSSIONS BY ROSS (1904) (PP. 84-89).

FIGURE 14: A VISUAL COMPARISON OF A REGULAR RHYTHM AND A PROGRESSIVE RHYTHM. BASED ON DESIGN DISCUSSIONS BY ROSS (1904) (PP. 59-61)...........46

FIGURE 15: A VISUAL DESCRIBING JUXTAPOSITION...............................................46

Figure 16: A VISUAL DESCRIBING OUTLINE AND SHAPE—BOTH GEOMETRIC AND ORGANIC. BASED ON SHAPE DISCUSSIONS BY GOLDSTEIN (1977) (PP. 18-21)..48

FIGURE 17: A VISUAL DESCRIPTION OF POSITION AND THE ORGANIZATION OBJECTS

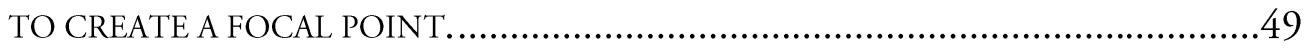

Figure 18: InITIAL DEVELOPMENT OF THE MODEL...........................................54

FIGURE 19: OTHER CONSIDERATIONS IN THE MODEL FOR CREATIVE DRAWINGS-

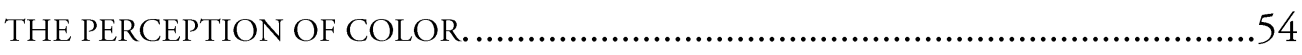

FIGURE 20: THE MODEL BEFORE DATA ANALYSIS OF THE MDS CARD SORT ACTIVITY.

Figure 21: AdDITIONAL MODIFICATIONS TO THE MODEL WITH THE IDENTIFICATION OF FEATURE EXTRACTION AND THE DEVELOPMENT OF OPERATIONAL PROCEDURES, AFTER THE ANALYSIS OF THE FIRST MDS FREE CARD SORT

FIGURE 22: A SAMPLE OF A DOWNLOADED FROM BRIDGEMAN’S EDUCATION WEBSITE IMAGE THUMBNAIL AND ASSOCIATED PDF FILE WITH BACKGROUND INFORMATION.

FIGURE 23: SAMPLE OF DATA CODING OF THE FIRST MDS CARD SORT ACTIVITY. ..72

FIGURE 24: THE COMPARISON OF MEASURES AND IMAGES SUGGESTING THE

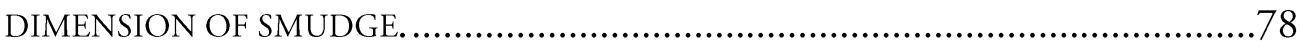

FigURE 25: THE PROGRESSION OF IMAGES SUGGESTING SPATIAL DEPTH.................79

FIGURE 26: THE COMPARISON OF IMAGES SUGGESTING THE DIMENSION OF GLOBAL TONE.

FIGURE 27: THE COMPARISON OF IMAGES SUGGESTING THE EXPRESSIVENESS OF LINE. 
FIGURE 28: EXAMPLE OF COORDINATE TRANSFORMATION TO MODIFY THE ORIGINAL DRAWN COLUMN IN THE MIDDLE .91

FIGURE 29: AN EXAMPLE OF A VISUALIZATION OF ARTIST'S DEFINITION OF LINE LENGTH.

Figure 30: A DETAIL VISUALIZATION OF A SECTION OF A DRAWING BY EGON SCHIELE ILLUSTRATING THE PROBLEMATIC DETERMINATION OF LINE LENGTH. .99

FIGURE 31: AN EXAMPLE OF A VISUALIZATION OF COMPUTER/PROGRAM DEFINITION OF LINE LENGTH. 100

FIGURE 32: AN EXAMPLE OF AN IMAGE CONVERSION TO GET MEASURES FOR LINE. THE IMAGE ON THE LEFT IS THE ORIGINAL RASTER IMAGE, THE IMAGE ON THE RIGHT HAS BEEN CONVERTED TO VECTOR DATA. 101

Figure 33: VISUALIZATION OF THE NUMBER OF POINTS NEEDED TO EXPRESS A LINE THAT IS MORE GESTURAL OR FREE FORMED VS. THE NUMBER OF POINTS NEEDED FOR A CONTROLLED LINE. 102

FIGURE 34: VISUALIZATION OF THE IMAGE TRACE PALETTE USED FOR THE IMAGE CONVERSION PROCESS USING ADOBE ILLUSTRATOR CS6.

FIGURE 35: VISUALIZATION OF GLOBAL TONE FOR AN IMAGE INCLUDING ITS HISTOGRAM. 105

FIGURE 36: VISUALIZATION OF A SELECTION USING EDGE DETECTION FOR A MEASURE OF LOCAL TONE FOR AN IMAGE INCLUDING ITS HISTOGRAM 106

FIGURE 37: COMPARISON OF THE HISTOGRAMS AND MEASURES FOR A MEASURE FOR LOCAL AND GLOBAL TONE. 106

Figure 38: VISUALIZATION OF A SYSTEMATIC MEASURE FOR DEPTH USING THE RULE OF THIRDS IN DRAWINGS USING A LINEAR PERSPECTIVE DRAWING SYSTEM....107 FigURE 39: A VISUALIZATION OF SMUDGE..... 109

FIGURE 40: A VISUALIZATION OF SMUDGE SELECTION AND MEASURE WITHIN PhOTOSHOP. .110 
FIGURE 41: LEFT: AN ATYPICAL DRAWING BY EGON SCHIELE COMPARED TO TWO TYPICAL DRAWINGS BY THE ARTIST ON THE RIGHT.

FIGURE 42: LEFT: AN ATYPICAL DRAWING BY VINCENT VAN GOGH COMPARED TO TWO TYPICAL DRAWINGS BY THE ARTIST ON THE RIGHT.

Figure 43: LEFT: MiSCLASSIFICATION OF A DRAWING BY SEURAT ON THE LEFT COMPARED TO 2 CORRECTLY CLASSIFIED DRAWINGS BY VAN GOGH ON THE RIGHT.

FIGURE 44: LEFT: MISCLASSIFICATION OF A DRAWING BY VAN GOGH ON THE LEFT COMPARED TO 2 CORRECTLY CLASSIFIED DRAWINGS BY SEURAT ON THE RIGHT.

FIGURE 45: THE DUALITY OF SMUDGE—DIRTY LINE AND TONAL QUALITY. 125

FIGURE 46: DIAGRAM INDICATING THE CURRENT STATE OF THE MODEL WITH GLOBAL TONE, SMUDGE, AND PATTERN/TEXTURE AS TRAITS OF THE VISUAL FEATURE-TONE 128

FIgURE 47: A GENERAL OVERVIEW OF DRAWINGS BY SEURAT (TOP) AND VAN GOGH (BOTTOM), FROM THE ANALYSIS OF MEASURES FOR VARIOUS FEATURES, THEY SHARE APPROACHES IN LINE LENGTH AND SMUDGE. 132

FIGURE 48: DiAGRAM INDICATING THE CURRENT STATE OF THE MODEL...............136

FIGURE 49: AN EXAMPLE OF A SYSTEMATIC EXPLORATION OF LINE.......................140

FIGURE 50: A DRAWING SAMPLE SHOWING THE EMPHASIS AND DE-EMPHASIS OF EDGE

FIGURE 51: THE VALIDATION OF TRAITS VIA THE MDS FREE CARD SORT.

FIGURE 52: THE CURRENT STATE OF THE MODEL WITH MEASURES FOR VISUAL FEATURES IDENTIFIED. DEPTH IS SHOWN BOXED, INDICATING THE VISUAL FEATURE IS IDENTIFIED BUT THERE ARE ISSUES WITH THE CURRENT MEASURE OBTAINED FOR THIS VISUAL FEATURE 


\section{List of Tables}

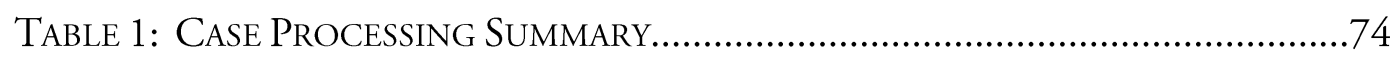

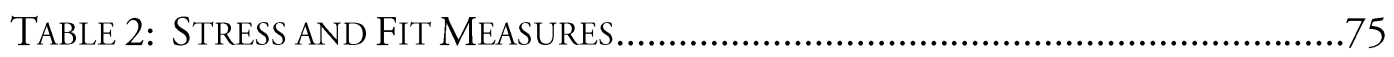

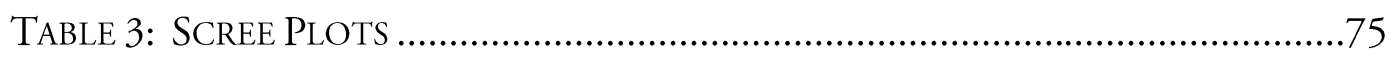

TABLE 4: ART EXPERT Group CATEGORICAL SORT …..............................................8

TABle 5: ArT Novice Group CATEGORICAL SORT ............................................84

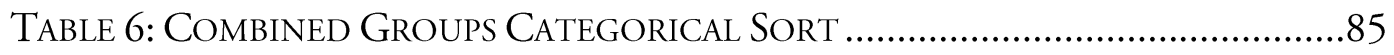

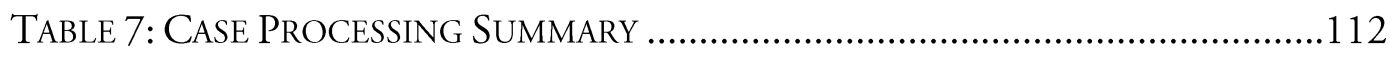

TABLE 8: LIKELIHOOD RATIO TESTS ...................................................................112

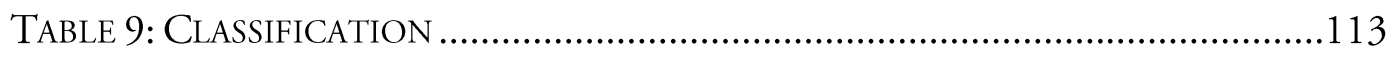

Table 10: Means \& Standard Deviations for Each Feature Comparison

AMONG THE THREE ARTISTS (NORMALIZED LINE LENGTHS) .......................113

TABLE 11: ES vS GS OMNIBUS TESTS OF MODEL COEFFICIENTS .............................114

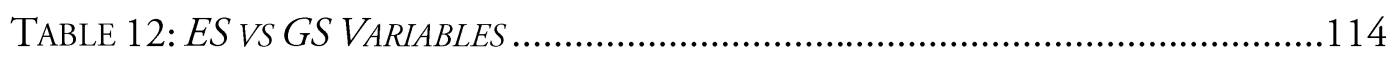

TABLE 13: ES vS GS Classification TABLES …................................................115

TABle 14: ES vs VG OMnibus Tests of Model CoefFicients ..........................115

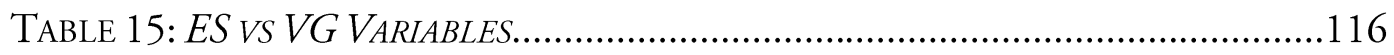

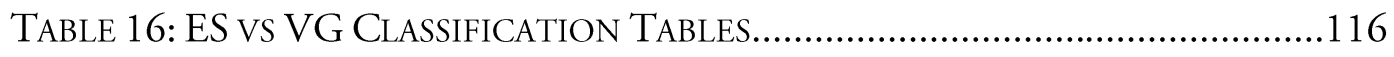

TABle 17: GS vs VG OMnibus Tests of Model CoefFicients..........................117

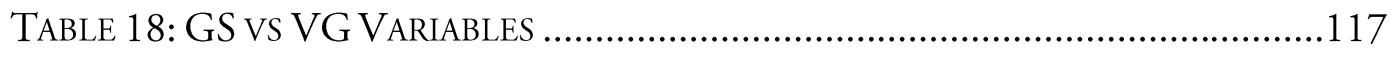

TABLE 19: GS vS VG ClasSification TABLE ..................................................118 


\section{Introduction}

\section{Statement of Problem}

One of the ways we learn to draw is through borrowing from similar drawings, pictures, designs and other made objects. Yet very little is known about the processes of borrowing. Developing a system that promotes intelligent borrowing can provide insight to the questions: what makes a drawing look a particular way to the viewer? Or what features need to be presented in a particular way to capture an essence of a thing?

Clive Ashwin (2016) stated that the essence of drawing resides in the articulation of planar space. I suggest that a central aspect to this type of articulation is the use of recurring organizational patterns and elements-perceived global impressions_ - or a drawing style. Psychology researchers working within the field of human perception such as Hartley and Homa (1981) have stated: "Styles are the perceived global impressions we retain after encountering various instances of an artist's work" (p. 33). Similarly, the art historian Margaret Finch (1974), wrote: "Style is any factor pertaining to form, matter, or meaning, which is sufficiently constant in a group of art works to establish a relationship among the works" (p. 4).

A drawing style can be examined as an artist's own formulated system to assist with their creation of art. These styles provide viewers with clusters of similarities that they understand in a particular way. They provide viewers a level of comfort and knowledge about what they are seeing in a drawing. But what visual features are critical to a style? How do we decide two pictures are similar enough for shared understandings? How do we teach students what to copy when trying to convey a style? There is a great amount of subjectivity and vagueness in the articulation of these processes towards the perception of style (Agrawala, Li, \& Berthouzoz, 2011; Buchanan, 1992; Lidwell, Holden, \& Butler, 2010). 


\section{Research Question}

A process for identifying key elements that make up a drawing style such as a visual grammar would make it much easier to teach drawing students how to borrow critical elements from a style. It would also help viewers of a drawing better understand their reactions to certain visual features. It may even improve the techniques for grouping drawings into style categories. These are the motivations behind this research towards developing a model of style grammar in creative drawing.

Even though drawings are the core of most designs, there is not yet a model of the traits that define a creative drawing style grammar. This research examines the steps necessary to build such a model towards answering the question: "What creates style in creative drawings?" More specifically the research question attempts to derive a model of style grammar that explains how style is created through a drawing process in creative drawings. Therefore the research question is:

\section{What are the visual features and their associated core traits that make up a model for style grammar for creative drawing?}

\section{Contribution of the Research}

Identifying visual features and defining extraction procedures to obtain measures for analysis are the first steps towards a model of style grammar for creative drawing. These steps of identification, definition and measurement allow for a discussion of drawing processes, the relationships between various features and promote understanding towards design reuse and intelligent borrowing. Because a style grammar is a principled rule set it allows for these things to happen within a formulated system that is objective, clear and systematic rather than subjective and vague. 
Creative drawings, which are the focus of this research, are defined as a type of visual communication that expresses spatial thinking-flat, abstract or realistic (Kasprisin and Pettinari, 1995). Additionally, this type of communication does not require a specific purpose to be stated outside of an artist's own intent (Hertzmann, 2010). The undefined nature of intent does not assume an artist is not aware of the concept of style or of grammar but any articulation of either can be vague and developed at a subconscious level (Kohut, 1957; Ehrenzweig, 1953, 1975).

Figure 1 shows an architectural drawing, specimen A, a type of task-oriented drawing which is discussed further on page 10 , that because of its nature demonstrates a rule set that is articulated on a conscious level. The rules used in this type of drawing allow for changes and modifications to be made that communicate specific information between viewer and artist. Figure 1 also shows an example of a creative drawing, specimen $B$, which because of its nature allows for a different type of dialog between a viewer and the artist. It is easy to imagine the dialog would be less about precise measures and specific materials and more of an interpretation of feelings.

It is also much harder in the creative drawing example to determine what changes and modifications would need to be done to affect a specific change in its interpretation. This is the advantage of a style grammar. It allows for a formalized and theoretical exploration and examination that provides a conscious articulation of rules for a creative drawing practice. Making the concept of a style grammar directly comparable to the formal and theoretical structure color theory provides within art education. 


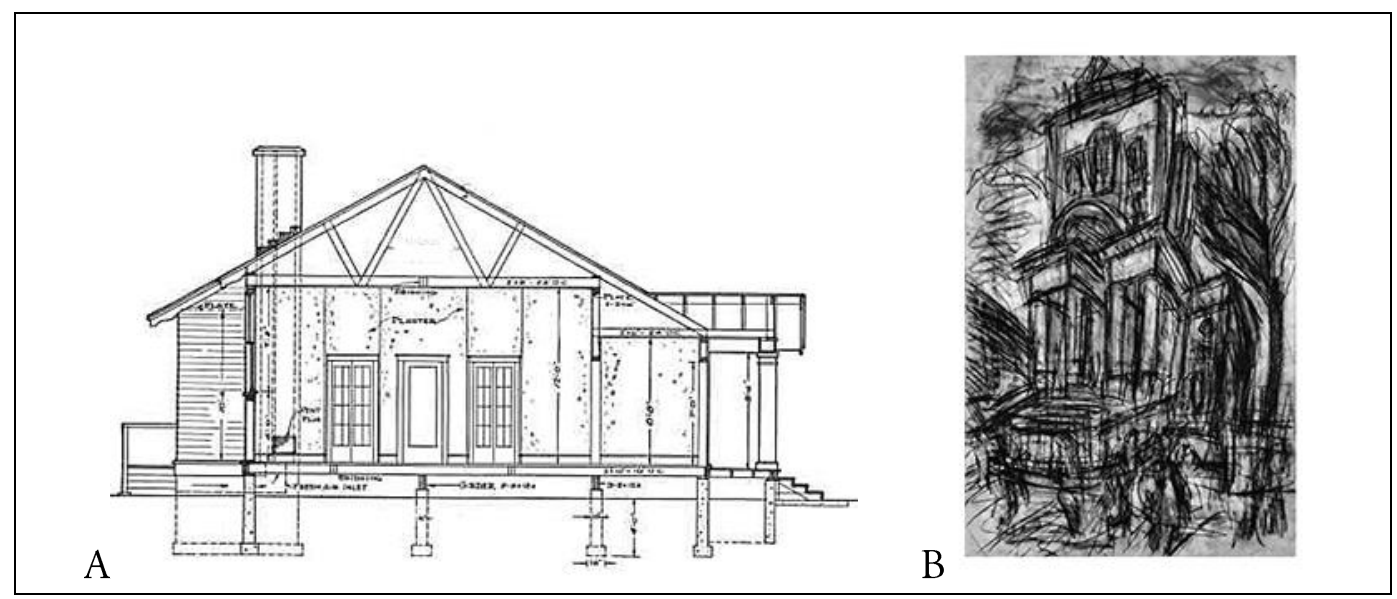

Figure 1: A visual comparison of two drawing types: $A$. Task-oriented and B. Creative drawings.

A. Unknown. (2016), Elevation Plan, website Homeplans.com: http://www.homeplans.com [Accessed: February 2016].

B. Leon Kossoff. (1990). Christchurch, Spitalfields No. 2, (charcoal on paper). Yale Center for British Art, New Haven, USA/Friends of British Art Fund, Bridgeman Education.

For beginning art students being able to identify various features in a drawing and test them by changing them quickly and repeatedly can be a very powerful learning technique. Students can create and evaluate relationships of core traits to help them build knowledge about the effects of changes on various properties. Exploring drawings through this type of model can assist with the generation of new skills and understanding of tools and materials (Ingold, 2009).

Defining the properties of visual features and their associated core traits, assists with stating assumptions so they can be studied in detail and guide data collection and analysis (Box, 1979, Kotler, 1971, Williams, 2013). Understanding visual elements and core traits of a drawing permits specific visualizations—graphical examples that can be used for style comparison when drawing (Garlan, 1995; Hertzmann, 2010). Specific visualizations can also be used to aid, automate, or augment design processes with computational support.

Applying specific visualizations afforded by the identification of visual features and core traits within the model allows for a different approach to grouping artworks together. It allows for a different approach to categorization. The use of the 
model and visual analysis can group creative drawings through use of similar visual features rather than a cultural or art historical context.

Many artists through history have formulated their own design systems to assist with the creation of art based on the "ideal" (Kleiner, 2013) whether it be for a drawn representation of space, human figure, or some other object. However, rule sets developed on the "ideal" are very subjective, vague and problematic. My research examines a more objective approach to developing a rule system that can assist with examining multiple drawing styles and how to borrow from them. Several artists using mathematical approaches to assist with visual understanding have developed shape grammars (Lauzzana \& Pocock-Williams, 1988; Martino, 2010; Ozkar \& Stiny, 2009) as a computational approach to developing objective rule systems. This research could allow a similar approach for creative drawings.

\section{Summary \& Organization}

\section{Summary}

By definition, a grammar is a principled rule set that governs the usage of elements within it. To develop a rule set of the elements - as they are termed in this research visual features, core traits or marks made as pertaining to the act of drawing, they must be clearly defined. To use the computer to evaluate measures based on the extraction of these features and traits, they must also be clearly defined in a way convenient for the computer. Since this type of model of visual style grammar does not currently exist in creative drawings a large part of this research deals with identifying, defining and evaluating visual features and building towards a model of style grammar in creative drawing.

Several researchers have begun to formalize similar systems for measuring and evaluating towards the development of style grammars in other areas of design. For example, within textiles and fashion design there is a research stream focusing on an integrated approach to fashion flat sketches classification for garment style queries 
(An \& Li, 2014). This research builds from earlier work on developing methods of shape grammars, feature extraction and objective evaluation of fabric pilling (Deng, Wang, \& Wang, 2011).

Using a similar approach, in my research I will identify and define visual features and their core traits. These features and traits will then be extracted from a set of creative drawings. Measures will be obtained for objective evaluation and tests of validity towards the development of a rule set. Using a modeling approach to the research gives organization to the analysis of traits and visual (Andrew, 2011; Epstein, 2008; Garlan, 1995). There are four main objectives to working with a model in this way:

1) Explanation

The model provides a robust vocabulary of the visual features for a drawing type, identified as creative drawings. The vocabulary is descriptive of noncomputational hand-made marks, as well as computational mark-making.

2) Segmentation

A combination of computational and non-computational visual feature descriptors assists with the second goal of parsing a drawn image.

3) Measurement \& Prediction

Measures obtained from the parsed image were used as predictors for the fourth objective.

4) Testing

Testing the measures obtained determines how accurately the model reflects reality through the visual features and the measures. The accuracy of the reflection validates the model and the strength of the measures.

\section{Chapter Organization}

Chapter 2: Background, supplies an overall view of drawings. It identifies and defines creative drawings. The concepts of realism, abstraction, and abstract as they pertain to the rendering of creative drawings are examined as a type of organization 
through categorization. Projection or drawing systems are examined and how they contribute to the organization of mark making is reviewed. Finally, the concept of style and other types of visual grammars are discussed.

Chapter 3: Model Development, provides a scope of the model itself as it is being developed. It provides the initial identification of the visual features and their definitions. It represents a timeline of development in this research through its various iterations. Implications of the model and the identification of visual features and core traits towards the practice of teaching drawing and design are discussed. This chapter concludes with a discussion of the overall approach to testing and validating the visual features and core traits.

Chapters 4: Phase 1 Testing the Model, examines the model development and the testing of visual features through human perception. I discuss the use of psychological procedures, techniques and analysis, specifically card sorts and multidimensional scaling (MDS). The free card sort procedure used in this research is described. A report of results is provided with discussions of the implications of findings towards the model development.

Chapter 5: Phase 2 Testing the Model, again examines testing and human perception but this time it is through a MDS categorical card sort. A report of results is provided with discussions of the implications of findings towards the model development.

Chapter 6: Phase 3 Testing the Model, describes testing and validating the visual features and their respective core traits through feature extraction and measures obtained through the use of the computer. This chapter begins with the examination of historical precedents of the use of machines to aid in visual perception of drawing up to the use of the computer. I continue with the addition of machine operations used to define each of the core traits for feature extraction and measurement. The discussion continues with an overview of the types of statistical analysis used to 
evaluate and validate each measure. This chapter concludes with a report of results and discusses the implications of findings towards the model development.

Chapter 7: The Overall Model, reviews the current state of the model.

Combining the results of human perception testing and analysis of the computer measures, I discuss the overall implications of findings and results towards the model development. Included in this discussion is an analysis of visual features and their impact on understanding style. The interaction of lines and other types of marks made and the beginnings of a rule set are examined with further implications towards teaching drawing.

Chapter 8: Future Research, visual features are reviewed and discussed towards future avenues of exploration to improve machine operations and feature extraction techniques to gain better measures. I explore other types of psychological procedures, techniques and analysis that can be used to further develop the model. I conclude with a brief discussion of other types of models that can be developed using various projection systems and influences upon teaching drawing.

Finally, in Chapter 9: Conclusions, the visual features and core traits identified are discussed and the current model is reviewed. 


\section{Chapter 2: Background}

\section{Drawing}

Drawing is the act of mark making on a surface (Goldstein, 1977; Hale, 2009; Ward, 2008). It is the visual documentation of imagery rendered in graphic form (Hale, 2009). Laing and Masoodian (2016) speaking further on the nature of graphics and design state the necessity for the production of visuals for communication of which a drawing is that end product. E. Beaudoin (2014) states the importance of visual imagery with the example of drawings as a facilitator of both inter-personal and intra-personal communication. To further stress this point of drawing as a form of communication Kasprisin and Pettinari (1995) state:

"Drawing is a way of speaking, a versatile language for spatial thinking that enables the designer to represent structure and organize an idea” (p. xiii).

The Grove Encyclopedia of Materials and Techniques in Art, Ward (2008) defines drawing as:

Drawing refers both to the act of marking lines on a surface and to the product of such manual work. Whether it is summary or complete, a drawing is defined less by its degree of finish or support than by its media and formal vocabulary. Manipulating line, form, value and texture, with an emphasis on line and value rather than color, drawing has been employed since ancient times for both aesthetic and practical purposes (http://www.oxfordartonline.com).

In the process of the general drawing review, subclasses of drawing types were uncovered. Further investigation of these subclasses could assist with developing a more specific definition for drawing to use in the model development. An examination of these subclasses could also assist with the identification and description of more specific visual features and core traits. This line of investigation could eventually lead to a form of encoding of the identified visual features and core 
traits for later use. One of these subclasses or drawing types identified and used in this research was creative drawing.

Another investigation was underway to determine what distinguishes creative drawings from other types of drawings as well as other forms of media.

\section{Drawing Types: Task-oriented \& Creative}

Aaron Hertzmann (2010) in his research on Non-Photorealistic Rendering (NPR) examined how artists create imagery and how observers respond to that imagery. Hertzmann in his article, Non-photorealistic Rendering and the Science of Art, discussed the need for both quantitative and qualitative analysis of art processes. $\mathrm{He}$ generally described the rendering goals of NPR algorithms as fitting into one of two categories:

(1) Task-oriented rendering-there is specific information to be visualized and communicated; and

(2) Creative or Artistic rendering-does not necessarily have a specific purpose outside of some artistic intent. (Hertzmann, 2010, p. 149).

It was important to review what was meant by task-oriented rendering to gain an appreciation of how this type of rendering or drawing differed from a creative or artistic drawing. The knowledge gained would assist in setting a parameter around what to include and exclude in an examination of creative drawings.

The term task-oriented rendering as it applies to drawings in this research is a broad categorization that includes technical drawings but also describes information graphics, logo, identity design, just about any type of drawing where there is an imposed limitation upon the execution of imagery with which an artist might have to contend (Hertzmann, 2010; Ward, 2008) (Figure 1).

This segmentation of drawings was helpful to the model development. It provided sources of generally agreed upon definitions (technical drawings) and sources of various types of expressions of style for exploration (creative drawings). To 
further explain this concept of technical drawings and why in this research they are being treated separately from creative drawings I refer to Sillitoe (2014) who explains:

In their original contexts - predominantly engineering and architecture-technical drawings were created as information artifacts that acted as authentic and reliable surrogates for physical artifacts. Their purpose was to communicate the information that was required to create, operate, maintain, or record such physical artifacts. Technical drawings graphically represented that information more concisely and coherently than was possible through a textural description-literally, "a picture tells a thousand words". Often, technical drawings were to be acted upon in circumstances remote from their time and place of creation. They were therefore necessarily drafted to act as clear and unambiguous documents. Technical drawings could be reasonably considered, therefore, to be reliable records_-accurate representations of the facts to which they attested (pp. 126-127).

This can be regarded as a conscious effort to constrain the act of drawing, so that certain types of marks are not even attempted, being inappropriate to the task (Ching, 2010; Guptill, 1976; Lohan, 1978; Watson, 1985). This constraint is further demonstrated by Ching (2015) in his book on graphical information used in architectural drawing as he discusses drawn line types and the specific information that is conveyed by each line type (Figure 2).

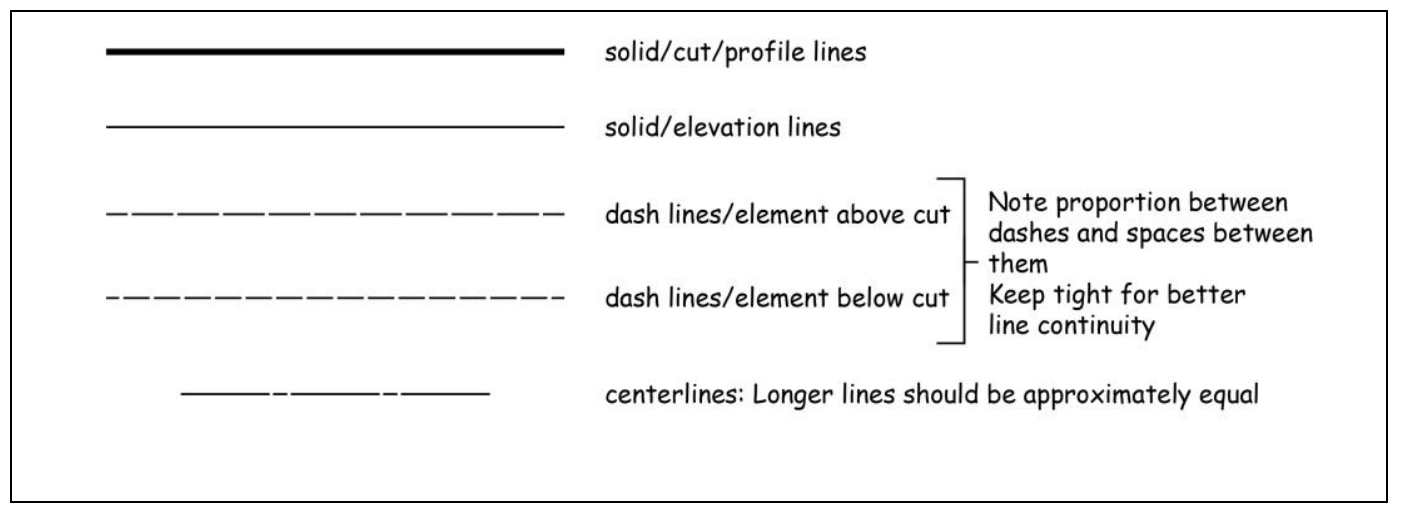

Figure 2: A visual of appropriate line types in the book: "Architectural Graphics" by Francis Ching, 2015, p. 15. 
Ching (2015), goes on to explain:

The basis for most architectural drawing is the line, and the essence of a line is its continuity. In a pure-line drawing, the architectural information conveyed (volumetric space; definition of planar elements, solids, and voids; depth) depends primarily on discernable differences in the visual weight of the line types used ( $\mathrm{p}$. 14).

Figure 2 demonstrates the idea of a general system of rules that encompass a very wide range of topical, temporal, and geographical variations that exist globally. These rules were adopted from British Standards for technical information and are universally accepted within the Rules for Archival Description known as RAD (Bearman \& Duff, 1996; Duff, 1999; Haworth, 1992; McKemmish, 1994; Sillitoe, 2014).

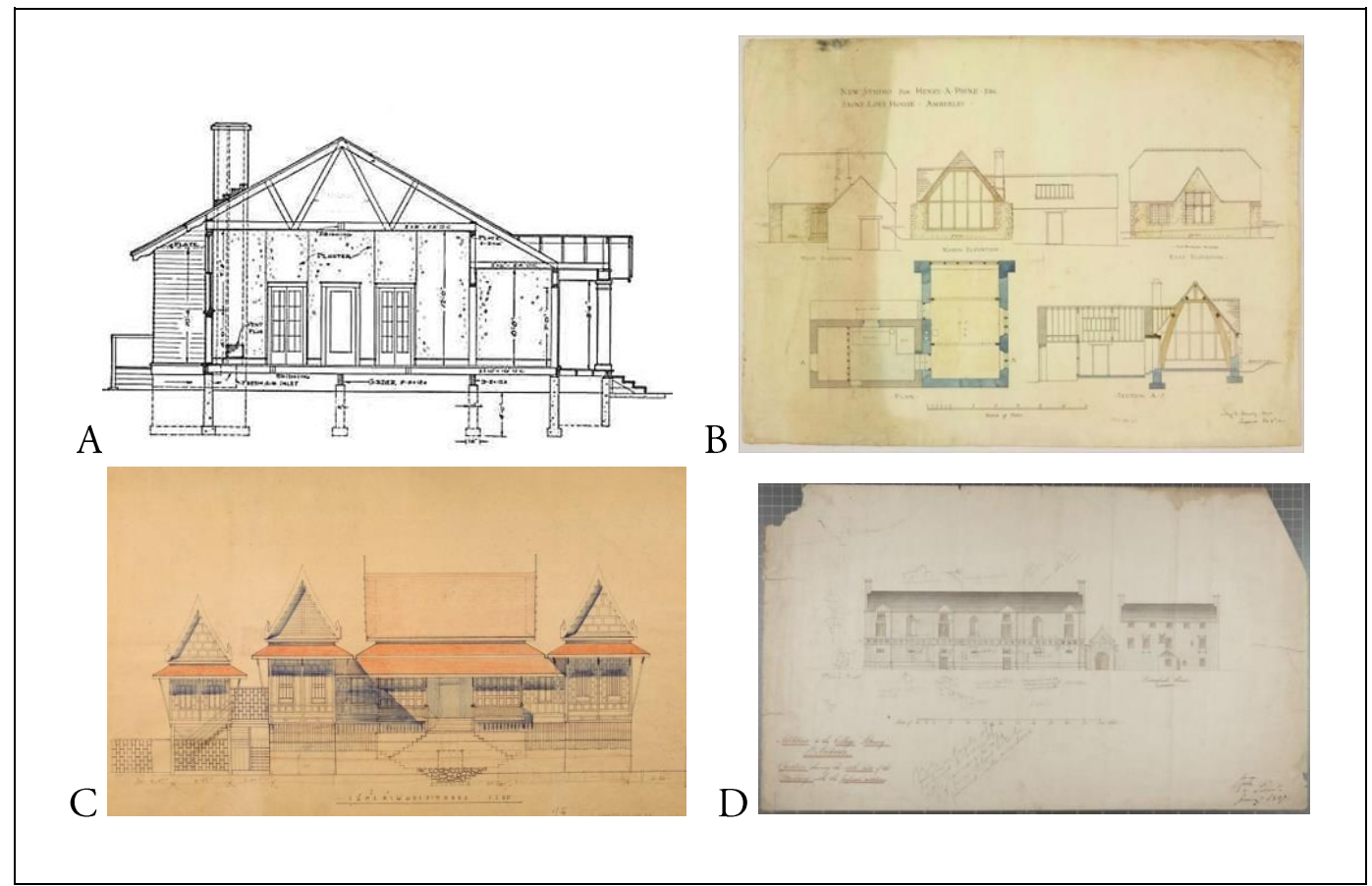

Figure 3: A visual comparison of the influence of standards set within task-oriented drawings.

A. Unknown. (2016), Elevation Plan, website Homeplans.com: http://www.homeplans.com [Accessed: February 2016].

B. Sidney Barnsley. (1911). New Studio for Henry A. Payne Esq. Saint Loes House, Amberley, (w/c on paper). (C) The Cheltenham Trust and Cheltenham Borough/Bridgeman Education.

C. Thai School. (20 $0^{\text {th }}$ Century). Original architectural drawing for Jim Thompson House, (pen, ink and pencil on paper). Jim Thompson House, Bangkok, Thailand/ Photo (C) Luca Tettoni/Bridgeman Education.

D. Robert Reid. (1827). Architectural drawing of the University Library, (pencil \& w/c on paper). The University of St. Andrews, Scotland, UK/Bridgeman Education. 
Looking at the variety of structures conveyed by Figure 3 this concept of standards has a great influence over the drawing process itself. The first drawing (A) is an elevation plan for a typical modern contemporary house which can be bought through a variety of internet sites such as http://www.homeplans.com. The other three elevation drawings show a variety of sources. While all four drawings are of very different buildings from different times and locations it takes very little in the way of assumptions to think that any one of these drawings could be handed to a builder today to work from with very little problem in the way of comprehension of the structure. A great part of the continued visual understanding communicated from these samples can be attributed to a standardized system of rules that is still in use today. This type of rule system does not exist to this extent, effecting the ideation of imagery within the realm of creative drawings.

Ross (1904) in his book, $A$ Theory of Pure Design, is a bit more general in stating there are two modes of drawing: one being pure design, and the other representational. The distinction Ross makes between the two is that pure design is rather meaningless beyond the idea of pure design, or design for design's sake. The use of design in representation means order and an arrangement of meanings. Ross goes on to state:

Truth of Representation in a form of expression which will be simple, clear, reasonable, and consistent, as well as true. The attention must be directed to what is important, away from what is unimportant. Objects, people, and things represented must be brought out and emphasized or suppressed and subordinated, according to the Idea or Truth, which the artist wishes to express. The irrelevant must be eliminated. The inconsistent and the incongruous must be avoided. That is what I mean by Design in Representation, the knowledge of Nature and Life presented in a systematic, logical, and orderly way (pp. 7-8).

The Grove Encyclopedia of Materials \& Techniques in Art, states that the completeness of a drawing is less important than the formal vocabulary used within the drawing to define it. This assessment of the "state of a drawing" is in agreement 
with others, like Roger Fry a well-known British art critic and painter, who published many art-related essays, and stated this in 1918:

... With both Gauguin and Van Gogh linear drawing becomes more important and even at times a complete expression, but it is not till we come to the artists of the present generation that drawing is used in an entirely new manner prompted by the new conception of what is implied in the artist's vision. It is in the work of Henri Matisse and Pablo Picasso that we find these principles dominating their linear designs, and both of them use drawing as an independent and compete statement of an artistic idea. . . Matisse practices two more or less distinct manners (of drawing). In one case, complex vision is recorded in a few lines which have the appearance of being, as it were, scribbled with great rapidity and extreme freedom. In the second case, the lines are forced into a scheme of extreme simplicity. Merely to distinguish these methods (not to define them) we may call them respectively calligraphic and structural (p. 202).

This suggests that creative drawings do not have to be in a completed state or "formally presented." Allowing for the consideration of sketches from sketchbooks and other types of drawings in progress into the model.

The distinction being made between task-oriented drawings and creative drawings is in the difference of universal rule sets which have been generally adopted by artists working with task-oriented drawings. Examining these rules because of their universal nature assisted with defining visual features of drawing and routes to explore when encoding.

Creative drawings by general comparison contain a variety of approaches to form. The role of drawing is continually being redefined and expanded with a variety of non-traditional artistic media making definitions and rule sets a challenge to develop (Artists on Art. From the XIV to the XX century, 1958; Campbell, 2011; Chu, 2003; Janson, 2001; Leavitt, 1976; Matisse \& Flam, 1995; Ward, 2008). However, once developed the model can prove to be a very useful and important tool for artists, designers, art teachers, as well as art students to examine and explore drawings through examination and comparison of visual features. 


\section{Categories of Creative Drawings}

Many researchers in art and aesthetics make use of the term 'art category' as a convenient way to explain the artistic qualities of artworks as well as content (Bullot \& Reber, 2013; Carroll, Moore, \& Seeley, 2012; Levinson, 1992; Seeley, 2013; Walton, 1970). Seeley (2013) has this to say about art categories:

Roughly speaking categories of art are defined by loosely unified formal-compositional vocabularies, productive strategies, and evaluative conventions associated with the works of individual artists, schools, or historical periods. The assumption is that categories of art play a constitutive role in our engagement with artworks that is analogous to the role knowledge of the structure and function of object and event types plays in ordinary perceptual contexts (p. 451).

The usage of art categories within the context of this research was for a general overview. This overview aided in the organization of large sets of visual data in the form of creative drawings. Art categories were examined as a way to employ a general rule set to examine large groups of creative drawings in a comprehensible manner. Art categories allowed a way to group creative drawings into small sets. Creative drawings and image creation were divided into three categories, the definitions of which were based on art historical reference materials (Chu, 2003; Janson, 2001; Krukowski; Moszynska; Rubin):

(1) Realism-imagery looks very much like it appears in real life, from Grove Art, Rubin (2016) gives this definition: to create objective representations of the external world.

(2) Abstraction—a reduction of realism but not abstract, from Grove Art, Krukowski (2016) gives this definition: only some of the visual elements usually ascribed to 'the natural world' are extracted.

(3) Abstract-imagery is intentionally non-representational, from Grove Art, Moszynska (2016) gives this denfinition: having no start or finishing point in nature. 


\section{A Summary of Creative Drawings}

Creative drawings unlike task-oriented drawings allowed for the consideration of different approaches to line and other types of marks without specific concerns of illustrating a mechanical function or the replication of specific imagery towards realism. Because of the variety of line and other types of marks within creative drawings a comprehensive understanding of composition and organization was needed. Art categories were examined. This examination revealed three issues of optical inconsistency that needed to be dealt with-the use of a projection or drawing system, the use of color and the use of tool/technique vs. style. Each issue is addressed. Tool/technique is discussed below followed by drawing systems (p. 17). Color is discussed later in chapter three (p. 50).

\section{Drawing Technique vs. Art Style}

An important distinction between comparison of an artist's style versus technique lies within the visual analysis of line and the traits of line as they are defined by an artist, versus the way a line looks because of a particular drawing implement. For instance, comparing the fineness of a line made via metal-point to the coarseness of a line made via charcoal and associating the technique of metal-point with one artist's style and the technique of charcoal with another would be erroneous. Artists employ a variety of techniques when drawing. While it is possible to categorize line and drawings by the way they look because of technique via tool implementation, this research seeks to understand the influence of an artist's style upon line and other visual features of drawing. Style in regards to tool and technique and how this issue is approached is explained in, Gardner's Art Through The Ages: The Western Perspective:

“... style can be defined as those qualities of line, texture, and composition which characterize a range of works by the same artist and which remain discernable regardless of subject, dominant colors, size or medium.” (pp. 3-4).

It was important to examine what effect tool and technique might have on the model. A constraint on tool, through this review, was unnecessary in the 
development of the model. The model's purpose is to identify and explain many different types of mark making within the sphere of creative drawings not to limit that descriptive process. The model would be descriptive of the correlations between many different types of marks and line rather than specific tool.

\section{Drawing Systems}

It was determined though general observation that similar line traits are used by artists, regardless of imagery. It was also determined through general observation that there is a general preference for the organization of particular types of marks through a projection or drawing system. The model's purpose is to identify and explain many different types of mark making within the sphere of creative drawings. Selecting a projection system would give organization without limiting the type of imagery.

Drawing systems translate the spatial relationship between objects from a three-dimensional space on to a flat surface (Dubery \& Willats, 1972, 1983; Goldstein, 1977; Hale, 2009; Lambert, 1984; Ward, 2008; Willats, 1997). Drawing systems are the underlying rule system that artists use to organize line (Figure 4). Dubery and Willats (1972) state:

Drawings can be placed into one of four categories depending on the translation of the objects onto the two-dimensional picture plane by the system used: objects will either appear to diverge, converge, run parallel or have characteristics that are a combination of systems (p. 10). 


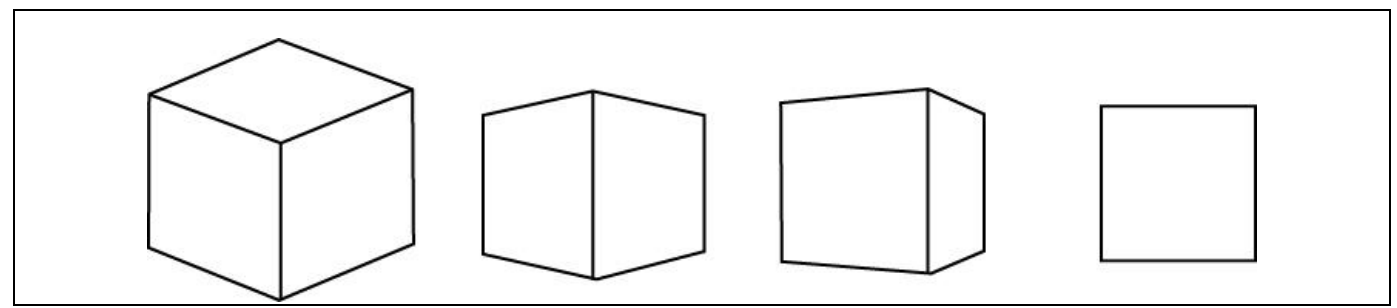

Figure 4: A visual comparison of the position of an object based on the drawing system used.

From left to right: Cube 1 demonstrates an axonometric projection, a special case of orthographic projection called isometric projection. Cube 2 demonstrates perspective projection or sight lines that radiate from a central point that represent a single eye of the observer. Cube 3 demonstrates oblique projection that is lines parallel to each other and oblique to the picture plane. Cube 4 demonstrates an orthographic projector that is lines parallel to each other and perpendicular to the picture plane Ching (2015), (p. 26).

Ching (2015) in his book Architectural Graphics, states "Drawing systems result from the way a three-dimensional subject is projected onto a two dimensional plane of projection or more simply, onto the picture plane.” (p. 26). In their book Perspective and Other Drawing Systems, Dubery and Willats give an historical account of drawing systems used in Western, Eastern and Asian art. They recount the decline and degeneration of perspective space into the non-spatial use of oblique projection in Byzantine art after the fall of the Roman Empire. It is not until the beginning of the Renaissance and the rediscovery of real space with formal laws of true scientific or artificial perspective that drawing gains importance as the foundation for artistic theory, training, and practice (Dubery \& Willats, 1972, 1983; Janson, 2001; Ward, 2008; Willats, 1997). Sketching and sketchbooks being produced by individual artists and the concept of artists having recognizable drawing styles were a part of artistic development in the Renaissance (Ward, 2008). The artistic issue of style has since remained a part of western art (Janson, 2001; Ward, 2008).

Latour (1986) explains why perspective was such an important invention or reinvention during the Renaissance: "Because of its logical recognition of internal invariances through all the transformations produced by changes in spatial locations" (pp. 7-8). He goes on to state that linear perspective gave artists the ability to 
translate or transfer an object in space, to modify its size and position while keeping other properties intact. Western art, uses the same homogeneous language or "optical consistency" of longitude, latitude, and geometry that allows artists to change scale, to make objects presentable and to combine them at will (Ivins, 1953; Latour, 1986) (Figure 5).

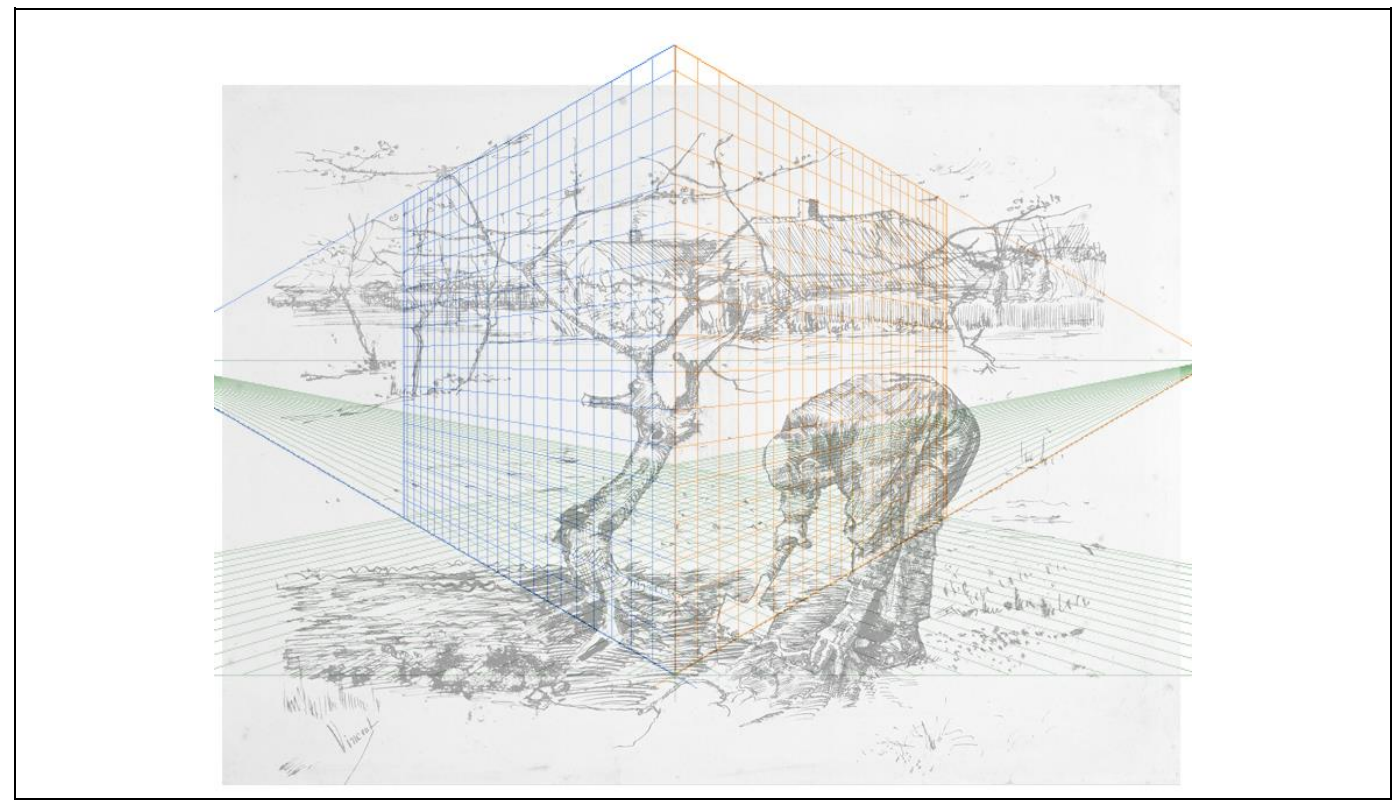

Figure 5: A visual the use of linear perspective in western European art tradition.

Vincent van Gogh. (1883), In the Orchard, (pen transferred to lithograph with pen \& ink). Private Collection, Photo (C) Christie’s Images/Bridgeman Images.

Artists like Piet Mondrian (1872-1944) consciously flattened space working from the same homogeneous language and art tradition of linear perspective of western art. Figure 6 shows how important and influential this drawing system is even in abstract work. Rather than starting from a tradition of orthographic projection for which Chinese imagery used in a consistent manner (Dubery \& Willats, 1972). The influence of having learned organizational rules first from a linear perspective drawing system is apparent in Mondrian's work when comparing it to works where the perspective element was never firmly established. 


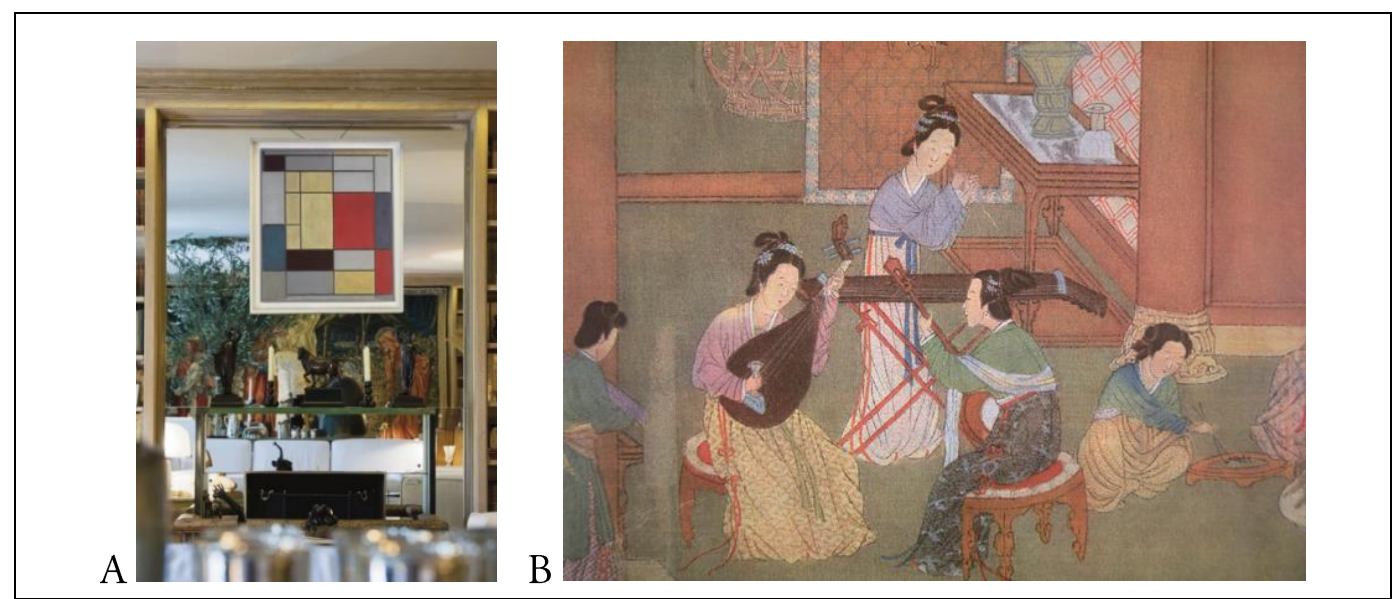

Figure 6: A visual comparison of a work by Piet Mondrian showing transformations of a linear perspective drawing system and a typical Chinese silk painting using orthographic projection.

A. Photographer Unknown. (date unknown), View of the interior of Maison Rue de Babylone, Paris, France. Photo (c) Christie's Images, Bridgeman Images.

B. Chinese School, Ming Dynasty. (1368-1644), Chinese lute, moon guitar and table zither, (painting on silk). Private Collection, Peter Newark Pictures, Bridgeman Education.

\section{Style}

The use of the word "style" or "art style" is wrought with misinterpretation and misuse. As stated earlier, the art historian Finch (1974), "Style in Art History", wrote:

"Style is any factor pertaining to form, matter, or meaning, which is sufficiently constant in a group of art works to establish a relationship among the works" (p. 4).

The behaviorist Herrnstein (1966), in his work entitled, "Superstition: A Corollary of the Principle of Operant Condition", defined style as:

“The non-instrumental aspects of instrumental behavior" (p. 49).

Style is termed as an ill-defined concept or ill-defined category by many researchers working in the fields of human perception and psychology. Hartley and Homa (1981) in their research on the abstraction of stylistic concepts state:

... Concepts resulting from categorization of natural stimuli for which clear-cut defining attributes and obvious classification rules do not exist. Yet, on exposure to many instances of the category, 
classification is possible, even though the rule being used is difficult to verbalize (p. 34).

Maitland-Gholson (1985) in their research explain that the definition of artistic style is dependent on a particular point of view. To briefly illustrate this point, approaching the idea of style from an art-historical context, it could include the examination of persons, cultural influences, political events, and marketplaces governing the production, evaluation, trade, and conservation of works of art (Bullot $\&$ Reber, 2013). There is a large stream of research that examines the relationship of an art style to social conditions within societies on a global scale as well as focusing on specific homogeneous societies (Fischer, 1961; Kim, 2000; Merrill, 1987).

However, art styles are more than a way of simply categorizing drawings and various influences. Looking at a particular style of art allows for a discussion of art processes (Munsterberg, 2009). The identification of visual features that describe a model for style grammars for creative drawings contributes directly to this discussion of art processes, which is important to art and design practitioners as well as teachers and students.

A common approach in examining works of art is as an artifact of style (Bullot \& Reber, 2013). Bullot and Reber describe a work of art as a physical manifestation of "style." Being physical, it can be measured. Stylometric techniques have been developed in literature that use statistical analysis of literary styles to assist with authenticity and attribution of texts (Belak, Belak, \& Radman Pesa, 2008). Other researchers point to early examples of the use of visual stylometry as used by Giovanni Morelli (1816-1891) to apply scientific outlook and visual classification skills to the problem of misattribution of art works (Daniel J. Graham, Hughes, Leder, \& Rockmore, 2012). Hughes et al. point out that qualitative techniques are more established in literary analysis but show great potential for augmenting the analysis of visual art providing objective, quantifiable measures that can assess artistic style. 
Work currently being done within visual stylometry is limited in scale to a specific artist or group of works from artists that worked together or in the same style around the same period. This type of research specifically targets questions that are art historical in nature such as attribution, cataloging, forensics, or historical ordering (Daniel J. Graham et al., 2012; Hughes, Graham, Rockmore, \& Mumford, 2010; Hurtut, Gousseau, Cheriet, \& Schmitt, 2008, 2011; Johnson et al., 2008; Qi \& Hughes, 2011).

The use of mathematical and statistical techniques for the analysis of artwork is termed "stylometry," or "digital stylometry" (Hughes et al., 2010). For purposes of attribution and art connoisseurship stylistic analysis relies heavily upon pictorial content as well as visual features of subject representation (Hurtut et al., 2011). Even though stylometry research relies on content, it suggests that pictures have a visual syntax or a pictorial grammar (Smith, 2011) and as such have parts that can be segmented out of larger structures. Examining the physical aspect of drawings- the visual features of marks made, allows for an analytical approach to a small element of style that can be identified, segmented, systematically analyzed and quantitatively explained.

This type of analytical approach aligns very well with other researchers like Freeman et al. $(1969,1974)$. In their research on comparing analysis of line-drawing modeling schemes H. Freeman and Saghri (1980), wrote:

Before any picture can be processed in a digital computer, it must be quantized and encoded into a form convenient for the computer. Quantization is implicit in any process. . Quantization is inherent in any description process. It requires that the whole be broken up into standardized elementary parts. The parts are 'elementary' in the sense that in the particular context in which they are used, no further subdivision (i.e. finer detail) is of interest. The assigning of a name to the elementary parts then constitutes encoding (p. 203). 
There is a significant body of research covering the analysis and interpretation of images, which falls under several areas of research such as pattern recognition, image analysis, and computer vision (Rosenfeld, 1984). Several researchers at Fitchburg State University have created a visual stylometry research group and are currently developing a tool called WAIVS: Workflows for Analysis of Images and Visual Stylometry (http://www.waivs.org). Using a similar approach to visual stylometry applying techniques and procedure developed in digital image analysis (Sethi, 2016). They approach the concept of style in a similar manner to Graham and his research group, citing statements made by Daniel J. Graham et al. (2012):

Artists within a given school of painting share a style by virtue of sharing similar formal, compositional, and productive techniques. One might assume that these similarities in productive practice should support similarities in texture among the works of members within a stylistic category (pp. 116-117).

Some artists who use other types of mathematical approaches to assist with visual understanding have developed shape grammars (Lauzzana \& Pocock-Williams, 1988; Martino, 2010; Ozkar \& Stiny, 2009) as a computational approach to develop rule systems. Martino (2010) states:

The algorithmic artist bases rules on a visual understanding. Algorithmic approaches facilitate formal understanding of visual productions and afford the artist repeatable processes. Additionally, the algorithmic approach affords a mechanism for the artist to explore new insights in a formal way (pp. 330-331).

It is in a statistical approach to quantifying various visual features that this model will establish a style grammar for creative drawing. This research examines an aspect of style which deals specifically with the measurability of line, other types of marks made, their usage and distribution within a drawing. With a specific interest in the interpretation of art processes rather than matters of cultural context or forensic and attribution of art works. 


\section{Visual Grammars}

T. Knight and Stiny (2015) in addressing the idea of style recently stated their research focuses on a computational point of view. They state their approach differs from humanists and social scientists, who concerned themselves with aspects of style that embodied the subjective, with situated relationships between people and material things. They described this distinct alternative to the concept of style:

Our view is rooted in computation but computation beyond the narrow, digital kind of computation to a more general and perceptual kind in which people carry out operations with things that may only have digital approximations. In a similar vein, we consider making to be processes carried out by people to form material things. From this perspective, the kinds of making are extensive and diverse ranging from drawing a picture on paper, to producing an image on a computer screen, to weaving a basket, to $3 \mathrm{D}$ printing a model, to machining engine parts, to constructing a building. In developing our computational approach to making, we also consider the relationship between making and designing, the latter often understood as an intellectual or cognitive activity resulting in a plan for action or making (pp. 8-9).

The use of computational methods to assist with stylistic decisions is

relatively new; however, the general alternative view of style presented by Knight and Stiny is not. Examining style-sensitive manufacturing companies, their use of styling and the expressiveness of products are focused on plans of action and making. Style has an effect on both the short-and long-term financial objectives of these companies (Higgins, 1932; Person, Schoormans, Snelders, \& Karjalainen, 2008; Person \& Snelders, 2010; Person, Snelders, \& Schoormans, 2016; Stewart, 1959). Dormer (1993) cites Raymond Lowey, in his book Never Leave Well Enough Alone, as stating that products should function as an expression of technological and social progress in the modern age. Person et al. (2016) in their research on styling cite Loewy (2002) and the importance of balance, stating that styling activities should appeal to the public and stimulate sales by striking a balance between newness and familiarity: 
"Designers should strive to produce expressive designs that are Most Advanced Yet Acceptable" (p. 35).

The financial benefits of styling and the expressiveness of products has long since been recognized in business (Higgins, 1932; Nash, 1937) and by the 1950s it was established that styling was key in seducing consumers to replace products prematurely and thereby boost sales (Stewart, 1959). The most cohesive body of empirical work on the contribution of styling activities has been carried out in the automotive industry (Person et al., 2016).

A closely related field of research examines working with style grammars and the representation of brand (Chen, 2005; McCormack, Cagan, \& Vogel, 2004; Pugliese \& Cagan, 2002). Brand can be interpreted as a style type-it is defined as a person's mental construct about a product, a service, or a company and serves to distinguish through the use of particular design grammar rules one type of product from another (Ahmad \& Chase, 2012; Andrew, 2011; Garlan, 1995). Pugliese and Cagan (2002) made use of rules based from a general motorcycle grammar to generate designs of the Harley Davidson brand, while McCormack et al. (2004) made use of representative car shapes to define a grammar for the car brand Buick.

These examples illustrate the idea that the primary focus of a style grammar is to identify design features and describe their relationships within a particular sphere whether it be architecture, cars, motorcycles, or creative drawings. This brings us back to statements made earlier on the development of a two-part process:

- Understanding how to create specific types of imagery; and

- Defining specific elements to look for, for comparison (pages 11-12).

One aspect of the model is the concept of a style grammar, which is based on a model of grammar in general. A key advantage to using such a model is familiarity with the basic concepts of how a grammar works. We are exposed to and begin to learn grammar before we start to learn how to draw (Stiny, 1980b). Similar to a 
language grammar, there are two main avenues of exploration in a visual grammar: the first being object as artifact; and secondly as the elements themselves as specimen.

In a visual grammar focusing on the artifact, questions similar to what a grammarian would ask are related to style: Why does this object mean (to me, or to anyone else)? Why is it valued as it is? Focusing on the elements as specimen questions reveals process: What do the marks reveal about the design process? Within grammars, these two avenues of exploration are complementary.

Another contribution from linguistic grammars are the concepts of ranking and organization of elements: Every language has some rank scale of elements, but with considerable variation in how the elements are organized (Halliday, Matthiessen, \& Matthiessen, 2014).

Smith (2011), in his article discusses Noam Chomsky’s ideas on pictorial grammar and John Willats' rules of representation. He describes the ideas of a visual grammar, which resonate with similar principles of linguistic grammar:

First, that pictures have parts which can be segmented out of their larger structures; second, that syntax operates on their component parts; third, that they map shapes and spatial relations in a grammatical way; fourth, that the grammar rules operating in any picture are innately grounded; and, finally, that these rules map, or transform, a 'deeper' perceptual content (p. 568).

Many of Chomsky's linguistic theories are highly contentious (Levine \& Postal, 2004), and the exactness of his ideals in a pictorial grammar may go too far in exact comparison to linguistic grammar. However, the basic concepts expressed towards visual grammars have been realized and are being worked with in other design fields (Ahmad \& Chase, 2012; Terry W Knight, 1992; Terry W. Knight, 1993; McCormack et al., 2004; Pugliese \& Cagan, 2002; Stiny, 1980a; Stiny \& Mitchell, 1978). This body of research substantiates two of Smith's ideas: 
1) That even a rudimentary account of pictorial grammar is capable of making sense of the complex meaning pictures achieve particularly when they bend or subvert the rules. And

2) That through a pictorial grammar it is possible to explain and explore aspects of depiction other than shape or spatial relationships.

Shape grammars have been developed and used as models of design "borrowing" within architecture for several decades (Ozkar \& Stiny, 2009; Stiny, 1980a; Stiny \& Mitchell, 1978; Yue, Krishnamurti, \& Grobler, 2011). Shape grammars are algorithmic systems that assist with identifying shapes for reuse in the creation of new designs through spatial computations and shape rules (Stiny \& Gips, 1971). Stiny and Mitchell (1978) developed a noteworthy shape grammar called the Palladian grammar, a parametric shape grammar based on the ground plans of Palladio's villas.

In their research on the representation of style in design grammars Ahmad and Chase (2012), depict a simple shape grammar using two rules, which is represented here to demonstrate the use of shape and space within the rule set (Figure 7). This illustrates the ideas of defining the visual features and the drawing system in which they are organized to later generate rules for "borrowing." 
Initial Shape

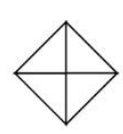

Rules

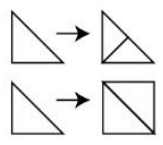

Derivation

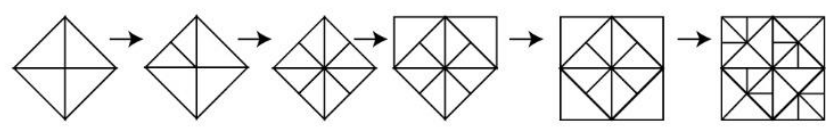

Designs in the language

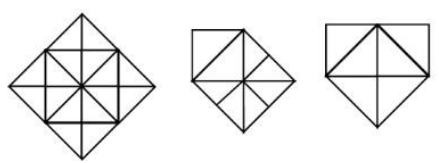

Figure 7: A visual describing a particular organization of space and a simple shape grammar using two rules, (based on a grammar example by Ahmad \& Chase, 2012, p.490).

The above diagram describes the process of how a typical shape grammar computation begins. Based on the work of Stiny (1980a) and Martino (2010) the explanation below is from Making Grammars, (T. Knight \& Stiny, 2015):

First, there is the initial design state. Next, a computation, or rule application is created. It consists of two parts and is defined by a left side and a right side. The first part is to recognize a shape in its current state. The second part is to replace the recognized shape with another shape. The replacement can be a transformation, a different shape, or an additional shape. The generalization of a rule is $A \rightarrow B$, and read as:

(see A, erase A and draw B in A's place) (p. 10).

One of the important aspects of a visual grammar model is that it allows for exploratory 'making' activities and illustratively supports the reasoning processes through which new designs can be developed (Harrison, Earl, \& Eckert, 2015). Exploring drawings through this type of model can assist with the generation of new knowledge, the use of tools and materials, and the designs themselves (Ingold, 2009). Furthermore, this type of exploration can play a role in both analysis and synthesis, 
supporting the process of generating new designs, while also affording reflection and reasoning about their properties (Harrison et al., 2015; Stiny, 2008). Harrison cites Stiny's work from 1981 on shape grammars to explain shape rules and schemas:

Shape rules allow division into parts in infinitely many ways, activities such as sketching that support the development of unstructured shape descriptions allow designs to be continually reinterpreted. As shapes are added or selected and transformed, they may interact or merge with other shapes, in ways not predictable in advance. Shape rules can be used to describe and document the distinct moves by which shapes within designs are recognized and transformed: rules identify spatial relationships between shapes and apply transformations to shapes and sub-shapes within designs (p. 56).

An important interest in developing a model of a style grammar for creative drawings is the examination of the function of relationships between the various visual features of a drawing and their connections in a design. Computational exploration can assist with a systematic consideration of possible design variations, and can provide insights into relationships between design properties. For my model of a style grammar for drawing, the relationships of interest are between properties of line and other visual features as they pertain to a drawing.

Using a model for this type of creative exploration has been likened to a process of searching within an abstract space of possibilities (Boden, 2004; Harrison et al., 2015; Wiggins, 2001). This analogy is attractive as it lends itself to the use of computation (Boden, 2004; Wiggins, 2001). In this view of creative discovery, theoretical spaces, containing both complete and partial solutions, can be explored to find new design possibilities. Boden suggests that individual creative processes enable the navigation of these spaces in distinct ways, with one method able to reach a solution that is inaccessible to another. Wiggins has further formalized this perspective, suggesting that these processes might be described using sets of rules.

Harrison et al. (2015), in their research on exploratory making had this to say about the models that they were developing for kinematic designs: 
We find that manipulation of physical models not only increases an appreciation of motions, but it is also an integral part of the making process itself. For the case considered here, a process of systematic experimentation using physical models yields a set of making rules, which in addition to describing actions to transform and join materials, also describe the manipulations required during making. A making rule can then be generalized into a schema, defining a wider set of rules of a particular type. A specific subset of the set of making schemas generates a set of designs that each exhibit similar motions to the original object. Once identified through making and testing physical models, this subset can also help to explain which relationships between shape and structure are essential for preserving motions for this class of designs (p. 53).

Developing a model supports ideas through constructing and modifying tangible representations. It involves reasoning about relationships and connections between materials and the drawn line, whilst considering the effects of design changes on properties of interest. 


\section{Chapter 3: Model Development}

\section{Establishing a Set of Visual Features \& Core Traits}

The initial list of visual features and core traits for the model were developed by examining research that covered task-oriented rendering, which included interests in non-photographic rendering (NPR), image processing, line-drawing processing, computer graphics, and line structure coding. The list of researchers who have made significant contributions to these fields and whose works are specifically reviewed and discussed include Herbert Freeman (1974), Goodwin, Vollick, and Hertzmann (2007), Grabli, Durand, and Sillion (2004), Winkenbach and Salesin (1994).

Examining NPR research allowed for the creation of a direct reference point between the act of drawing, the drawn artifact and the computer. Many researchers in the area of NPR directly related the development of computer drawing tools to hand drawn pen and ink technical (task-oriented) drawing tasks. Winkenbach and Salesin $(1994,1996)$ stated these reasons for their approach:

... Using this medium in computer analysis of line (referring to pen and ink technical illustrations): it is monochromatic and therefore binary; shading, tone, and texture is suggested by combinations of lines; pen and ink has a simple directness that other mediums lack (p. 92).

The model is focused on the visual features and their associated core traits from a large and varied set of creative drawings. It was important to define each of these features and their associated traits. This would assist with identifying the best way to obtain computer measures that could be used to express a drawing process from a quantitative perspective. Even though the grammar model being constructed involves creative drawings, examining task-oriented drawings proved useful in providing sources of generally agreed upon definitions for many of the core traits (page 10). 


\section{Line}

There is substantial support for line being the most identified feature of drawing from artists' writings to books on drawing, art and design (Artists on Art. From the XIV to the XX century, 1958; Goldstein, 1977; Guptill, 1976; Hale, 2009; Kepes, 1995; Lohan, 1978; Rand, 2014). Goldstein (1977), in his book The Art of Responsive Drawing states this about line:

... line as the primary means of drawing is universal. . . and blinds us to the fact that line does not exist in the physical world of matter. Virtually everything we regard as a line in nature is, in fact, a thin, solid volume such as a wire, branch, or convex fold, or else a thin depression such as a wrinkle, fissure, interspace, or concave fold. In drawing, then, line should be understood as a wholly abstract device for conceptualizing a symbol that stands for the thing seen or envisioned (p. 40).

The artist Paul Klee (1961) wrote:

One of the greatest charms of drawing-namely, that the conflict between the infinite complexity and fullness of matter, on the one hand, and the bare geometric abstraction of mind, is brought, not indeed, to a point, but literally to a line (pp. 5-6).

Herbert Freeman (1974) in his research in NPR dealing with computer processing of line-drawing images and the comparison of different schemes of quantization wrote:

A line drawing is one of man's most common and effective means of communication, and its processing by computer has attracted the attention of computer engineers for more than a decade ... In a simple sense, a line drawing is a picture that conveys to its viewer information through the shape, size, and manner of interconnection of thin lines on a contrasting background. The thickness of the lines, their color, or the color or texture of the background are either of no or at most of symbolic significance (p. 57).

Gardner's Art Through The Ages: The Western Perspective, presents this definition for line: 
Line is one of the most important elements defining an artwork's shape or form. A line can be understood as the path of a point moving in space, an invisible line of sight or a visual axis. But, more commonly, artists and architects make a line concrete by drawing (or chiseling) it on a plane, a flat and two-dimensional surface. A line may be very thin, wire-like, and delicate; it may be thick and heavy; or it may alternate quickly from broad to narrow, the strokes jagged or the outline broken (p. 7).

Goldstein (1977), Hale (2009), and Ching (2010) all describe line as a visually concise and familiar device for communicating many kinds of visual information. Ching describes line usage as a way to communicate and define spatial edges and planar corners. Goldstein specifically writes:

A drawn line has certain properties. It always has direction, interrupts or divides the picture plane, has along its course one or more values, is consistent or varied in width and has a certain length. Line is an efficient means for noting a form's length, width, depth, and long axis (pp. 40-41).

Kasprisin and Pettinari (1995) in their book on visual thinking define line this way:

Line is a thin mark made by a pen, pencil, or other graphic tool. A line is a dot extended, a thin shape with a discernable beginning and end. In pen and ink techniques, the line is the basic unit of construction. It can be altered by width; it can be placed next to and over other lines to form patterns (p. 7).

Line itself was identified as having three distinct traits—length, width, and a gestural or expressive quality, which can be described as line expressiveness, with each of these traits having a variability. It was suggested that drawn lines by computer were too consistent, too regular in comparison to hand-made marks, which were termed more "lively." Winkenbach and Salesin (1994) describe this as a problem in mechanical and task-oriented drawings produced using computer drawing tools. Ching (2010) describes the perception of a line as dominated by a length-width ratio. Line length dominates line width, but a precise measure for this ratio is not given. 
One issue faced in this research was how to define the various traits of line in a concise enough manner to be useful for quantification and encoding. The review of various drawing books, artists' own writings and other research materials suggested that there is a general agreement of the importance of line in drawing. However, how line and its qualities or visual features were defined varied greatly.

Artists generally defined the purpose of line as an efficient means for describing a form's basic shape, its length, width, and depth and describe various line qualities_-thickness, expressiveness, and length (Freeman, 1974; Goldstein, 1977; Grabli et al., 2004; Guptill, 1976; Hale, 2009; Winkenbach \& Salesin, 1994). The definition used in this research for line comes from The J. Paul Getty Museum art education site (http://www.getty.edu/education/teachers/building lessons/formal analysis.html) which states:

"Line is the identifiable path created by a point moving in space" (Figure 8).

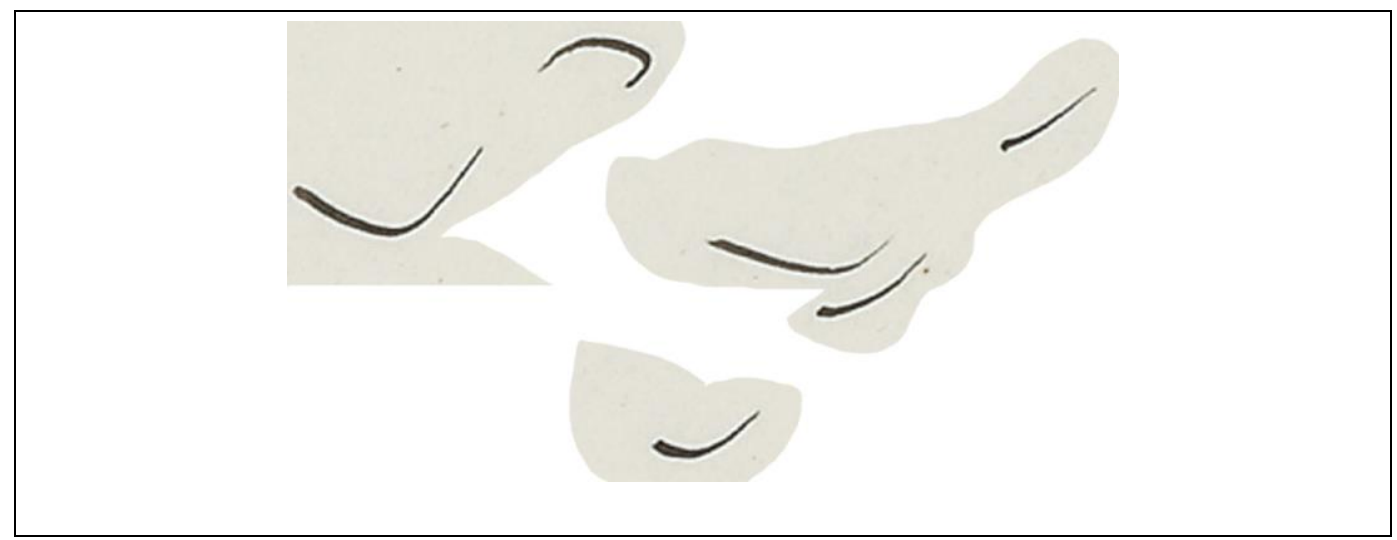

Figure 8: A visual definition for line. Line sample segments.

Extraction from: Henri Matisse. (1944), Self Portrait, Auto portrait (pen and India ink on paper). Private Collection, Bridgeman Images. 


\section{Line Length}

Books and journals related to task-oriented drawings are more concise in how the various features of line are defined. Ching (2015) in his book on architectural graphics described line length this way:

"All lines should start and end definitely, always touching at their ends, always bearing a logical relationship to other lines from beginning to end" (p. 15).

In contrast to this statement, when describing line length in creative drawings Goldstein (1977) writes:

"Sometimes a line's length is determined by various calligraphic or textural requirements, and often by the artist's need to establish dimension" (pp. 40-41).

Looking at line as a type of 'edge' Kasprisin and Pettinari (1995) categorized edges has being hard, soft, interlocking, merged, and lost and found. While these qualities and categorizations do not necessarily help with defining a line's length, they certainly help with identifying problematic issues of measuring a line's length. For example, hard edges are easy to recognize. They attract attention due to contrast and immediacy of the change between two areas. Kasprisin and Pettinari (1995) wrote:

Hard edges have more contrast than other types due to the abrupt nature of the change. They are effective when mixed with other different edge conditions, but can become monotonous when overused, losing the ability to connect shapes and patterns (p. 10).

Figure 9 points out this problem of discerning a line's end or beginning because of the loss of connect-ability. 


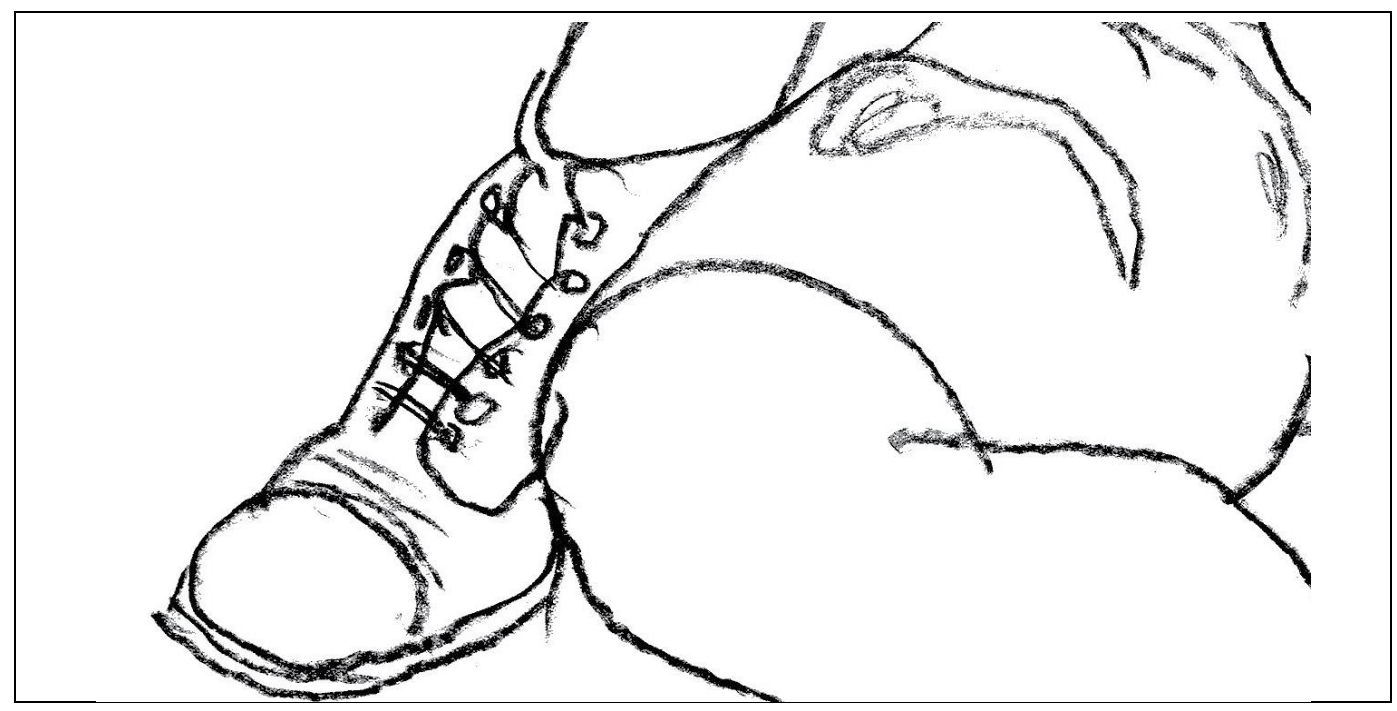

Figure 9: A detail visualization of a section of a drawing illustrating hard-edges and the problematic determination of line length.

Egon Schiele. (1918), Young Man Reclining with his Head Resting on His Crossed Leg; Liegender Knabe mit Aufgestutztem Kopf und Ubergeschlagenen Linken Bein, (charcoal on tan paper). Private Collection, Photo (C) Christie's Images, Bridgeman Images.

However soft edges, interlocking edges and merged edges are also problematic when trying to discern the length of a line. These types of qualities have a blending effect. Kasprisin and Pettinari (1995) describe this blending effect as melting, writing:

"This melting is easy to accomplish with techniques such as scribbling and hatching" (p. 10).

Figure 11 is an example of this melting together of lines and explores line usage through techniques of hatching and cross-hatching. This technique is discussed later in relation to tone (page 40). Here I am addressing the perceptual problem of line length. Kasprisin and Pettinari (1995) suggest that when hatching techniques are used to such a degree as they are in figure 11 that the individual lines are not the message, the picture plane is the message, and in the case of figure 10 this might be true. However, in this research a good measure for length is needed for each image with the knowledge that some measures will be less important than others. This may 
assist with determining and defining an artist's drawing style by identifying what traits and measures are the most important.

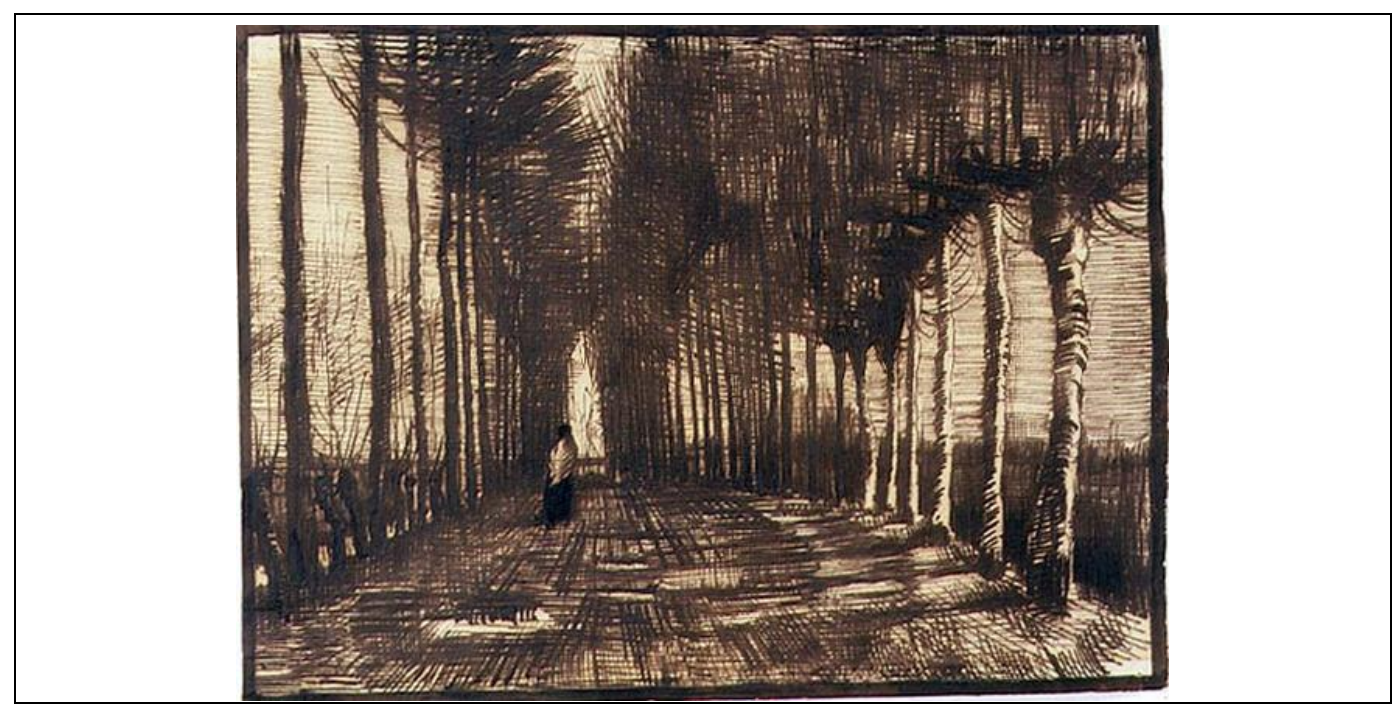

Figure 10: A visualization illustrating issues of blending and the perception of line-length. Vincent van Gogh. (1884), Figure on a Road, (pen and brown ink on buff paper). Private Collection, Photo ( Christie's Images, Bridgeman Images.

The last issue examined in terms of line length and edge is "lost and found". Goldstein (1977) describes this as a device used intentionally by artists to leave forms vague or hidden from view (Figure 11). Guptill (1976) in his book on rendering in pen and ink describes this type of treatment as "a matter of intelligent omission". Another way to look at lost and found is through the concept of "implied line" which suggests that for a line, edge or shape to be perceived an artist needs to draw some portion of it but not all of it (Ching, 2010; Hale, 2009; Lohan, 1978). This emphasizes a statement made earlier by Kasprisin and Pettinari (1995) that line may not always be the dominant factor in a drawing. An interesting point to make here is that while artists will de-emphasize line or edge the degree of that de-emphasis is determined initially by the artist's perception but it is eventually decided by the viewer's perception. 


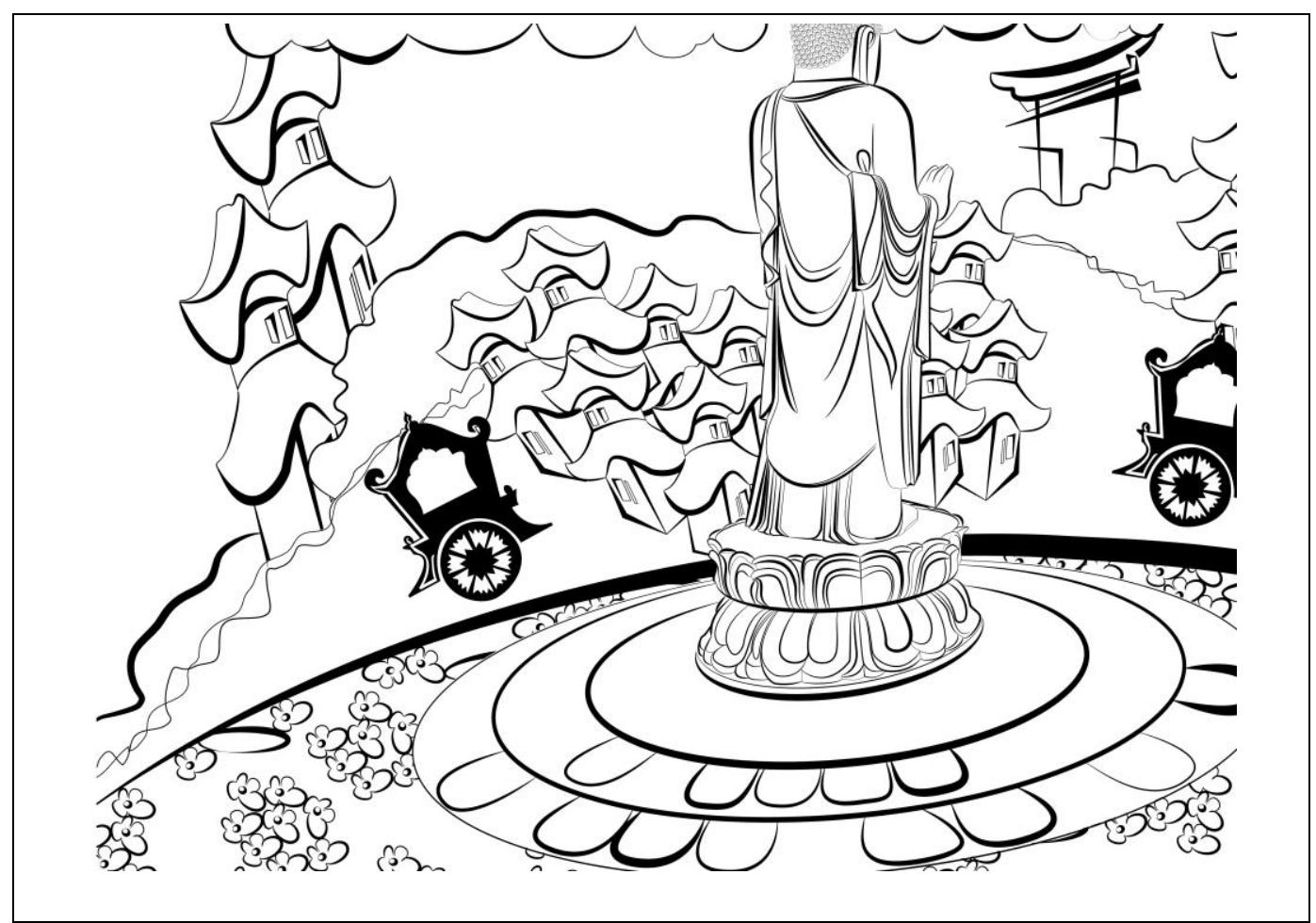

Figure 11: A visualization illustrating the concept of lost and found and implied line in an illustrated piece of work.

J Sweo. (2016), Untitled, (computer drawing based on a pen and pencil drawing).

A concise and objective definition for line length that would be useful for quantification and encoding for the computer needed to be developed. It was determined that the best approach to obtaining this particular definition would be through machine operations and computer drawing tools as shown in the methodology section under line length (page 102).

\section{Line Width}

As stated earlier Ching (2010) describes the perception of a line as dominated by a length-width ratio. He explains that even though a line has only one dimension, it needs to have some degree of thickness to be visible. Others describe this degree of thickness as line strength or line width (Goldstein, 1977; Grabli et al., 2004). Hale (2009) in his drawing book describes one of the purposes for the variability of a line's strength is as an artist's way to suggest tone. He writes: 
A line of varying strength can be run across an object: where the line is heavy, it will suggest deep shade on the object; where it is light, the line will suggest light shade; if the line is very light or absent, it will suggest a highlight (p. 528).

This concept that heavier strokes are used to describe the darkest areas within a shaded area has been examined by researchers in NPR (Ejiri, Morimoto, \& Takahashi, 2014; Goodwin et al., 2007). Goodwin et al. (2007) within their research describe the width of a stroke as the depiction of depth, radial curvature, and light direction upon a contour of a three-dimensional model.

In this research line width is defined as a line's thickness. As simple as this definition seems it is still quite complex in discerning when a line in its length becomes dominated by its width, again becoming an issue of perception (Figure 12).

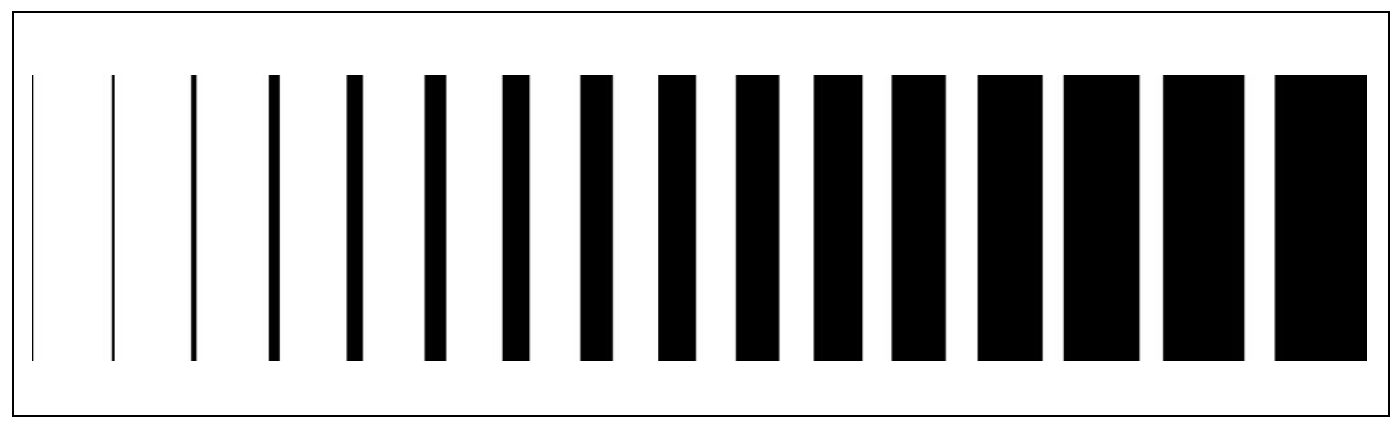

Figure 12: A visualization illustrating the concept of line length-width. When does line stop being line and becomes a shape?

\section{Line Expressiveness}

Winkenbach and Salesin (1994) in describing the fundamental characteristics of stroke in their research talk about the hand-drawn pen and ink strokes versus computer drawn strokes, suggesting that strokes must look natural or irregular as opposed to mechanical or precise. They state that even-weighted line drawings appear lifeless suggesting the width or thickness of a line should vary. Ching (2010) described the character of line as having an extreme nature or variability such as taut/limp, and graceful/bold. 
Goldstein (1977) describes the felt attitude, personality or character of line. He writes:

Lines of a strongly curvasive and rhythmic quality, often more the result of dynamic rather than structural stimuli, are called calligraphic lines. And some lines seem so charged with emotive energy that we regard their dominant role to be expressive. All lines, of course, are expressive, but some appear to issue more from an artist's intuition, empathy, and temperament than from either structural or organizational motives (pp. 40-41).

In this research line expressiveness is therefore defined as the variability in the appearance of a line. The more it changes its appearance whether it be through its weight or smoothness of its edge the more expressive. The less a line varies in appearance the less expressive.

\section{Tone}

Tone is defined as a ratio of dark marks to the white of the drawing surface over a given region of a drawing (Grabli et al., 2004; Guptill, 1976; Lohan, 1978; Winkenbach \& Salesin, 1994). The degree of light or dark of an area of a drawing, the variation from bright white where marks sparsely populate an area, through shades of grey, to the blackest shadows where there is a high concentration of marks (Guptill, 1976; Klitment, 1984; Lohan, 1978). Goldstein (1977) defines tone as a perceived value of grey:

Value can be produced in just two ways: (a) by variously hatched lines creating optical greys, that is, impressions of value resulting from the collective tone of massed lines, their value resulting from the density of the hatching; and (b) by deposits of actual grey tone by chalk, pencil, or diluted washes of ink or paint. Value, whether the result of optical or actual tones or both, is the necessary (except for color) the only tool for modelling form with light (p. 74).

Because of the simplicity of pen and ink drawings the same strokes that convey tone can also be used to achieve texture (Guptill, 1976; Lohan, 1978; Winkenbach \& Salesin, 1996). 
Winkenback and Salesin $(1994,1996)$ cite general principles that govern lines as they are used to depict tone, stating:

- Tones should be created from lines of roughly equal weight and spacing;

- It is not necessary to depict each individual tone accurately; however presenting the correct arrangement of tones among adjacent regions is essential; and

- To disambiguate objects, it is sometimes important to "force tone" by enhancing contrast or inventing shadows (p. 93).

Goldstein (1977) describes tone as being either global or local. Global refers to an overall perception of the entire drawing and local refers to areas within a drawing. There are many different ways to achieve both within a drawing. The commonality that both local and global tone have within a drawing is their expression of light and dark.

Robert M. Haralick and Shanmugam (1973) in their research defining textural features for image classification compare the concept of tone and texture:

"Tone is based on the varying shades of gray of resolution cells in a photographic image, while texture is concerned with the spatial (statistical) distribution of gray tones" (p. 611).

Haralick goes on to explain these two concepts: texture and tone are not independent from each other. Texture and tone are always present in an image, and that one can dominate the other. He also suggests a strategy of using image areas from black and white photographs to be most effective for image processing tone and texture.

\section{Pattern/Texture}

Texture is the perceived surface quality of an area which can translate into a tactile illusion (Goldstein, 1977; Guptill, 1976; Hale, 2009). Texture has been identified as an important element of vision and has been analyzed extensively by researchers in psychophysics and computer vision (Amadasun \& King, 1989; Beck, 
Prazdny, \& Rosenfeld, 1981; Robert M. Haralick \& Shapiro, 1985; Julész \& Bergen, 1983; Karoui, Fablet, Boucher, Pieczynski, \& Augustin, 2008; A. Ravishankar Rao, 2012; A. R. Rao \& Lohse, 1993; Syeda-Mahmood, 1999; Tamura, Mori, \& Yamawaki, 1978).

One of the most prominent reasons for the interest of texture/pattern within NPR research is generative- how to create NPR algorithms in order to have a computer create specific types of pattern/texture. Salisbury, Anderson, Barzel, and Salesin (1994) in their research on interactive pen-and-ink illustration discuss the application of texture:

We present an interactive system for creating pen-and-ink illustrations. The system uses "stroke textures"-collections of strokes arranged in different patterns - to generate texture and tone. The user "paints" with a desired stroke texture to achieve a desired tone, and the computer draws all the individual strokes (p. 101).

Grabli et al. (2004) in their research looked at density measures for line drawing simplification, with an emphasis on developing tools to simplify the rendering of textures:

"We present an approach for clutter control in NPR line drawing where measures of view and drawing complexity drive the simplification or omission of lines." (p. 309).

Winkenbach and Salesin (1994), in their research on computer-generated pen and ink illustrations and automated rendering systems, wrote:

Our research describes the principles of traditional pen-and-ink illustration, and shows how a great number of them can be implemented as part of an automated rendering system. It introduces "stroke textures," which can be used for achieving both texture and tone with line drawing. Stroke textures also allow resolution-dependent rendering, in which the choice of strokes used in an illustration is appropriately tied to the resolution of the target medium (p. 91).

Working on the identification of textures, many researchers in computer vision have used Brodatz's album (Brodatz, 1966) as a standard source for 
photographic images of textures in human perception testing (A. R. Rao \& Lohse, 1993; Tamura et al., 1978). Researchers have focused on what they have identified and defined as various features of texture such as regularity, disorder, and global orientation rather than describing these as specific traits of a particular texture such as wood, marble, or canvas (A. R. Rao \& Lohse, 1993).

Tamura et al. (1978) considered coarseness, contrast, directionality, line likeness, regularity, and roughness to be important features of texture while Amadasun and King (1989) placed focus on busyness, complexity, and texture strength. A great deal of this research has been useful in developing systems of analysis for biomedical images for such things as identifying cancer cells, tumors, and for process control of manufactured surfaces (A. Ravishankar Rao, 2012; A. R. Rao \& Lohse, 1993).

A review of some of the definitions they used for each type of texture lends insight to various ways to describe line usage in creative drawings and assists with ways to define measures for various line useage. Some of these definitions also coincide with pattern definitions used by artists within the drawing process.

The first property both Amadasun and King (1989) and Tamura et al. (1978) defined for texture was coarseness, which they related to the size of the basic primitives that describe the texture. This could relate to the overall size of a pattern within a drawing or a size variation of the way line itself or other types of marks are handled that describe the texture. This sets up a juxtaposition between areas of a drawing where there is texture or pattern and where there is very little or none. It also sets up a contrast of size ratios between two or more different textures within a single drawing. Tamura et al. (1978) in their research also identified roughness as a tactile sense of texture and approximated it to coarseness. Within drawing, this could be another way of describing a gestural line, which is a graphical expression of movement or motion. 
The second property that both research groups identified was contrast (Amadasun \& King, 1989; Tamura et al., 1978). Contrast as is defined as different levels of intensity that are clearly visible and can be measured through a clear change in the range of grey scale pixels between two neighboring areas. This gives insight into a possible machine measure for contrast. From an artistic standpoint both contrast and juxtaposition need two opposites for this trait. However, in a drawing this could be done through an arrangement of size, negative to positive, dark to light, motion to stillness.

The next set of properties discussed by both groups are identified using different names but point to the same concepts busyness and complexity. The greater the amount of variability whether it be size changes, value changes, or a large amount of lower level contrasts, the more complex or busy the overall image appears to be. Amadasun and King (1989) in their research on texture define busyness:

A busy texture is one in which there are rapid changes of intensity from one pixel to its neighbor; that is the spatial frequency of intensity changes is very high. If these changes are very small in magnitude, they may not be visually noticeable. While the spatial frequency of intensity changes reflects the level of busyness, the magnitude of these changes depends upon the dynamic range of grey scale, and thus relates to contrast (p. 1265).

Amadasun and King (1989) go on to explain that a suppression of the contrast aspect from information about the spatial rate of change in intensity may assist with indicating the degree of busyness within a texture.

Similarly identified was line-likeness and directionality, which can also be used to set up a contrast. However, when two edges are nearly equal, it sets up a comparison of similarities rather than dissimilarities and can add to a regularity of repetition.

Artists often describe the traits of texture through pattern usage. Pattern is the combination of lines that can create perceived shape or surface texture that repeat in a regular arrangement within a drawing (Goldstein, 1977; Guptill, 1976). The 
strength of a texture depends on how easily a pattern can be perceived within an image (Amadasun \& King, 1989). Many artists describe pattern usage as a visual rhythm (Brown, 2015; Klee, 1961; Ross, 1904).

Goldstein (1977) in his book on drawing makes the comparison between visual rhythm and a musical meter. It is a regulated visual occurrence between elements that can be similar or dissimilar and is explained by intervals of space between elements or how they overlap (Goldstein, 1977; Hale, 2009; Ross, 1904). Similar to a musical meter, visual rhythm can be described as regular, alternating, flowing or progressive (Flye, 2011; Goldstein, 1977; Ross, 1904) (Figure 13 and Figure 14).

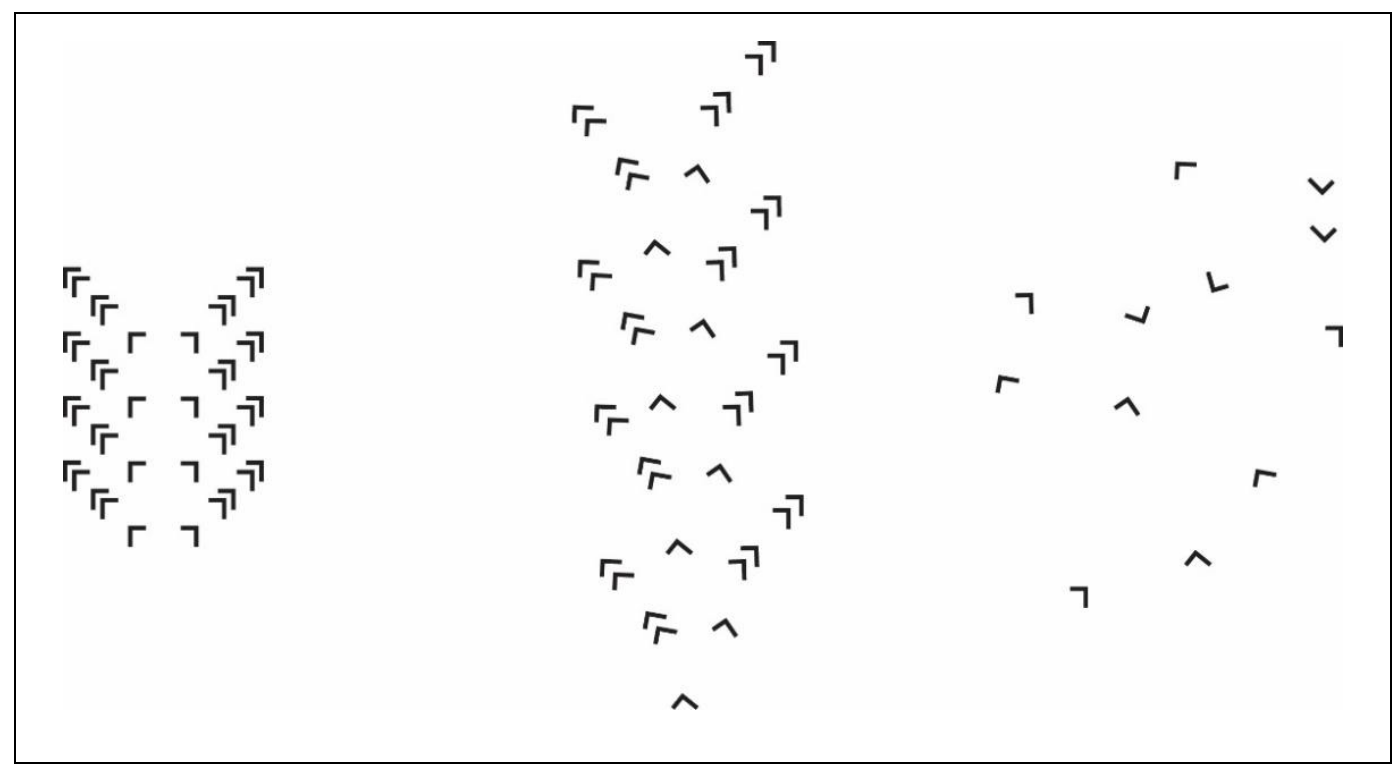

Figure 13: A visual describing various types of rhythm and their visual effect on pattern. From left to right regular rhythm, alternating rhythm, and randomness - the lack of pattern. Based on design discussions by Ross (1904) (pp. 84-89). 


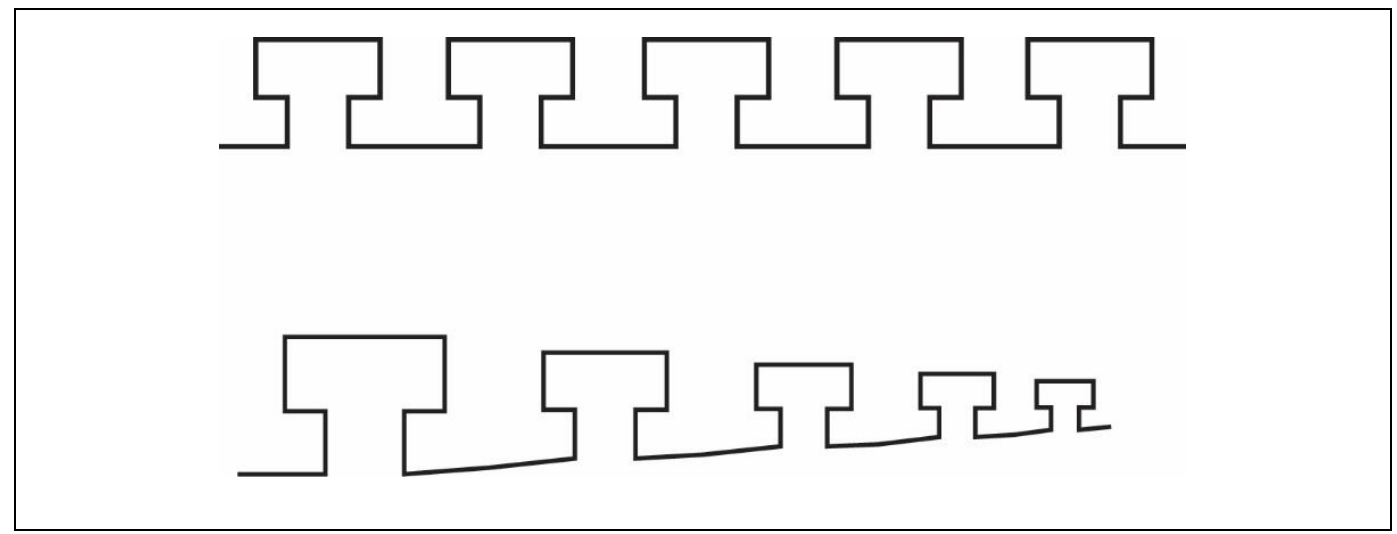

Figure 14: A visual comparison of a regular rhythm and a progressive rhythm. Based on design discussions by Ross (1904) (pp. 59-61).

Along with rhythm, juxtaposition (Figure 15) was also identified as a feature of pattern. Juxtaposition is the placing of elements side-by-side done with the intention of bringing out a comparison of similarities or differences between opposing elements (Goldstein, 1977; Hale, 2009; Ross, 1904).

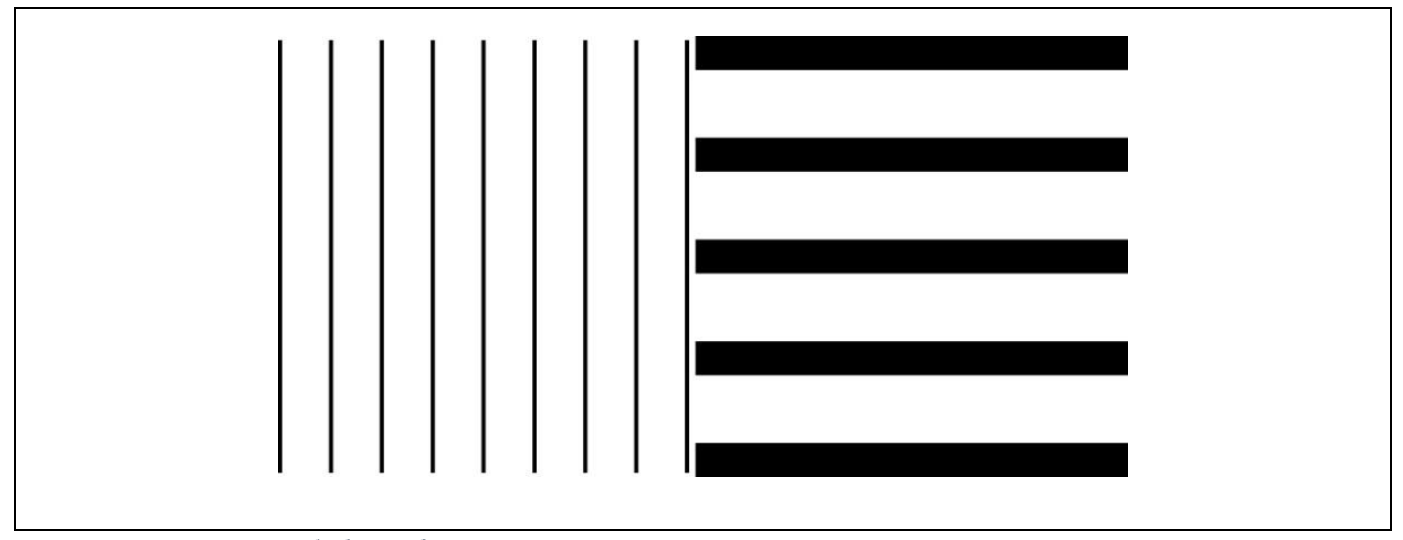

Figure 15: A visual describing juxtaposition.

\section{Depth}

Depth has been defined by many as the graphic representation of space and visually communicates the spatial relationship between elements (Dubery \& Willats, 1983; Goldstein, 1977; Hale, 2009). It is this definition of space that will be used in 
this research. Also under examination are various ways to approach depth which can be compared to local and global tone.

Approaching depth in a varied manner as local depth—the volumetric property of specific shapes, and global depth-the overall arrangement of shapes in the drawing surface allowed for the examination and comparability of several elements at one time. Two elements were identified that could assist with obtaining a measure for depth, tonal density and position.

Through the identification of the tonal density of shapes, and their position a workable machine measure for depth could be obtained. In creative drawings, an objective selection of shape even with the use of the edge detection tool can be difficult. Often times a specific shape whether organic or geometric is obscured by tonal qualities, which can include pattern and texture. While the shape may be lost the density of tone remains. Position deals with where on the drawing surface the shape or the area of tonal value is located.

The initial model focuses on drawings using a linear perspective drawing system. It was observed that the organization of shape and tone are similar within this drawing system. Shapes in the foreground are larger and become smaller and less distinguished the further they recede in the picture plane. Tones are generally clearer and more distinctive in the foreground in comparison to those used in the background.

\section{Outline Shape \& Position}

How space is organized through the usage of depth and how that organization is perceived through shape and position were examined. Spatial organization emphasizes the importance of a drawing system or the type of projection being used. The type of depth represented has direct bearing on the defined configuration rules of the model as stated earlier. There are several traits that influence the perception of depth—outline, shape, and position. (Ching, 2010; Dubery \& Willats, 1972, 1983; Goldstein, 1977). 
Outline is a spatial descriptor of form. It has all the possible traits of line as already discussed: line thickness, line length, line expressiveness, but because it is a line which returns to itself and makes an enclosure it also describes areas of space that can be measured (Guptill, 1976; Lohan, 1978; Salisbury et al., 1994; Winkenbach \& Salesin, 1996).

Shape is referred to as the principle aspect by which form is identified and categorized (Ching, 2010). Goldstein (1977) states that a shape is any flat area bounded by an outline or value or both and can be classified into one of two categories: geometric or organic also referred to as biomorphic or amoebic (Figure 16).

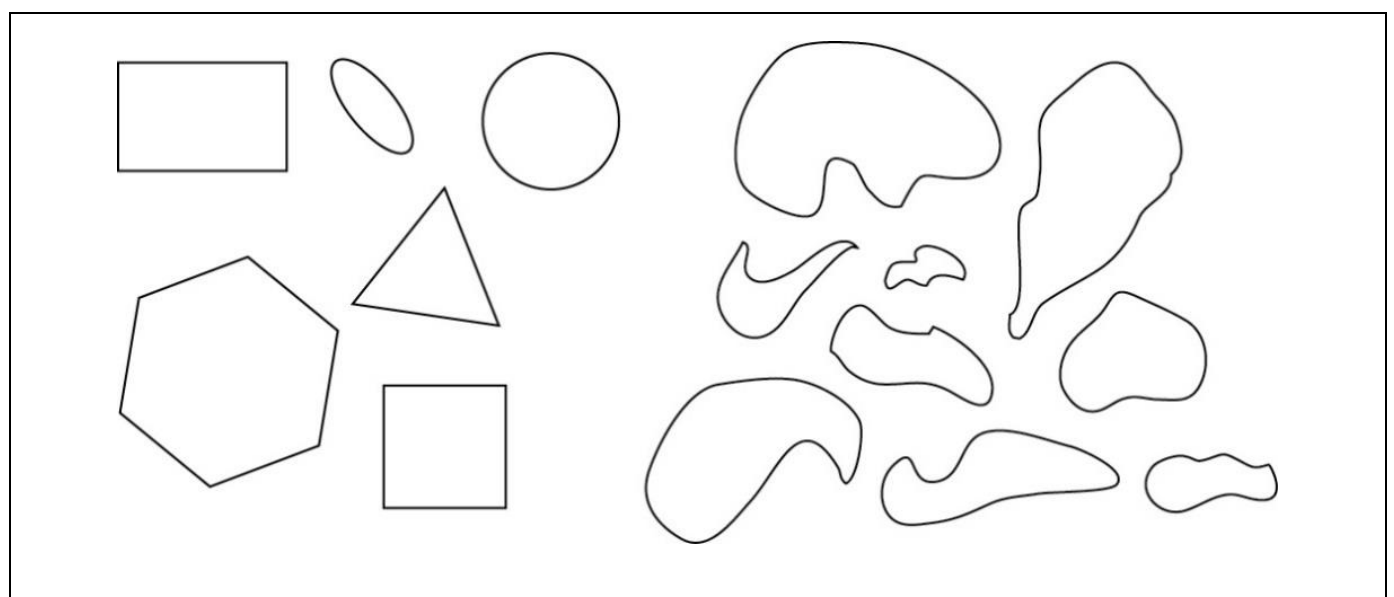

Figure 16: A visual describing outline and shape-both geometric and organic. Based on shape discussions by Goldstein (1977) (pp. 18-21).

Goldstein (1977) describes geometric shapes as being precise and pure forms that consist of circles, squares, spirals, triangles while Hale (2009) describes geometric forms as simple volumes such as cubes, cylinders, and pyramids. Again this points to the importance of a drawing system-how space is organized. In contrast, both Goldstein and Hale describe organic shapes as free-form, unpredictable and flowing in appearance. Many artists state that understanding the geometry of an observed shape is essential to determining a shape's volume and position in space as 
well as allowing for the visual representation of its dimensional form (Artists on Art. From the XIV to the XX century, 1958; Ching, 2010; Goldstein, 1977; Guptill, 1976; Hale, 2009; Ruskin, 1907).

Initial shape grammars that were examined used an orthographic drawing system to assist with image analysis. The simplicity of the shapes allow for the learning of grammar rules and their functions (Terry W Knight, 1992; Mahfoud \& Willis, 2013; Martino, 2010; Mitchell, 1991; Ozkar \& Stiny, 2009; Stiny, 1980a; Stiny \& Gips, 1971; Xiu Wu, Dudek, Sharman, \& Szabo, 2005). Other types of drawing systems can also be used in a shape grammar. The more complex the shapes become the more complex the rule set.

The last spatial descriptor examined was position. Position refers to the location of form relative to the picture plane and deals with the drawing system in use (Ching, 2010). An organizational trait of a drawing system is the creation of a focal point. The focal point is the center of interest meant to be the most significant part of an image (Goldstein, 1977; Hale, 2009). On the other end of the spectrum there is "all over space." Forms are seen as occupying the same spatial depth on the picture plane and possess the same degree of importance (Anfam, 2015) (Figure 17).
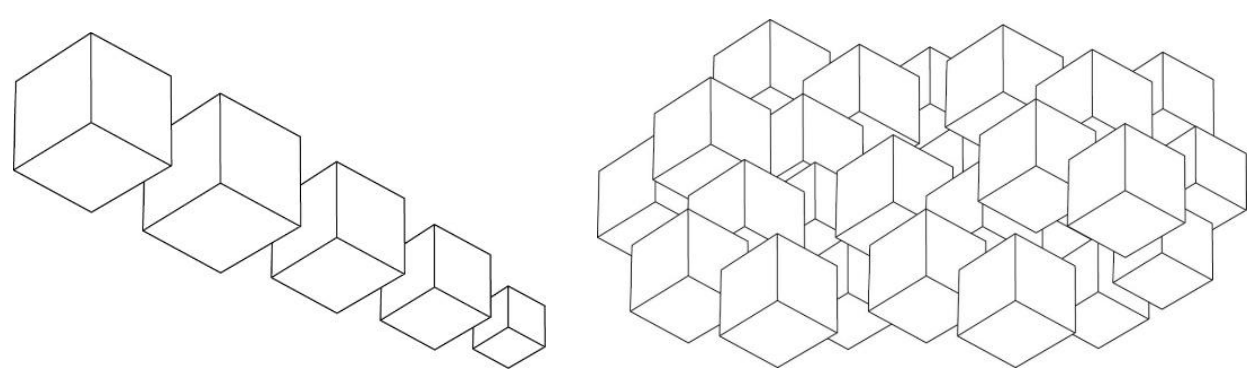

Figure 17: A visual description of position and the organization objects to create a focal point. 


\section{Color}

The literature on drawing generally refers to marks-made rather than the selection of color, or the particular choice of one color scheme over another. Color is an important element of design, and drawings can use color. The observation made in this research was that the usage of color in a drawing was more of an exception to the general practice of mark making than the rule. Similarly, using grey scale or black and white rather than color in painting is an exception to the general practice of painting.

The artist Paul Klee (1961) in discussing drawing said:

All pictorial form begins with the point that sets itself in motion ... The point moves ... and the line comes into being - the first dimension. If the line shifts to form a plane, we obtain a twodimensional element. In the movement from plane to spaces, the clash of planes gives rise to body (three-dimensional). A summary of the kinetic energies which move the point into a line, the line into a plane, and the plane into a spatial dimension (pp. 5-6).

To further, support this examination, I include this from Colette S. Bangert talking about her work:

The subject of all my work has been landscape. The elements of both the computer work and my handwork are often repetitive, like leaves, like trees, grass and other natural landscape elements are. There is a sameness and similarity, yet everything is changing. Landscape yields both texture and form. The pictorial form is usually all-over, with non-focus details, which form patterns, since I feel these are essential properties of landscape. A field has no center, and is not really flat, so I use no flat areas. The grass as grass, leaves as leaves, is what I'm exploring. Landscape form is itself the subject. Line as form. Grass as form. . . I always seem to be in the process of learning about line and land forms (as cited in Leavitt, 1976, pp. 18-20).

The point made by both Klee and Bangert, in talking about drawing and approaching imagery from very different points of view is the association of line to drawing. Similar to many of the other artists whose works are included in the larger 
set of drawings in this research, they paint as well as draw. When discussing drawing they speak of line and quite a few aspects of line rather than color. An interesting comment to be made in Bangert's description of grass, she spoke of the repetition of form and line never the color green. Generally, the first association made with the word grass is the color green-not repetition of form or line. Suggesting that in drawing, generally there is a greater concern in deciding how form and line rather than color effect the drawing process.

Since validation of the initial list of visual features would be sought through psychological testing of human perception before, defining the list of visual features through machine measures, looking at the effect color could have on this testing was a concern that needed to be examined (Thurstone, 1927). The Law of Comparative Judgment as initially developed by Louis Thurstone assists with the selection of stimuli to be tested. The first requirement is the specification as to what it is that will be judged or compared. He describes that this specification can be any quantitative or qualitative attribute about which we can think 'more' or 'less' for each specimen. The attribute may be assigned, as it were, in differing amounts to each specimen and defines what he termed "the psychological continuum" for that particular project in measurement. Along this continuum is what he termed "discriminable dispersion":

An ambiguous stimulus which is observed at widely different degrees of weight on different occasions will have of course a large discriminable dispersion. Some other stimulus or specimen which is provocative of relatively slight fluctuations in discriminable process will have, similarly, a small discriminable dispersion (pp. 266-267).

Color is a visual feature that is not present within the majority of creative drawings examined. This suggests that participants' comparative judgments could greatly affect the outcomes of what visual features are identified. Through review of the literature it was determined at this point in the research that line and other types of marks are not dependent upon the use of color within drawings. Yet through perception testing color could greatly affect the outcome of the types of marks perceived. 
The most important aspect of the model at this formative stage is the accuracy of identified marks as they pertain to line within the larger set of creative drawings. Maitland-Gholson (1985) in their research dealing with psychology and the visual arts stress the importance of controlling variables. They state that the use of many stimuli may allow for greater generalization, but this needs to be weighed against fatigue which reduces reliability in similarity judgements.

The conclusion was made that in this first version of the model, it was most important to understand and recognize the qualities of line and other types of marks associated with line in creative drawings. Adding a visual feature such as color which is used in an unsystematic way would prohibit clear identification of other visual features.

There is a body of research to indicate that some objects automatically attract attention away from other objects in the visual field, and color could create what is termed selective visual attention away from other visual features (Dresp \& Grossberg, 1999; Guibal \& Dresp, 2004; Yantis \& Jones, 1991). A good example of this is the red signal in traffic lights (Verhoeff, 1928).

Guibal and Dresp (2004) in their research on color and geometric cues in depth perception point out that color is assumed to have an independent status as a cue to depth perception because of the competitive nature of short-wave-length colors and long-wave-length colors in the well-known phenomenon of color stereopsis.

The question being asked in the identification of visual features in creative drawings is: "What is it that we see or perceive when we don't have color as a visual feature?"

The following are used as justifications for excluding the chromatic color hue from the model and using its corresponding grey value: 
1. Since this is the first model being developed for a style grammar in creative drawing, it was important to clearly identify visual features as they pertain to drawing and specifically their relationship with line.

2. The large amount of documentation, which supports the theory that line not color was most important to drawings.

3. Color affecting tone rather than line-reviewing the range and effect of tone through non-chromatic means in this version of the model would assist to articulate clearer definitions of the visual feature of tone as well as texture for measures to be developed.

4. The need for an initial set of measures and features that could be tested consistently — a larger portion of creative drawings used in the model did not use color.

5. The initial list was a descriptive list of traits and visual features based solely on line and line usage not color usage (A. A. Gooch, Long, Ji, Estey, \& Gooch, 2010; B. Gooch, Sloan, Gooch, Shirley, \& Riesenfeld, 1999; Goodwin et al., 2007; Grabli et al., 2004; Kaplan, Gooch, \& Cohen, 2000; Winkenbach \& Salesin, 1994, 1996).

6. The Law of Comparative Judgement developed by Louis Thurstone (1927) (Macmillan \& Creelman, 2004; Podsakoff, MacKenzie, Lee, \& Podsakoff, 2003; Zimmermann, 1996). Color as an element is a very powerful visual feature and could supersede the perception and visualization of line and mark-making (Daniel J Graham \& Meng, 2011; David O'Hare, 1980; D.P.A. O'Hare \& Gordon, 1977; Winn \& Everett, 1979).

\section{Initial Iterations of the Model}

The model of style grammar based on the visual features of creative drawings went through many iterations. First, it was described through visual features identified in the examination of research on task-oriented drawings, then with the addition of features as described in drawing manuals, and artists' sketchbooks (Figure 
18 and Figure 19). The specific consideration of color was identified and addressed at an early stage of the model development (Figure 20).

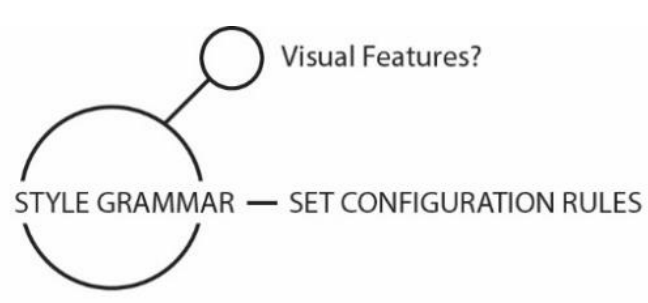

TASK ORIENTED DRAWINGS

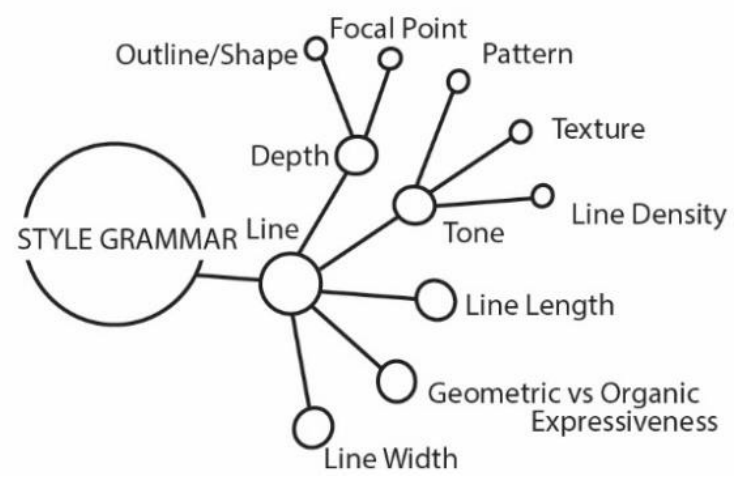

Other Considerations

Color

Types of Pattern \& Movement

undulating

alternating

progressive

Figure 18: Initial Development of the Model.

CREATIVE DRAWINGS

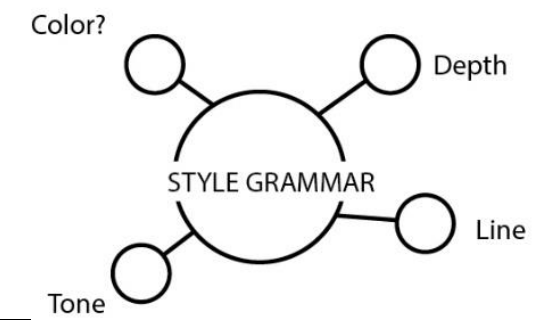

The Perception of Color vs Other Traits

Color usage vs other traits

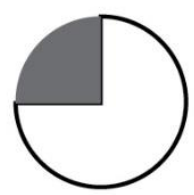

Color perception vs other traits

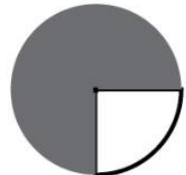

Figure 19: Other considerations in the model for creative drawings-the perception of color. 


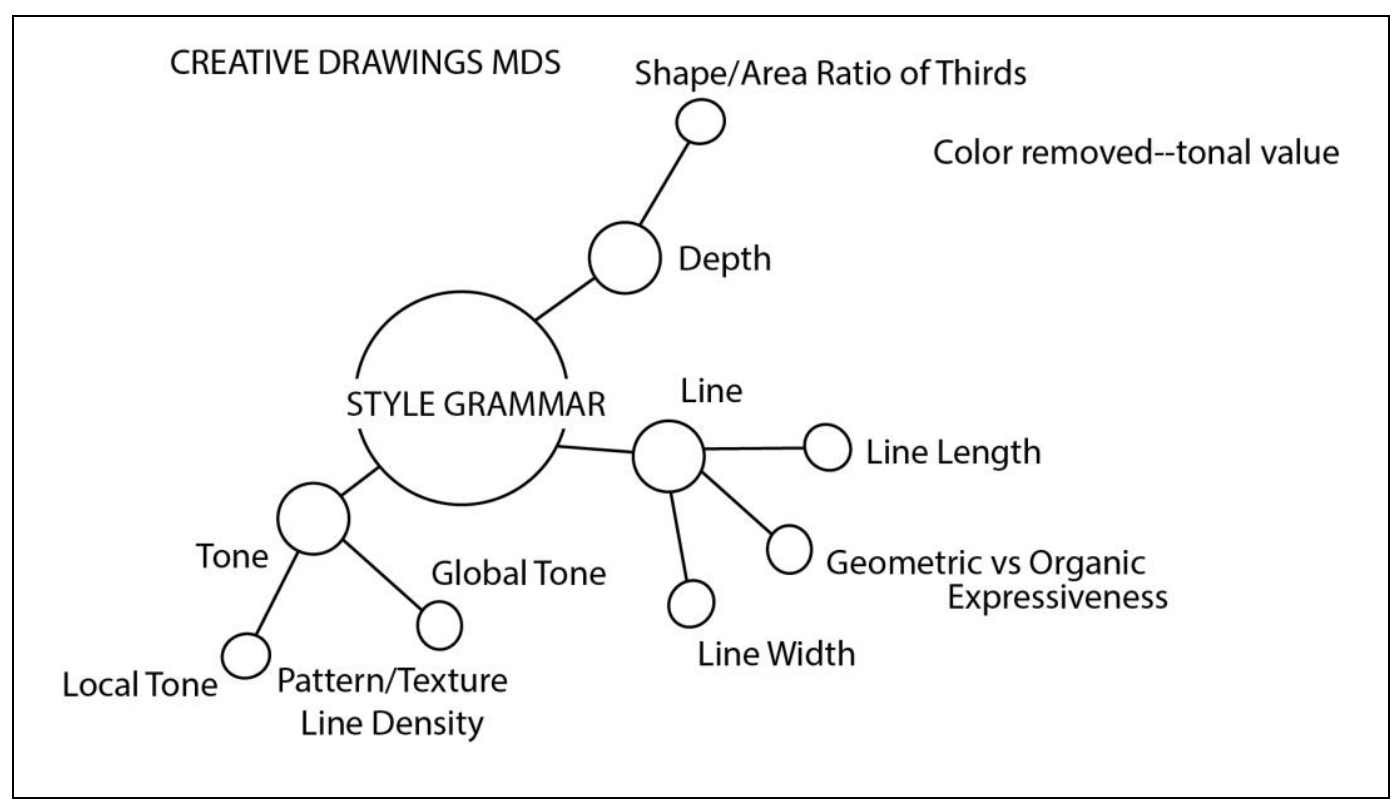

Figure 20: The model before data analysis of the MDS card sort activity.

Once the initial list of visual features seemed complete, an MDS procedure was run to test the validity of the features identified. The model was then modified after the analysis of data collected from the MDS procedure with the addition of smudge, which was determined to be an additional trait of tone. Additional modifications occurred through the identification of feature extraction and the development of operational procedures to obtain measures of specific traits (Figure 21). 


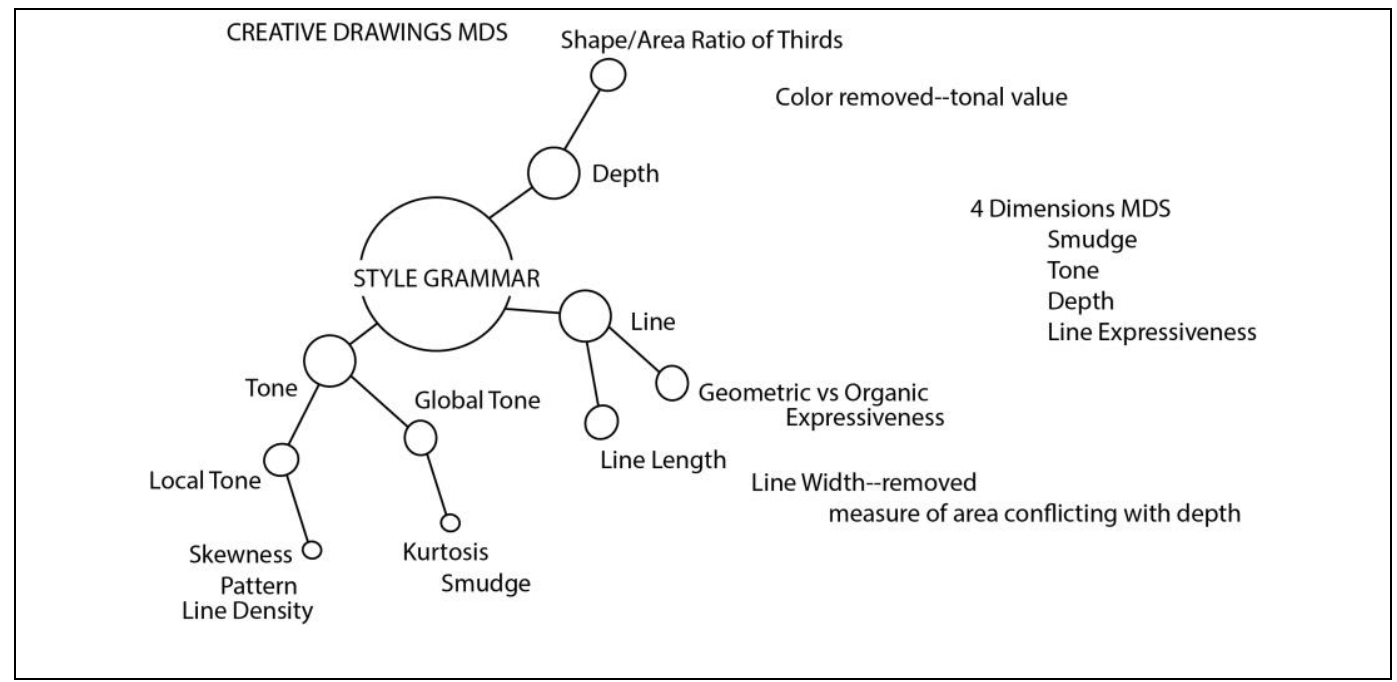

Figure 21: Additional modifications to the model with the identification of feature extraction and the development of operational procedures, after the analysis of the first MDS free card sort.

\section{Implications of the Model on Teaching Drawing}

Teaching drawing from a principled borrowing approach is very different from an ad hoc approach to drawing and trying to discern what you have after the fact. A borrowing approach to teaching style in design is also very different from teaching the imitation of style in design. Forgery, parody, and emulation all have in common the basic idea of imitation. There is of course the aspect of intent that influences the imitation as being deceitful, deliberately exaggerated for effect, or the attempt of mastery. A principled borrowing approach, using a style grammar is a general-purpose approach for exploiting style in a drawing/design process.

The model exemplifies what traits and features have significant measures—in a sense determining what is important to borrow through quantitative analysis. This analysis also points out where measures are similar between groups of drawings there can be confusion or misinterpretation. Taking the analysis further is the ranking of features used as well as the ability to identify those features that were not used by an artist. Both of which have significant impact and importance in the model. It is 
possible for a complete art process to be based on the examination and exploration of a single identified feature.

Laing and Masoodian (2016) in their research found that simply looking at imagery was not an effective tool for design ideation and creative output. They determined that 'providing scope' was far more important for creative output. A model of style grammar in creative drawing provides a basis for a different visual framework that encourages the reinterpretation of ideas and provides scope. The idea of computational design practices using various types of grammars like shape grammars offers a formalism to represent visual reasoning in design (Gürsoy \& Özkar, 2015).

There are many views and conceptions on the best placement and use of the computer as well as traditional design foundations practices in current art education. Examining different opinions and explaining how those opinions developed can assist with finding ways to move forward towards a clearer and better integration of design concepts, drawing processes and the computer.

Leavitt (1976), in the preface to her book on artists and the computer talks about the vast areas and different levels of exploration the computer affords the artist and the possibilities of new types of art these explorations can generate. She goes further to explain how the tools and medium used by artists changes the meaning of the artifact made. She describes two functions of the artist as being completely separate, suggesting that there are even two different types of artist- the artist who goes to the art store to purchase a given set of tools to create art and the artist who first creates the tools they use via the computer-meaning programs to create art.

Leavitt's description cuts to the crux of the problem facing design education today-the lack of integration between traditional practices and tools and not so much the problem of using the computer as yet another tool, which a great many traditional artists use, but as a machine to create new and personal tools. As I discuss in my research (page 89), artists are not unfamiliar with creating their own tools, but 
to do so effectively they need to grasp rules of scientific investigation, which include skills in math and computer science towards the purpose of integration in an art process.

I include three syllabi for general discussion (Appendix B). There is a fair amount of agreement over what should be taught in a beginning level university drawing class within the North American education system. The first syllabus is from the United States Department of Education College Board (2013). In the United States, the College Boards Advanced Placement (AP) system designates what should be included in a secondary education curriculum for credits to be accepted by a tertiary education institution. The College Board thoroughly researches university curricula and maintains boards of university educators to assure its syllabi meet high standards of expectations for university credit. AP syllabi are thus usually seen as standards for the content of introductory university courses in the United States.

The second syllabus is from Cat Normoyle of the Memphis College of Art. Using Google's analytics, it was shown to be the most popularly downloaded introductory drawing syllabus on the internet and has been used as a model for many other faculty syllabi.

The final syllabus is from Alaiyo Bradshaw from the Parsons School of Design. The Parsons school is currently the third ranked school of design in the world by QS (Quacquarelli Symonds Limited), an organization that gathers data on universities worldwide and provides ranking information on those universities based on academic reputation, employer reputation and research impact (http://www.topuniversities.com). The first, being the Royal College of Art in England, and is only graduate studies. Suggesting the Parsons' syllabus represents some of the highest quality education in drawing one can receive at a university. As you can see, there are many similarities between the three syllabi. All three syllabi note the importance of a demonstrated reflection of skills learned and creative choices made through a portfolio of work. All three use similar approaches to how that portfolio is developed. They all include some form of the computer as tool—either 
for drawing or for presentation. Not as a tool for analyzing imagery in a method driven systematic way to assist with design ideation and making processes. All three rely on traditional methods of life drawing to develop observational skills.

An artist using the computer as a scientist would a microscope to explore and segment a drawing into visual features and traits could greatly add to the development of observational drawing skills. To link associations and specific responses with each visual feature and trait would foster a different type of exploratory process to develop one that can include a quantitative reference to assist with the translation of observations, relationship analysis, the organization of form to communicate visually.

The model of style grammar would fit well into any and all three of these syllabi as an added tool to aid, automate, or augment design processes with computational support (Bernal, Haymaker, \& Eastman, 2015). The model supports both systematic and heuristic methods of learning which shape the process experiences of students. The model provides students with a frame of reference to assist with learning how a drawing is carried out. Self-learning is an important skill that needs to be developed through design foundations and beginning drawing courses. Daalhuizen, Person, and Gattol (2014) in their research have shown that the use of self-learning methods are an effective part of teaching students work practices and processes for handling design activities and analyzing objects of design.

Learning processes for creative ideation are considered an important aspect of design education and involves divergent reasoning process to generate useful and unexpected ideas (Maher, 2010; Schunn, Paulus, Cagan, \& Wood, 2006; Sosa, Rojas, Gero, \& Qinqi, 2016). A majority of methods and techniques for idea generation prioritize quantity particularly in the early stages of the design process, suggesting more ideas allow for the realization of several outcomes and deferring evaluation of ideas to later stages (Sosa \& Gero, 2012; Yang, 2009). 
Many researchers have identified two different types of reasoning within the design process—divergent and visual (Goel, 1995; Kavakli \& Gero, 2001; Schunn et al., 2006; Stiny, 2008). They define divergent reasoning as the process of generating as many different alternatives as possible is usually tied to linguistic formats rather than visual formats. They define visual reasoning as being tied to visual formats and dealing with perception, encoding, mental transformation and representation. Exercises based on visual features within the framework of the model could develop both of these types of reasoning skills.

An additional benefit in learning how visual features work within the model could facilitate other types of learning and development. It could encourage students to think about the augmentation of design process with tools of their own making that they can develop themselves as design aids for the transference of imagery onto a drawing surface. Ironically, the use of the model in this way harkens back to the Bauhaus which was grounded in craft ideology and stressed intuitive solutions to design problems. This led to the development of design foundation curriculum for the New Bauhaus in Chicago in the 1930s and 1940s by Laszlo Moholy-Nagy which is now the Institute of Design at Illinois Institute of Technology (Catterall \& Nugent, 1999; Findeli, 1990; Swanson, 1994; Tavin, Kushins, \& Elniski, 2007). 


\section{Chapter 4: Testing the Model Phase 1}

This chapter examines the model development and the testing of visual features through human perception. I discuss the use of psychological procedures, techniques and analysis. I begin with an overview and discuss activities that were a part of all three phases of testing.

\section{Overview: Testing the Model}

This research was conducted in three phases with ancillary activities used across the three phases. Phase 1 obtains measures of human perception and identity of visual features through a Multi-Dimensional Scaling (MDS) free card sort procedure. Phase 2 discusses the limited use of a second categorical MDS procedure that produced poor results. This avenue of exploration was abandoned and the third phase was developed. In phase 3, machine measures of the visual features were created and statistical analysis was run to determine if the measures could appropriately divide artworks into their respective artist styles.

\section{Ancillary Activities - Image Selection}

Bridgeman Images, an academic arts database was identified as a valuable source for images. Bridgeman was chosen because they have one of the largest archives for reproductions of works of art in the world. Founded in 1972, the Bridgeman Art Library, based in London, Paris, New York and Berlin, provides content for the Grove Macmillan Dictionary of Art Online and ArtWeb-an online gateway to museum collections built in collaboration with Reunion des Musees Nationaux. Their image bank was used for the selection of all the drawings under examination.

A subscription was purchased for access to Bridgeman Education as stated on Bridgeman Education website at https://www.bridgemaneducation.com:

"Bridgeman Education is a complete visual resource offering over 1,000,000 digital images of art, history and culture from global 
museums, galleries, private collections and contemporary artists all copyright cleared for educational use."

Initially, thumbnails of images with a corresponding pdf file that gave brief descriptions of each art work were downloaded (Figure 22).

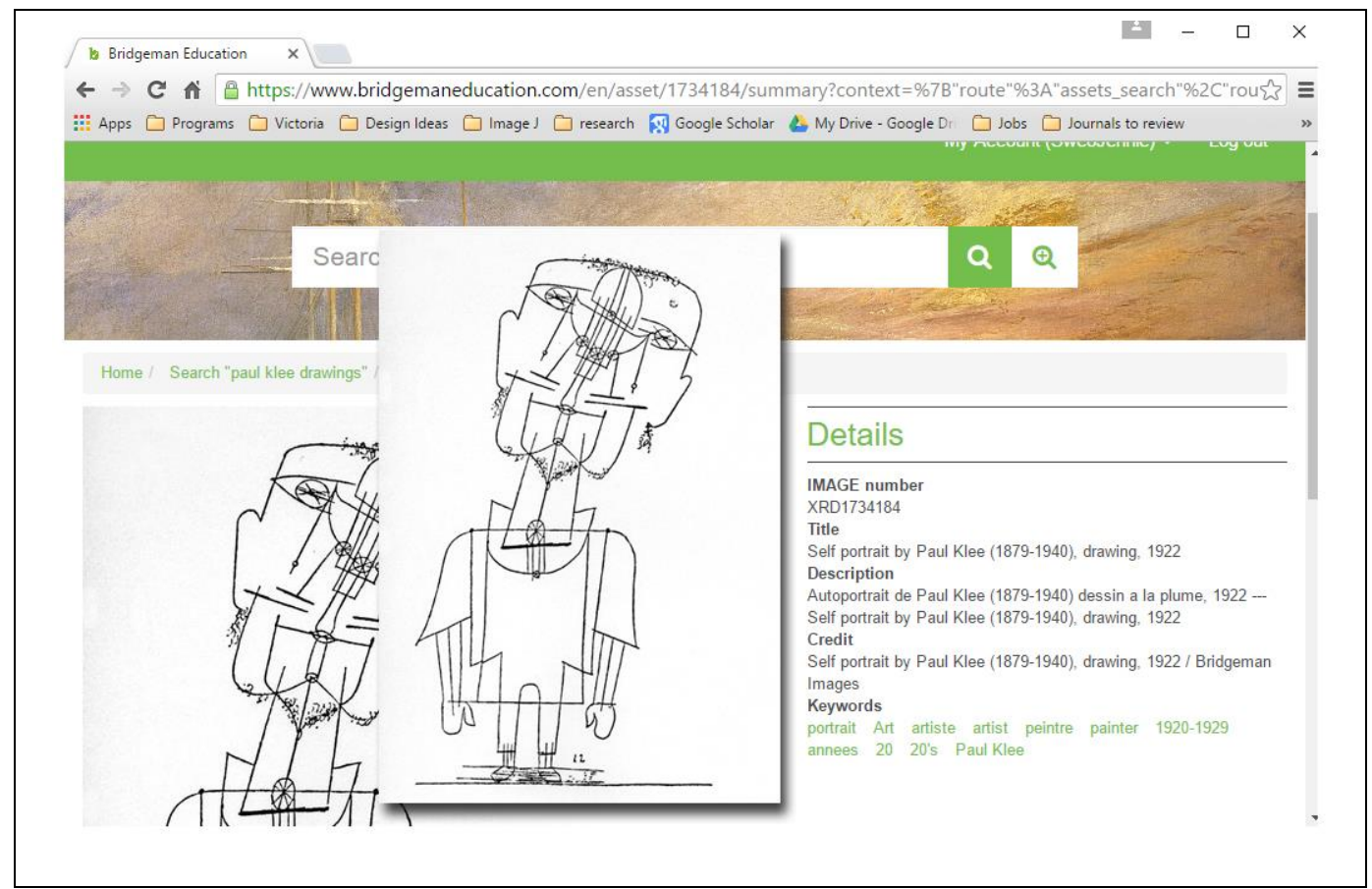

Figure 22: A sample of a downloaded from Bridgeman's Education website image thumbnail and associated pdffile with background information.

Paul Klee. (1922), Self-portrait, (drawing). Bridgeman Images.

120 drawings were randomly selected from Bridgeman Images using these generalized categories to choose artworks from: Renaissance, $19^{\text {th }}$ century, postimpressionistic, expressionistic, and abstract. The images chosen were from various artists using a variety of tools and techniques. Each category was initially populated with 350 images per category. Each image was numbered and labeled as 1-350. A random numbers generator from https://www.random.org was used to select images for each category until 24 images for each category was met. Once an image was selected it was removed from the pool of total images that could be selected. No image was repeated within the 120 images used for the two MDS sorts. 
All images used for machine measures and the two MDS card sorts in this research were downloaded as raster images from Bridgeman's image bank. All operations for image preparation were executed systematically. Except where noted, steps 2, 5, and 6 of the list below did not apply to imagery used in Phase Two for the collection of measures for the multinomial and bivariate logistic regression analysis. Since image access from Bridgeman's Education site only allowed for small thumbnails, the administrator of the site was contacted to obtain high resolution images for the purpose of obtaining measures for both MDS card sorts and the multinomial and bivariate logistic regressions. Access was granted for 200 high resolution images in total for the purpose of obtaining measures. These images were placed on a secure FTP site. Following these steps, always done in this order, images were obtained in the following manner:

1. Downloaded from Bridgeman's FTP Site as high resolution jpegs.

2. Conversion of color to greyscale using Adobe Photoshop version CS6 (applied only to the MDS card sorts where applicable). No color images of drawings were used for Phase Two computer measures and logistic regression analysis.

3. All images were scaled proportionately to a height of 3200 pixels, with a resolution of 300 pixels/centimeter.

4. No cropping was done to the downloaded images.

5. All images used for the two MDS card sorts were printed individually on high quality sheets of A4 paper (applied only to the two MDS card sorts).

6. All images were number coded on the back (applied only to the two MDS card sorts).

With the MDS procedures identified and imagery selection and presentation determined, it was important to define the participants, and define the interview protocol. 


\section{Testing Human Perception of Visual Features}

A review of studies in psychology for visual arts research identified multidimensional scaling (MDS) analysis as the best type of tool and procedure to use in this step of possible visual feature list identification and validation (Amadasun \& King, 1989; Maitland-Gholson, 1985; Tamura et al., 1978). Multidimensional scaling (MDS) refers to a set of statistical techniques that translate perceived proximities among stimulus objects into a spatial representation of points (Kruskal \& Wish, 1978; Schiffman, Reynolds, \& Young, 1981). Using MDS researchers can obtain quantitative estimates of similarity among groups of items. Similar items are located in a closer proximity to one another, while dissimilar items are located further apart (Hout, Papesh, \& Goldinger, 2013). Maitland-Gholson (1985) list various studies of perception including:

- Helm and Tucker (1962) who worked with color and human perception. Subjects arranged triads of color swatches against a neutral background so that physical distances represented perceptual differences. The analysis they used was a precursor of modern multidimensional scaling and identified three distinctive dimensions.

- Silver, Landis, and Messick (1966) who worked with visual form and human perception. They analyzed similarity judgments of 30 geometric figures using an MDS technique. The results indicated several dimensions. The most prominent dimension being number of sides. However, their results did not exhaustively determine or clearly define all dimensions of the perception of form.

- Isaac (1970) who worked with analyzing dissimilarity judgements and human perception. Twelve photos of varying facial expressions of one man were used. This study did not attempt to name dimensions. The study rather supported the hypothesis that multidimensional-scaled similarity judgments are indicators of a general perceptual structure, point to the differences in the 
configurations of the 12 photos were directly tied to individual differences in perception of participants in the study.

The above studies indicate the wide variety of stimuli, which MDS procedures can effectively accommodate. MDS is an accepted approach that has been used by researchers to measure and understand the relationshipsimilarity/dissimilarity between objects (Berlyne, 1975; Dew, 2008; Gardner, 1970; Hardiman \& Zernich, 1982; Hartley \& Homa, 1981; Hout et al., 2013; Kruskal, 1964; Kruskal \& Wish, 1978; Maitland-Gholson, 1985; Netemeyer, Bearden, \& Sharma, 2003; Schiffman et al., 1981; Takane \& De Leeuw, 1987).

Schiffman et al. (1981) outline many advantages to using multidimensional scaling procedures:

- They are low in experimenter contamination;

- They do not require a prior knowledge of the attributes of the stimuli to be scaled;

- They provide a space that reveals dimensions relevant to the subjects;

- Experiments designed to collect similarity data for MDS analysis generate a large amount of information and generally yield stable spaces with only a few subjects.

Schiffman et al. (1981) go on to state that the disadvantages to MDS are that experiments can be time consuming and expensive. This research used sorting procedures that kept data collection time down and were cost effective as outlined by Whaley and Longoria (2009), who also state that card sorting is a popular technique because of its advantages:

- Ease of administration;

- Low susceptibility to experimental demand characteristics;

- Economy in handling large number of objects or stimuli; 
- Grounding in a theoretical framework such as Kelley's personal construct theory, and utility with different types of objects or stimuli such as pictures.

Other researchers have stated that card sorting is a preferred method of data collection for MDS analysis because it is more natural, participants usually enjoy it, the whole operation takes relatively little time, and underlying dimensions can be uncovered without contamination of researchers' preconceptions (Coxon, 1999; Rosenberg \& Park Kim, 1975; Whaley \& Longoria, 2009).

\section{The Identification of Test Subjects \& Protocols}

As discussed earlier, MDS is a tool that provides a way to quantify similarity judgments (Hout et al., 2013). The outcome of the MDS is expected to describe a proximity map of particular relationships where some items that are similar are closer together and those that are perceived as dissimilar are further apart in the map (Fincher \& Tenenberg, 2005; Whaley \& Longoria, 2009). Many human perception studies report that results from sorting tasks can vary based on the knowledge associated with the categories as well as the amount of time, supervision or explanation needed to complete a sorting task (Chi, Feltovich, \& Glaser, 1981; Hillerbrand, 1989). Chi et al. (1981) in their research specifically discuss the difference in the knowledge base associated with categories when dealing with novices and experts. This suggested that participants be divided generally into 2 different groups for the sorting tasks:

(1) Non-art experts: individuals with tertiary degrees in fields outside of visual arts who are working on advanced degrees in fields excluding visual arts and or who are working professionally in fields other than one associated with visual arts. 
(2) Art experts: individuals with tertiary degrees in a visual arts field who are working on advanced degrees in a visual arts field and or who are working professionally in a visual arts field.

Many classes in a visual arts education, particularly courses in art history deal with reviewing slides of artworks by various artists and include tests that are based on memory recall pairing an artist with an artwork. There are many more courses outside of art history where art students go to museum talks, gallery openings with the intent of building awareness in the variety of artworks in public spaces. There is also an appreciation and experience developed on how to go about looking at a work of art. These sorts of activities suggest while the participants in the expert group may not have seen some of the specific imagery selected for testing; it was considered likely that they would be familiar with similar types of works and even have a sense of general familiarity with the sorting task.

Compared to non-art experts who might lack a sense of familiarity with comparing artworks and feel a bit more time pressure. Both groups would be given the same instructions for the MDS card sort, but if extra assistance or time was needed, it was anticipated, participants unfamiliar with the imagery would most likely need it more than those with some familiarity at comparing artworks would.

Speed was not a principle component of the study to be conducted. It was expected that participants would take their time to review the stack of images for each card sort activity. This approach of evaluations/reevaluations based on the increasing set of images as more were revealed and displayed by each participant (from one stack to many) is a well-documented approach used by researchers in the assessment of similarity/dissimilarity judgements (Bijmolt \& Wedel, 1999; Whaley \& Longoria, 2009). This approach allowed for groups participating in the sorting tasks to be small, no more than 3 individuals at one time, in a relaxed and as much as possible a stressfree environment. 
Another aspect of comparing data from these two groups was in the possibility of having different visual features identified by each group because of familiarity and non-familiarity with the imagery.

Since the two MDS procedures involved human participants, it was necessary to develop the procedures to be used and submit them in written form to the Victoria University Human Ethics Committee, along with copies of the solicitation email, flyers, consent forms, and any additional information that would be given to participants (Appendix A). Additionally, ethics was also sought and approval was granted to solicit participants from International Pacific College (IPC, now IPU) a higher education institute located in Palmerston North, New Zealand.

Once approval from the Victoria University Human Ethics Committee and from IPC was received, a pilot test involving 5 participants was performed to develop and refine procedures. The pilot test is a recommended standard procedure of MDS data collection and assists with determining the suitability of the pool of drawings, item-trimming, and reveals any issues with the instructions given and procedure being considered (Coxon, 1999; Netemeyer et al., 2003; Schiffman et al., 1981).

Pilot tests were conducted at IPC. Since the school is geared towards higher education in fields of business rather than visual arts, all the participants were art novices, rather than art experts. This would help to identify any issues with instructions and assure art specific terms were clear, concise, and understandable.

Pilot tests were conducted in the same classroom at IPC that was later used for the actual testing. The pilot tests were run on an individual basis with the researcher as the only observer, exactly the way the actual tests were run.

While the instructions given and all other aspects of the testing were the same as normal testing, pilot testing of imagery was limited to 15 images in total. The images themselves were used in both MDS card sorts, five for the first MDS and 10 for the second MDS. In the pilot tests each participant received the initial stack of images in a uniquely randomized order (the images were just shuffled). It was 
apparent from simply watching the pilot tests, participants always compared an image with the previous image seen. This suggested a strong order effect to the stacking of the images. To control for the order effect in the actual study, the images were randomized once.

This randomized order was used on every initial stack that was given to each participant. All five test pilot participants felt the instructions were clear and understandable so no changes were made to them. The same set of printed instructions were used throughout the testing as recommended by several researchers to avoid the risk of participants behaving differently due to a change in instructions (Rugg \& McGeorge, 2005). It was determined that keeping the participant number to a maximum number of three and the use of a large classroom with many large tables would allow for both card sort activities to be setup in advance. It allowed for participants to spread the images out in a comfortable manner. The tabletops were kept clear of clutter apart from the cards themselves. All the participants left a good amount of space between stacks of images as a clear demarcation of segmentation.

This allowed for the collection of data—each participant's card stacks/sorts to be collected in an organized and systematic manner with no errors. The collection process consisted of each stack bound with a paperclip and then placed in a folder. All the folders were then put into a large envelope. Each participant had two envelopesone for the first MDS sort and one for the second MDS sort. This allowed for each participant's data to be entered into an EXCEL spreadsheet for later analysis.

Pilot test participants were solicited the same way as regular participants and even though the actual testing time took far less than the actual MDS procedures (15 to 20 minutes) they were given the same remittance choices for their participation as regular participants. Specific data of the card sorts was not saved for the test pilot participants. The pilot testing was run over a 5-day period of one participant a day.

The targeted number of participants for each group was set at a minimum of 10. A review of other researchers who conducted similar types of MDS procedures 
indicated that a small number of participants listing the number at 10 or fewer than 25 would allow for good performance (Bijmolt \& Wedel, 1999; Takane, 1978; Takane \& De Leeuw, 1987). Büyükkurt and Büyükkurt (1990) reported in their research on the robustness of small-sample sizes in MDS procedures that even when the number of subjects was as low as nine, the goodness of recovery was remarkable. Whaley and Longoria (2009) in their research on developing a methodological approach for card sort data for MDS analysis reported the solicitation of 10 participants.

Participants were solicited primarily from two universities: Victoria University of Wellington via flyers and a student email notice which was sent out by the administrative staff of the design school and IPC located in Palmerston North, New Zealand via flyer and solicitation in classes. All participants were notified that the amount of time needed for the card sort activities was approximately $11 / 2$ hours. Because of the amount of time involved, at the end of the second card sort and filling out a small questionnaire each participant selected a remittance of either $\$ 40$ or a $\$ 50$ gift certificate. They were made aware they could withdraw from the activities at any time for any reason and any individually identifiable data collected would be destroyed but there would be no remittance for partial participation.

A schedule was posted at both locations and a classroom was reserved for the activity. Participants generally showed up at scheduled times in groups of 2 or 3 . All the participants that showed up for testing in either location completed both card sorts as well as filling out the consent form. All participants received their selected remittance.

\section{Multidimensional Scaling Procedure Protocols}

Two card sort activities were prepared following a procedure recommended by Whaley and Longoria (2009). All images were randomly assigned a stacking order, numbered on the back, and each participant received the images in that same order. 
All the participants were instructed that they would be viewing a unique image on each sheet of paper that would depict people, persons, places and inanimate objects.

The first card sort activity involved a free sort: there was no restrictions on the number of piles or groups that were generated. The number of piles or groups was completely dependent on the participant's own judgement. Participants were instructed to categorize or sort by creating mutually exclusive piles comprised of visually similar traits of line.

The first card sort was comprised of 40 images, each printed to the highest quality possible on a single sheet of quality A4 white cotton paper. Review of MDS card sort procedures particularly those that used a similar procedure to what was used in this first sort suggested anywhere from 8 to 99 entities or stimuli (Rugg \& McGeorge, 2005). Whaley and Longoria (2009) whose work is being referenced on how to conduct the free sort card analysis used 99 cards. Takane (1978) used 29 stimuli. Silver et al. (1966) in their research suggested 40-50 stimuli. Rugg et al (2005) give a suggestion of 20 to 30 entities as a manageable number, but also state:

"As a rough rule of thumb, if the results are to be analyzed statistically, then the lowest number of entities should be about eight; otherwise, the lowest number is a matter for the questioner to decide" (p. 85).

The second card sort which is a more typical, categorical card sort used the remaining 80 cards.

\section{Card Sort Activity One}

Participants were directed to a classroom where testing took place. Two handouts were given to each participant. The first handout was a review of the purpose of the card sort activities and the research being done with contact information, which they kept. The second handout was a consent form, which each participant filled out and returned to the researcher administering the activities 
(Appendix A). Every participant received the same instructions via a written script (Appendix A).

This activity usually took about 30-45 minutes to complete and the general observation was that most people found it fun.

\section{Data Analysis of the Card Sorts}

The collected data from the first sort was initially recorded in EXCEL. As recommended by Whaley and Longoria (2009), independent variables were constructed to systematically quantify:

(a) Each participant (subject),

(b) Separate piles created by each participant (pile),

(c) The presence of absence of an image in a specific pile (1-40),

(d) The number of cards in in each pile (cards)

(e) Whether a participant was an expert or novice $(\mathrm{E} / \mathrm{N})$

Each pile created by a participant was organized as a row in the spreadsheet and coded the 40 images as binary variables ( 1 or 0$)$ in the columns (Figure 23).

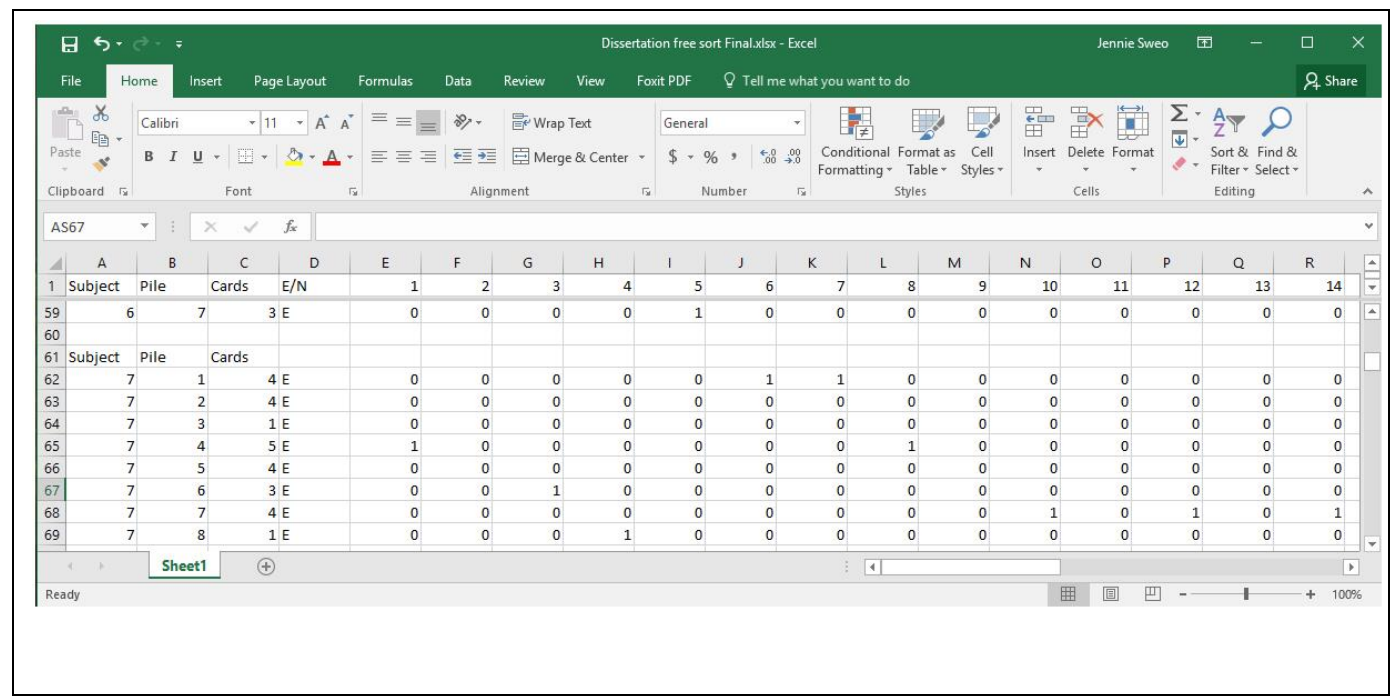

Figure 23: Sample of data coding of the first MDS Card sort activity. 
Once all the data was recorded it was then imported into SPSS and the PROXSCAL procedure was used for analysis. PROXSCAL creates a matrix of proximities into a geometric configuration (or map of points) in $n$-dimensional space to uncover meaningful categories encompassing the visual relations in the proximity data (i.e., the participants' card sorts). The participants' card sort data was converted into proximity matrixes based on the Euclidean distance formula and then analyzed using PROXSCAL within SPSS. Analysis of the data was run for each group, experts and novices, as well as combining the two groups together for examination and review.

The analysis of the accuracy of image placement by all the participants in the second categorical card sort was performed using EXCEL. EXCEL was used to calculate the number of images correctly placed in each category, the percent correctly placed in each category and overall group percentage scores. Analysis of the data from the second sort was similarly run for each group, experts and novices, as well as combining the two groups together for examination and review. The cards from the second sort were also divided and color coded into two piles. The initial plan was that 40 images be used for initial testing and development of operational measures and that the remaining 40 would be used for a general validation of those measures.

\section{Human Perception and MDS Results}

The analysis of this data provided:

- A set of images that were categorized by human perception of line traits;

- A ranked order of line traits based on the participants' perceptions;

- An ordinal scale of the drawings ranked on each dimension; and

- A common space map that allows for the clustering of images based on the similarities of line traits rather than a linear art historical mapping.

Initial data analysis was run on the two groups of participants: art novices and art experts. A larger amount of stress than expected was apparent in both groups. 
Stress is the primary measure used in MDS to determine if two items belong in the same category or different groups. More stress indicates more groups are needed. Three outliers, 1 from the art experts group and 2 from the art novices group, were discovered and removed from the data. Close examination of the data suggested that the three outliers used an inordinately large number of stacks of images with only one image in them, greatly increasing stress levels. In both art expert and novice groups the average number of stacks for the overall group was 9. The average for the 1 outlier in the art expert group was 15, and for the 2 in the art novices group it was 17.

Removing outliers brought the total number of subjects for each group down but they were still within acceptable numbers: 9 participants in the art expert group and 15 participants in the art novice group. Further analysis was run to see if there were significant differences between using 9 art novices or 15 and no significance was found. The final data analysis was run using 9 art experts and 15 art novices.

The data analysis was run three times: once for each group: art experts, art novices and the combination of both groups together. Table 1 is from the analysis running both groups together and shows that there was no missing data.

\section{Table 1: Case Processing Summary}

\begin{tabular}{|c|c|c|c|c|c|}
\hline \multicolumn{4}{|c|}{ Cases } \\
\hline \multicolumn{2}{|c|}{ Valid } & \multicolumn{2}{c|}{ Missing } & \multicolumn{2}{c|}{ Valid } \\
\hline N & Percent & N & Percent & N & Percent \\
\hline 264 & $100.0 \%$ & 0 & $0.0 \%$ & 264 & $100.0 \%$ \\
\hline
\end{tabular}

a. Euclidean Distance used

Further analysis showed the level of stress and goodness of fit for all 3 data groups: art novices, art experts, and the combination of novices and experts (Table 2). Analysis revealed that for all 3 groups the MDS solution was good at 4 dimensions and that 4 dimensions could be inspected visually in an attempt to 
interpret them in terms of particular visual features (Table 3). The higher levels of stress indicated in the novice group and the combined group were closely examined. Further analysis indicated more noise in the art novice group was caused by less agreement in the ordinal progression of the images within each dimension. This influenced the stress and noise level of the group data as well.

\section{Table 2: Stress and Fit Measures}

\begin{tabular}{|c|c|c|c|}
\hline & Art Experts & Art Novices & Both Groups Combined \\
\hline Normalized Raw Stress & .00277 & .00499 & .00423 \\
\hline Stress-I & $.05261^{\mathrm{a}}$ & $.07061^{\mathrm{a}}$ & $.06506^{\mathrm{a}}$ \\
\hline Stress-II & $.014904^{a}$ & $.18658^{\mathrm{a}}$ & $.18232^{\mathrm{a}}$ \\
\hline S-Stress & $.00369^{b}$ & $.00834^{b}$ & $.00834^{b}$ \\
\hline $\begin{array}{l}\text { Dispersion Accounted For } \\
\text { (D.A.F.) }\end{array}$ & .99723 & .99501 & .99577 \\
\hline $\begin{array}{l}\text { Trucker's Coefficient of } \\
\text { Congruence }\end{array}$ & .99861 & .99750 & .99788 \\
\hline & $\begin{array}{l}\text { PROXSCAL minimizes Normalized } \\
\text { Raw Stress. } \\
\text { a. Optimal scaling factor }=1.003 \text {. } \\
\text { b Optimal scaling factor }=1.000 \text {. }\end{array}$ & $\begin{array}{l}\text { PROXSCAL minimizes Normalized } \\
\text { Raw Stress. } \\
\text { a. Optimal scaling factor }=1.005 \text {. } \\
\text { b Optimal scaling factor }=1.000 .\end{array}$ & $\begin{array}{l}\text { PROXSCAL minimizes Normalized } \\
\text { Raw Stress. } \\
\text { a. Optimal scaling factor }=1.005 \text {. } \\
\text { b Optimal scaling factor }=1.000 \text {. }\end{array}$ \\
\hline
\end{tabular}

Table 3: Scree Plots

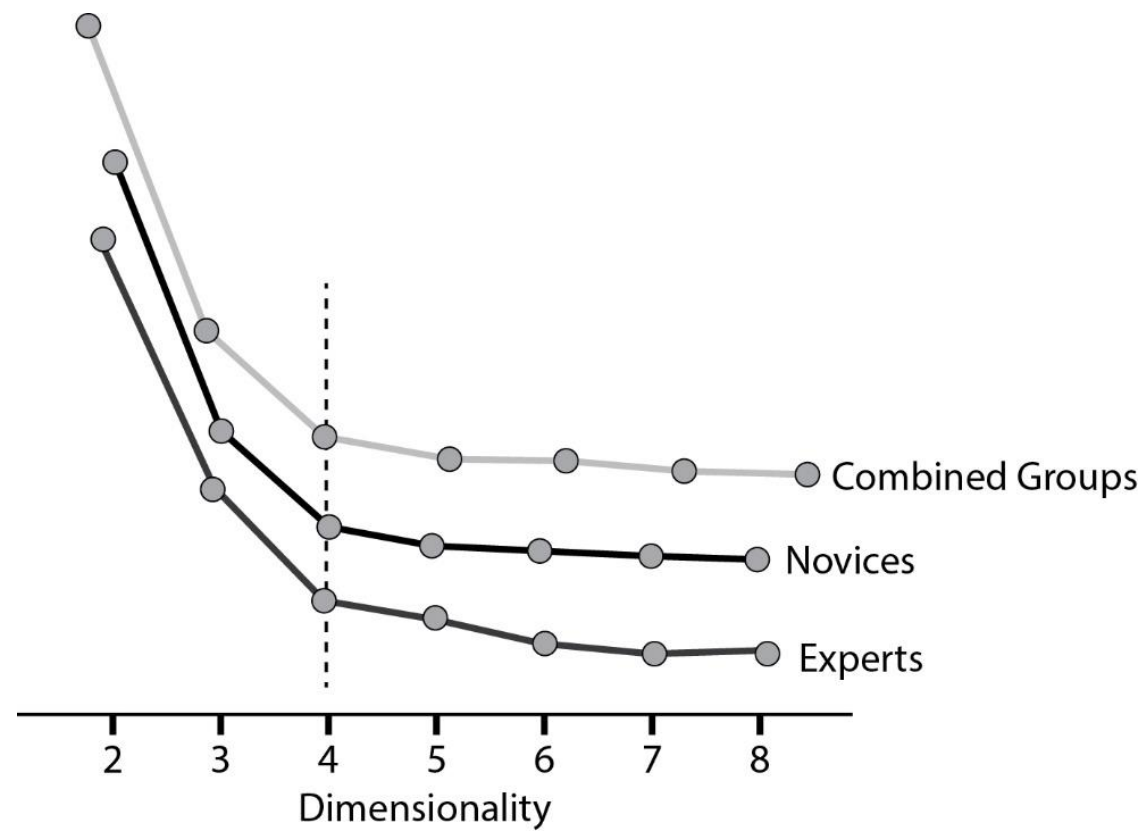


Lastly, the residuals plots for each group and the combined group of art novices and experts was examined for stress and goodness of fit. The rule of thumb is the presence of a 45-degree angle which indicates the linearity of the data and an acceptable goodness of fit (Appendix E).

Once the goodness of fit for the data was confirmed, analysis continued with the examination of the 4 dimensions. SPSS using PROXSCAL displayed the ordinal progression between two poles or end points of how the participants arranged the images. PROXSCAL also creates a common space map that visually displayed the correlations between these 4 dimensions. Subjective determinations of what the 4 dimensions are were made by arranging the images in the same ordinal progressions and observing the images in the common space maps.

The examination and analysis of the 4 dimensions though subjective were important to determine the completeness of the list of features that would be used for machine measures. Initial comparison of the ordinal progressions of the images for the 4 dimensions between the art expert and art novice groups strongly suggested that both novices and experts were sorting images using the same 4 dimensions. The expert group were more consistent as a whole and had less noise indicated by the better stress. Therefore, discussion of the 4 dimensions observed and defining them moved forward using the data analysis from the expert group.

The subjective determination of the 4 dimensions was based on:

(1) Examination of the ordinal progression of the 40 images in a linear fashion (Appendix E)

(2) Images were also examined in the ordinal progression from right to left and left to right creating a pairing of polar opposites. 


\section{The Discovery of Smudge}

Dimension 1 is seen as an indication of line clarity or cleanliness through an ordinal progression to line dirtiness or smudge (Figure 24). This was a new finding in this research. The initial list of visual features did not include smudge. The initial list was developed largely from research in non-photorealistic rendering (NPR), which focused on particular drawing tools and techniques, in particular pen and ink drawings. Other research sources were also examined which verified the list that was developed but similarly did not suggest smudge.

Smudge can be approached as an output of line quality_clean lines vs. "dirty" lines. It can also be approached as an indication of the quality of an edge, or edge detection-hard edges are easy to recognize because of the strong degree of contrast they create between two areas. 


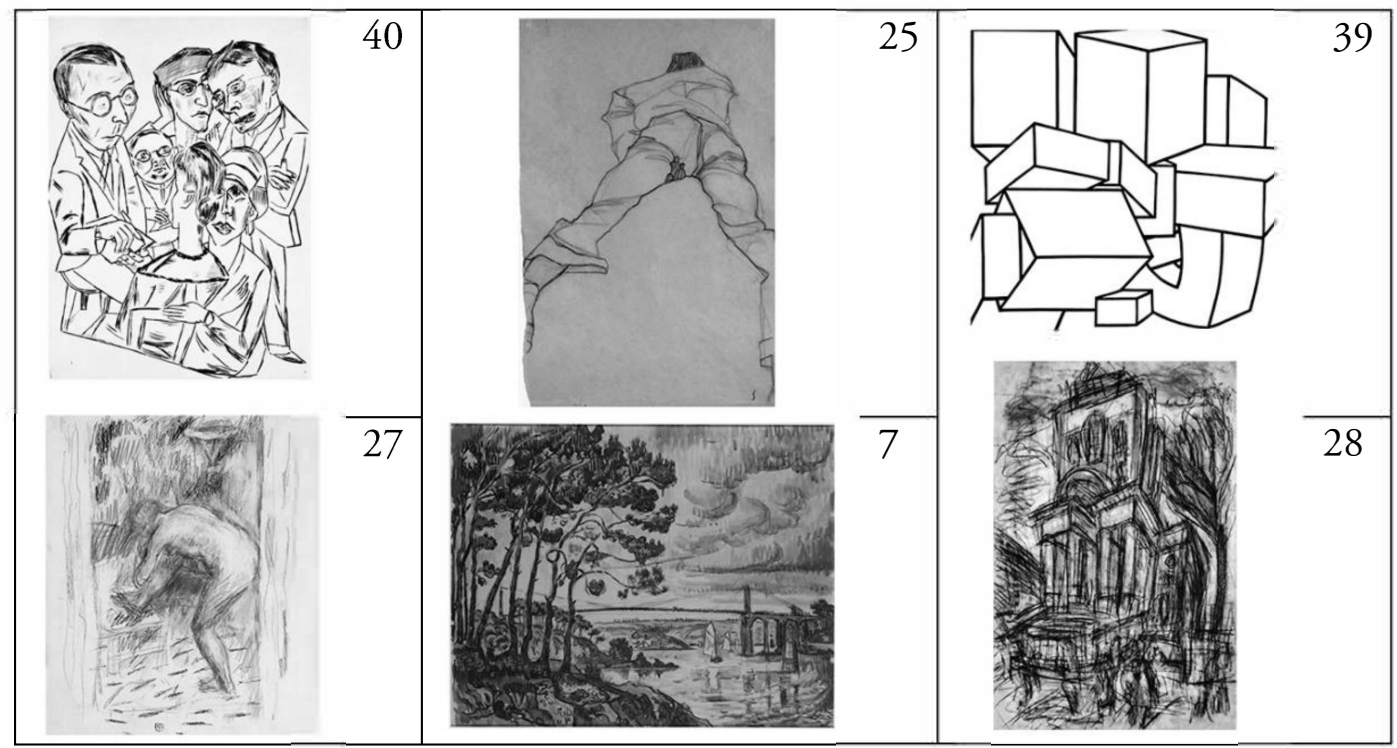

Figure 24: The comparison of measures and images suggesting the dimension of smudge.

Image \#40 (.697) \& Image \#27 (.141).

Image \#25 (.631) \& Image \#7 (.170).

Image \#39 (.620) \& Image \#28 (.184).

40. Beckmann, Max. (1922), The Artist in Society, (dry point). Private Collection, Bridgeman Education. 27. Pierre Bonnard. (1924), After the Bath, (graphite on paper), San Diego Museum of Art, USA, Bequest of Earle W. Grant, Bridgeman Education.

25. Egon Schiele. (1910), Man Lying Face Down, back view, (pencil \& w/c). Private Collection, Bridgeman Education.

7. Paul Signac. (1922), The Lezardrieux Bridge, (charcoal over black chalk on tan paper). Private Collection, Bridgeman Education.

39. Al Held. (1967), Untitled, (oil on canvas). Private Collection, Bridgeman Education.

28. Leon Kossoff. (1990), Christchurch, Spitalfields No.2, (charcoal on paper), Yale Center for British Art, New Haven, USA/Friends of British Art Fund, Bridgeman Education.

\section{Spatial Depth}

Dimension 2 was seen as an indication of the organization of spatial depth, although tone and texture through pattern was also present. Reviewing the entire dimensional space of all 40 images revealed a stronger case for the sorting of images by depth rather than texture and tone through pattern (Figure 25). 


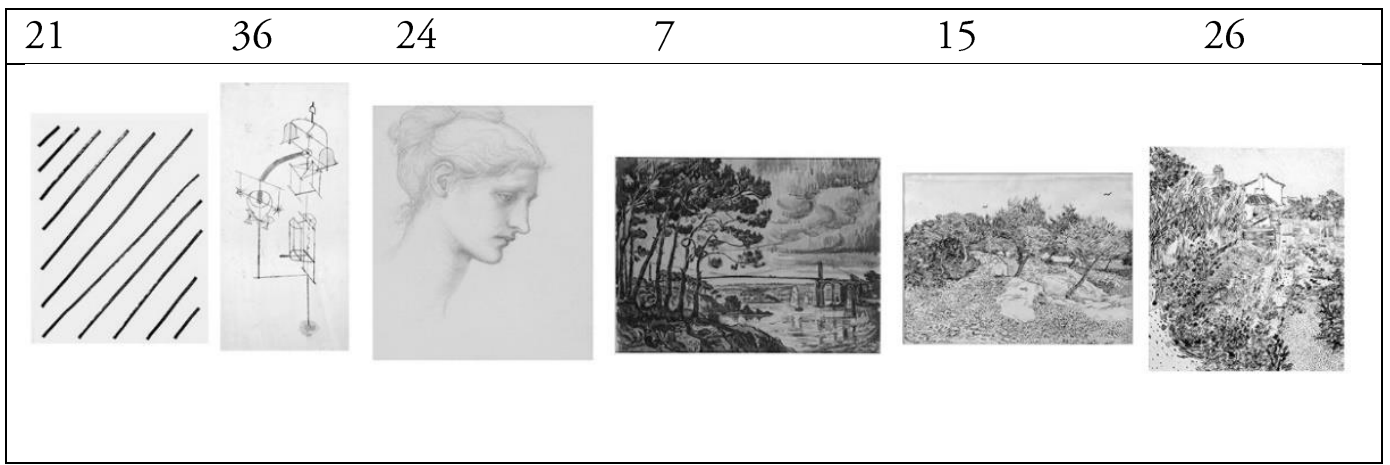

Figure 25: The progression of images suggesting spatial depth.

Image \#21 (.692), Image \#36 (.482), Image \#24 (.449), Image \#7 (-.735),

Image \#15 (-.768), Image \#26 (-.829).

21. Martin Creed. (2006), Work No. 517 (triptych), (highlighter \& marker pen on paper). Private Collection, Bridgeman Education.

36. Paul Klee. (1922), Apparatus from the consulting room of Dr. Ph., (no 121), (oil transfer drawing w/c and pencil on primed paper). Miyagi Museum of Art, Sendai, Japan, Bridgeman Education.

25. Edward Coley Burne-Jones. (1875), Study for Laus Veneria, (pencil on paper). Private Collection, Bridgeman Education.

7. Paul Signac. (1922), The Lezardrieux Bridge, (charcoal over black chalk on tan paper). Private Collection, Bridgeman Education.

39. Vincent van Gogh. (1888), The Olive Trees, (pen \& ink on paper). Musee des Beaux-Arts, Tournai, Belgium, Bridgeman Education.

26. Vincent van Gogh. (1888), Garden of Flowers, (ink \& pencil on Whatman paper). Private Collection,

Bridgeman Education.

\section{Contrast of Tone}

Dimension 3 was seen as an indication of tone and tonal qualities. Tone defined as a quality of light—an output of the ratio of mark to drawing surface. This dimension is approached as being descriptive of those elements within a drawing that affect the Dark/Light of a drawing (Figure 26). 


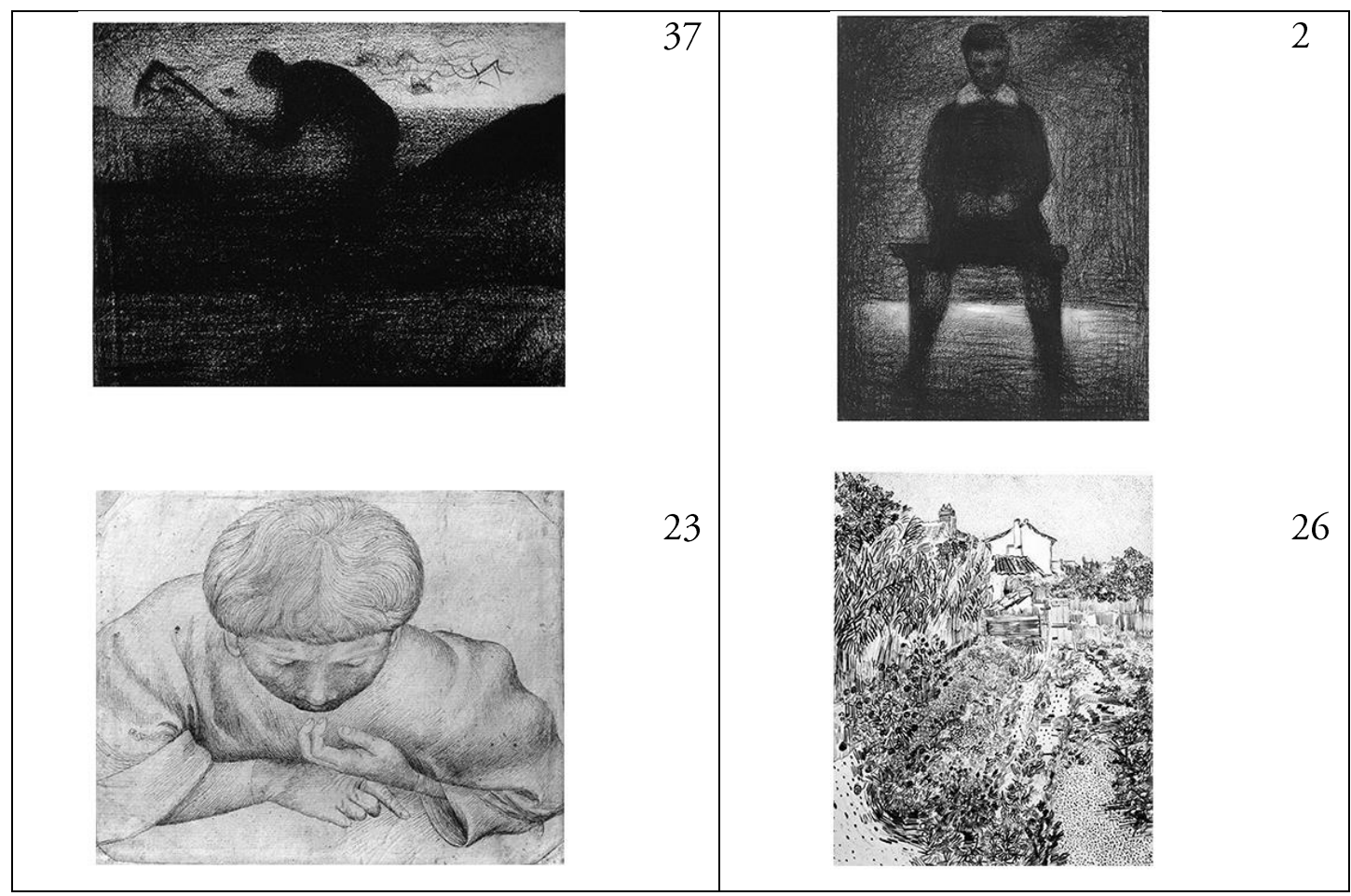

Figure 26: The comparison of images suggesting the dimension of global tone.

Image \#37 (.746) \& Image \#23 (.432).

Image \#2 (.604) \& Image \#26 (-.829).

37. Georges Pierre Seurat. (1883), Man with a Pick, (crayon conte). Private Collection, Bridgeman Education.

23. Antonio Pisanello. (date unknown), Boy reading, from the Vallardi Album, (pen \& ink on paper). Louvre, Paris, France, Bridgeman Education.

2. Georges Pierre Seurat. (1886-88), Maurice Appert Seated, (conte crayon and gouache on paper). Private Collection, Bridgeman Education.

26. Vincent van Gogh. (1888), Garden of Flowers, (ink \& pencil on Whatman paper). Private Collection, Bridgeman Education.

\section{Expressiveness of Line}

Dimension 4 was seen as contrast of line variability an indication of gestural to controlled line. Line expressiveness is defined as a line's overall variability or as some have described it as a type of liveliness. This dimension is approached as being descriptive of line's nature or quality (Figure 27). The expressive quality of line was a visual feature on the list. 


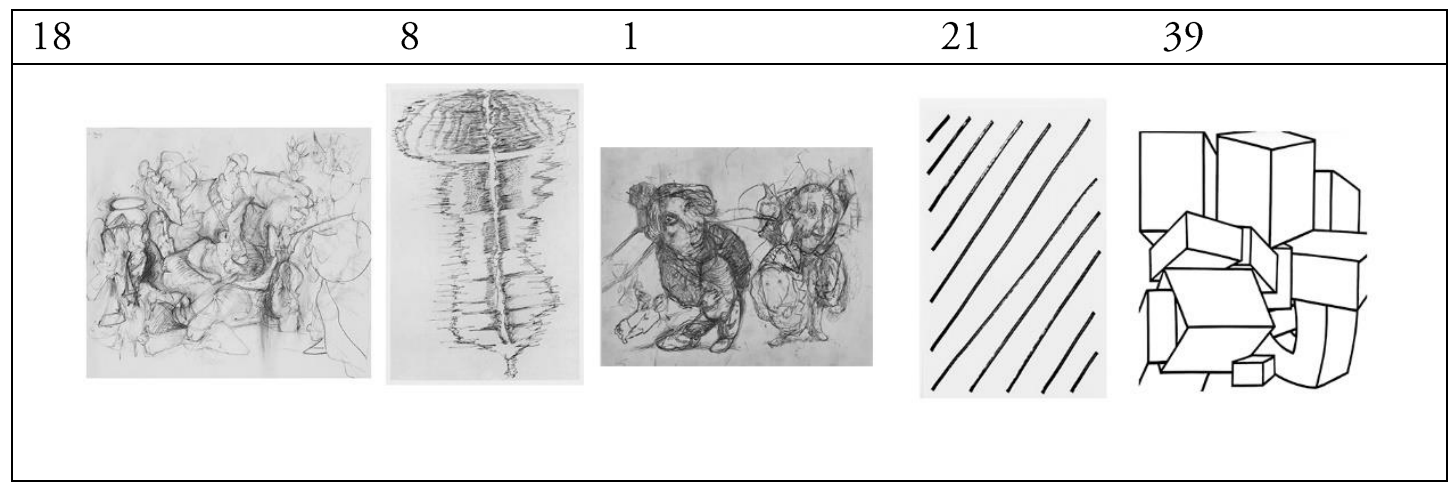

Figure 27: The comparison of images suggesting the expressiveness of line. Image \#18 (.363), Image \#8 (.354), Image \#1 (.327), Image \#35 (-.337), Image \#39 (-.922).

18. Arshile Gorky. (1944), Untitled, (pencil, black chalk \& colored wax crayons on paper). Private Collection, Bridgeman Education.

8. Henri Michaux. (1956), Illustration from 'Miserable Miracle (La Mescaline)', Editions du Rocher, Monaco, (engraving). Private Collection, Bridgeman Education.

1. Frank Günzel. (1985), Untitled, (graphite on paper). Saint Louis Art Museum, Missouri, USA, Partial and promised gift of Betsy Millard, the Earl and Betsy Millard Collection, Bridgeman Images. 21. Martin Creed. (2006), Work No. 517 (triptych), (highlighter \& marker pen on paper). Private Collection, Bridgeman Education.

39. Held, Al. (1967), Untitled, (oil on canvas). Private Collection, Bridgeman Education.

\section{Human Perception and MDS Discussions}

The MDS was a test of the list of visual features and traits. It showed that people can sort imagery by visual features and traits of mark making. How they categorized each image suggested what features and traits were important in the sort and assisted with assigning an order to those features: smudge, depth, tone, and line expressiveness.

As the researcher and facilitator leading the MDS card sort activities, several observations were made. The first observation dealt with the sorting task itself. The idea of sorting imagery by visual feature or trait did not seem an unnatural assumption to either the art expert or art novice group. Everyone seemed very comfortable with the sort activity particularly once it was realized there was no right or wrong way to sort. It was observed that the activity was not overtly taxing and all participants seemed to enjoy sorting into groups they each found logical. Initially, it 
seemed to take everyone a few minutes to decide on their own sorting system, but once they started, the participants seemed to sort and resort, based on whatever insight was gained assessed, and reassessed through their own processes for examining the images.

Through data analysis of the sort using SPSS, both groups, art experts and art novices, appeared to have used the same four dimensions to group the images. The dimensions being the visual features. At this point the list of features has validation and a suggested ranking of visual features. The described dimensions above were the determining elements used for comparison by the participants in this study to organize and categorize the drawings.

1. Smudge or edge detection or edge quality through smudge.

2. Depth or the organization of elements within the describe space of each drawing.

3. Tone or the quality of light and dark within each drawing.

4. Line Expressiveness or the emotion conveyed by a line within each drawing.

These outcomes support a general practice rule in design reuse and intelligent borrowing that suggests first smudge, then depth, then tone, and then line quality are the most significant elements to use for style comparison. 


\section{Chapter 5: Testing the Model Phase Two Failed Categorization}

This chapter discusses the MDS categorical card sort that was conducted in this research its results and implications towards development of the model.

\section{Card Sort Activity Two}

The second card sort activity involved a categorical sort. Participants were instructed to place all the images into one of five categories, selecting the best fit for each image. The category name as well as a description for each category was given. For the second card sort activity, every participant was given the same instructions (Appendix A).

This activity usually took up the remainder of the time. Usually, participants completed this activity in about 45 minutes. No one took longer than 50 minutes to complete the second card sort. The general observation on the second card sort was that it was a bit of a challenge but still enjoyable. The general sense was that 80 images was near the upper limit for this type of card sort.

\section{Card Sort Activity Two Results}

A second categorical card sort with the same participants as the first card sort was done using the remaining 80 of the 120 images. Overall, the art experts group were more accurate in the placement of imagery into the respective art categories with $55.1 \%$ of the images correctly placed (Table 4 ). The art novice group overall had a 38\% accuracy rating (Table 5). Everyone did the best with category 5-the abstract category. However, it is surprising that even though that category is the highest of scored correct answers, it is nowhere near 100\%, which suggests the possibility that some participants still saw representational imagery. 
Table 4: Art Expert Group Categorical Sort

\begin{tabular}{|c|c|c|c|}
\hline \multicolumn{4}{|c|}{ Expert Group } \\
\hline \multicolumn{2}{|c|}{ Overall Group } & \multicolumn{2}{|c|}{ Total of Participant Selections By Category } \\
\hline $\begin{array}{l}\text { Average of } \\
\text { Correctly } \\
\text { Placed } \\
\text { Images for } \\
\text { Group }\end{array}$ & $\begin{array}{c}\text { Percentage of } \\
\text { Correctly Placed } \\
\text { Images for Group }\end{array}$ & $\begin{array}{c}\text { Number of } \\
\text { Correctly Placed } \\
\text { Images Overall in } \\
\text { each Category }\end{array}$ & $\begin{array}{l}\text { Percentage of Correctly Placed Images by } \\
\text { Category }\end{array}$ \\
\hline 44.1 & $55.1 \%$ & $\begin{array}{l}\text { Category } 1-74 \\
\text { Category } 2-73 \\
\text { Category } 3-73 \\
\text { Category } 4-81 \\
\text { Category } 5-140\end{array}$ & $\begin{array}{l}46.3 \% \\
45.6 \% \\
45.6 \% \\
50.6 \% \\
87.5 \%\end{array}$ \\
\hline
\end{tabular}

Table 5: Art Novice Group Categorical Sort

\begin{tabular}{|c|c|c|c|}
\hline \multicolumn{3}{|c|}{ Novices } \\
\hline \multicolumn{2}{|c|}{ Overall Group } & \multicolumn{2}{|c|}{ Total of Participant Selections By Category } \\
\hline $\begin{array}{c}\text { Correctly } \\
\text { Placed } \\
\text { Images for } \\
\text { Group }\end{array}$ & $\begin{array}{c}\text { Percentage of } \\
\text { Correctly Placed } \\
\text { Images for Group }\end{array}$ & $\begin{array}{c}\text { Number of } \\
\text { Correctly Placed } \\
\text { Images Overall in } \\
\text { each Category }\end{array}$ & $\begin{array}{c}\text { Percentage of Correctly Placed Images } \\
\text { by Category }\end{array}$ \\
\hline 30.41176 & $38.0 \%$ & Category 1-80 & $29.4 \%$ \\
& & Category 2-122 & $44.9 \%$ \\
& & Category 3-75 & $27.6 \%$ \\
& & Category 4-57 & $21.0 \%$ \\
& & Category 5-183 & $67.3 \%$ \\
\hline
\end{tabular}

Accuracy of image placement within categories 1, 2, and 3 for the art experts group was very even with category 4 being slightly better, but still not as good as category 5 . For the art novice group, categories 1,3 , and 4 are very even with category 2 being their second best category.

A discrepancy was discovered after the collection of the data dealing with the labeling of the second category. In the selection of imagery: $19^{\text {th }}$ century a more specific label of neo-classicism was given. While some of the artists within the category could be considered neo-classical not all artists or imagery was chosen to be that specific. The description used for the category is general and covers other aspects 
of $19^{\text {th }}$ Century art. The description given: looks very real but on close inspection, it seems better than real—striving for perfection or idealistic. Review of the data suggests that the category name was of little importance in the final determination of image placement for the participants, in fact category 2 was the second best accuracy placement for both groups overall with $45.1 \%$ correct image placement (Table 6). The actual naming of the art categories and their descriptions are of no relevance for the computer.

Table 6: Combined Groups Categorical Sort

\begin{tabular}{|c|c|c|c|}
\hline \multicolumn{3}{|c|}{ Novices \& Experts } \\
\hline \multicolumn{2}{|c|}{ Overall Group } & \multicolumn{2}{c|}{ Total of Participant Selection By Category } \\
\hline $\begin{array}{c}\text { Average of } \\
\text { Correctly } \\
\text { Placed } \\
\text { Images for } \\
\text { Group }\end{array}$ & $\begin{array}{c}\text { Overall Percentage of } \\
\text { Correctly Placed } \\
\text { Images for Group }\end{array}$ & $\begin{array}{c}\text { Number of } \\
\text { Correctly Placed } \\
\text { Images Overall in } \\
\text { each Category }\end{array}$ & $\begin{array}{c}\text { Percentage of Correctly Placed Images } \\
\text { by Category }\end{array}$ \\
\hline 35.48148 & $44.4 \%$ & Category 1-154 & $35.6 \%$ \\
& & Category 2-195 & $45.1 \%$ \\
& & Category 3-148 & $34.3 \%$ \\
& & Category 4-138 & $31.9 \%$ \\
& & Category 5-323 & $74.8 \%$ \\
\hline
\end{tabular}

\section{Card Sort Activity Two Discussions}

The second MDS card sort was categorical based on the concept of style. As stated earlier in this research (page 20) style is an ill-defined concept or ill-defined category (Hartley \& Homa, 1981; Neisser, 2014). Developing the card sort and selecting images proved to be a difficult task. The examination of art history texts showed disagreements between historians as to which artists and which artworks were in any given category based on an art style. Close examination of various texts revealed there were contentious explanations and definitions for an art style, an art movement, an art era. To work around all these issues, the categories developed for this card sort became extremely cumbersome. The final five categories used were very 
large and through the final data analysis many discrepancies were discovered, even though a great deal of planning had gone into the categories.

The general observation made of this card sort task in comparison to the first card sort activity was that this sort was more difficult and time consuming. The use of 80 images was approaching some of the participants' upper limit for this type of task. Looking at the data analysis the accuracy level of placing the imagery into the appropriate category revealed the difficulty of the task with less than a 50\% accuracy rate for an overall score of both art experts and art novices. A multinomial regression analysis was run using measures obtained from the first 40 images used in this card sort and it revealed problems (page 97). Variance of measures was in fact greater within a category than the variance of measures between categories.

It was determined that part of the problem was because the categories were too broadly set. It was also determined that another part of the problem had to do with inappropriate sample sizes.

\section{Categorical Art Findings}

The analysis of data from the second MDS card sort showed that approaching the idea of style this broadly would not work. This led to the idea of a model for a style grammar, if approached from smaller sets of categories could work and prove useful. A different approach could get away from the art historical categorization of styles and enable an exploration of category based on mark making — a far more useful approach for a practitioner, student, or art teacher of creative drawing.

The data from the first MDS free card sort was re-examined for the purpose of choosing three artists that have large bodies or works—specifically drawings that would be available in high resolution to obtain measures to place categorically for the model. Two of the artists were contemporaries, Georges-Pierre Seurat and Vincent Willem van Gogh, so that similarity comparisons could be done, and one was not, 
Egon Schiele for dissimilarity comparison. The list of variables tested were: line length, line expressiveness, global tone, smudge, depth, and pattern. 


\section{Chapter 6: Testing the Model Phase 3}

This chapter begins with a recap of the previous phases of testing and continues with the examination of historical precedents of the use of machines to aid in visual perception of drawing up to the use of the computer. I describe machine operations used to define each of the core traits for feature extraction and measurement. The discussion continues with an overview of the types of statistical analysis used to evaluate and validate each measure. The chapter concludes with reporting results and a continued discussion of the model development.

\section{Recap \& Background}

The model developed provided the following independent variables: line length, line expressiveness, line width, global tone, local tone, depth, pattern/texture and smudge added after the first MDS (page 77). The results from the second MDS procedure revealed the need for stricter identification of parameters for art style and categories of artworks (page 83).

Typically, multinomial logistic regression is used to predict categorical membership (dependent variable) based on multiple independent variables (Kwak \& Clayton-Matthews, 2002; Sandoval-Mejia \& Wang, 2016; Starkweather \& Moske, 2011), the exact configuration of the dependent and independent variables in this study. Starkweather and Moske (2011), describe the attractiveness of multinomial logistic regression analysis because it does not assume normality, linearity, or homoscedasticity. It is also recommended that data analysis be thorough and include other regression models such as bivariate logistic regression. Sample size guidelines for multinomial logistic regression are 10 cases per independent variable (Kwak \& Clayton-Matthews, 2002; Schwab, 2002; Starkweather \& Moske, 2011). 
Multinomial logistic regression analysis allows for the examination of each independent variable, its interpretation and analysis in terms of the model for building a style grammar allowing for the of usage of the "borrowed" visual features.

The use of the computer to assist with issues of style and borrowing is not the typical use of this tool by artists in a drawing practice. There is historical precedence that demonstrates artists have used drawing machines and other mechanical devices to assist with drawing and perception. The addition of the computer to this arsenal of devices as a tool that can lend objectivity to an artist's perception and the measuring of style would be beneficial.

\section{Devices, Tools \& Operators: An Historical Perspective}

Science and mathematics have always played an important role in the creation of many works of art, citing a well-known essay on Neo-Impressionism written by Robert L. Herbert with an anecdote he once gave:

At an exhibition of Neo-Impressionism in 1893, a woman peered over the entrance turnstile at the paintings inside, while debating whether or not to pay the modest fee to one of the painters seated at the cash box. 'Were these done by machine, Monsieur?' she asked. 'No, Madame, they were done by hand,' the artist replied (as cited in Leavitt, 1976, p. 1).

At this particular exhibit, the artist was Georges Seurat, who had displayed paintings in which he had divided colors by uniform color-bearing dots repeated in a calculated manner using scientific studies of color and optical theories developed in modern chromatics (Rood, 1881). Leavitt (1976), in her book Artist and Computer, describes other scientific principles of human perception dealing with linear movement and color that interested Seurat in his attempts to evoke a particular mood in those who viewed his paintings.

Seurat was also familiar with the latest processes involved in weaving and textiles from where some of his color concepts were derived. An interesting concept from the looms used at this period was the punch card, which foreshadowed early 
computer programs. He like several of his contemporaries was very interested in 'scientific esthetique' term coined by friend and librarian, Charles Henry (18591926) (Leavitt, 1976). Georges Seurat was far from the first artist to be interested in the pursuit of a 'scientific aesthetic' in art.

Filippo Brunelleschi (1377-1446) and Leon Battista Alberti (1404-1472) are attributed with the development of artificial or scientific perspective (Cole, 1921; Dubery \& Willats, 1983; Edgerton, 1978; White, 1957). Leonardo da Vinci's contribution to the technique of artificial perspective concerns using perspective backwards, taking linear measurements from drawings and paintings to gain information about the position of objects in space. Working through this process of transferring imagery, da Vinci developed his own drawing machine (Cole, 1921; Dubery \& Willats, 1983; Edgerton, 1978; White, 1957).

Albrecht Dürer's treatise on measurement, published in 1525 included four illustrations of drawing machines, which the artist was known to have used and are similar to a sketch of a drawing machine found in Leonardo da Vinci's notebooks (Cole, 1921; Conway, 1960; Dubery \& Willats, 1983; Edgerton, 1978; Strauss \& Dürer, 1974; White, 1957). Dubery and Willats (1983) suggest that Dürer learnt of the device when he travelled to Venice and met with Da Vinci. Another important contribution from Dürer's treatise on measurement came from his development of the grid and his method of coordinate transformations. Rectilinear grids were of course used through ancient times. Dürer introduced a method of modifying figures to obtain deformed views of the original. Some of these when pushed to extremes could become bizarre—which Dürer himself heavily criticized as not his intent (Conway, 1960; Strauss \& Dürer, 1974)(Figure 28). 


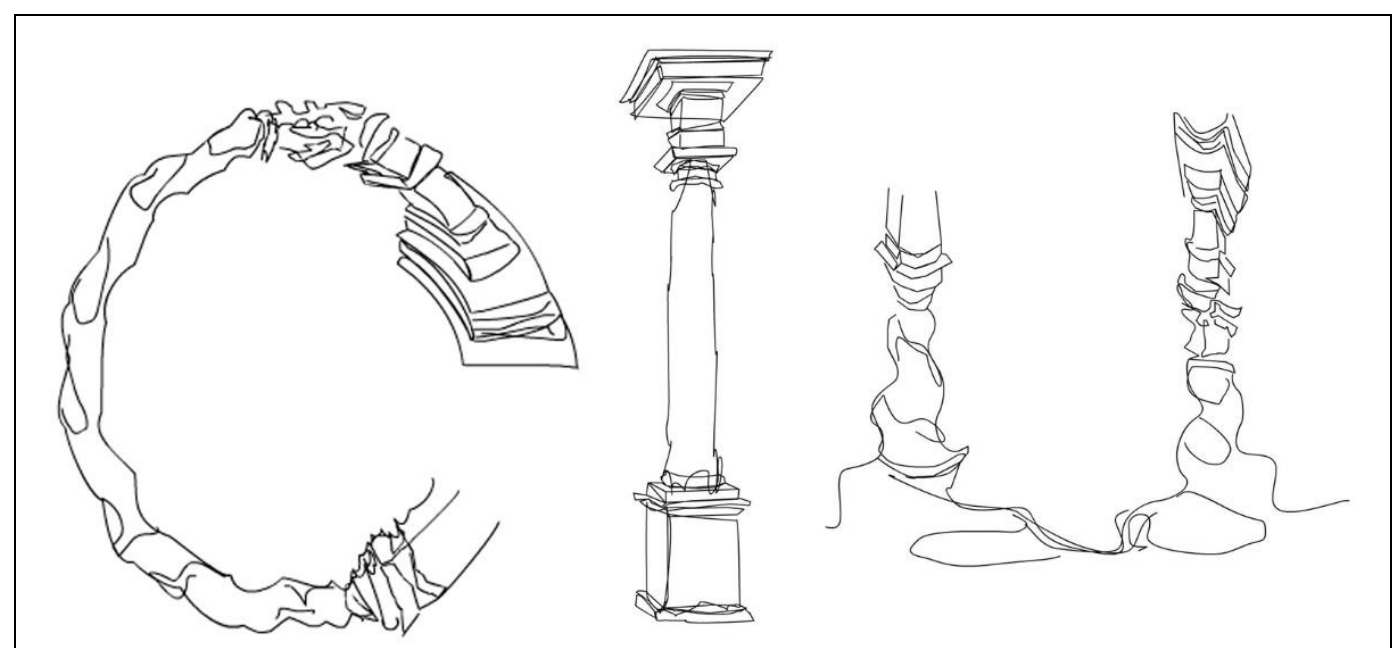

Figure 28: Example of coordinate transformation to modify the original drawn column in the middle.

J Sweo. (1993), Invented Space: The Columns, (computer drawing based on a pen and pencil drawing).

Dubery and Willats (1983)in their book on "Perspective and Other Drawing Systems," go on to explain that Dürer's drawing machine has its counterpart in modern computing equipment:

In the two-dimensional versions, a sighting device or 'hedgehog' is run around lines or contours by hand. The coordinates of a very large number of points along the lines are automatically recorded on magnetic tape. After filtering, these coordinates may be transformed by computer, according to any projection system, and the result display on a cathode ray tube or line plotter (p. 71).

Drawing machines were not the only tools used by artist as drawing aids. Giovanni Battista della Porta popularized the use of the camera obscura in the midsixteenth century as a way to trace around the contours of a projected picture. The camera lucida, similar to the camera obscura, with the advantage of being portable was invented by William Hyde Wollaston in 1807 and used by a number of artists to trace a projected image onto a drawing surface (Cole, 1921; Dubery \& Willats, 1983; White, 1957).

The invention of the daguerreotype in 1839 and later, photography has assisted many artists from Delacroix to Chuck Close with art processes. Even Matisse who favored a serial method of working would photograph his works at different 
stages of their development (Brown, 2015; Coke, Lipchitz, \& Arnason, 1972;

Matisse \& Flam, 1995). The use of the computer by artists as both drawing tool and aid seems a natural progression, especially in light of viewing modular art like Sol LeWitt's wall drawings. Leavitt (1976) explains that modular art is an approach often used in computer art. While a discourse on the history of the computer as drawing tool would be fascinating, in my research I will be looking at the computer as an aid to the scientific investigation of the interpretation of visual features and traits to be discussed as a part of the further development of the model towards a style grammar for creative drawing. In this vein I will continue and conclude this historical perspective of tools and operators of past partnerships between science and art with an outlook towards the future.

Goodyear (2004), in her article, "American Art of the 1960s: Defining Attitudes Toward Science and Technology," compares the outlooks and philosophies of two individuals who were instrumental in stimulating partnerships between art, science, and engineering. The artist Gyorgy Kepes, who help found the Center for Advanced Visual Studies at the Massachusetts Institute of Technology (CAVS), and the engineer Billy Kluver, who help found the New York based organization, Experiments in Art and Technology (E.A.T.).

Goodyear (2004) explains, that Kepes was very much influenced by Laszlo Moholy-Nagy and sought to raise art to the level of scientific investigation. Kepes felt that science and art could positively inform one another. Kulver, who was always interested in art, while working at Bell Labs just outside New York City began to acquaint himself with a group of emerging avant garde artists. Goodyear (2004), in her article, describes Kulver's involvement with the New York art scene as a part of his experiences that had an important impact on his work as an engineer at Bell Labs. He saw a connection between artistic process and the engineer's experiment (Shanken, 2006). Kluver argued that art could redefine the goals of engineering, while technology could expand the possibilities of art. Goodyear (2004) quotes Kulver from an early E.A.T. Newsletter: 
The collaboration between artists and engineers should produce far more than merely adding technology to art. The possibility of a work being created that was the preconception of neither the artist nor the engineer is the raison d' etre of the organization. The engineer must come out of the rigid world that makes his work the antithesis of his life and the artist must be given the alternative of leaving the peculiar historic bubble known as the art world. The social implications of E.A.T. have less to do with bringing art and technology closer together than with exploring the possibilities of human interaction (p. 627).

At its core design is a system for applying structure and form to an object or process so that the object better meets its competing design goals (Agrawala et al., 2011; Buchanan, 1992; Lidwell et al., 2010). The development of a model for visual features towards style grammar provides a creative synthesis between computer tools, teaching strategies, and content that offers lasting and invaluable approaches for engaging learning. It allows for a different type of interaction with content.

\section{The Computer, Tools \& Operators: A Modern Perspective}

One task of the research dealt with the development and creation of a list of visual features. Once the visual features were identified, the next task of the research dealt with the development of processes that would make it possible to: (1) select a trait of the identified feature, (2) isolate the trait, and (3) obtain a measure for that trait.

As stated earlier, a picture to be processed in a computer, must be quantized and encoded into a form convenient for the computer (Freeman \& Glass, 1969). The two operations: obtaining a set of discrete values and sequencing those values into a format for efficient transmission are intrinsic to any description process (H. Freeman \& Saghri, 1980). The Software Studies Initiative has developed a tool called FeatureExtractor a MatLab script that extracts a variety of visual features from image files, https://code.google.com/p/softwarestudies/wiki/FeatureExtractor. The site lists 399 quantifiable parameters for visual features of imagery and is organized into 14 categories. Garcia (2013) in his research references the Group Mu who stated any 
visual image has three properties: color, shape, and texture and each property can be broken into smaller analytic parts.

The number of feature extraction and image segmentation schemes available made it clear it was important to tailor a list that had relevance between artistically drawn marks and machine vision/machine measures. The development of a viable process was necessary to correlate and identify hand drawn marks that would link them to a measure with accuracy and no collinearity.

The tools and operators selected for the task to (1) select a trait of the identified feature, (2) isolate the trait, and (3) obtain a measure for that trait would have significant impact in describing the set of methods used to obtain measures. Image J was identified as a viable image processing program to use for a portion of this task.

ImageJ is a public domain, Java-based image processing program developed at the National Institutes of Health, an agency of the United States Department of Health and Human Services, a biomedical research facility located in Bethesda, Maryland. Its open plugin architecture and built-in development environment has made it a popular platform for teaching image processing in scientific fields, primarily medicine https://imagej.nih.gov/ij/index. It can read many file formats including TIFF, PNG, GIF, and JPEG. Similarly to the FeatureExtractor tool developed by the Software Studies Initiative Group it also does standard image processing functions such as Fourier analysis, sharpening, smoothing, edge detection, and median filtering (Mateos-Perez \& Pascau, 2013). ImageJ was chosen in this research because of the program's accessibility to calculate area and pixels value statistics of user-defined selections, intensity-threshold objects, and ease of importing and exporting images with other image software primarily Adobe Photoshop and Adobe Illustrator.

Adobe Photoshop is recognized as an industry standard software for editing raster graphics. All the tools mentioned so far use raster images and most of the 
measures used in this research were obtained from raster based procedures, However, to obtain measures of line a different approach was needed.

Raster programs store information in a grid of pixels. Adobe Illustrator is a vector drawing program and uses mathematical equations to draw lines and shapes. It would be possible to obtain measures for the lines of the various images used in this research but first an image conversion procedure was implemented. A great deal of research has been done to address image conversion with many different approaches and options for raster to vector imagery and much of this research has gone into the development of a built-in image conversion tool in Adobe Illustrator (Gibson \& Lucas, 1982; Hori \& Tanigawa, 1993; Kaneko, 1992; Parker, 1988; Zao, Hong, Jiren, \& Junan, 1998). The use of the Adobe Illustrator's built-in raster to vector conversion tool allowed for a simplified systematic approach for image conversion to obtain consistent measures for line across all the images used in this research.

The ability of computer software to read imagery or group pixels based on edge detection was developed from human principles of vision (Nixon \& Aguado, 2012). The human perception of edge detection is the contrast of tone between one area of an image and another. Edge detection in the computer is the name for a set of mathematical methods which aim at identifying points in a digital image where image brightness changes sharply (Fu \& Mui, 1981; Marr \& Hildreth, 1980; Pal \& Pal, 1993). The use of edge detection operations is important in this research as a part of the task to detect and extract a trait for measurement. The edge detection operation run was a Canny-Deriche filtering for edge detection in ImageJ. The parameter for pixel smoothing of the edge was left at the default setting of 1.0. This setting was used systematically for all images using the edge detection process.

Thresholding is a procedure used for image segmentation (Pal \& $\mathrm{Pal}, 1993$; Sahoo, Soltani, \& Wong, 1988; Sezgin, 2004). Thresholding converts greyscale images into bi-level images (black and white). This was a very useful process in this research to create masks for areas of images that had already been identified through edge detection filtering. Masks were created in Photoshop. The auto threshold setting 
was used within ImageJ to convert the Photoshop masks into a mask-selection in ImageJ to isolate and obtain measurements for specific areas.

Using a variety of image processing tools computer measures were developed that correspond to the visual features of the set of creative drawings identified. Analysis of these measures then tested the model and gave insight into a particular aspect of style which can be used towards a style grammar in creative drawings.

\section{Feature Extraction \& Machine Measures}

There are similarities as well as differences within the human perception and machine measures of a drawing. Visual reasoning is often studied in relation to cognitive constructs such as perception, encoding and chunking (Sosa et al., 2016). Human perception of a drawing is the organization of marks that create imagery. A computer image is a matrix of pixels. The human articulation of those marks are often vague whereas the computer measure is a known number associated with each pixel.

Statistical measures taken of the pixels within a defined area characterize the content of that area. Higher order statistics (dealing with three or more pixels) describe properties of pixels occurring at specific locations relative to each other. This research examines the computed co-occurrence of these higher-order statistical parameters and their frequency as a way to link particular marks to an art category. This approach is similar to style-metric techniques developed in literature that use statistical analysis of literary styles to assist with authenticity and attribution of texts (Belak et al., 2008).

\section{Image Preparation}

The specific versions of the image processing and image drawing programs used for all these operations was ImageJ 1.50g, Adobe Photoshop CS6, and Adobe Illustrator CS6. As stated earlier all the images were downloaded from Bridgeman's FTP Site as high resolution jpegs. No color images of drawings were used. All images 
were scaled proportionately to a height of 3200 pixels, with a resolution of 300 pixels/centimeter. No cropping was done to the downloaded images.

The need to be consistent and systematic in obtaining each operational procedure was a top priority. That meant a common denominator was always sought across all imagery. Where some images were of a higher quality of 600 pixels/centimeter or larger than a height of 3200 pixels they were resized and some quality would be lost. This would keep a procedure systematic in obtaining a measure. It was also important that all measures be obtained through the computer, if a procedure included a subjective determination of an element by the operator an alternative objective procedure was sought. The best measure was not the perfect measure for each image it was the measure obtained through a consistent and systematic procedure.

\section{Initial Testing of Operational Measures}

An operational measure refers to the measure obtained through feature extraction. A first set of measures were tested using the same first 40 of 80 images in the second MDS categorical card sort. Analysis of the first multinomial logistic regression run from these measures yielded no significant results. Variance of measures was in fact greater within a category than the variance of measures between categories. With inconclusive results, it was determined that collecting further measures from the second 40 images would not yield significant findings to assist with the model development.

This presented an opportunity to review and question the overall approach of categories taken within the second MDS. The art categories used were ill defined. They were too large, varied and did not contain enough images for any one artist to yield any meaningful results from the measures by human perception or machine measure. While a broad scope was helpful in the first MDS to identify and develop an initial set of visual features and linked traits, it was shown that a different 
approach was needed to determine the accuracy of measures and to validate the traits to further develop the model.

Two problems were identified and addressed. The first problem arose from the categories being set too broadly, this was remedied by setting smaller categories. The second had to do with inappropriate sample sizes this was remedied by increasing the sample size. Both issues are discussed later in this chapter (pages 110140).

This heightened awareness of identification issues led to a review of each operational measure to ensure a strict systematic process was developed to obtain the best possible measure in a consistent and repeatable way. This process is reviewed below.

\section{Feature Extractions for Line}

One issue faced was the issue of how to define line length. There is a computer definition and varying artists' definitions to consider. The simplest artist's definition takes into account the action of drawing a line: first point of contact between drawing tool and surface and second point of ending contact between drawing tool and surface. The visual result is the graphical journey from point-a-topoint-b. There are any number of ways to consider what this type of line might look like. Figure 29 is an example of a visualization based on an artist's definition for line length following this drawing procedure. Figure 30 shows an enlarged section of a pencil drawing by the artist Egon Schiele illustrating further the problematic issue of line length, and being able to clearly determine a line's beginning and end. 


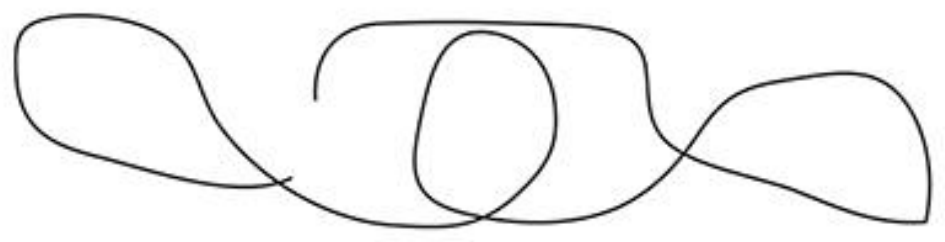

Figure 29: An example of a visualization of artist's definition of line length.

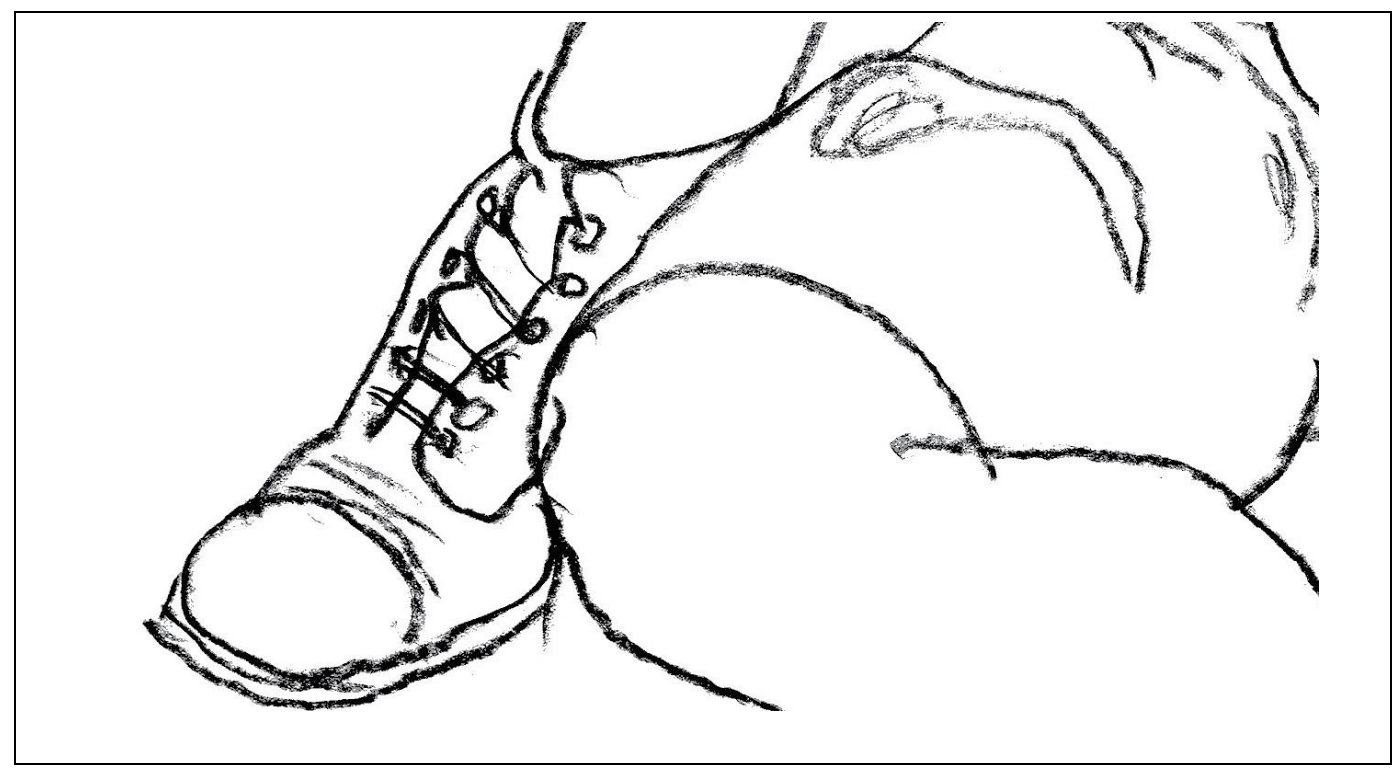

Figure 30: A detail visualization of a section of a drawing by Egon Schiele illustrating the problematic determination of line length.

Egon Schiele. (1918), Young Man Reclining with his Head Resting on His Crossed Leg; Liegender Knabe mit Aufgestutztem Kopf und Ubergeschlagenen Linken Bein, (charcoal on tan paper). Private Collection, Photo (C) Christie's Images, Bridgeman Images.

Vector graphics programs, which deal with the generation of lines or paths rather than pixels, were examined. The computer definition used in this research comes from Adobe Illustrator which states: line is a path of straight and curved segments made up of mathematical objects called vectors, which describe each segment according to its geometric characteristics (Figure 31). 


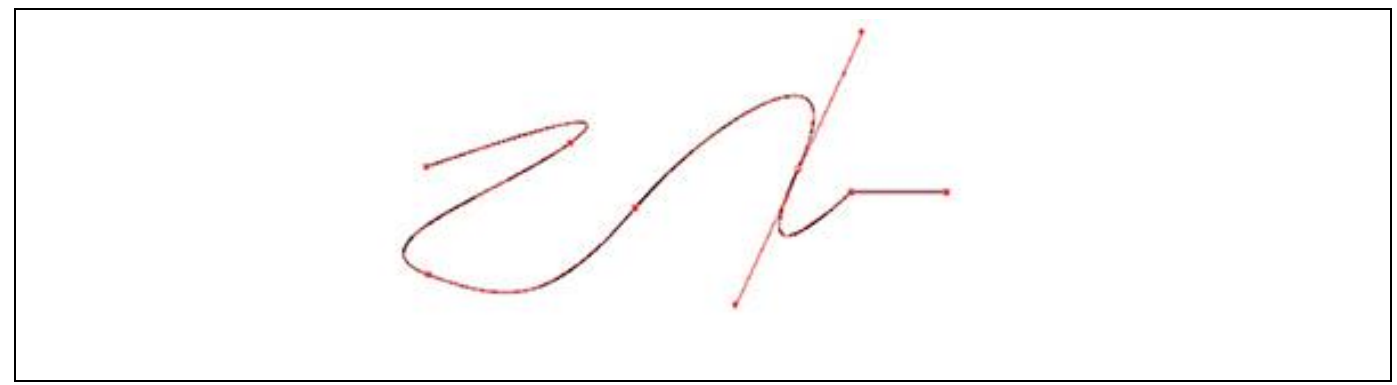

Figure 31: An example of a visualization of computer/program definition of line length.

All the images used were downloaded from Bridgeman's image bank as raster images. It was necessary to create a consistent process to convert the images into vector paths so statistical measures for path could be obtained. The approach was considered optimal for these reasons:

1. The detection quality of line was clear, and all existing edges were marked with no occurrence of multiple responses/selections.

2. The accuracy of the marked edges were as close to the edges of the image as possible.

Using Adobe Illustrator's image conversion tools would allow for an objective procedure with a minimal amount of systematic input from the operator. There was some loss of pixel information, particularly where lines blended in the tone of the drawing surface. However, the overall gain of getting lines measurements objectively controlled by the computer was considered far more substantial (Figure 32). 

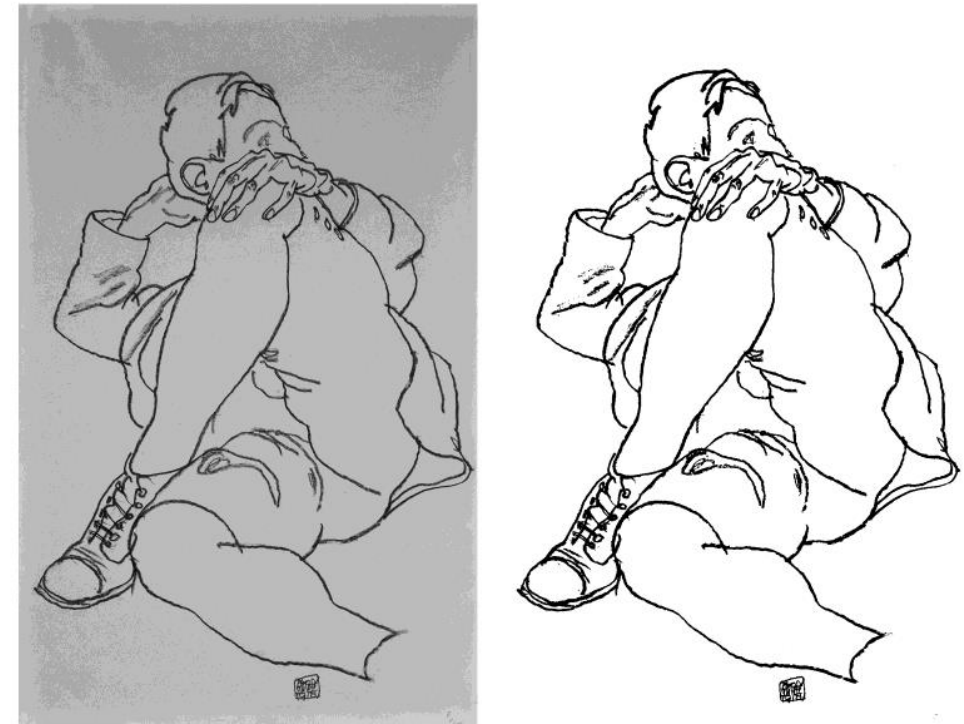

Figure 32: An example of an image conversion to get measures for line. The image on the left is the original raster image, the image on the right has been converted to vector data. Egon Schiele. (1918), Young Man Reclining with his Head Resting on His Crossed Leg; Liegender Knabe mit Aufgestutztem Kopf und Ubergeschlagenen Linken Bein, (charcoal on tan paper). Private Collection, Photo $\odot$ Christie's Images, Bridgeman Images.

Using the method described the following measures for line length were obtained for each image: total number of paths, total length of all paths, and the average length of a path. The development of this extraction method for line length gave insight into how to extract a measure for the quality of line expressiveness.

\section{Line Expressiveness}

Goldstein (1977) in his drawing text describes line expressiveness as a line feature which is calligraphic or gestural, offering numerous variations of appearance. Goodwin et al. (2007) described the variation of a line's appearance as liveliness: short-long, thick-thin, light-dark, curved-angular, etc. Adobe Illustrator segments a path into sections according to its geometric characteristics. Linking the visual observation of the "liveliness" of a gestural line to Illustrator's segmentation by geometric characteristics, the use of the number of points along a segment of path can be used as a measure for this gestural quality. The more gestural or calligraphic a line equating to the greater number of points and the less gestural or calligraphic a line equating to the fewer number of points (Figure 33). 


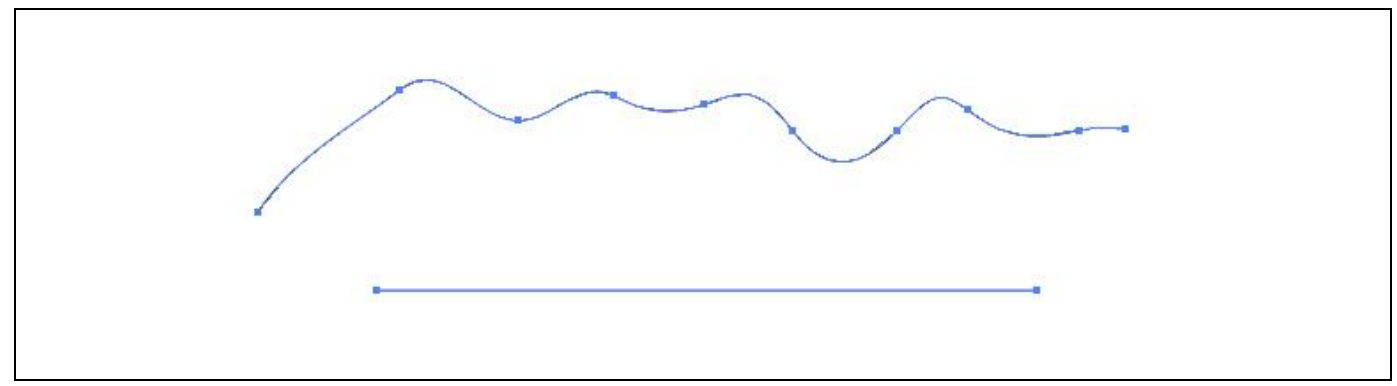

Figure 33: Visualization of the number of points needed to express a line that is more gestural or free formed $v$ s. the number of points needed for a controlled line.

Using the method described above for collection of the measure of line length the additional measure of number of points could also be collected and was used for the line expressiveness characteristic. This measure is expressed as an average gained from the total number of points and total number of paths.

\section{Line Length \& Expressiveness of Line Measures}

To obtain line length and expressiveness measures each image was opened in Adobe Illustrator and an image conversion operation was run on the original image using the Adobe illustrator image trace function. Several options were tested. The option discussed here is what was observed to yield the most accurate conversion. The image trace function was used with the sketch art selection initially selected. Thresholding was kept to the default setting of 128. Under the Advance options a custom set of operations were performed. Path fitting was set to $100 \%$. Corner emphasis was set to $100 \%$. Noise was set to a low value of one pixel. These were the only options that were changed from their default positions to allow for the most accurate and tightest image conversion. The black and white vector art that these actions produced was expanded and ungrouped (Figure 34). 


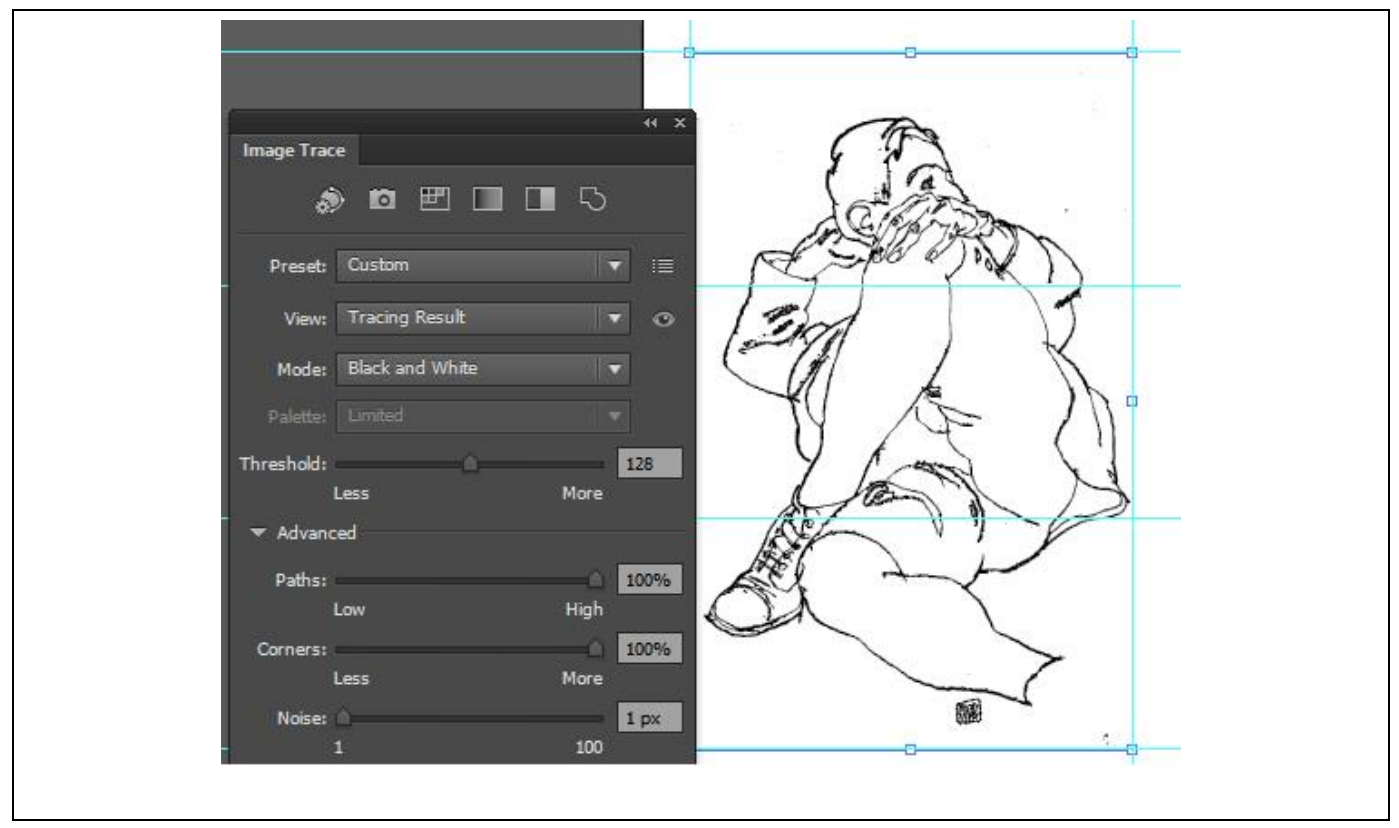

Figure 34: Visualization of the image trace palette used for the image conversion process using Adobe Illustrator CS6.

Egon Schiele. (1918), Young Man Reclining with his Head Resting on His Crossed Leg; Liegender Knabe mit Aufgestutztem Kopf und Ubergeschlagenen Linken Bein, (charcoal on tan paper). Private Collection, Photo () Christie's Images, Bridgeman Images.

From the created vector paths the following measures were obtained: number of paths, number of points, and the total length of all paths. These numbers were placed in an EXCEL spreadsheet and the following statistical measures were produced for every image: the average length of a path:

Average Path Length $=\underline{\text { Total length of all paths }}$

Total number of paths and the average number of points on a path:

\section{Line Expressiveness $=\underline{\text { Total number of points }}$ \\ Total number of paths}

\section{Line-width}

Computationally the definition of a line is one-dimensional having zero width. However, in a drawing to perceive line information some line thickness has to be employed. Ching (2010) addresses this problematic issue of line width, stating a line has only one dimension, but to be visible, a line needs to have some degree of 
thickness. He also describes the length-width ratio of line and how a line is perceived as such because its length dominates its width.

A problem arose in measuring line width. There appeared to be multicollinearity with the shape measure. Adobe Illustrator supplied measures for lengths of paths, path segments and number of points but not a width measure. Further analysis revealed that the very definitions of line width and shape are essentially identical and any attempt to separate them left a diminished measure for shape. Having other measures for the traits of line-line length and line expressiveness but no other measures for shape, which would assist with a measure for depth, line width was disregarded at this time.

\section{Feature Extractions for Tone}

The collection of machine measures for tone whether it be global or local are statistical and are expressed visually through a histogram. The histogram for an image plots the number of pixels with a particular brightness level (the original image) against the brightness level (a standard set). For 8-bit pixels, the brightness ranges from 0 (black) to 255 (white). The measures collected for tone include a mean, standard deviation, median, and a mode. While the statistics collected for both local and global tone are similar, what the measures signify in relation to marks made within a drawing are very different.

\section{Global Tone Measure}

Global tone gives a visual overall measure for brightness of a drawing. Within human perception, it could be describing the first impression given of a drawing when it is examined. Global tone is approached as a classifier of the overall image including the entirety of the drawing surface as downloaded from Bridgeman's image bank (Figure 35). Global tone takes into consideration the quality of the brightness of the drawing surface as well as all the marks contained on that surface. The measures collected for global tone include a mean, standard deviation, median, and a mode. 


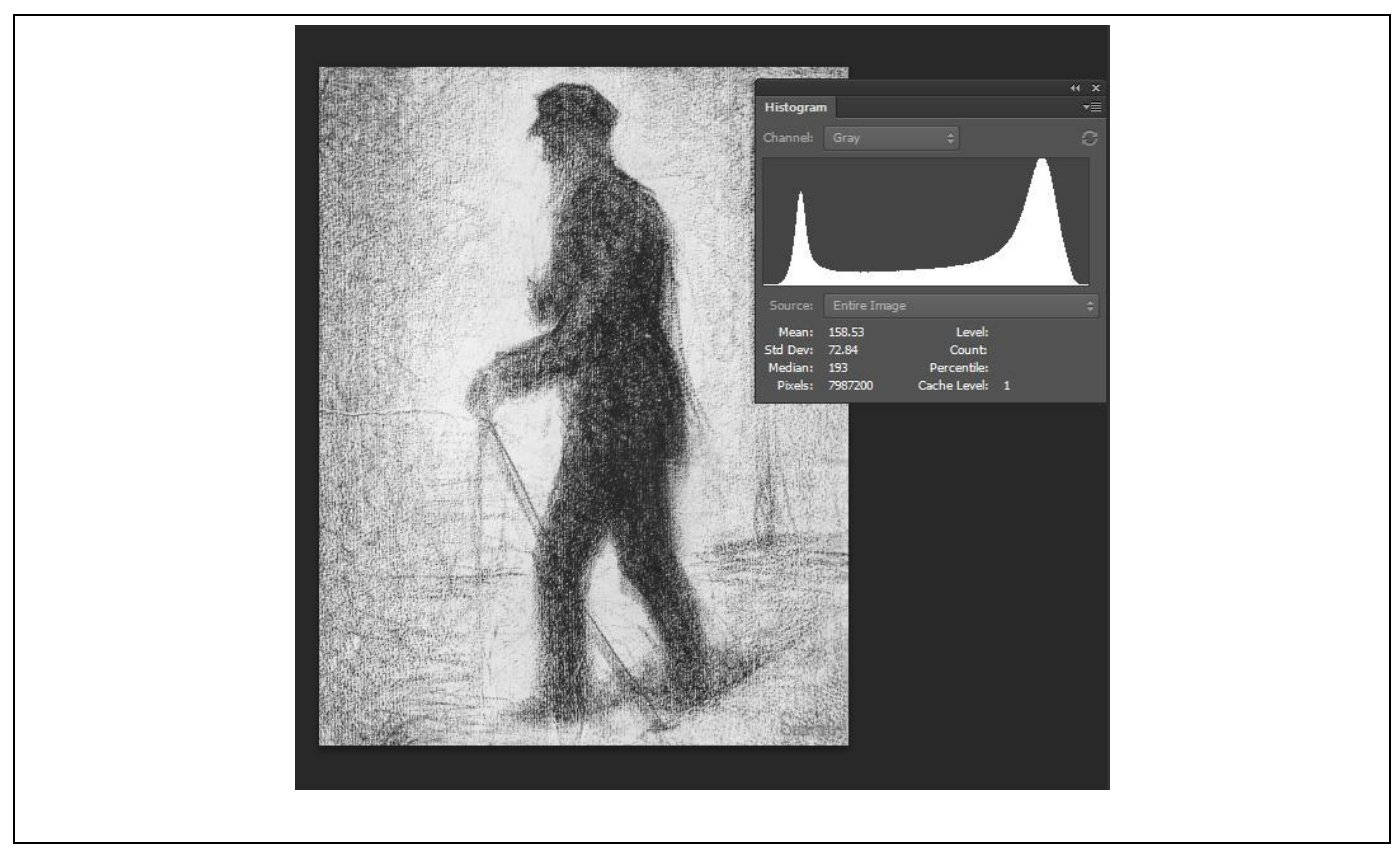

Figure 35: Visualization of global tone for an image including its histogram.

Georges Pierre Seurat. (1882), Walking, (conte crayon on paper). Private Collection, Photo @ Christie's Images, Bridgeman Images.

The measurement for global tone was taken from Adobe Photoshop. All images were set to $8 \mathrm{Bits}$, giving them a scale of black to white pixels of $0-255$ with 0 being black and 255 white. The histogram window with the extended view was opened, the histogram was updated and the mean was recorded.

\section{Local Tone Measure}

Local tone describes smaller areas or particular planes of rendered objects within a composition and subtle changes of light within those areas. Within local tone texture and pattern through mark making are perceived.

This research first identifies the area to select for statistical measures of local tone as those areas within the perimeter of shapes defined by the use of an area detection procedure. Since tone is still a measure of the spectrum from white through grey to black it is in the selection of specific areas of pixels' measures that will be recorded (Figure 36). The specificity of pattern is in the ratio of black and white pixels (Figure 37). 


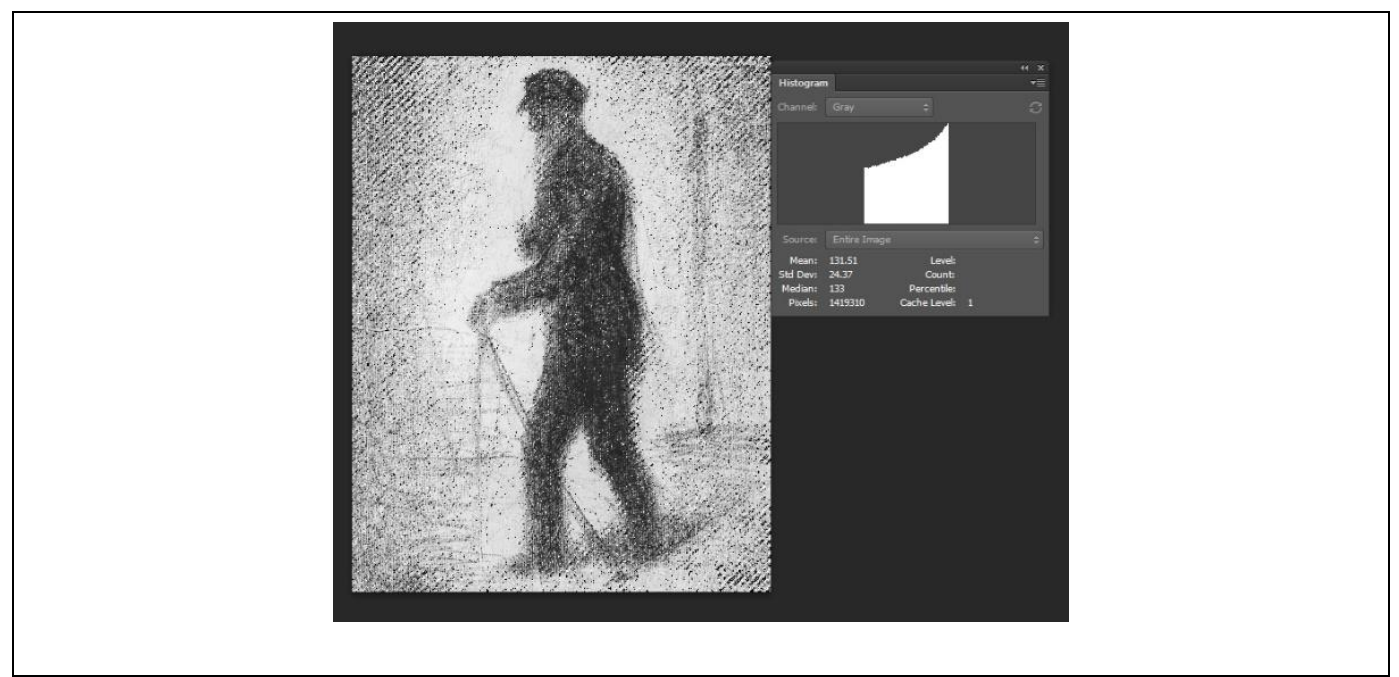

Figure 36: Visualization of a selection using edge detection for a measure of local tone for an image including its histogram.

Georges Pierre Seurat. (1882), Walking, (conte crayon on paper). Private Collection, Photo @ Christie's Images, Bridgeman Images.

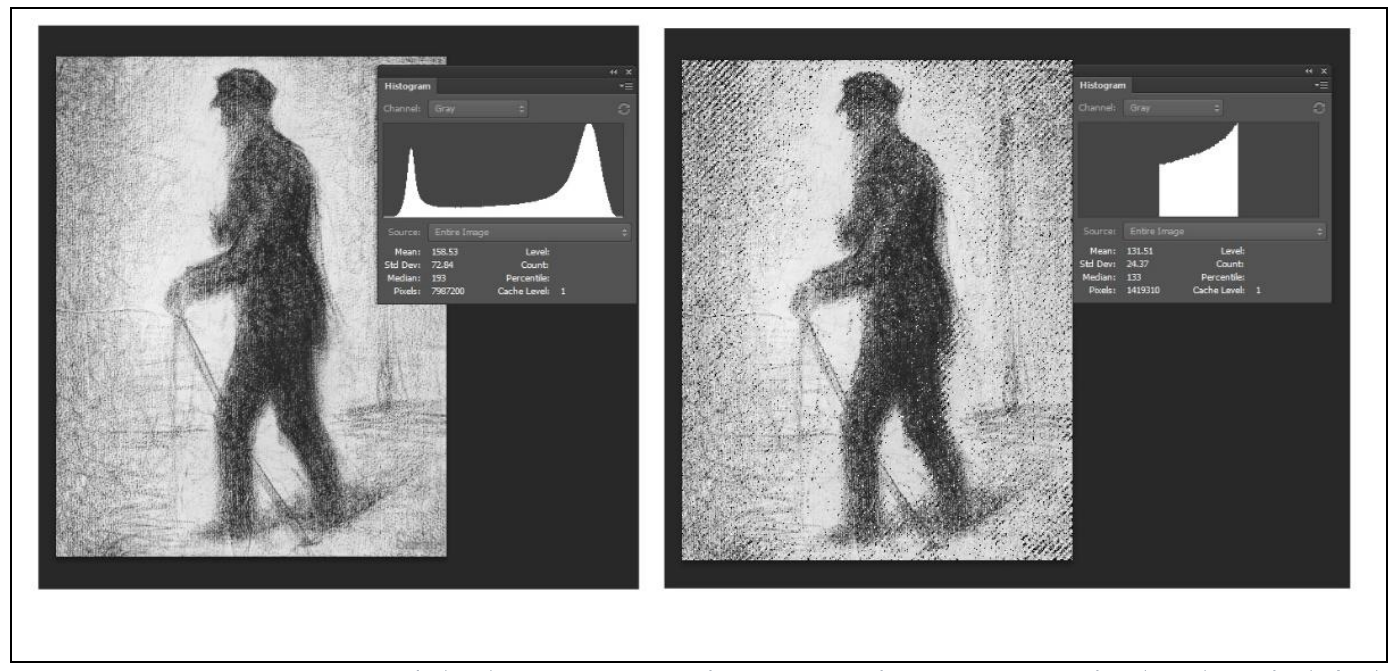

Figure 37: Comparison of the histograms and measures for a measure for local and global tone.

Georges Pierre Seurat. (1882), Walking, (conte crayon on paper). Private Collection, Photo $\odot$ Christie's Images, Bridgeman Images.

It was not in the initial scope of the model build to specifically target a type of texture or pattern for the style grammar. The interest of texture and pattern lies within its influence in local tone-more texture or pattern signifying darker tonal values and a shift in the histogram (the statistical skewness of the shift). Determining 
how the general measure of pattern correlates with other types of measures will assist in obtaining measures without covariance.

\section{Texture/Pattern Measure}

To capture this measure each image was first opened in Photoshop the shadow tones selection was chosen. This selection was then inversed and saved for export into Adobe Illustrator.

Similar to the operation for line length and line expressiveness, the same image conversion procedure was used to obtain a measure for the number of negative paths. The texture/pattern measure used was the total number of negative paths.

\section{Feature Extraction for Depth}

The use of a linear perspective drawing system naturally divides the picture plane into thirds — foreground, middle ground, and background. This type of division coincides with the Golden Mean or rule of thirds to divide a drawing surface by thirds (Yelizaveta, Chua, Irina, \& Jain, 2004). The measure for depth in this research compared average measures obtained for tonal density of objects in the foreground to the background (Figure 38).

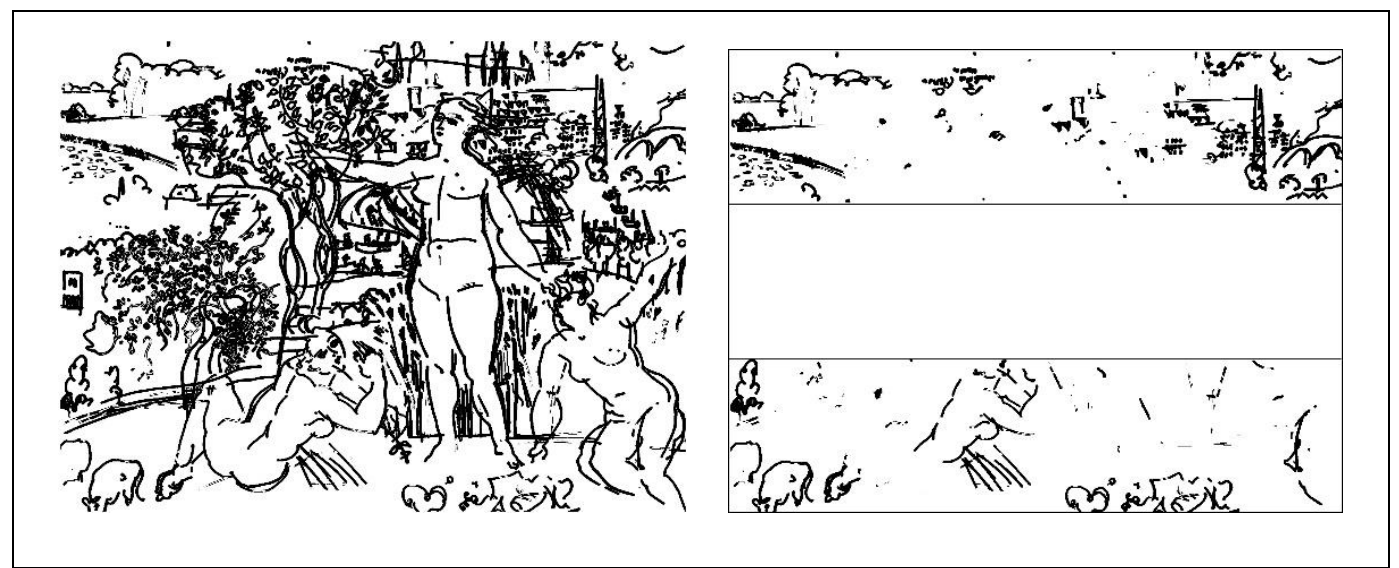

Figure 38: Visualization of a systematic measure for depth using the rule of thirds in drawings using a linear perspective drawing system.

Raoul Dufy. (1938), Study for the Palais de Chaillot Bar; Etude pour le Bar du Palais de Chaillot, (pen and black ink on tracing paper). Private Collection, Photo @ C Christie's Images, Bridgeman Images. 


\section{Depth Measure}

Since one of the key features of depth perception in a drawing is the relative size of objects in the foreground and background, depth was determined to be a ratio of an area measure between the bottom third of an image/to the top third area measure of an image. Each image was opened in Adobe Illustrator and the image conversion from line length/expressiveness was used.

Every image was divided into three equal sections and the mid-section was deleted. The top section was then selected and the number of paths that were left for that section was recorded. This selection was opened in Photoshop and saved as a selection of black pixels and the total number of black pixels for the top area was recorded. The average size of objects in the top section of the picture was calculated as the total number of pixels in the top divided by the total number of paths on the top. This process was then repeated to record a measure of total paths and total pixels for the bottom third. The equation used for depth calculation was:

$$
\begin{gathered}
\text { If (avg. size bottom }>\text { avg. size top then pixels bottom / paths bottom else 0) } \\
\text { paths bottom paths top }
\end{gathered}
$$

That meant that if the pixels on the top were larger than the pixels on the bottom then the score for depth was zero because the image was essentially flat. If the pixels on the top were less than the pixels on the bottom, then the relative size of the objects on the top compared to the objects on the bottom was used as the measure for depth.

\section{Feature Extraction for Smudge}

Smudge was not included in the original model for this research because it had little support in existing literature. However, the first MDS results showed smudge to be the first element subjects used to categorize drawings. One of the important uses of the MDS was to make a determination how accurate the initial list of visual features was and if it was complete. Since smudge was an identified dimension it was added to the analysis for machine readings. 
Within task-oriented drawings, such as technical illustrations smudge, would most likely be seen as a mistake obscuring clarity of the visual communication (page 10). It would be seen as something that needed to be corrected. However, within creative drawings smudge takes on a different set of characteristics. It is an integral part of the drawing, not a mistake. In creative drawing, smudge adds to the tonal value of an image (Figure 39). It is through the tonal quality of smudge that a measure will be obtained.

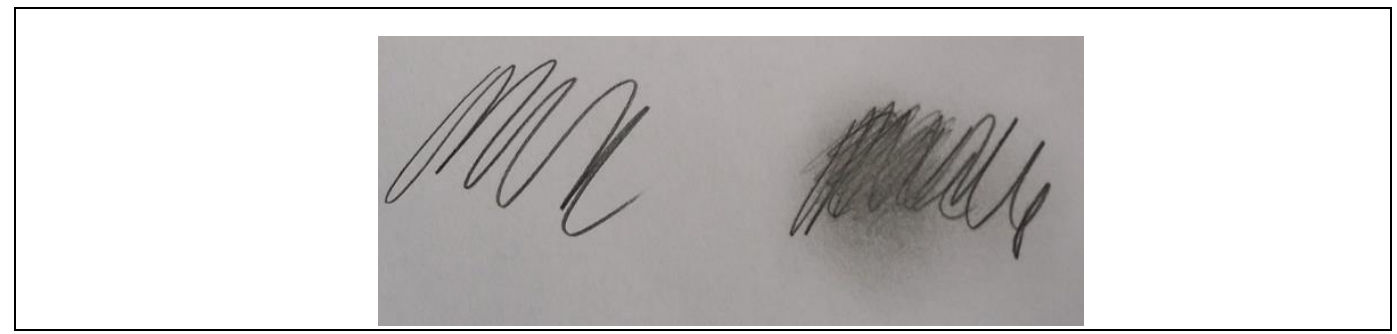

Figure 39: A visualization of smudge.

\section{Smudge Measure}

As previously stated in this research line density is approached as a measure of the intensity of darker areas of tone within an image affecting local tonal values and to an extent indicating the presence of pattern. Smudge because of its dispersion of tone adds more to the middle greys rather than adding to the intensity of darker areas. This suggests a measure of the median grey pixels can be used as an indicator of smudge.

All imagery was opened in Photoshop and a selection of the mid tones (as defined in Photoshop) was made. The number of pixels for this selection was recorded. Smudge was defined as: a ratio measure of the total number of mid tone pixels divided by the total number of pixels within an image (Figure 40).

\section{Smudge $=\underline{\text { Total Number of MidTone Pixels }}$. \\ Total Number of Pixels in the Image}




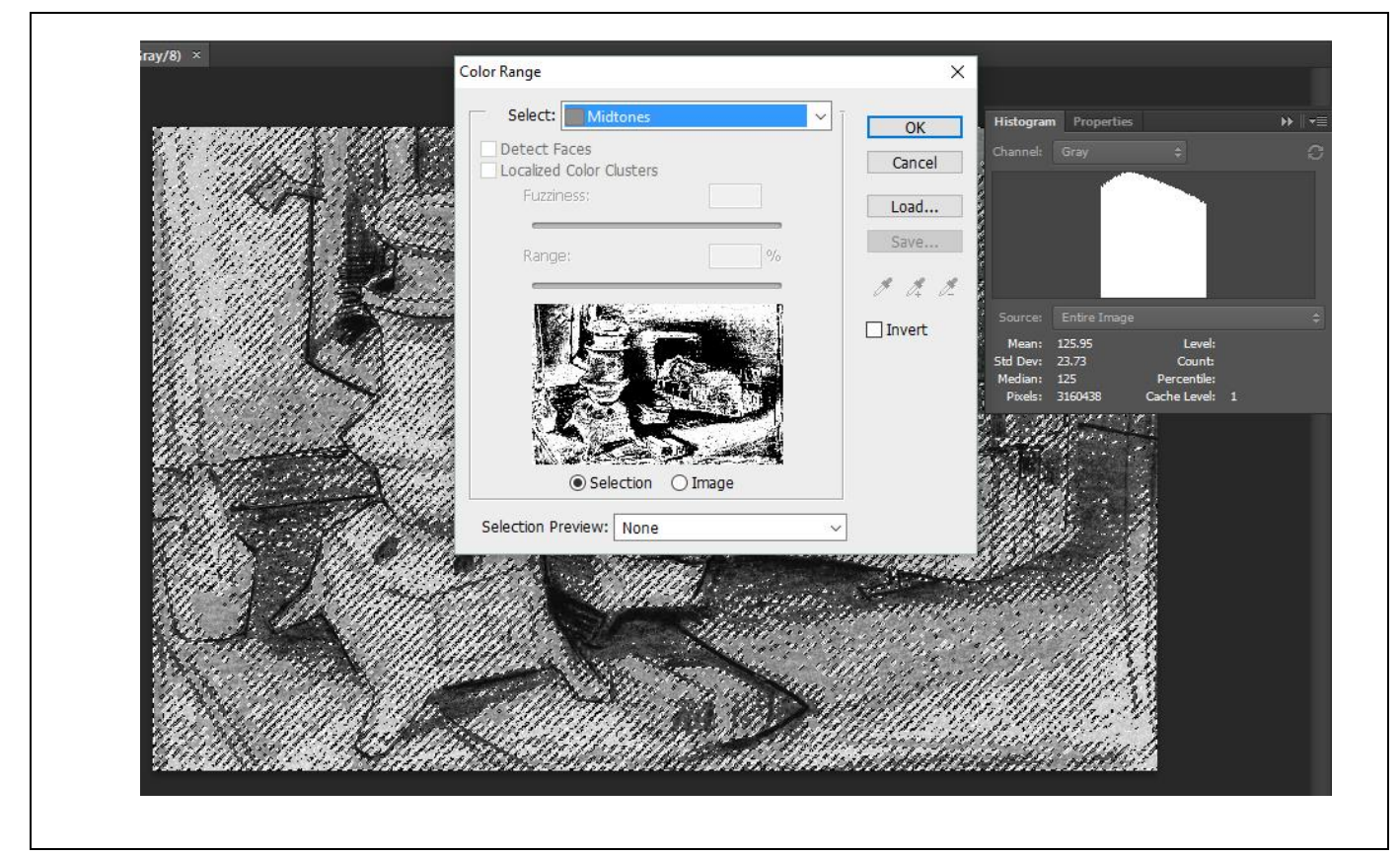

Figure 40: A visualization of smudge selection and measure within Photoshop.

Vincent van Gogh. (date unknown), Cradle (pencil on paper). Van Gogh Museum, Amsterdam, the Netherlands, Bridgeman Images.

\section{Improved Image Categories}

The first MDS assisted with the establishment of a list of visual features and linked traits to test in the model. The results of the second MDS were inconclusive and identified many problems with the use of such large, ill-defined categories.

A different approach to testing the measures of traits to validate the model was needed. Instead of using broad, generalized categories, three artists, recognized historical figures within art, were chosen from the initial MDS. The use of an artist's work as category has been established by other researchers working within digital stylometry (Daniel J. Graham et al., 2012; Hughes et al., 2010; Hurtut et al., 2011).

The work from these three artists were set as three specific categories. All three artists have large bodies of black, white and tonal drawings, which could be used to test measures and validate the model. Their works were available to me in the form of high resolution jpegs for measure through Bridgeman. 
The 3 artists chosen had enough of a base sample size available through Bridgeman (10 cases per independent variable) that fit the guidelines for multinomial logistic regression (Kwak \& Clayton-Matthews, 2002; Schwab, 2002; Starkweather \& Moske, 2011). A general observation was also made that two of the artists' works were similar in nature both being contemporaries while the third was not a contemporary and less similar from the other two. It would therefore be of great interest to see how the model dealt with comparisons between the three. The three artists chosen were:

Artist 1 -Egon Schiele, an early $20^{\text {th }}$ century Austrian artist whose works are considered to be Expressionistic.

Artist 2-Georges-Pierre Seurat, a late $19^{\text {th }}$ century French artist whose works are considered post-impressionistic.

Artist 3-Vincent Willem van Gogh, a late $19^{\text {th }}$ century Dutch artist whose works are considered post-impressionistic.

\section{Phase 3 Machine Measures Results}

The initial multinomial logistic analysis was run using 38 images for artist one, 22 images for artist two, and 22 images for artist three. Four outliers were discovered and removed, 2 images from artist one and 2 images from artist three. Bringing the final number of images for artist one-36 images, artist two-22 images, and artist 3-20 images. The multinomial logistic regression was run with this sample. The case summary shows that there is no missing data for any of the variables. (Table 7). 
Table 7: Case Processing Summary

\begin{tabular}{|ll|r|c|}
\hline & & $\mathrm{N}$ & $\begin{array}{c}\text { Marginal } \\
\text { Percentage }\end{array}$ \\
\hline Artist & 1 & 36 & $46.2 \%$ \\
& 2 & 22 & $28.2 \%$ \\
& 3 & 20 & $25.6 \%$ \\
Valid & 78 & $100.0 \%$ \\
Missing & 0 & \\
Total & 78 & \\
Subpopulation & $78^{\mathrm{a}}$ & \\
\hline
\end{tabular}

Next, the significance of each variable in the model was examined. Table 8 displays significant values for line expressiveness at .000 , global tone at .000 , smudge at .001, and pattern at .00. Line length is almost significant at .069, and depth is not significant at .341. Also of interest is the Chi-square results which are similar to an $\mathrm{r}$ score, the larger the score the more significance the trait in the model.

Table 8: Likelihood Ratio Tests

\begin{tabular}{|c|c|c|c|c|c|c|}
\hline \multirow[b]{2}{*}{ Effect } & \multicolumn{3}{|c|}{ Model Fitting Criteria } & \multicolumn{3}{|c|}{ Likelihood Ratio Tests } \\
\hline & $\begin{array}{c}\text { AIC of Reduced } \\
\text { Model }\end{array}$ & $\begin{array}{c}\text { BIC of Reduced } \\
\text { Model }\end{array}$ & $\begin{array}{c}-2 \text { Log } \\
\text { Likelihood of } \\
\text { Reduced Model }\end{array}$ & Chi-Square & df & Sig. \\
\hline Intercept & 78.870 & 107.151 & 54.870 & 22.960 & 2 & .000 \\
\hline LineLength & 61.247 & 89.527 & 37.247 & 5.337 & 2 & .069 \\
\hline LineExp & 77.504 & 105.785 & 53.504 & 21.595 & 2 & .000 \\
\hline GlobTone & 73.948 & 102.229 & 49.948 & 18.039 & 2 & .000 \\
\hline Smudge & 69.333 & 97.613 & 45.333 & 13.423 & 2 & .001 \\
\hline Depth & 58.064 & 86.345 & 34.064 & 2.154 & 2 & .341 \\
\hline Pattern & 72.232 & 100.513 & 48.232 & 16.323 & 2 & .000 \\
\hline
\end{tabular}

Next, the predictive scores for the measures of the traits were examined. Interestingly the two artists, which are contemporaries and have the most similarity, have the most missed placed cases (Table 9). 
Table 9: Classification

\begin{tabular}{|l|r|r|r|r|}
\hline \multirow{2}{*}{ Observed } & \multicolumn{5}{|c|}{ Predicted } \\
\cline { 2 - 5 } 1 & 1 & 2 & 3 & Percent Correct \\
\hline 2 & 36 & 0 & 0 & $100.0 \%$ \\
3 & 1 & 18 & 3 & $81.8 \%$ \\
Overall Percentage & 0 & 4 & 16 & $80.0 \%$ \\
\hline
\end{tabular}

The means and standard deviations for each artist and trait are shown in Table 10. Significant mean differences were in the expected direction. Schiele, the expressionist had much greater difference in mean to the two post-impressionists. The two post-impressionists were similar in mean but still different. For example, the global tone in the Seurat images was far darker than in van Gogh's images as demonstrated by the lower mean.

Table 10: Means \& Standard Deviations for Each Feature Comparison Among the Three Artists (normalized line lengths)

\begin{tabular}{|c|c|c|c|c|c|c|c|c|}
\hline & $\mathrm{N}$ & & $\begin{array}{l}\text { Line } \\
\text { Length }\end{array}$ & $\begin{array}{l}\text { Line } \\
\text { Exp }\end{array}$ & $\begin{array}{l}\text { Glob } \\
\text { Tone }\end{array}$ & Smudge & Depth & Pattern \\
\hline \multirow[t]{2}{*}{1 Schiele } & 36 & Mean & 16.79 & 12.08 & 201.20 & 5.83 & 1.40 & 3.57 \\
\hline & & SD & 13.01 & 5.99 & 18.16 & 11.05 & 1.97 & 2.76 \\
\hline \multirow[t]{2}{*}{2 Seurat } & 22 & Mean & 7.95 & 6.03 & 117.19 & 27.61 & 0.98 & 60.96 \\
\hline & & SD & 7.78 & 1.47 & 50.12 & 13.81 & 1.44 & 37.67 \\
\hline \multirow[t]{2}{*}{3 van Gogh } & 20 & Mean & 6.32 & 8.31 & 150.71 & 34.92 & 0.88 & 29.62 \\
\hline & & SD & 3.84 & 2.26 & 29.63 & 25.01 & 0.96 & 15.41 \\
\hline
\end{tabular}

\section{Styles Comparisons}

Next a styles comparisons using Bivariate Logistic Regression was run which allowed for comparisons between 2 artists rather than a group. Since there are three artists the comparison results are between artists 1 and 2, 1 and 3, and 2 and 3 . 


\section{Egon Schiele \& Georges-Pierre Seurat}

As can be seen in Table 11, the Chi-Square for the model is 76.992 with a significance of .000 . Showing that the overall model is highly significant.

Table 11: ES vs GS Omnibus Tests of Model

Coefficients

\begin{tabular}{|rl|r|r|r|}
\hline & & Chi-square & df & \multicolumn{1}{c|}{ Sig. } \\
\hline Step 1 & Step & 76.992 & 6 & .000 \\
& Block & 76.992 & 6 & .000 \\
& Model & 76.992 & 6 & .000 \\
\hline
\end{tabular}

When looking at each variable in Table 12, Line Length $(\mathrm{p}=.006)$, Line Expressiveness $(\mathrm{p}=.000)$, Global Tone $(\mathrm{p}=.000)$, Smudge $(\mathrm{p}=.000)$, and Pattern $(\mathrm{p}=.000)$ were all very highly significant. Depth $(\mathrm{p}=.379)$ is not significant. So when comparing Egon Schiele and George Seurat, all the model variables save Depth have a significant effect.

Table 12: ES vs GS Variables

\begin{tabular}{|c|c|c|c|c|c|}
\hline & & & Score & $\mathrm{df}$ & Sig. \\
\hline \multirow[t]{7}{*}{ Step 0} & \multirow[t]{6}{*}{ Variables } & LineLength & 7.494 & 1 & .006 \\
\hline & & LineExp & 16.092 & 1 & .000 \\
\hline & & GlobTone & 34.789 & 1 & .000 \\
\hline & & Smudge & 25.454 & 1 & .000 \\
\hline & & Depth & .775 & 1 & .379 \\
\hline & & Pattern & 34.760 & 1 & .000 \\
\hline & \multicolumn{2}{|c|}{ Overall Statistics } & 42.687 & 6 & .000 \\
\hline
\end{tabular}

With the highly significant model and many significant traits, it came as no surprise that the bivariate logistical regression was able to use the model measures to place $100 \%$ of the pictures into the correct artist style (Table 13). Since Egon Schiele most often considered an expressionist and Georges Seurat a post- 
impressionist, it was heartening to see the measures and model accurately designate all the pictures.

Table 13: ES vs GS Classification Tables

\begin{tabular}{|c|c|c|c|c|c|}
\hline & & & \multicolumn{3}{|c|}{ Predicted } \\
\hline & \multirow{2}{*}{\multicolumn{2}{|c|}{ bbserved }} & \multicolumn{2}{|c|}{ Artist } & \multirow{2}{*}{$\begin{array}{c}\text { Percentage } \\
\text { Correct }\end{array}$} \\
\hline & & & 1 & 2 & \\
\hline \multirow[t]{3}{*}{ Step 1} & Artist & 1 & 36 & 0 & 100.0 \\
\hline & & 2 & 0 & 22 & 100.0 \\
\hline & Overa & rcentage & & & 100.0 \\
\hline
\end{tabular}

a. The cut value is .500

\section{Egon Schiele \& Vincent Willem van Gogh}

The results were then examined for a comnarison of artist 1 and artist 3 . As can be seen in Table 14, the Chi-Square for the model is 72.997 with a significance of .000. Showing that the overall model was highly significant.

\section{Table 14: ES vs VG Omnibus Tests of Model Coefficients}

\begin{tabular}{|rl|r|r|r|}
\hline & & Chi-square & df & \multicolumn{1}{c|}{ Sig. } \\
\hline Step 1 & Step & 72.997 & 6 & .000 \\
& Block & 72.997 & 6 & .000 \\
& Model & 72.997 & 6 & .000 \\
\hline
\end{tabular}

When looking at each variable in Table 15, Line Length $(\mathrm{p}=.001)$, Line Expressiveness $(\mathrm{p}=.010)$, Global Tone $(\mathrm{p}=.000)$, Smudge $(\mathrm{p}=.000)$, and Pattern $(\mathrm{p}=.000)$ were all very highly significant. Depth $(\mathrm{p}=.269)$ was still not significant however, the score was better. So when comparing Egon Schiele and Vincent van Gogh, all the model variables save Depth had a significant effect. 
Table 15: ES vs VG Variables

\begin{tabular}{|c|c|c|c|c|c|}
\hline & & & Score & $\mathrm{df}$ & Sig. \\
\hline \multirow[t]{7}{*}{ Step 0} & Variables & LineLength & 10.383 & 1 & .001 \\
\hline & & LineExp & 6.648 & 1 & .010 \\
\hline & & GlobTone & 30.092 & 1 & .000 \\
\hline & & Smudge & 22.535 & 1 & .000 \\
\hline & & Depth & 1.220 & 1 & .269 \\
\hline & & Pattern & 36.177 & 1 & .000 \\
\hline & \multicolumn{2}{|c|}{ Overall Statistics } & 42.367 & 6 & .000 \\
\hline
\end{tabular}

Again, with the highly significant model and significant traits, the bivariate logistical regression was able to use the model measures to place $100 \%$ of the pictures into the correct artist style (Table 16). Since the model was able to differentiate between Egon Schiele, an expressionist and Georges Seurat a post-impressionist, it was expected that the model would be able to do similarly well comparing Egon Schiele to Vincent van Gogh.

Table 16: ES vs VG Classification Tables

\begin{tabular}{|c|c|c|c|c|c|}
\hline & & & \multicolumn{3}{|c|}{ Predicted } \\
\hline & \multirow{2}{*}{\multicolumn{2}{|c|}{ Observed }} & \multicolumn{2}{|c|}{ Artist } & \multirow{2}{*}{$\begin{array}{c}\text { Percentage } \\
\text { Correct }\end{array}$} \\
\hline & & & 1 & 3 & \\
\hline \multirow[t]{3}{*}{ Step 1} & Artist & 1 & 36 & 0 & 100.0 \\
\hline & & 3 & 0 & 20 & 100.0 \\
\hline & Overa & rcentage & & & 100.0 \\
\hline
\end{tabular}

a. The cut value is .500

\section{Georges-Pierre Seurat \& Vincent Willem van Gogh}

The results were then examined for a comparison of artist 2 and artist 3.

These results were of particular interest since these two artists are considered contemporaries, and from general observation of the artworks as they were measured share similarities in visual traits. As can be seen in Table 17, the Chi-Square for the 
model is 33.784 with a significance of .000 . Showing that the overall model was highly significant.

Table 17: GS vs VG Omnibus Tests of Model Coefficients

\begin{tabular}{|rl|r|r|r|}
\hline & & \multicolumn{1}{c|}{ Chi-square } & \multicolumn{1}{c|}{$\mathrm{df}$} & \multicolumn{1}{c|}{ Sig. } \\
\hline Step 1 & Step & 33.784 & 6 & .000 \\
& Block & 33.784 & 6 & .000 \\
& Model & 33.784 & 6 & .000 \\
\hline
\end{tabular}

Next is an examination of how each variable held up with these two artists. Table 18 shows the results. Line Expressiveness $(\mathrm{p}=.001)$, Global Tone $(\mathrm{p}=.014)$, and Pattern $(\mathrm{p}=.002)$ were all highly significant. Line Length $(\mathrm{p}=.388)$, Smudge $(\mathrm{p}=.231)$, and Depth $(\mathrm{p}=.803)$ were not significant. In fact, the depth score is far worse. Therefore, when comparing Georges Seurat and Vincent van Gogh, Line Length and Smudge as well as Depth had no significant effect in a categorical prediction.

Table 18: GS vs VG Variables

\begin{tabular}{|c|c|c|c|c|c|}
\hline & & & Score & df & Sig. \\
\hline \multirow[t]{7}{*}{ Step 0} & Variables & LineLength & .746 & 1 & .388 \\
\hline & & LineExp & 11.683 & 1 & .001 \\
\hline & & GlobTone & 6.087 & 1 & .014 \\
\hline & & Smudge & 1.432 & 1 & .231 \\
\hline & & Depth & .062 & 1 & .803 \\
\hline & & Pattern & 9.688 & 1 & .002 \\
\hline & \multicolumn{2}{|c|}{ Overall Statistics } & 18.103 & 6 & .006 \\
\hline
\end{tabular}

The model placed $85.7 \%$ of the pictures into the correct artist style (Table 19). This outcome was surprisingly good since these two artists Georges Seurat and Vincent van Gogh share more similarities in particular types of mark making, as well as being contemporaries. 
Table 19: GS vs VG Classification Table

\begin{tabular}{|c|c|c|c|c|c|}
\hline & & & \multicolumn{3}{|c|}{ Predicted } \\
\hline & & & & & Percentage \\
\hline & \multicolumn{2}{|c|}{ Observed } & 2 & 3 & Correct \\
\hline \multirow[t]{3}{*}{ Step 1} & \multirow[t]{2}{*}{ Artist } & 2 & 19 & 3 & 86.4 \\
\hline & & 3 & 3 & 17 & 85.0 \\
\hline & \multicolumn{2}{|c|}{ Overall Percentage } & & & 85.7 \\
\hline
\end{tabular}

a. The cut value is .500

Overall there were good results for most measures. The implications of the results are discussed in the following section.

\section{Phase 3 Machine Measures Discussions}

The data analysis of the multinomial logistic regression proved the use of an artist as a category a better way to test visual features and validate the style grammar model. The analysis gives several ways to examine and discuss results including outliers, and their visual features and significance in the model. The general concept of the model is to be able to determine when borrowing from a design source, what elements need to be identified for usage and their significance within the overall model to create a general ranking of their usage (page 24). Since there was no evidence to suggest an order to the traits to place them step wise into the regression, all the measures were input simultaneously.

Outliers are of interest in this type of analysis because they may suggest parameters for a particular trait. If an outlier is thought of as being atypical of a group, being able to identify what makes it so dissimilar could lead to insights on aspects of borrowing. Decisions based on quantitative qualities of a trait or feature can be made when something has gone beyond boundaries and is hard to associate with a particular group, whether to follow that design stream or set specific measurable limitations. Four outliers were discovered and removed, 2 images from 
artist one (Egon Schiele) and 2 images from artist three (Vincent van Gogh).

Choosing one image from each artist I will discuss the significance of measures that identify these images as outliers.

Figure 41 compares one of the images identified as an outlier and two images used in the data analysis. Visually it might be easy to see that the image on the left was identified as an outlier based on global tone. It also had atypical measures on smudge, and line length. This shows two courses of action that can be followed in the process of design borrowing of visual features-one that is atypical and one that would be more similar to Egon Schiele's typical mark making style.

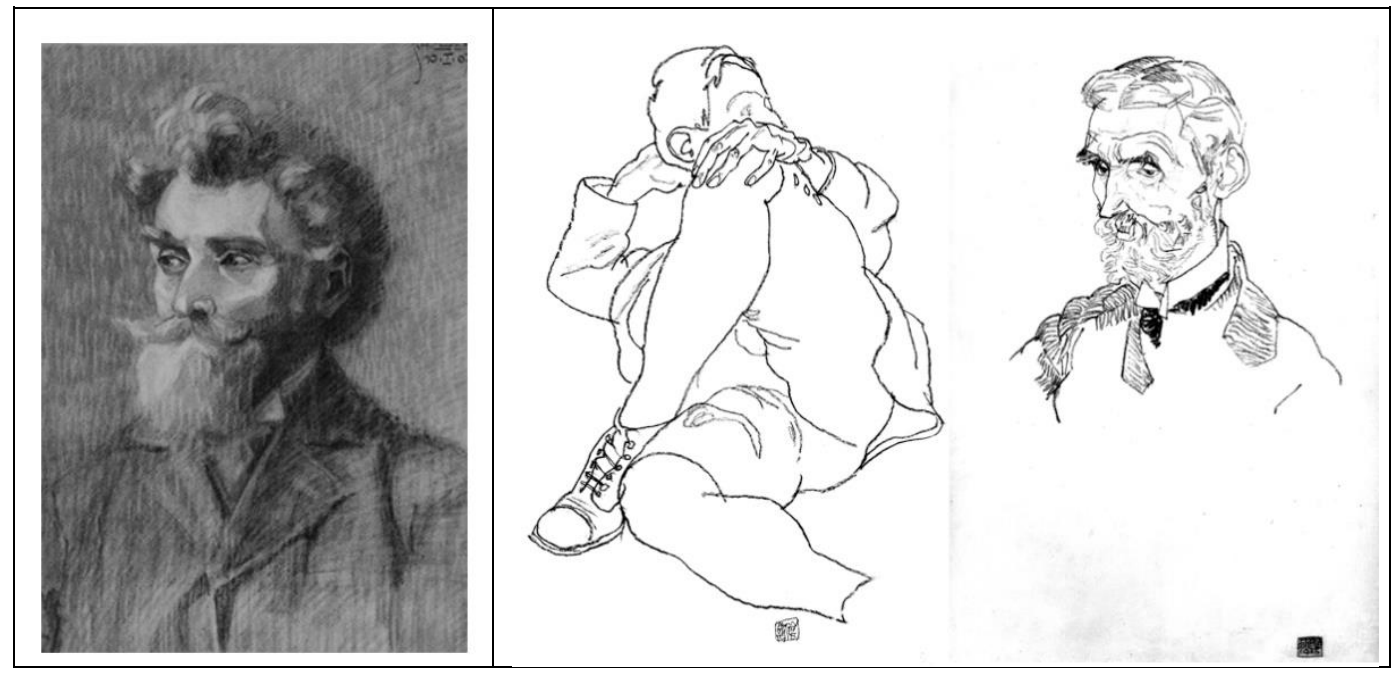

Figure 41: Left: an atypical drawing by Egon Schiele compared to two typical drawings by the artist on the right.

From left to right: Egon Schiele. (1907), Portrait of Man; Mannerportrait, (soft pencil on paper). Private Collection, Photo (C) Christie's Images, Bridgeman Images.

Egon Schiele. (1918), Young Man Reclining with his Head Resting on His Crossed Leg; Liegender Knabe mit Aufgestutztem Kopf und Ubergeschlagenen Linken Bein, (charcoal on tan paper). Private Collection, Photo (C) Christie's Images, Bridgeman Images.

Egon Schiele. (1915), A Portrait of the Artist's Father-in-Law, Johann Harms, (pencil on paper). Private Collection, Bridgeman Images.

Figure 42 compares another one of the images identified as an outlier and two images used in the data analysis, this time by Vincent van Gogh. Visually it may be a bit harder to identified the image on the left as an outlier. Comparison of most of the measures of the drawing are within typical range, however, the long line 
separating the image from the handwriting and the handwriting itself greatly affected the measure of line length. Placing the image in the a-typical range of a single measure. This again shows two courses of action that can be followed in the process of design borrowing of visual features_-one that is a-typical and one that would be more similar to Vincent van Gogh's typical mark making style. This example illustrates possible design outcomes that may be well out of a style range influenced by a single a-typical measure.

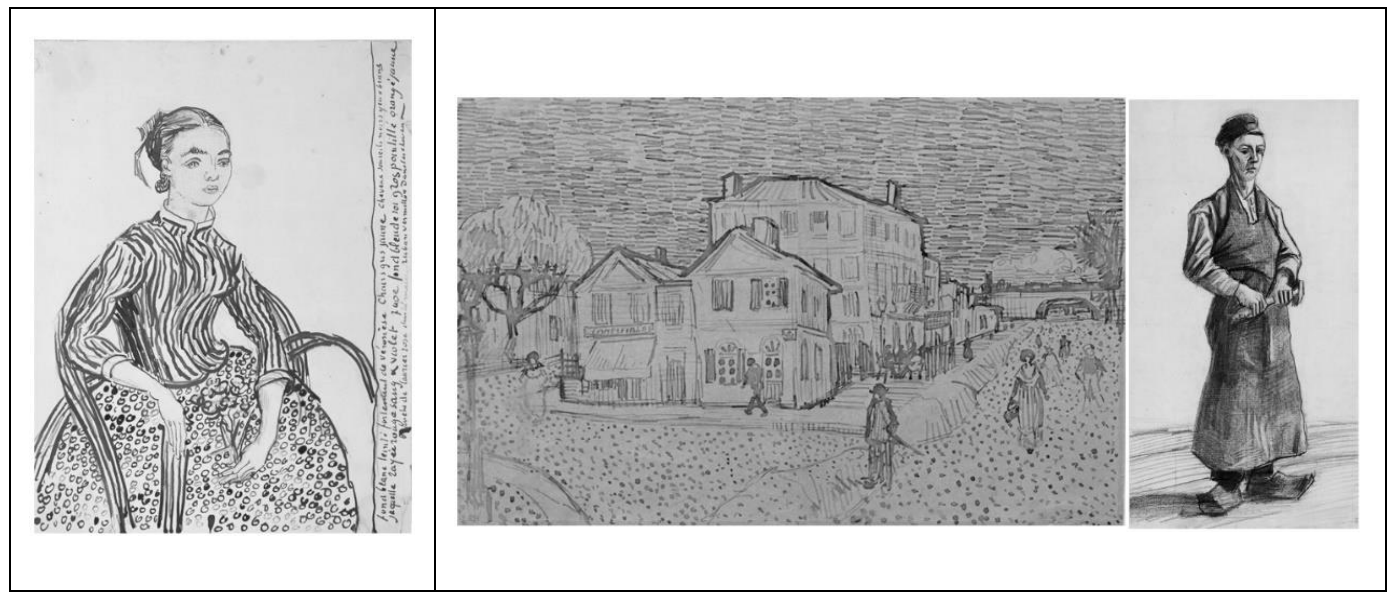

Figure 42: Left: an atypical drawing by Vincent van Gogh compared to two typical drawings by the artist on the right.

From left to right: Vincent van Gogh. (1888), Portrait of a Young Girl, (ink on paper). Pushkin Museum, Moscow, Russia, Bridgeman Images.

Vincent van Gogh. (1888), The Artist's House in Arles, (pen \& ink on paper). Private Collection, Photo (C) Christie's Images, Bridgeman Images.

Vincent van Gogh. (1882), The Blacksmith's Boy, (black chalk \& pencil on paper). Private Collection, Photo (C) Christie's Images, Bridgeman Images.

\section{Multinomial Logistic Regression Main Effects}

Looking at the overall model, four traits proved to be significant at the .001 level suggesting the importance of these traits and their measures as style predictors. They were line expressiveness_-.000, global tone-.000, smudge-.001 and pattern-.000 (page 112). It can be argued that directly effecting the appearance of these four traits can effectively change the stylistic appearance of a drawing without touching any other feature such as line length which had a measure of .069. Taking 
this type of approach to the identification of traits and measures suggests what should be targeted in a stylistic borrowing first. Line expressiveness, global tone, and pattern should be the first traits targeted and strategies developed for borrowing should focus on them, followed by smudge. The outcomes of the measure for line length suggest that it should not be the first trait targeted for borrowing. Depth is a problematic at a measure of .341.

\section{Predicted Classification of Images}

Another approach to examining features and traits for similarity/dissimilarity between the three artists' styles was through analysis of the measures and how well they predicted which category the artwork was placed. Not surprisingly, the measures of the traits placed all of Egon Schiele's work correctly, while it was far more difficult between Georges-Pierre Seurat and Vincent van Gogh, who have more in common in their styles of mark making. While it could be argued that an art expert through image memorization could place $100 \%$ of the images correctly, it is a different type of examination that the model holds for practitioners, students and art teachers, particularly in the design practice of borrowing. It may be quite easy to visually distinguish between two types of drawing styles that are very different from one another, but where two drawing styles are similar the misclassification of works leads to further examination of particular parameters and where borrowing choices may be far more significant (Figure 43 and 44). 


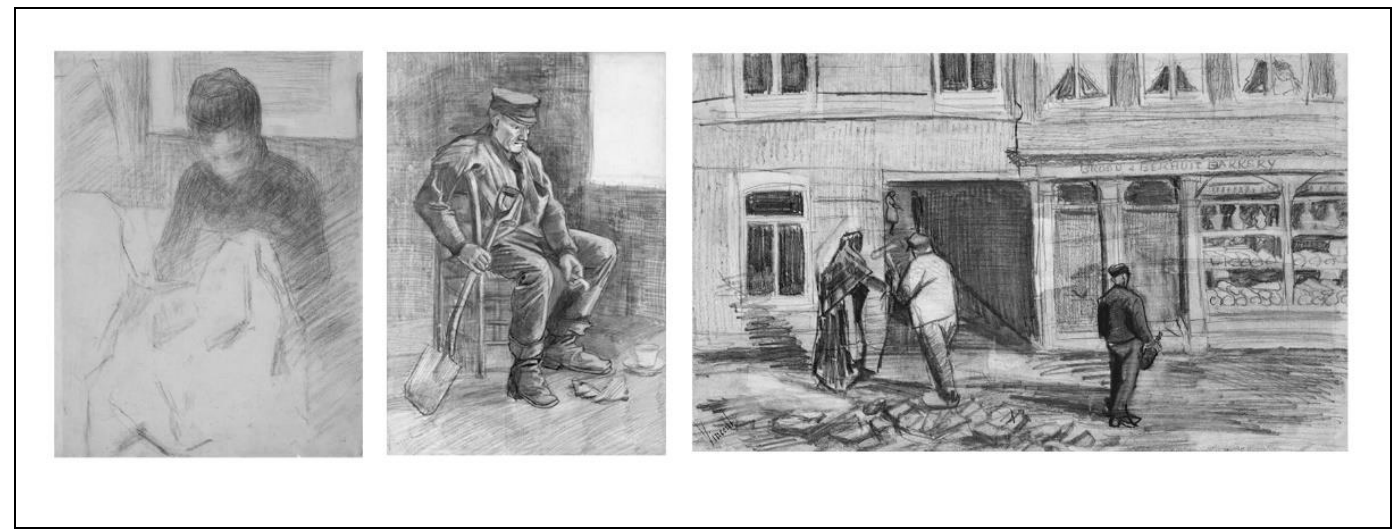

Figure 43: Left: Misclassification of a drawing by Seurat on the left compared to 2 correctly classified drawings by van Gogh on the right.

From left to right: Georges Pierre Seurat. (1881-82), Une Couseuse, Un Tableau au Mur, (crayon on paper). Whitworth Art Gallery, University of Manchester, UK, Bridgeman Images.

Vincent van Gogh. (1882), Man with a Spade Resting, (pencil \& chalk). Private Collection, Bridgeman Images.

Vincent van Gogh. (1882), The Bakery in de Geest, (pencil and charcoal on vellum). Haags Gemeentemuseum, The Hague, Netherlands, Bridgeman Images.

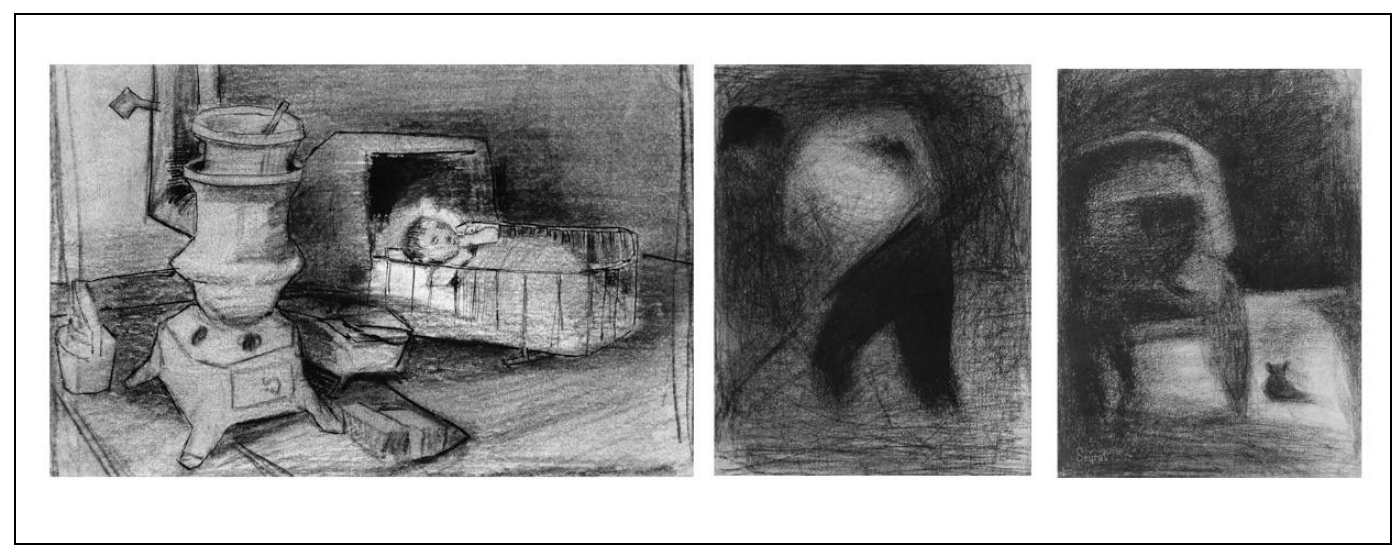

Figure 44: Left: Misclassification of a drawing by van Gogh on the left compared to 2 correctly classified drawings by Seurat on the right.

From left to right: Vincent van Gogh. (date unknown), Cradle (pencil on paper). Van Gogh Museum, Amsterdam, The Netherlands, Bridgeman Images.

Georges Pierre Seurat. (1883), Man with a Pick, (crayon conte). Private Collection, Bridgeman Education. Georges Pierre Seurat. (1882-84), Carriage and Dog, (conté crayon on paper). Museum of Modern Art, New York, USA, Bridgeman Images.

\section{Bivariate Logistic Regression Findings}

To be thorough in the data analysis, bivariate logistic regressions were run comparing measures for visual features and traits for each pair of artists: Schiele and 
Seurat, Schiele and van Gogh, and Seurat and van Gogh (pages 114-118). The comparisons of similarities/dissimilarities measures in the traits and features are clearer in this analysis. It is far easier to see than in the bivariate data analysis van Gogh and Seurat share similarities in some mark making processes—particularly smudge and line length. This might signify in a borrowing process that great attention needs to be given in the combined usage of these two traits. While a great many people might automatically think of van Gogh as using short, choppy lines when used in combination with smudge, the borrowing process becomes less distinctive of van Gogh's drawing style. This type of analysis allows for two approaches:

1) To borrow closer to a look in a van Gogh style or

2) To borrow but look more distinguished and less reminiscent of van Gogh's drawing style.

Consideration and care need to be taken because of where this might place a design in a sense intentionally or unintentionally starting to borrow from another artist's style of drawing which has not yet been identified in the model.

The data analysis revealed that Egon Schiele in comparison to both van Gogh and Seurat has a very different and distinct drawing style. While visually this may seem very obvious, looking at the measures for each feature and trait, particularly the means and standard deviations, a far more quantitative exploration and comparison can be made that would assist with a more accurate process of design borrowing.

While both the multinomial and bivariate logistic regressions showed the significance for many of the measures, it also showed the weakness of the measure for depth. Implications of this issue will be discussed thoroughly in traits/measures below. 


\section{Traits/Measures}

Linking the measure of a trait to a visual feature was important. It allowed for a clear examination of the segmentation process. It also gives relevance to the measures and how they can be used to interpret mark making in a design/drawing process. Measures obtained for the model would have no occurrence of multiple responses/selections which could lead to ambiguity in the measures. Four goals were identified for collecting measures:

1. Avoid collinearity among the measures;

2. Develop a systematic and objective approach to obtaining each measure by computer operation with as little human interference as possible;

3. Every measure while quantitative, also explains a trait or feature visually and logically; and

4. While the measure needs to be understood logically for visualization the operation for obtaining the measure also needs to be easily accessible to the art/design practitioner, the art/design student, and the art/design teacher.

\section{Smudge}

I begin the discussion of traits/and measures with smudge since it was introduced as a trait for the model from the first MDS card sort. An interesting observation from the MDS card sort is the suggestion of smudge as an output of line quality_clean lines vs. "dirty" lines. This is interesting because in the final output of computer measures in the model for smudge, it is linked as a trait of tone and measured by looking at the amount of grey pixels and mid tones within a drawing.

Smudge can be explained statistically in the histogram of an image as the kurtosis of the histogram's curve. Kurtosis is a statistical term used in the description of a distribution of a set of data and quantifies whether the data are sharply peaked (leptokurtic) or flat (platykurtic) (Dodge, 2006). The most accessible way to get a measure for smudge was by using Adobe Photoshop's histogram palette window and the selection tool (page 109). Selecting the mid tones of an image and noting the 
number of grey pixels and comparing that number to the total amount of pixels overall allowed a ratio to be used for the measure of smudge. This proved to be a better measure and yielded better results in the model than the actual kurtosis measure of the overall histogram itself, which can also be obtained quite easily through a selection process in ImageJ.

The measure for smudge illustrates two very different aspects of the trait and how it links two visual features-line and tone. Smudge can be interpreted as an approach to line quality within the drawing process, but its affect is measured not through line segmentation but through area and the spread of mid tone pixels and tone. Reexamining the example used earlier for smudge, it is possible to see the duality of the feature (Figure 45).

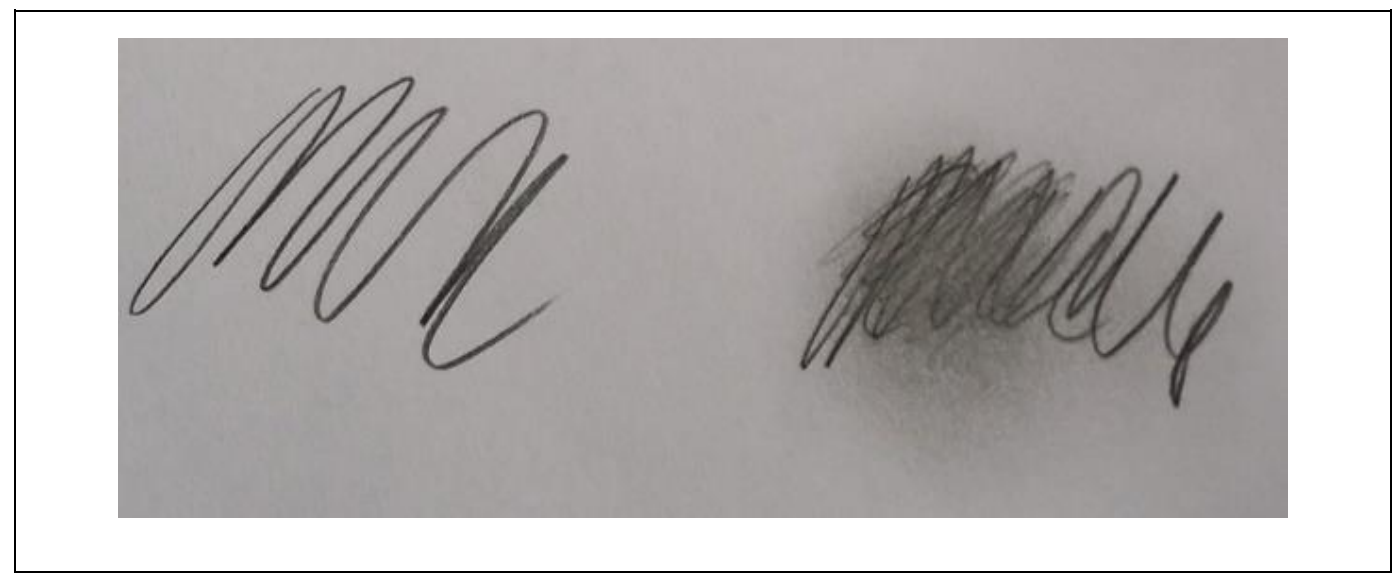

Figure 45: The duality of smudge-dirty line and tonal quality.

The data analysis of the measure for smudge in both the multinomial logistic regression and the bivariate logistic regression showed this trait was significant and gave good results in the model. In the multinomial logistic regression, the significance of this measure was .001. In the bivariate logistic regression, it was again significant in the comparison of works between Schiele and van Gogh, Schiele and Seurat with a measure of .000 (pages 112-118), confirming the visual observation that Schiele used this feature in a significantly different way to van Gogh and Seurat. 
This measure was insignificant in the bivariate logistic regression comparing works between van Gogh and Seurat, at .231, confirming the visual observation that van Gogh and Seurat used this particular feature in similar ways.

Currently, because the model contains the works of three artists, only a limited set of suggestions can be made towards the borrowing of this feature towards a style grammar. But a limited example can be made:

- More emphasis is placed on the quality of line and other features related to line when there is little to distract from it. So, if what is desired is emphasis on line don't use smudge or limit its usage.

- More emphasis is placed on shape when line becomes obscured.

- Tonal qualities also become more important since they are emphasized over line.

- To emphasize line, where tonal qualities are also emphasized, it will be necessary to make line far darker and possibly thicker. This will also affect the overall tonal quality of the drawing surface—-making it darker. Areas of light or where there is no mark will become more significant.

This may seem very intuitive to some, particularly those accustomed to drawing and this research may seem like a very complex way to arrive at some very simple statements. It can be argued that grammars, however, are very simple. They use principled rule sets to govern the organization of very complex ideas, and because of their principled nature they expose underlying structures which are often times obscured, making them a very good teaching tool.

\section{Global Tone}

It is suggested that humans interpret whole scenes even when answering simpler visual questions such as image segmentation as well as interpreting groupings of objects (Martin \& Fowlkes, 2001; Wertheimer, 1938). An extension of these ideas can be seen in tone. On the one hand, there is the consideration of global tone-the overall value of an image, its overall lightness or darkness. On the other there is local 
tone- the tonal quality of areas within the drawing, which sets up various juxtapositions within a composition, assisting with movement throughout the compositional space.

Global tone is therefore approached as the first impression of a drawing, an overall value judgement. Since the standard deviation is seen as a good marker to assist with developing parameters for traits, the mean measure which again can be obtained through Adobe Photoshop's histogram palette window is an appropriate measure and descriptor for global tone.

The perception of the global tonal quality of drawn imagery was the third dimension identified in the MDS free card sort. The measure of global tone in both the multinomial logistic regression and the bivariate logistic regression data analysis was significant across all three artists and gave good results in the model. The multinomial logistic regression showed the significance of .000. The bivariate logistic regression showed significance of .014 when comparing works by van Gogh and Seurat, .000 when comparing works by Schiele to both Seurat and van Gogh (pages $112-118)$.

This could point to the significance in the identification of local tone vs. global tone and link pattern/texture and smudge as a trait of local tone. Comparing the significance of these three measures: pattern/texture, smudge, and global tone if both pattern/texture and smudge were directly linked to global tone one or all of the measures would be insignificant because of the collinearity created, suggesting there is a separate trait of local tone which both smudge and pattern/texture are linked to. This is an interesting idea and will require more analysis to confirm.

It had been originally thought through general observation of the imagery that pattern/texture was linked to local tone, smudge had not been considered. Further examination and more data analysis has to be done but for now the model has been updated to show tone as the visual feature with three core traitspattern/texture, smudge, and global tone. It is still thought that tonal qualities can be 
segmented by identifying local regions in a drawing and comparing those measures to the overall tonal quality of the drawing (Figure 46).

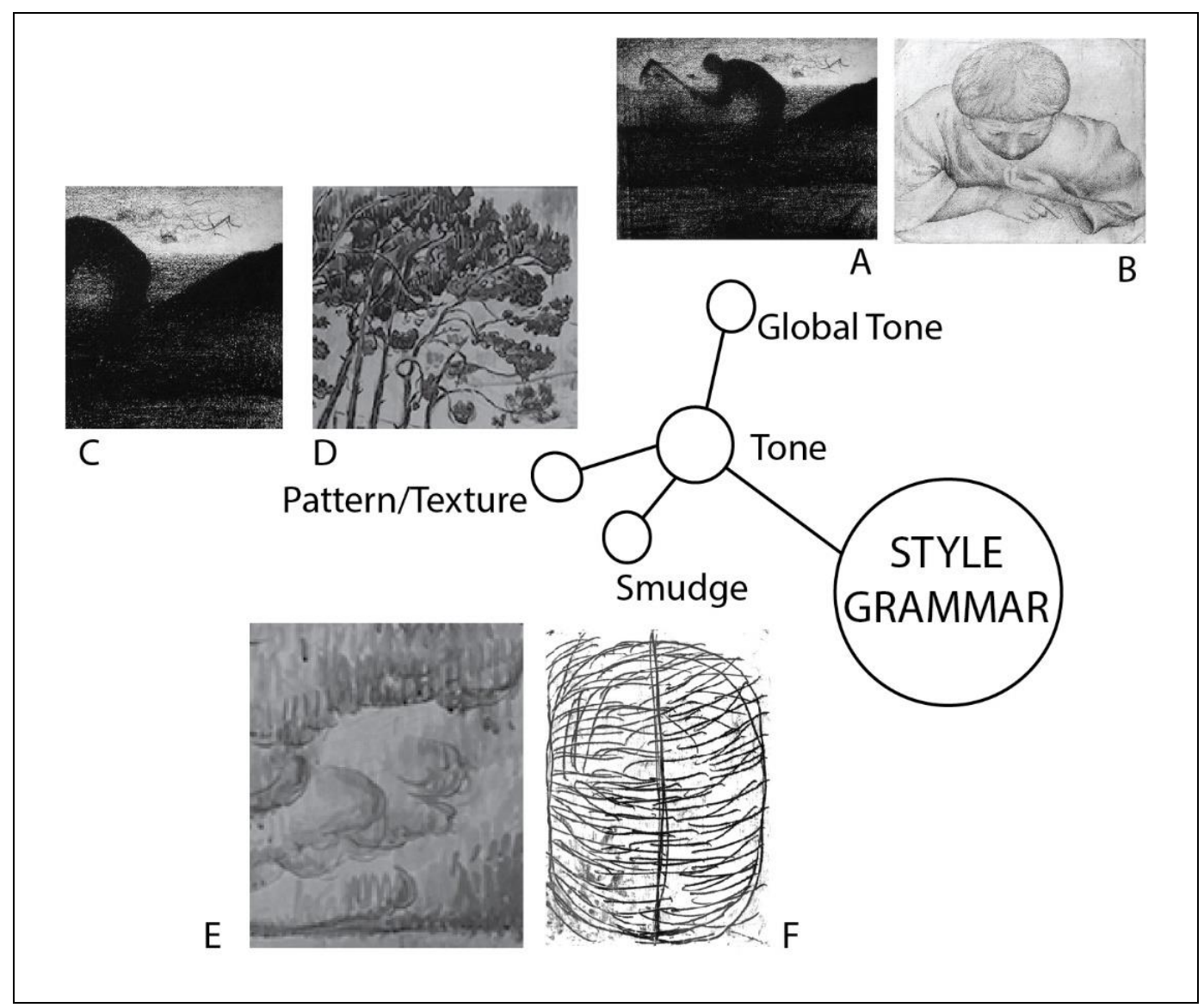

Figure 46: Diagram indicating the current state of the model with global tone, smudge, and pattern/texture as traits of the visual feature-tone.

A \& C. Georges Pierre Seurat. (1883), Man with a Pick, (crayon conte). Private Collection, Bridgeman Education.

B. Antonio Pisanello. (date unknown), Boy reading, from the Vallardi Album, (pen \& ink on paper). Louvre, Paris, France, Bridgeman Education.

D \& E. Paul Signac. (1922), The Lezardrieux Bridge, (charcoal over black chalk on tan paper). Private Collection, Bridgeman Education.

F. Venturino Venturi. (1976), Belly, (oil on paper). Vatican Museums and Galleries, Vatican City, Photo (C) Stefano Baldini, Bridgeman Images.

The initial implications of borrowing for this feature are:

- Emphasis is placed on an overall balance of most or all features with the exception of one feature that is used as a counter balance. 
- The first impression determines a great deal so emphasis on recording an accurate assessment of perception is important before altering the overall design.

- Smudge and pattern/texture even though they both add to tone have very little in common and are used differently.

- Emphasis needs to be placed on either smudge or pattern/texture using both together could be considered ineffective and therefore a bad design decision.

\section{Pattern/Texture}

Local tone is approached as a part of the visual image segmentation process and deals with interpreting groupings of objects, which suggests the identification of patterning and visual movement or rhythm throughout the compositional space. The various types of rhythm as discussed earlier are regular, alternating, flowing and progressive. This measure for pattern is currently a bit more complicated to obtain since it seems to share some pixel qualities similar to smudge and also a measure of line quality—specifically line density. While pattern is similar to smudge its significance lies in its difference which is not in the mid tone areas but rather the darker tone areas. In fact, it is suggested the darker the areas- the more intense the patterning due to excessive mark making.

The current measure used in the model which is proving to be valid looks at a way to collect both the information of the darker tonal areas as well as a sense of the line density, so both Adobe Photoshop and Illustrator are used to obtain the measure for pattern as an inverse or the total number of negative paths.

Pattern/texture was a measure similar to global tone in the data analysis of both the multinomial logistic regression and the bivariate logistic regressions comparing the three artists. The multinomial regression showed a significance of .000 . The bivariate regressions showed a significance of .000 in the comparisons of works between Schiele and Seurat, and Schiele and van Gogh. The significance was 
.002 in the bivariate logistic regression comparison of van Gogh and Seurat. This suggests in general that pattern/texture was approached very differently between the three artists (pages 112-118).

This gives no quantitative indications however, of the different strategies or approaches each artist took to the usage of pattern/texture. Far more research is needed in regards to pattern information and processing to be able to use this visual feature effectively within the model, even though the initial measure is significant. Effective logical explanations can be developed based on observation, but they would lack quantitative analysis and be suspect in their objective quality.

\section{Line Length}

Line length looks at the average length of lines within a drawn image. It was observed early in the research that various artists use different types of line lengths. This is easily seen within the drawings of the three artists used in the logistic regression analysis. Egon Schiele typically used long lines while van Gogh and Seurat used rather short lines. The line length measure is fairly easy to obtain through a process of image conversion in Adobe Illustrator and then the object information panel is viewed where various measures for line can be recorded. Some of the measures are used for the average length of line used within a drawing and others are used for the measure of line expressiveness:

Average Line Length $=$ Total length of all paths

Total number of paths and the average number of points on a path:

$$
\text { Line Expressiveness }=\frac{\text { Total number of points }}{\text { Total number of paths }}
$$

The measure for line length in the multinomial logistic regression was not significant - the cut off being .05 and the measure coming in at .069 . In the bivariate 
logistic regressions run it was significant between Egon Schiele and both van Gogh and Seurat, but between van Gogh and Seurat the measure was insignificant. This can suggest a similarity in line approach, which can be seen in many images between van Gogh and Seurat (pages 112-118).

This suggestion was held suspect; it was hard to believe that these two artists shared similarities in their approach to line length. A closer examination of several images however, does indicate that this suggestion is not unfounded. Figure 47 compares three images from each artist used to obtain measures, and the visual observation does suggest similarity between the two artists in their usage of line length. This illustrates the difference between art styles as they are typically used to group paintings rather than drawings.

These two artists have vastly different painting styles and part of the problem of thinking about their drawings being similar as is clearly indicated by many of the measures comes from a residual impression of the differences in their paintings. Particularly since there is a renewed interest in the popularity of artworks by these two artists and the popular display of reproductions of paintings by these two artists out in the general public. 


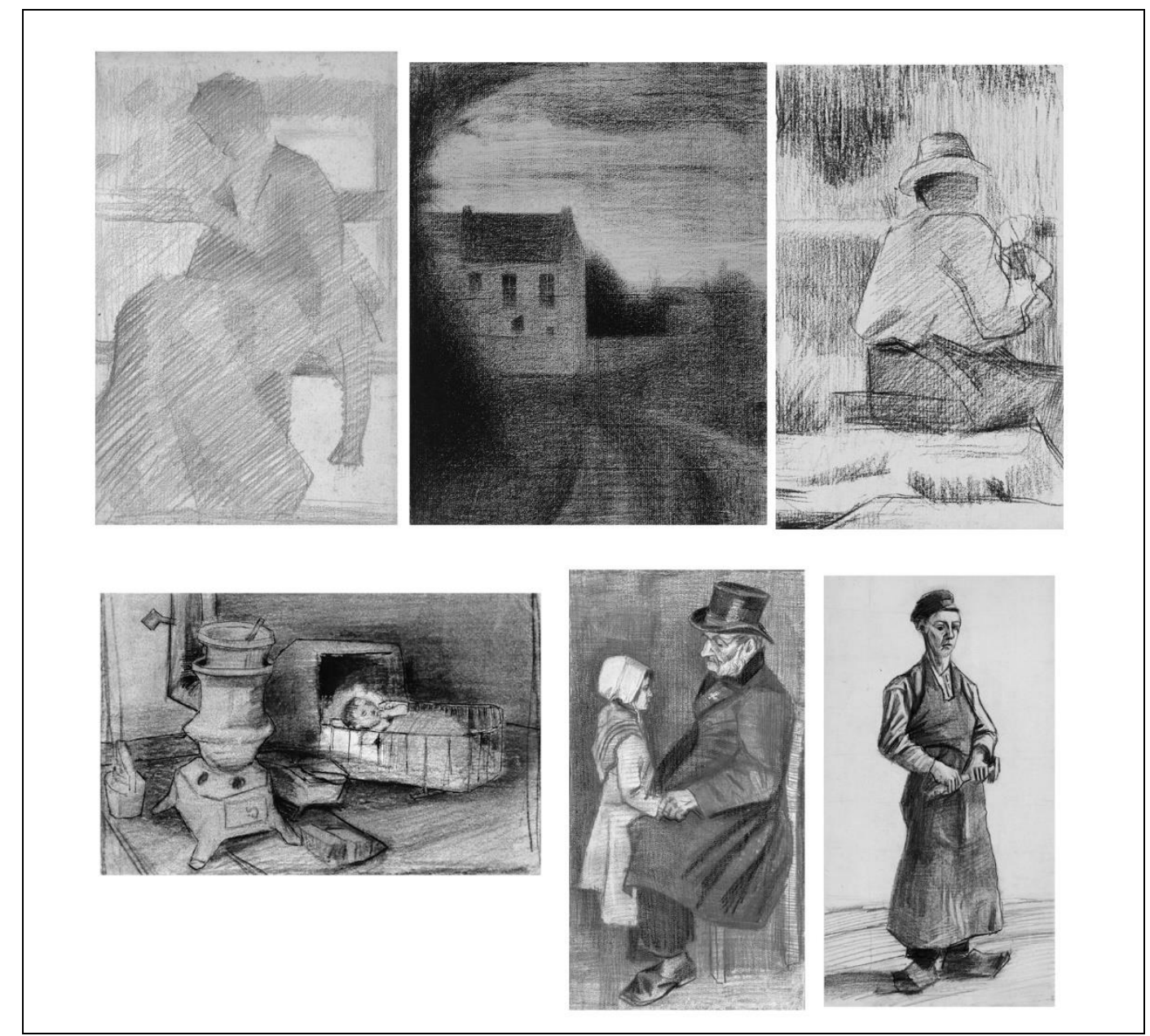

Figure 47: A general overview of drawings by Seurat (top) and van Gogh (bottom), from the analysis of measures for various features, they share approaches in line length and smudge.

Top left to right: Georges Pierre Seurat. (1881-82), Une Couseuse, Un Tableau au Mur, (crayon on paper). Whitworth Art Gallery, University of Manchester, UK/Bridgeman Images.

Georges Pierre Seurat. (1882-84), Square House; Maison carree, (crayon on paper laid down on board). Private Collection, Bridgeman Images.

Georges Pierre Seurat. (1881), The Painter and His Palette; Le Peintre a la palette, (crayon on paper). Private Collection, Bridgeman Images.

Bottom left to right: Vincent van Gogh. (date unknown), Cradle (pencil on paper). Van Gogh Museum, Amsterdam, The Netherlands, Bridgeman Images.

Vincent van Gogh. (1882), Seated Man with his Daughter, (black chalk, pencil on paper). Private Collection, Photo $\odot$ Christie's Images, Bridgeman Images.

Vincent van Gogh. (1882), The Blacksmith's Boy, (black chalk \& pencil on paper). Private Collection, Photo $(\bigodot$ Christie's Images, Bridgeman Images.

Determining the operation to obtain a measure of line length was quite challenging. There was a continuous running comparison between computer drawing and hand drawing while determining how to collect measures that were objective not subjective to human perceptual interpretation. It was important to maintain 
objectivity so that every measure would be systematic, assuring repeatability. This meant the measure selected was ultimately based on machine vision and interpretation rather than human interpretation. Line length proved to be a particular challenge in this respect. Examining the measure from an artistic point of view or from a human observer's perception, where a line starts, where it actually starts, where it ends, where it actually ends is open to vast interpretation and reinterpreted with every image. Using the systematic computer measure provided by Adobe Illustrator currently proves to be a decent solution. However, the computer's current interpretation of what is a line is far from perfect. This shows better measures and a better definition for what is a line are needed.

\section{Line Expressiveness}

Line expressiveness has many adjectives. It is sometimes referred to line liveliness or gestural. Goldstein (1977) described the appearance of line from opposite poles-line could be neat, orderly and controlled or it could be emotional and agitated. The interesting and initially the most difficult aspect of looking at the traits and features was discerning how the computer could interpret something like an emotional line. What does gestural mean to a computer?

The measure was arrived at by looking at the quality of line from the other end of the spectrum—controlled and neat. When I was a graphic design student I remember spending hours developing motor control and the skill of drawing perfectly straight lines. Then came computer drawing programs — and a straight line could be obtained within seconds-no T-squares, triangles, or French curves needed. Looking at how the computer interprets a perfectly straight line- using just two points to plot it, a gestural line would contain many "imperfections" or "mistakes," that are interpreted as extra lines and extra points. The more points, the more linesthe more gestural the overall line. 
The interesting observation is that while all three sets of drawings are hand drawn there is still a noticeable variability within the expressiveness of line between the three artists and this measure shows significance in the logistic regression data analysis. The multinomial logistic regression showed a significance for this measure of .000. The bivariate logistical regressions showed a significance of .001 in the comparison of works between van Gogh and Seurat, a .010 significance between the comparison of works by van Gogh and Schiele, and a .000 significance between the works of Schiele and Seurat. This again suggests that all three artists had very unique ways in which they each approached this particular trait of line (pages 112-118).

\section{Depth}

Depth is the visual description or depiction of a 3-dimensional space on a flat drawing surface. Particular interest was paid to trying to obtain a good systematic approach to obtaining a measure for depth. This was the second most important visual feature observed in the first MDS free card sort. This particular feature is tied to the usage of a drawing system and assists with the organization of other visual features and traits within a composition. Since this was the only measure that consistently came up insignificant in both the multinomial and bivariate logistic regression analyses, it is believed the current procedure is insufficient in capturing the measure for depth. Various approaches were tested: ratio comparisons of object size, area size and pixel count of the lower third to the upper third of the drawn surface, with similar negative results. Further research needs to be done to obtain a good measure for this particular visual feature. Other possible bodies of research to review entail spatial frequency analysis and examining the relationship of brightness to depth. 


\section{Chapter 7: The Overall Model}

This chapter reviews the current state of the model. Combining the results of human perception testing and analysis of the computer measures, I discuss the overall implications of findings and results towards the model development. Included in this discussion is an analysis of visual features and their impact on understanding style. The interaction of lines and other types of marks made and the beginnings of a rule set are examined with further implications towards teaching creative drawing.

\section{Discussion of Combined Outcomes}

Figure 48 shows the current model, depth is indicated as an identified visual feature but a better measure and clear segmentation of traits for this feature is needed. An emphasis on measures and other systematic schemes for trait segmentation in future research will help improve the measures obtained. The data analysis proved the general strength of the model and the significance of the measures obtained for all of the features, except Depth. Future research would include operations for better measures as well as look at other features that need to be examined and added to complete the model for the development of a robust visual style grammar. 


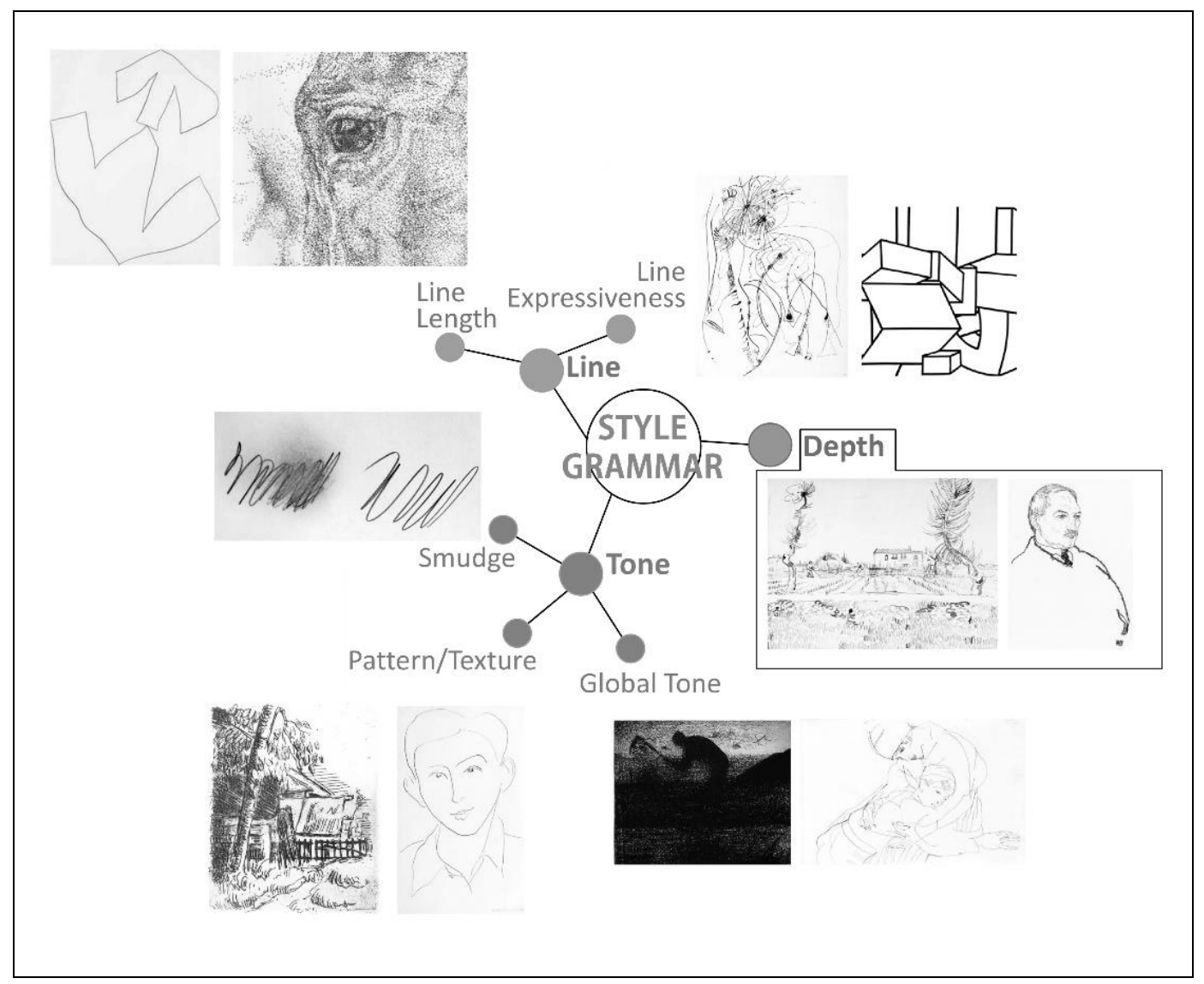

Figure 48: Diagram indicating the current state of the model.

Ellsworth Kelly. (1987), Magnolia, (pencil on cream paper). Brooklyn Museum of Art, New York, USA, Gift of Henry Persche, Bridgeman Education.

J. Sweo. (2012), Pointillist study of a horse head, (pen on paper).

Al Held. (1967), Untitled, (oil on canvas). Private Collection, Bridgeman Education.

Jackson Pollock. (date unknown), Untitled (O'Connor-Thaw 776) from a suite of notebook drawings, (India ink on paper). Museum of Fine Arts, Houston, Texas, USA, Museum purchase funded by Caroline Wiess Law, Bridgeman Images.

Vincent van Gogh. (1888), Working the Fields at Arles; Laboureur dans les Champs a Arles, (reed pen and ink over pencil on paper). Private Collection / Photo @ Christie's Images, Bridgeman Images.

Egon Schiele. (1907), Portrait of Man; Mannerportrait, (soft pencil on paper). Private Collection, Photo @ Christie's Images, Bridgeman Images.

Georges Pierre Seurat. (1883), Man with a Pick, (crayon conte). Private Collection, Bridgeman Education. Egon Schiele. (1914), Embrace, (pencil on paper). Private Collection, Photo @ Christie's Images, Bridgeman Images.

Henri Matisse. (1946), Paul Matisse (IV), (pen and black ink on paper). Private Collection, Photo $\odot$ Christie's Images, Bridgeman Images.

Paul Cezanne. (1873), Landscape in Auvers, (etching on paper). Sterling and Francine Clark Art Institute, Williamstown, Massachusetts, USA, Bridgeman Images.

\section{Visual Feature Analysis}

A common approach in examining works of art is as an artifact of style

(Bullot \& Reber, 2013). Bullot and Reber describe a work of art as a physical 
manifestation of "style." Being physical, it can be measured. The model created in this research describes techniques used to systematically describe the visual communication of creative drawings. It provides a quantitative description of specific visual features and their respective core traits. Data analysis run through both a multinomial and bivariate logistic regression show the significance of each of the quantitative descriptors as they apply to a specific artist's drawing style.

The approach of this research in developing this model towards a style grammar for creative drawings is very much in line with the computational point of view towards making and material things expressed by T. Knight and Stiny (2015) as discussed earlier. The model is a digital expression through computation that describes perceptions of how people carry out operations, processes of making to form material things. Even though this research has only proved concept and developed a preliminary model towards a style grammar for creative drawings, there are many useful applications of the data.

\section{Understanding and Creating Styles}

A visual style grammar assists with problematic decisions of visual tasks by creating a set of rules. It allows for an objective approach to identifying and segmenting important elements of a design. Once elements are segmented an exploration of variation and design possibilities can emerge, problematic issues can be identified and addressed. A rule set can be approached and explored in two different ways:

1) The possible parameters that allow for recognition; and

2) Possible parameters that need to be avoided if these shapes are going to be used in a design.

This also illustrates two different aspects of style and artifact. The first aspect of an artifact is simply the way it looks. The second aspect deals with recognition of an artifact and the human emotional response to that artifact. The idea of a style grammar for creative drawing is in the identification of particular elements-in the 
case of this research the identification of particular marks made that can then be borrowed and used to evoke a particular emotional response.

The current state of this research is to create a model that identifies the various elements towards the development of a model of style grammar that can be used in a creative drawing process by practitioners, art and design students and teachers. It is important to initially identify correctly the various visual features that can be used to create the style grammar. Once measures are obtained and tested for significance, the parameters of each visual feature by measures of its traits can be examined and an understanding of relationships of one trait to another and how those relate to a style can be achieved.

\section{The Interaction of Line}

Color theories create a logical structure for the analysis of color.

Understanding this structure does not make one a great artist or guarantee the creation of a great masterpiece. What it does do for the artist is give them a tool to observe color and make informed educated decisions about color choices. Many artists have developed and published their color theories. Most notably are those works by Johannes Itten, Josef Albers, Johann Wolfgang von Goethe, and Michel Eugene Chevreul (Taboada, 2015). Using the theories developed by these artists as example, I see creating a logical structure for the analysis of line in creative drawings. This is not an exercise in the creation of pure design but a logical structured analysis to assist with an informed decision of line choice in the representational structure of a drawing (Ross, 1904).

Systematic approaches to the exploration of line and various features can also be developed towards studying their influence on image and subject matter, by selecting a particular image and recording the visual outcomes. The image used can be art historical but could also be of other significant importance. As stated earlier (pages 124-169) an investigation of this type can use several visual features or target a single visual feature. 
Once the entire set of drawings is completed—an examination of various combinations of visual features can occur. Such as linking various specific aspects of different types of mark to an emotional response. Measures can be obtained for images selected for groupings and a compared to similar groups of images of known artists and their works for further comparison of marks and their effects upon the drawn image and a viewer's emotional response. A corresponding assignment can emphasize the identification of line traits from observation rather than relying on the computer to identify them and a combination of the two can add to levels of visual acuity. This does not solve problematic issues of style but it works towards an objective segmentation of the "way something looks" of style that can be assessed both quantitatively and qualitatively. The idea of grouping and comparing by the quantitative nature of visual features enriches the borrowing process by including far more similar objects for a qualitative analysis of style.

Exploring both qualitative and quantitative features of an art work or a group of artworks for comparison, allows for the examination of the old to create new possibilities, challenging assumptions of artistic means of expression. I present as a part of this discussion the beginnings of an assignment an example of a systematic exploration into line where only line changes never the figure or its size (Figure 49). 


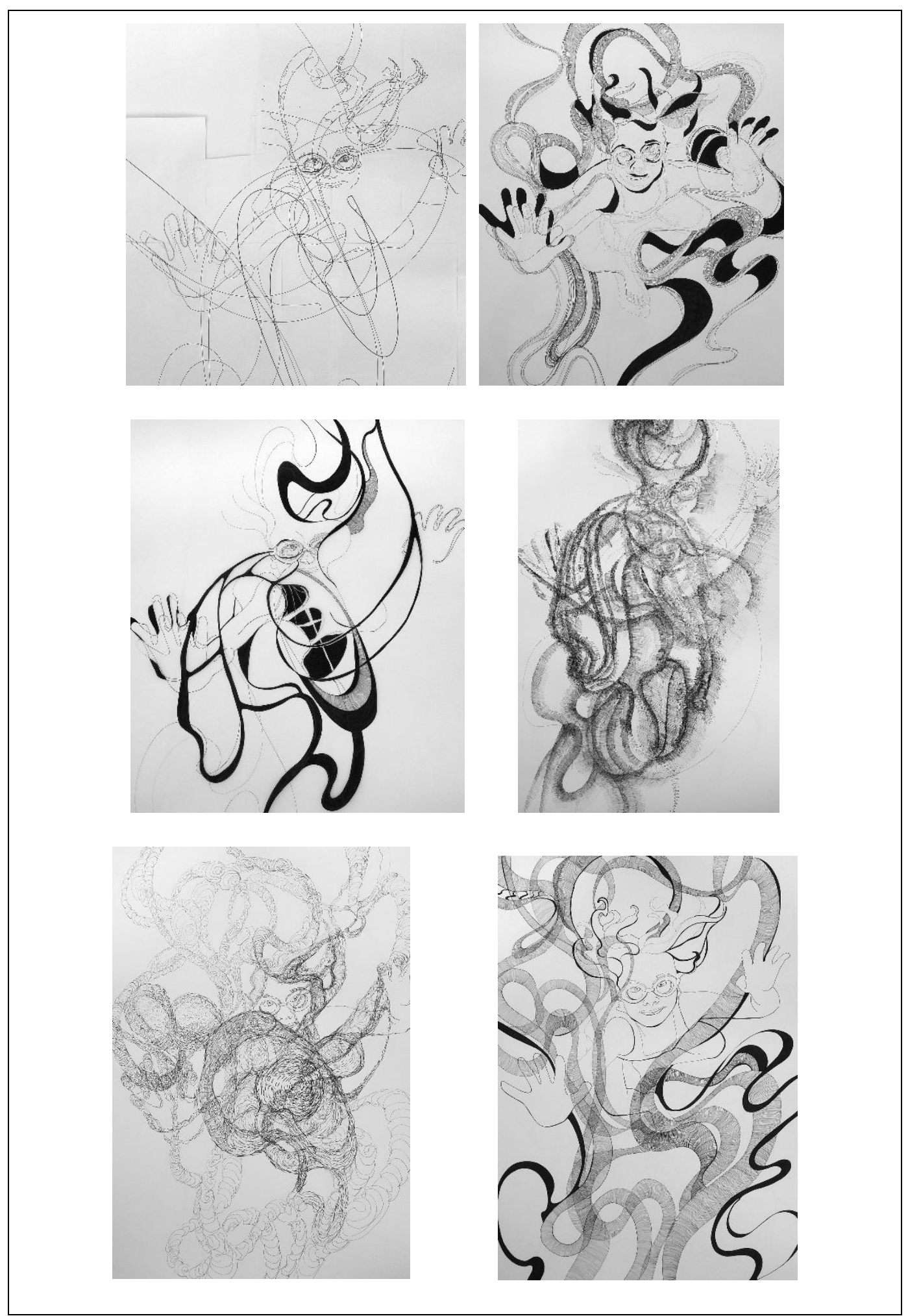

Figure 49: An example of a systematic exploration of line.

J. Sweo. (2015-2016), The swimmer series (pen, ink, pencil and computer). 


\section{Chapter 8: Future Research}

Future research will focus on improving measures and procedures of feature extraction for traits already obtained as well as adding visual features that are not in the current model. The first MDS procedure proved to be beneficial in the identification process of visual features and while the second MDS failed to produce good results it did lead to other avenues of exploration to further develop the model development. A second avenue of future research will examine other types of physiological procedures and tests that can be employed in developing visual features and the model further. I will end with a discussion of future versions of the model and other teaching implications. Accompanying the discussion in Appendix $\mathrm{C}$ is a preliminary modular 2D Foundations exercise.

\section{Visual Features \& Feature Extraction}

\section{Pattern/Texture}

This feature was identified early in the research as an important trait of tone (page 41). The measure, while significant and important in the data analysis of the model, simply identifies the overall presence of pattern/texture but not specific usage. Strategies will need to be developed to determine the best way to obtain measures for different types of patterning within imagery which can be helpful in determining an artist's style.

There is a large body of research to review in regards to pattern information processing and various schemes that are suggested in the classification and segmentation of pattern types (Amadasun \& King, 1989; Dasarathy, 1991; Duda, Hart, \& Stork, 2012; Lindsay \& Norman, 2013; Tamura et al., 1978). The body of work reviewed so far suggests an approach to texture and pattern recognition that is similar to the approach taken in this research for the recognition of marks of drawing. Which is to first develop a perceptual mechanism of identification using predetermined artificial patterns (Julesz \& Bergen, 1983; Julész, Gilbert, Shepp, \& 
Frisch, 1973). And then to develop a corresponding set of computational measures derived from the psychological specifications (Amadasun \& King, 1989; Charalampidis, 2001; Tamura et al., 1978).

This could be used to not only identify and define patterns and textures but also give them a perception ranking. This would assist in determining for example how strong a pattern using dots—stippling is in comparison to a pattern using hatched lines.

\section{Line Width}

Line width was also identified early as a trait of the visual feature- - line. Computationally the definition of a line is one-dimensional having zero width. However, in a drawing to perceive line information some line thickness has to be employed (Ching, 2010). A problem arose in measuring line width. The current measure for line width showed massive multi-collinearity with other trait measures that also relied on shape, namely depth. This exposed the problematic measure of line width—and its validity as a measure without ambiguity.

This ambiguity starts with the initial definition used for line width as a line's thickness. This definition becomes quite complex in discerning when a line in its length becomes dominated by its width, particularly when the computer segments a line according to its geometric characteristics (page 98, Figure 28). Another cause for the ambiguity lies in perception and when a line becomes a shape. Ching (2010) describes the perception of a line as dominated by a length-width ratio (page 42), but he never actually states what that ratio is numerically. It may prove the best way to determine a measure for line width is to set an actual ratio keeping in mind the goal of any measure in this research is the need to be consistent and systematic, as discussed earlier (page 85). That means a common denominator can be sought for testing across all imagery and that it may not fit all imagery perfectly.

Determining a process and defining where line stops being line and morphs into area or shape and determining where the ratio lies in line length to line width 
will prove useful for other features and measures. It is suspected that a similar problem will arise with stippling-when does the dot stop being a mark and morphs into an area or shape? How to handle that determination in a clearly defined systematic way for a repeatable operational procedure will be important.

\section{Color}

Color is an obvious visual feature that was intentionally taken out of the initial development of the model so that other traits and visual features such as smudge could be examined more thoroughly (Mack \& Rock, 1998; Palmer, 1977). It is possible that smudge would have gone unnoticed as a quality of both line and tone, particularly since color also adds to tone. The tonal aspect of color could have interfered with obtaining other tonal measures as well.

Strategies will need to be developed to test the importance of color as a visual feature. As discussed earlier when defining the basic principles and identity of a "drawing" color is not the most important visual feature-it is line (page 9). It will be interesting to discover the weight of importance the visual feature of color has within the model as it is further developed. Another consideration is the psychological effects of color its effect on a drawing process (Batchelor, 2000; Davis, 2000; Fehrman \& Fehrman, 2000; Itten, 1964).

\section{Depth}

The measure used for depth consistently came up insignificant in both the multinomial and bivariate logistic regression analyses. There are two likely possibilities:

(1) The current procedure is insufficient in capturing the measure for depth; or

(2) Depth is consistently used between the three artists and could not be distinguished.

Goldstein (1977) in his book on drawing suggests that some of the guises volume and space are difficult to uncover because we are conditioned to see things 
rather than the spaces that separate them. He defines this space as "negative interspaces.” Discussing this concept, he writes:

An important dividend of a patient study of the shapes adjacent to a form results from the common tendency to see concavities in a form's edge (especially on its shaded side) as a deeper and more pronounced than they really are. Too often the forms in beginner's drawings look sort of withered because their shape boundaries undulate too much. For some reason, perhaps because we are conditioned to think of convexities as containing something, and concavities nothing, the line we draw to represent a convexity on an edge is more likely to accurately reflect the scale and degree of the observed convex passage than a line that notes a concave one. Hence, by drawing the convexities of shapes that abut a form we are simultaneously and more accurately establishing the form's concavities (pp. 18-19).

This concept gives some insight to possible strategies for segmenting textured areas further but clearer definitions will still need to be developed for such features as busyness, coarseness, and line-likeness. It suggests a possible idea of looking at space from the concept of removing selected areas and measuring what is left-the negative area. While a similar approach to this was used to identify the presence of texture once those areas are eliminated and measures are done on the areas left in the picture plane to gain a "negative value" for the overall image area it could be possible to get a depth measure based on the amount of negative space within a drawing.

Other research that is working on similar types of measures the WAVIS Group (http://www.waivs.org/info.phtml) uses a foreground/background extraction tool.

In my opinion, the most obvious issue with this tool while trying to be systematic is the edge selection of foreground/background particularly as it pertains to the perception of space. The WAVIS group is working on paintings and not drawings but to an extent, the depiction of space can be similar in drawings as paintings. The tool displays a lack of selection of middle ground-which clearly exists and which is divided between the foreground and background. 
I would argue that a very strong pixel value manipulation on the part of parameters set had to take place which would not necessarily be up to the computer program to decide but rather an operator of the program. In my opinion, this weakens the value of the tool since it would leave judgements up to a human operator rather than a systematic and consistent quantifiable approach afforded by the sole use of a computer operation. This emphasizes a point that Goldstein (1977) as well as others like Kasprisin and Pettinari (1995) make while discussing volume of shapes, that artists avoid emphasizing edges, stating that edge, contour and outline are not always the dominant graphic factor in a drawing or painting (Figure 50).

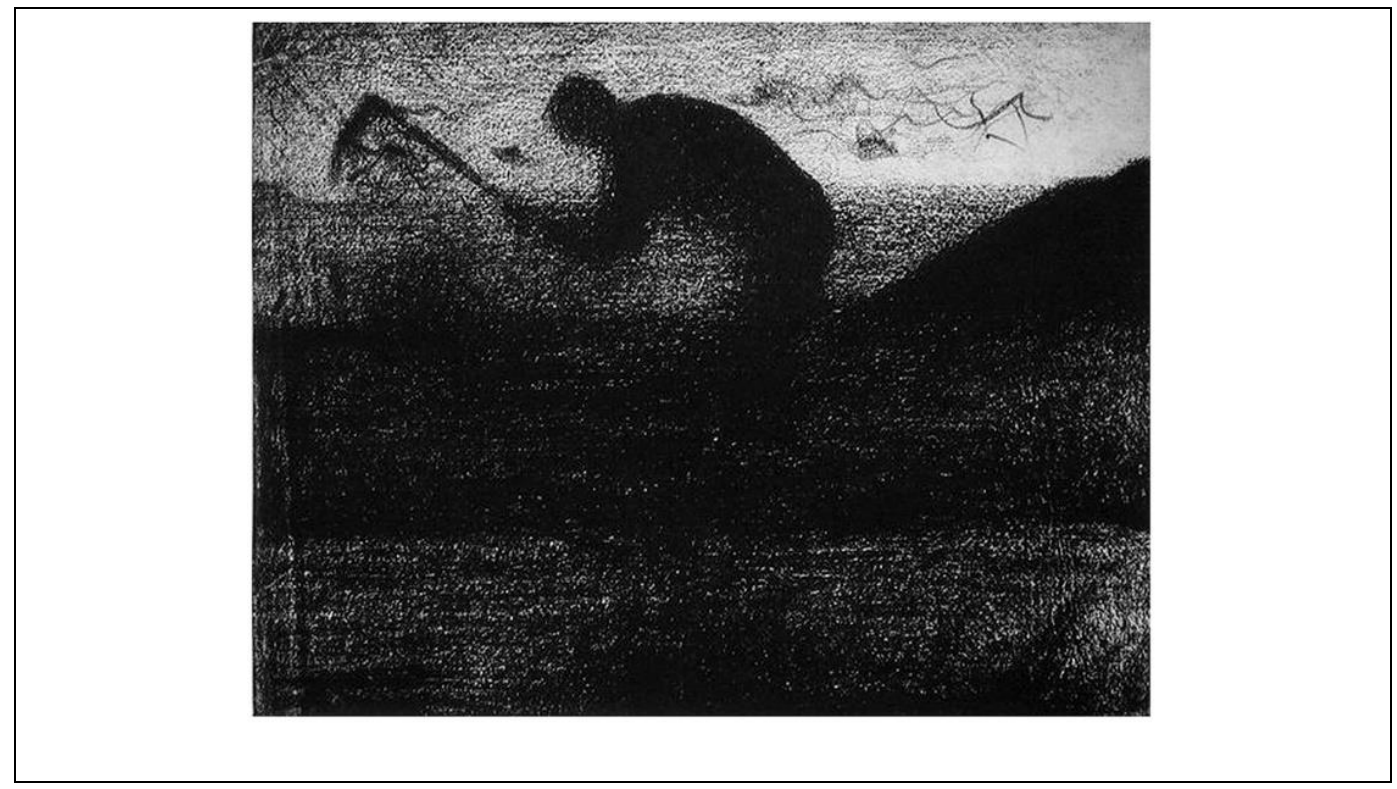

Figure 50: A drawing sample showing the emphasis and de-emphasis of edge. Georges Pierre Seurat. (1883), Man with a Pick, (crayon conte). Private Collection, Bridgeman Education.

Future research will include the development of a systematic operation for depth. However, in developing an operation for depth it may be possible to make determinations that can also attribute to better operational measures for other visual features and answer such questions as:

1. Can a line or edge clearly be defined for a computer as a boundary to determine foreground, middle ground, and background? 
2. Which area of an image holds the most significance in determining a style_-foreground, middle ground or background? Or is it a comparison between any two or all three areas?

3. What are the perceptual cues humans use to determine where they are located in the space?

4. What role does negative space play in the perception of depth?

5. What would be the best use of negative space towards a stylistic measurement?

\section{The Human Perception of Line \& Other Marks}

The psychological effects of color within human perception have been studied and tested in a variety of contexts (Batchelor, 2000; Davis, 2000; Fehrman \& Fehrman, 2000; Itten, 1964). There are many empirical experiments exploring the synesthesia or link between color and emotion by asking participants to associate various colors to words (Bradley \& Lang, 1994; Osgood, 1952; Saffran, Coslett, \& Keener, 2003). Other similar avenues of research look into the effect that shape and color can have on the perception of flavor (Delwiche, 2012; Wan, Woods, Seoul, Butcher, \& Spence, 2015). While even other similar avenues of human perception and color have looked at the influence of university affiliation to color preferences (Schloss, Poggesi, \& Palmer, 2011). Leavitt (1976) in her book, Artist and Computer, discussed Georges Seurat's fascination with experiments being conducted involving the effects of color on mental patients and his attempts to apply the results of these studies in his paintings in his own attempts to evoke a particular mood from viewers looking at his artwork.

My main interest in looking at this body of research on color and its effects on perception is to determine processes that can be borrowed to develop similar types of testing on various types of marks made in creative drawings. Explorations that can assist in furthering the model development. 
An interesting note here as made by Hillier (2008) in his research on designing a typeface for the adult dyslexic reader, is that the tests presented below are primarily conducted by psychologists rather than artists and are summative. Meaning they are conducted after the design process—not during. It would be interesting to develop some of these tests in such a way as to be a formative aspect to the drawing and design process.

\section{A "Pleasantness" Test}

Some researchers have concluded that people respond better to a color they perceive as "most pleasant" not a color that is prototypical or conspicuous (Schatz \& Bowers, 2005; Wiegersma \& Van Loon, 1989).

Imagery aside, one set of tests that can be developed would assist with determining what combinations of marks are perceived as "pleasant" and what combinations of marks would be perceived as prototypical or conspicuous. Would hatching or cross-hatching be perceived as prototypical, where as a combination of smudged lines might be perceived as more pleasant? Would the type of tool used to draw the lines and marks have an influencing effect? Is a charcoal line more pleasant than an inked line? Does pleasantness equate to the softness of the line and marks made? Do lines that carry lighter or mid grey tones have a pleasanter nature than darker or heavier lines and marks? Are certain types of texture/pattern more pleasant than others?

\section{Exciting Marks vs. Calming Marks}

Researchers have found evidence to suggest that color can influence a person's mood (Kwallek \& Lewis, 1990; Levy, 1984; Stone, 2001, 2003; Stone \& English, 1998). They all concluded that red could stimulate and create anxiety and stress while cool-colors like blue were calming and depressive.

Again, without looking at imagery but rather examining various types of marks and combinations of marks and lines what could be perceived as exciting or agitating? What could conceivably portray calmness? Would the perception of 
high contrast translate to anxiousness? What different directionalities of lines could be associated with calmness or excitement? Would the busyness of a texture be perceived as exciting? Would variability of texture/pattern be perceived as exciting? How would this relate back to the perception of pleasantness?

\section{Can Various Combinations of Line Affect Appetite?}

It has been proven that different colors of food, in different contexts and for different audiences, can affect people's appetites (Garber Jr, Hyatt, \& Starr Jr, 2001). Again, Schatz and Bowers (2005) warn against over extending conclusions from this, but could different types of marks and lines have similar even if limited types of effects?

\section{Future Versions of the Model}

\section{Culture \& Art Tradition Influences on the Model}

It has been made clear in various types of color perception testing that culture plays a significant role in color preferences (Garber Jr et al., 2001; Hutchings, 2004; Schatz \& Bowers, 2005). Dubery and Willats (1983) in discussing drawing systems point to the cultural link between a particular drawing system and an art tradition. Since the general organization of line and other visual features in a creative drawing are based on the use of a drawing system, it may be possible to test in a similar manner if there is cultural bias towards the selection of types of line and other visual features of drawings. This may give insight on how to incorporate different sets of creative drawings that use different drawing systems and line types into one large cohesive model towards a style grammar for creative drawings.

An investigation into how these other drawing systems influence the identification of visual features, what those features are and how they interact within a drawing would assist in different types of model development. Thereby modifying the research question: What are the visual features that make up a model of style grammar for creative drawings using an orthographic drawing system? 


\section{Other Uses of the Model in Teaching}

The model being developed in this research explores a different approach to the general practice of learning how to draw. Emphasis is currently placed on the identification of visual features, extraction methods for those visual features and a quantitative analysis of measures to develop a style grammar for creative drawing. The use of a style grammar is a different approach to the development of drawing skills which emphasize motor skill development and promote an understanding of drawing tools and techniques. It may be possible that this approach can become so highly developed that eventually a better artist is an individual with better trained visual cognitive skills than motor skills. This could lead to the creation of great artworks by persons with limited physical mobility but highly trained visual cognitive skills through the development of sophisticated tool set that can assist with content analysis.

Once a fuller and more developed set of extraction methods and measures is developed they can be taught to a computer. The computer can then be a tool to assist in an increased workflow, with better and more accurate extraction procedures and measures. 


\section{Chapter 9: Conclusions}

A style grammar is a visual grammar and like any grammar it is a principled rule set to govern the organization of very complex ideas. It is because of this principled nature, an examination of underlying structures which are often times obscured is made easier. Making a grammar a useful tool for many applications.

Important to a visual grammar is the identification of the various elements or visual features that will be used. Clear explanations of the rules governing each visual feature as well as its interactions are developed in the grammar. Visual style grammars are popularly based on shape. To create a style grammar for creative drawings, elements or traits and visual features based on mark making which are important to a drawing need to be identified and a rule set developed.

A model gives organization to the analysis of traits and visual features based on mark making for borrowing and reuse. The model allows for "identification" while the style grammar allows for the interpretation and analysis of usage of the "borrowed" visual features. The model identifies a step process to be used for the identification of visual features:

1. A psychological approach and the perceptual mechanism of identification using predetermined traits and visual features.

2. A corresponding set of computational measures derived from the psychological specifications identified in step one.

This process allows for a different way of perceiving creative drawings through both computational and non-computational mark making promoting a clearer understanding of visual features. Allowing for an analysis of similarities and differences of identified visual features and how they work separately and together.

The interpretation of the analysis identifies possible style parameters for a grammar that allows for recognition of visual features for inclusion and exclusion, where elements have gone beyond the rule set of the grammar. 
The model was organized developing an initial set of traits and visual features from secondary research. Validation and further identification of traits and visual features for the list was done through a psychological approach, using the perceptual mechanism of an MDS free card sort. Smudge was detected as a trait in the MDS data analysis and added to the list.

The ordination of the four dimensions obtained from the first MDS analysis were used to identify and define general organizing principles:

1. Smudge or edge detection or edge quality through smudge.

2. Depth or the organization of elements within the described space of each drawing.

3. Tone or the quality of light and dark within each drawing.

4. Line Expressiveness or the emotion conveyed by a line within each drawing.

These outcomes support a general practice rule in design reuse and intelligent borrowing that suggests first smudge, then depth, then tone, and then line quality are the most significant elements to use for style comparison (Figure 51). 


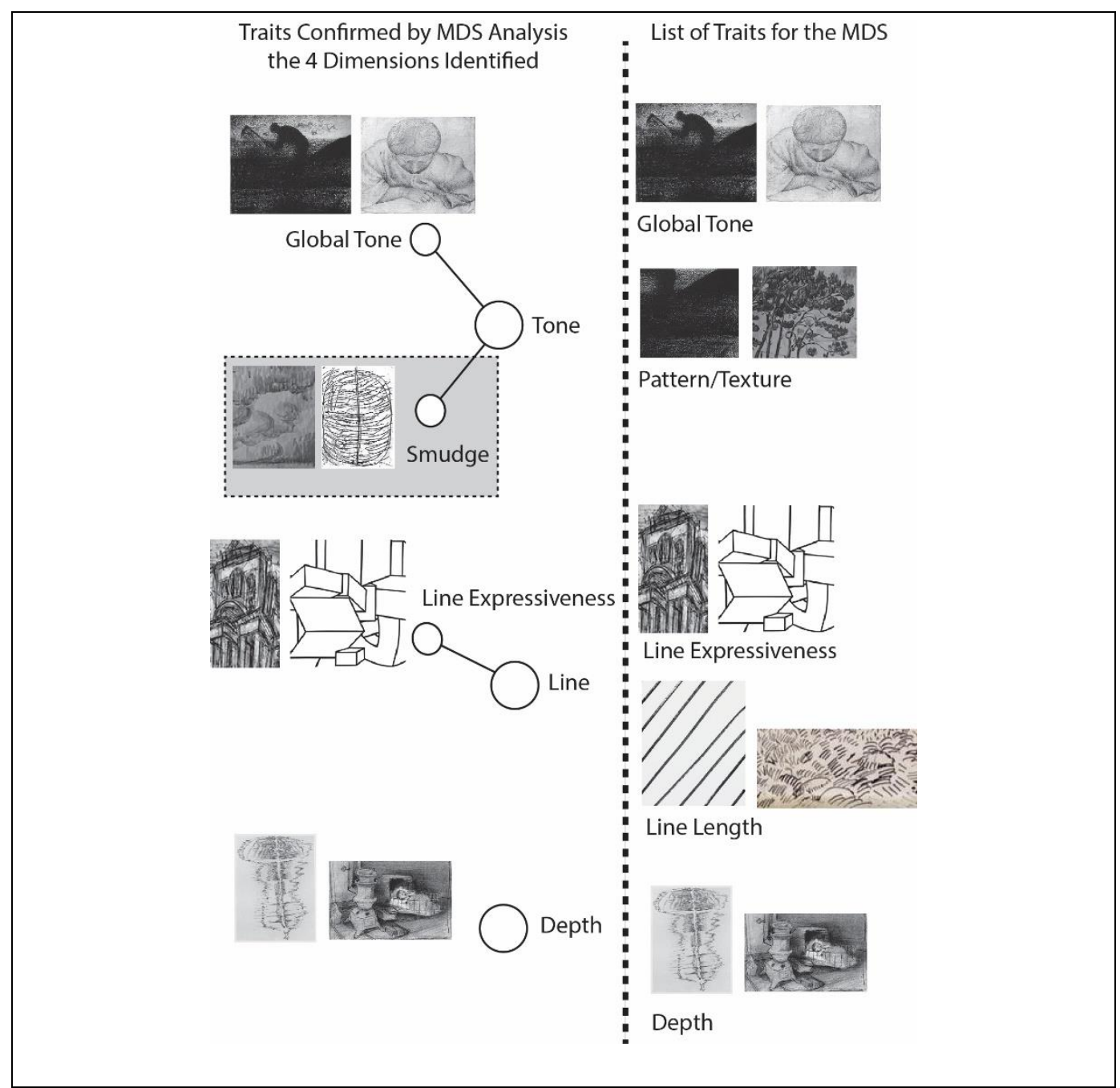

Figure 51: The validation of traits via the MDS free card sort.

Vincent van Gogh. (date unknown), Cradle (pencil on paper). Van Gogh Museum, Amsterdam, The Netherlands, Bridgeman Images.

Georges Pierre Seurat. (1883), Man with a Pick, (crayon conte). Private Collection, Bridgeman Education. Antonio Pisanello. (date unknown), Boy reading, from the Vallardi Album, (pen \& ink on paper). Louvre, Paris, France, Bridgeman Education.

Paul Signac. (1922), The Lezardrieux Bridge, (charcoal over black chalk on tan paper). Private Collection, Bridgeman Education.

Al Held. (1967), Untitled, (oil on canvas). Private Collection, Bridgeman Education.

Leon Kossoff. (1990), Christchurch, Spitalfields No.2, (charcoal on paper), Yale Center for British Art, New Haven, USA/Friends of British Art Fund, Bridgeman Education.

Martin Creed. (2006), Work No. 517 (triptych), (highlighter \& marker pen on paper). Private Collection, Bridgeman Education.

Vincent van Gogh. (1888), The Olive Trees, (pen \& ink on paper). Musee des Beaux-Arts, Tournai, Belgium, Bridgeman Education.

Henri Michaux. (1956), Illustration from 'Miserable Miracle (La Mescaline)', Editions du Rocher, Monaco, (engraving). Private Collection, Bridgeman Education.

Venturino Venturi. (1976), Belly, (oil on paper). Vatican Museums and Galleries, Vatican City, Photo @ Stefano Baldini, Bridgeman Images. 
The second categorical MDS exposed problems with large categories of artworks, an initial multinomial logistic regression for measures obtained from imagery used in this MDS sort were inconclusive supporting this type of categorization as ill-defined.

A second selection of categories was created using larger sets of drawings from three artists—Egon Schiele, Georges Seurat and Vincent van Gogh. The corresponding set of computational measures derived from the list of traits and visual features previously identified as: global tone, smudge, pattern/texture, line length, line expressiveness, and depth were tested using sets of drawings from these three artists. An important aspect of the operations developed for the measures was the level of accessibility for art practitioners, art students and teachers. Final operations needed to be easy to do and understand with very little supervision.

Analysis of the measures using both a multinomial logistic regression and bivariate logistic regression validated this model approach. Through the multinomial logistic regression significance was shown for measures of line expressiveness, global tone, pattern/texture and smudge. The measure for line length was at .069. The measure for depth was not significant at all with a measure of .341 .

Analysis of the bivariate logistic regression data proved to be quite fascinating and revealed many comparisons of visual features through both observations of the artworks and quantitative analysis of the measures. Identifying both similarities and differences in approaches each artist took in their approach to a particular visual feature. The analysis suggests a different type of art categorization that is beneficial to art/design practitioners, art/design students and teachers by suggesting groups by a specific visual feature. Placing emphasis on the actual artifact of the drawing and marks made rather than other problematic issues of style. Further research needs to be done to fully develop the model but the current findings and analysis suggest the foundation of the model to be valid. Figure 52 illustrates the model in its present state. 


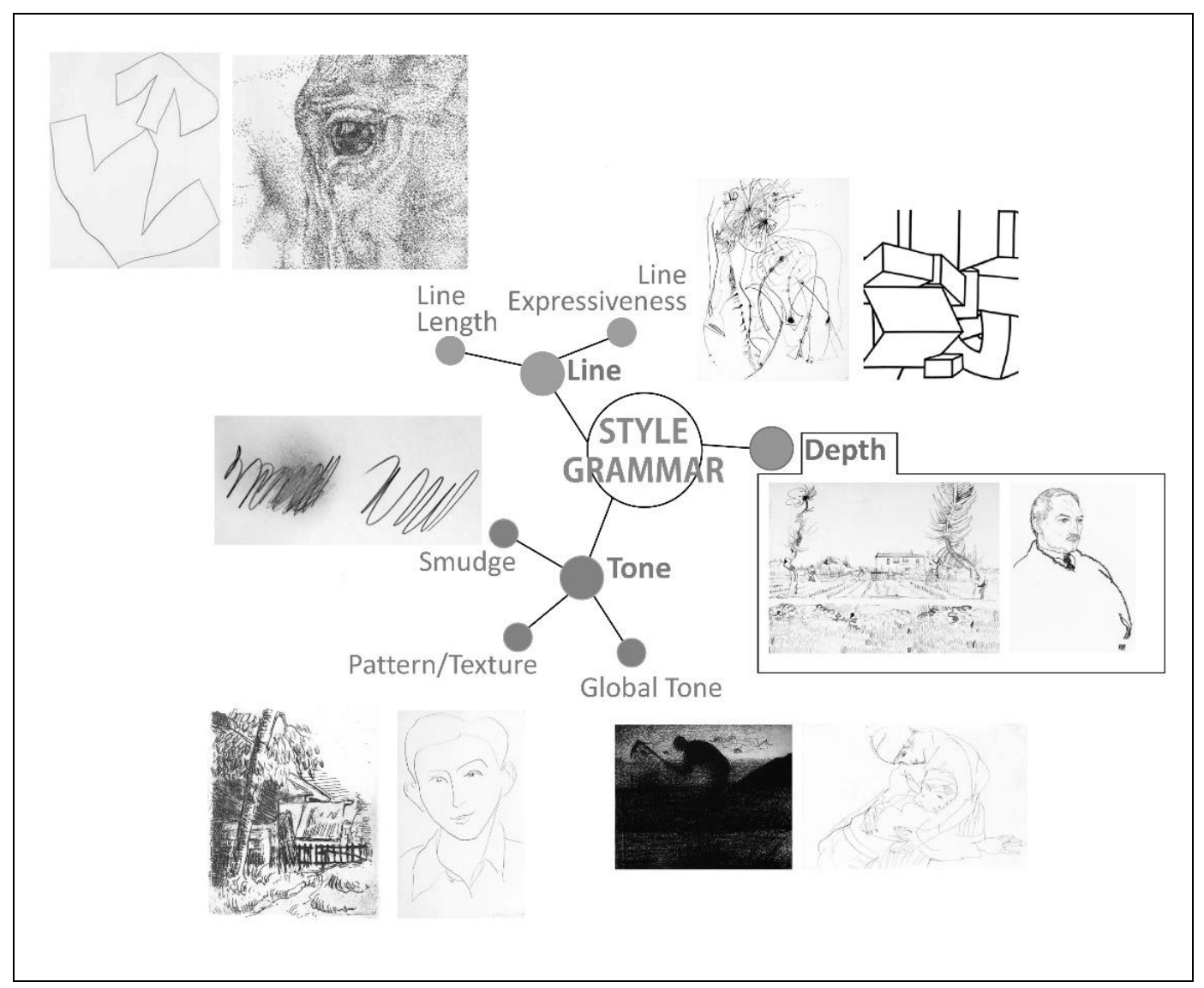

Figure 52: The current state of the model with measures for visual features identified. Depth is shown boxed, indicating the visual feature is identified but there are issues with the current measure obtained for this visual feature.

Ellsworth Kelly. (1987), Magnolia, (pencil on cream paper). Brooklyn Museum of Art, New York, USA, Gift of Henry Persche, Bridgeman Education.

J. Sweo. (2012), Pointillist study of a horse head, (pen on paper).

Al Held. (1967), Untitled, (oil on canvas). Private Collection, Bridgeman Education.

Jackson Pollock. (date unknown), Untitled (O'Connor-Thaw 776) from a suite of notebook drawings, (India ink on paper). Museum of Fine Arts, Houston, Texas, USA, Museum purchase funded by Caroline Wiess Law, Bridgeman Images.

Vincent van Gogh. (1888), Working the Fields at Arles; Laboureur dans les Champs a Arles, (reed pen and ink over pencil on paper). Private Collection / Photo (C) Christie's Images, Bridgeman Images.

Egon Schiele. (1907), Portrait of Man; Mannerportrait, (soft pencil on paper). Private Collection, Photo (C) Christie's Images, Bridgeman Images.

Georges Pierre Seurat. (1883), Man with a Pick, (crayon conte). Private Collection, Bridgeman Education. Egon Schiele. (1914), Embrace, (pencil on paper). Private Collection, Photo @ Christie's Images, Bridgeman Images.

Henri Matisse. (1946), Paul Matisse (IV), (pen and black ink on paper). Private Collection, Photo (C) Christie's Images, Bridgeman Images.

Paul Cezanne. (1873), Landscape in Auvers, (etching on paper). Sterling and Francine Clark Art Institute, Williamstown, Massachusetts, USA, Bridgeman Images. 


\section{Bibliography}

Agrawala, M., Li, W., \& Berthouzoz, F. (2011). Design principles for visual communication. Communications of the ACM, 54(4), 60-69.

Ahmad, S., \& Chase, S. C. (2012). Style representation in design grammars. Environment and planning B: Planning and design, 39(3), 486-500.

Amadasun, M., \& King, R. (1989). Textural features corresponding to textural properties. Systems, Man and Cybernetics, IEEE Transactions on, 19(5), 1264-1274. doi:10.1109/21.44046

An, L., \& Li, W. (2014). An integrated approach to fashion flat sketches classification. International Journal of Clothing Science and Technology, 26(5), 346-366.

Andrew, I. (2011). Computing style. Nexus Network Journal, 13(1), 183-193.

Anfam, D. (2015). Abstract Expressionism. Grove Art Online. Oxford Art Online. Oxford University Press. Retrieved from http://www.oxfordartonline.com/subscriber/article/grove/art/T000252>.

Artists on Art. From the XIV to the XX century. (1958). (R. Goldwater \& M. Treves Eds. 3rd ed.). New York: Pantheon Books.

Ashwin, C. (2016). What is a drawing? Drawing: Research, Theory, Practice, 1, UK, Intellect, LTD. pp. 197-209.

Batchelor, D. (2000). Chromophobia: Reaktion books.

Bearman, D., \& Duff, W. (1996). Grounding archival description in the functional requirements for evidence. Archivaria, 275-303.

Beck, J., Prazdny, S., \& Rosenfeld, A. (1981). A theory of textural segmentation: Computer Vision Laboratory, Computer Science Center, University of Maryland.

Belak, B., Belak, S., \& Radman Pesa, A. (2008). Stylometry--definition and development. Annals of DAAAM \& Proceedings, 85+.

Berlyne, D. (1975). Dimensions of perception of exotic and pre-renaissance paintings. Canadian journal of psychology, 29(2), 151-173. 
Bernal, M., Haymaker, J. R., \& Eastman, C. (2015). On the role of computational support for designers in action. Design Studies, 41, 163-182. doi:10.1016/j.destud.2015.08.001

Bijmolt, T. H. A., \& Wedel, M. (1999). A Comparison of Multidimensional Scaling Methods for Perceptual Mapping. Journal of Marketing Research, 36(2), 277-285. doi:10.2307/3152099

Boden, M. A. (2004). The creative mind: Myths and mechanisms: Psychology Press.

Box, G. E. (1979). Robustness in the strategy of scientific model building. Robustness in statistics, 1, pp. 201-236.

Bradley, M. M., \& Lang, P. J. (1994). Measuring emotion: The self-assessment manikin and the semantic differential. Journal of Behavior Therapy and Experimental Psychiatry, 25(1), 49-59. doi:http://dx.doi.org/10.1016/0005-7916(94)90063-9

Brodatz, P. (1966). Textures: a photographic album for artists and designers (Vol. 66): Dover New York.

Brown, K. (2015). Against Autobiography: Henri Matisse's Essays on Art. Life Writing, 12(1), 43-58. doi:10.1080/14484528.2014.915284

Buchanan, R. (1992). Wicked problems in design thinking. Design Issues, 8(2), 5-21.

Bullot, N. J., \& Reber, R. (2013). The artful mind meets art history: Toward a psychohistorical framework for the science of art appreciation. Behavioral and Brain Sciences, 36(02), 123-137.

Büyükkurt, B. K., \& Büyükkurt, M. D. (1990). Robustness and small-sample properties of the estimators of probabilistic multidimensional scaling (PROSCAL). Journal of Marketing Research, 139-149.

Campbell, C. (2011). Turning the Viewing Device Around: A Critical Approach to Drawing as Design Research. Anti-po-des design journal.org.nz, 45-52.

Carroll, N., Moore, M., \& Seeley, W. P. (2012). The philosophy of art and aesthetics, psychology, and neuroscience. Aesthetic science. Connecting minds, brains, and experience, 31-62. 
Catterall, K. M., \& Nugent, H. M. (1999). WARP: A radical solution to teaching foundations. Art Journal, 58(1), 4-9.

Charalampidis, D. (2001). Novel textural features and techniques for image segmentation and classification. (3013886 Ph.D.), University of Central Florida, Ann Arbor. ProQuest Dissertations \& Theses Global database.

Chen, X. (2005). Relationships between product form and brand: A shape grammatical approach. University of Leeds.

Chi, M. T., Feltovich, P. J., \& Glaser, R. (1981). Categorization and representation of physics problems by experts and novices*. Cognitive science, 5(2), 121-152.

Ching, F. D. (2010). Architecture: Form, space, and order: Wiley.

Ching, F. D. (2015). Architectural graphics. John Wiley \& Sons.

Chu, P. T. D. (2003). Nineteenth-century European art. Abrams.

Coke, V. D., Lipchitz, J., \& Arnason, H. (1972). The painter and the photograph, from Delacroix to Warhol.

Cole, R. V. (1921). Perspective: the practice \& theory of perspective as applied to pictures, with a section dealing with its application to architecture by Rex Vicat Cole... Illustrated by 436 drawings \& diagrams by the author \& 36 pictures chiefly by old masters. Seeley, Service \& Company.

Conway, W. M. (1960). The Writings of Albrecht Dürer.

Coxon, A. P. M. (1999). Sorting data: Collection and analysis (Vol. 127): Sage Publications.

Daalhuizen, J., Person, O., \& Gattol, V. (2014). A personal matter? An investigation of students' design process experiences when using a heuristic or a systematic method. Design Studies, 35(2), 133-159. doi:10.1016/j.destud.2013.10.004

Dasarathy, B. V. (1991). Nearest neighbor $(\{\mathrm{NN}\})$ norms: $\{\mathrm{NN}\}$ pattern classification techniques.

Davis, S. (2000). Color perception: philosophical, psychological, artistic, and computational perspectives.

Delwiche, J. F. (2012). You eat with your eyes first. Physiology \& behavior, 107(4), 502-504. 
Deng, Z., Wang, L., \& Wang, X. (2011). An integrated method of feature extraction and objective evaluation of fabric pilling. The Journal of the Textile Institute, 102(1), 1-13.

Dew, D. (2008). Construct. Encyclopedia of Survey Research Methods. Sage Publications, Inc. Thousand Oaks, CA: Sage Publications, Inc.

Dodge, Y. (2006). The Oxford dictionary of statistical terms: Oxford University Press on Demand.

Dormer, P. (1993). Design since 1945: Thames and Hudson London.

Dresp, B., \& Grossberg, S. (1999). Spatial facilitation by color and luminance edges: boundary, surface, and attentional factors. Vision Research, 39(20), 3431-3443.

Dubery, F., \& Willats, J. (1972). Drawing Systems. London, England: Studio Vista Blue Star House.

Dubery, F., \& Willats, J. (1983). Perspective and Other Drawing Systems. New York, New York: Van Nostrand Reinhold Company, Inc.

Duda, R. O., Hart, P. E., \& Stork, D. G. (2012). Pattern classification: John Wiley \& Sons. Duff, W. M. (1999). The Acceptance and Implementation of the Rules for Archival Description by Canadian Archives: A Survey. Archivaria, 1(47).

E. Beaudoin, J. (2014). A framework of image use among archaeologists, architects, art historians and artists. Journal of Documentation, 70(1), 119-147.

Edgerton, S. Y. (1978). The Renaissance rediscovery of linear perspective.

Ehrenzweig, A. ([1953] 1975). The Psychoanalysis of Artistic Vision and Hearing. The Hidden Order of Art, London: Sheldon.

Ejiri, T., Morimoto, Y., \& Takahashi, T. (2014). Shading approach for artistic stroke thickness using $2 D$ light position. Paper presented at the ACM SIGGRAPH 2014 Posters, Vancouver, Canada.

Epstein, J. M. (2008). Why Model? Journal of Artificial Societies and Social Simulation, 11(4), 12.

Fehrman, K., \& Fehrman, C. (2000). Color: The secret influence: Prentice Hall. Finch, M. (1974). Style in art history. 
Fincher, S., \& Tenenberg, J. (2005). Making sense of card sorting data. Expert Systems, 22(3), 89-93. doi:10.1111/j.1468-0394.2005.00299.x

Findeli, A. (1990). Moholy-Nagy's design pedagogy in Chicago (1937-46). Design Issues, $7(1), 4-19$.

Fischer, J. L. (1961). Art styles as cultural cognitive maps. American Anthropologist, 63(1), 79-93.

Flye, R. (2011). http://flyeschool.com/content/repetition-rhythm-and-pattern.

Freeman, H. (1974). Computer Processing of Line-Drawing Images. ACM Comput. Surv., 6(1), 57-97. doi:10.1145/356625.356627

Freeman, H., \& Glass, J. M. (1969). On the Quantization of Line-Drawing Data. Systems Science and Cybernetics, IEEE Transactions on, 5(1), 70-79. doi:10.1109/TSSC.1969.300247

Freeman, H., \& Saghri, J. A. (1980). Comparative analysis of line-drawing modeling schemes. Computer Graphics and Image Processing, 12(3), 203-223. doi:http://dx.doi.org/10.1016/0146-664X(80)90012-X

Fu, K. S., \& Mui, J. K. (1981). A survey on image segmentation. Pattern Recognition, 13(1), 3-16. doi:http://dx.doi.org/10.1016/0031-3203(81)90028-5

Garber Jr, L. L., Hyatt, E. M., \& Starr Jr, R. G. (2001). Placing food color experimentation into a valid consumer context. Journal of Food Products Marketing, 7(3), 3-24.

Gardner, H. (1970). Children's sensitivity to painting styles. Child Development, 813-821.

Garlan, D. (1995). What is style? School of Computer Science at Research Showcase@CMU.

Gibson, L., \& Lucas, D. (1982). Vectorization of raster images using hierarchical methods. Computer Graphics and Image Processing, 20(1), 82-89.

Goel, V. (1995). Sketches of thought. MIT Press.

Goldstein, N. (1977). The art of responsive drawing. Englewood Cliffs, New Jersey: PrenticeHall, inc.

Gooch, A. A., Long, J., Ji, L., Estey, A., \& Gooch, B. S. (2010). Viewing progress in nonphotorealistic rendering through Heinlein's lens. Paper presented at the Proceedings of 
the 8th International Symposium on Non-Photorealistic Animation and Rendering, Annecy, France.

Gooch, B., Sloan, P. P. J., Gooch, A., Shirley, P., \& Riesenfeld, R. (1999). Interactive technical illustration. Paper presented at the Proceedings of the 1999 symposium on Interactive 3D graphics, Atlanta, Georgia, USA.

Goodwin, T., Vollick, I., \& Hertzmann, A. (2007). Isophote distance: a shading approach to artistic stroke thickness. Paper presented at the Proceedings of the 5th international symposium on Non-photorealistic animation and rendering, San Diego, California.

Goodyear, A. C. (2004). Gyorgy Kepes, Billy Klüver, and American Art of the 1960s: Defining Attitudes Toward Science and Technology. Science in Context, 17(04), 611635.

Grabli, S., Durand, F., \& Sillion, F. X. (2004, 6-8 Oct. 2004). Density measure for linedrawing simplification. Paper presented at the Computer Graphics and Applications, 2004. PG 2004. Proceedings. 12th Pacific Conference on.

Graham, D. J., Hughes, J. M., Leder, H., \& Rockmore, D. N. (2012). Statistics, vision, and the analysis of artistic style. Wiley Interdisciplinary Reviews: Computational Statistics, 4(2), 115-123. doi:10.1002/wics.197

Graham, D. J., \& Meng, M. (2011). Artistic representations: clues to efficient coding in human vision. Visual neuroscience, 28(04), 371-379.

Guibal, C. R. C., \& Dresp, B. (2004). Interaction of color and geometric cues in depth perception: When does “red” mean "near"? Psychological Research, 69(1), 30-40. doi:10.1007/s00426-003-0167-0

Guptill, A. L. (1976). Rendering in Pen and Ink. New York: Watson-Guptill Publications. Gürsoy, B., \& Özkar, M. (2015). Visualizing making: Shapes, materials, and actions. Design Studies, 41, 29-50. doi:10.1016/j.destud.2015.08.007

Hale, R. B. (2009). Drawing Lessons from the Great Masters (D. Holden Ed. 45th Edition ed.). New York: Watson-Guptill Publications.

Halliday, M., Matthiessen, C. M., \& Matthiessen, C. (2014). An introduction to functional grammar: Routledge. 
Haralick, R. M., \& Shanmugam, K. (1973). Textural features for image classification. IEEE Transactions on systems, man, and cybernetics(6), 610-621.

Haralick, R. M., \& Shapiro, L. G. (1985). Image segmentation techniques. Computer Vision, Graphics, and Image Processing, 29(1), 100-132. doi:http://dx.doi.org/10.1016/S0734-189X(85)90153-7.

Hardiman, G. W., \& Zernich, T. (1982). The Relative Influence of Parts and Wholes in Shaping Preference Responses to Paintings. Studies in Art Education, 23(3), 31-38. doi:10.2307/1320014.

Harrison, L., Earl, C., \& Eckert, C. (2015). Exploratory making: Shape, structure and motion. Design Studies, 41, 51-78. doi:10.1016/j.destud.2015.08.003.

Hartley, J., \& Homa, D. (1981). Abstraction of stylistic concepts. Journal of Experimental Psychology: Human Learning and Memory, 7(1), 33.

Haworth, K. M. (1992). The voyage of RAD: from the old world to the new. Archivaria, $1(35)$.

Helm, C. E., \& Tucker, L. R. (1962). Individual differences in the structure of colorperception. The American Journal of Psychology, 75(3), 437-444.

Herrnstein, R. J. (1966). Superstition: A corollary of the principles of operant conditioning. Operant behavior: Areas of research and application, 33-51.

Hertzmann, A. (2010). Non-Photorealistic Rendering and the science of art. Paper presented at the Proceedings of the 8th International Symposium on Non-Photorealistic Animation and Rendering, Annecy, France.

Higgins, J. W. (1932). Fine arts in mass production: Harvard University. Graduate School of Business Administration.

Hillerbrand, E. (1989). Cognitive differences between experts and novices: Implications for group supervision. Journal of Counseling \& Development, 67(5), 293-296.

Hillier, R. (2008). Sylexiad. A typeface for the adult dyslexic reader. Journal of Writing in Creative Practice, 1(3), 275-291. 
Hori, O., \& Tanigawa, S. (1993, 20-22 Oct 1993). Raster-to-vector conversion by line fitting based on contours and skeletons. Paper presented at the Document Analysis and Recognition, 1993., Proceedings of the Second International Conference on.

Hout, M. C., Papesh, M. H., \& Goldinger, S. D. (2013). Multidimensional scaling. Wiley Interdisciplinary Reviews: Cognitive Science, 4(1), 93-103.

Hughes, J. M., Graham, D. J., Rockmore, D. N., \& Mumford, D. (2010). Quantification of Artistic Style through Sparse Coding Analysis in the Drawings of Pieter Bruegel the Elder. Proceedings of the National Academy of Sciences of the United States of America, 107(4), 1279-1283. doi:10.2307/40536318.

Hurtut, T., Gousseau, Y., Cheriet, F., \& Schmitt, F. (2008). Pictorial analysis of linedrawings. Paper presented at the Proceedings of the Fourth Eurographics conference on Computational Aesthetics in Graphics, Visualization and Imaging.

Hurtut, T., Gousseau, Y., Cheriet, F., \& Schmitt, F. (2011). Artistic line-drawings retrieval based on the pictorial content. J. Comput. Cult. Herit., 4(1), 1-23. doi:10.1145/2001416.2001419.

Hutchings, J. (2004). Colour in folklore and tradition—The principles. Color Research \& Application, 29(1), 57-66.

Ingold, T. (2009). The textility of making. Cambridge Journal of Economics, bep042.

Isaac, P. (1970). Dissimilarities as indices of individual perceptual structure. Perception \& Psychophysics, 7(4), 229-233. doi:10.3758/BF03209367.

Itten, J. (1964). The art of color.

Ivins, W. M. (1953). Prints and visual communication (Vol. 10): MIT Press.

Janson, H. (2001). History of art. New York: Harry N. Abrams: Inc.

Johnson, C. R., Hendriks, E., Berezhnoy, I. J., Brevdo, E., Hughes, S. M., Daubechies, I., . . . Wang, J. Z. (2008). Image processing for artist identification. Signal Processing Magazine, IEEE, 25(4), 37-48. doi:10.1109/MSP.2008.923513.

Julész, B., \& Bergen, J. R. (1983). Human factors and behavioral science: Textons, the fundamental elements in preattentive vision and perception of textures. Bell System Technical Journal, The, 62(6), 1619-1645. doi:10.1002/j.1538-7305.1983.tb03502.x 
Julész, B., Gilbert, E., Shepp, L., \& Frisch, H. (1973). Inability of humans to discriminate between visual textures that agree in second-order statistics—revisited. Perception, 2(4), 391-405.

Kaneko, T. (1992). Line structure extraction from line-drawing images. Pattern Recognition, 25(9), 963-973. doi:http://dx.doi.org/10.1016/0031-3203(92)90061-M.

Kaplan, M., Gooch, B., \& Cohen, E. (2000). Interactive artistic rendering. Paper presented at the Proceedings of the 1st international symposium on Non-photorealistic animation and rendering. Annecy, France.

Karoui, I., Fablet, R., Boucher, J. M., Pieczynski, W., \& Augustin, J. M. (2008). Fusion of textural statistics using a similarity measure: application to texture recognition and segmentation. Pattern Analysis and Applications, 11(3-4), 425-434. doi:10.1007/s10044-008-0108-z

Kasprisin, R. J., \& Pettinari, J. (1995). Visual thinking for architects and designers: Visualizing context in design: Van Nostrand Reinhold.

Kavakli, M., \& Gero, J. S. (2001). Sketching as mental imagery processing. Design Studies, $22(4), 347-364$.

Kepes, G. (1995). Language of vision: Courier Corporation.

Kim, Y. Y. (2000). Becoming intercultural: An integrative theory of communication and crosscultural adaptation: Sage Publications.

Klee, P. (1961). Paul Klee: the thinking eye: the notebooks of Paul Klee (Vol. 15): G. Wittenborn.

Kleiner, F. (2013). Gardner's Art through the Ages: The Western Perspective (Vol. 1): Cengage Learning.

Klitment, S. (1984). Architectural Sketching and Rendering: Techniques for Designers and Artists. New York: Whitney Library of Design.

Knight, T., \& Stiny, G. (2015). Making grammars: From computing with shapes to computing with things. Design Studies, 41, 8-28. doi:10.1016/j.destud.2015.08.006 Knight, T. W. (1992). 2. Designing with Grammars. CAAD Futures' 91: Computer Aided Architectural Design Futures: Education, Research, Applications, 33. 
Knight, T. W. (1993). Color Grammars: The Representation of Form and Color in Designs. Leonardo, 26(2), 117-124. doi:10.2307/1575896

Kohut, H. (1957). Observations on the Psychological Functions of Music. J. Amer. Psychoanal. Assn., Vol. 5, 389-407.

Krukowski, L. "Abstraction." Encyclopedia of Aesthetics. Oxford Art Online. Retrieved from http://www.oxfordartonline.com/subscriber/article/opr/t234/e0003.

Kruskal, J. B. (1964). Multidimensional Scaling. Multidimensional Scaling. SAGE

Publications, Inc. Thousand Oaks, CA: SAGE Publications, Inc.

Kruskal, J. B., \& Wish, M. (1978). Multidimensional scaling (Vol. 11): Sage.

Kwak, C., \& Clayton-Matthews, A. (2002). Multinomial logistic regression. Nursing research, 51(6), 404-410.

Kwallek, N., \& Lewis, C. M. (1990). Effects of environmental colour on males and females: A red or white or green office. Applied ergonomics, 21(4), 275-278.

Laing, S., \& Masoodian, M. (2016). A study of the influence of visual imagery on graphic design ideation. Design Studies, 45, 187-209. doi:10.1016/j.destud.2016.04.002

Lambert, S. (1984). Reading Drawings an Introduction to Looking at Drawings. New York, United States: Pantheon Books, a divison of Random House, New York.

Latour, B. (1986). Visualization and cognition: Drawing things together. Knowledge and Society, 6, 1-40.

Lauzzana, R. G., \& Pocock-Williams, L. (1988). A Rule System for Analysis in the Visual Arts. Leonardo, 21(4), 445-452. doi:10.2307/1578709.

Leavitt, R. (1976). Artist and computer: Crown.

Levine, R. D., \& Postal, P. M. (2004). A corrupted linguistics. The Anti-Chomsky Reader, Lanham, Md.: Encounter Books, 203-231.

Levinson, J. (1992). Intention and interpretation: A last look. Temple University Press.

Levy, B. I. (1984). Research into the psychological meaning of color. American Journal of Art Therapy. 
Lidwell, W., Holden, K., \& Butler, J. (2010). Universal principles of design, revised and updated: 125 ways to enhance usability, influence perception, increase appeal, make better design decisions, and teach through design: Rockport Pub.

Lindsay, P. H., \& Norman, D. A. (2013). Human information processing: An introduction to psychology: Academic Press.

Loewy, R. (2002). Never leave well enough alone: JHU Press.

Lohan, F. (1978). Pen and Ink Techniques. Chicago: Contemporary Books, Inc.

Mack, A., \& Rock, I. (1998). Inattentional blindness (Vol. 33): MIT press Cambridge, MA.

Macmillan, N. A., \& Creelman, C. D. (2004). Detection theory: A user's guide: Psychology press.

Maher, M. L. (2010). Evaluating creativity in humans, computers, and collectively intelligent systems. Paper presented at the Proceedings of the 1st DESIRE Network Conference on Creativity and Innovation in Design.

Mahfoud, E., \& Willis, A. (2013, 4-7 April 2013). Volumetric shape grammars for image segmentation and shape estimation. Paper presented at the Southeastcon, 2013 Proceedings of IEEE.

Maitland-Gholson, J. C. (1985). Implications of Selected Studies in Psychology for Visual Arts Research. Visual Arts Research, 11(2), 21-30. doi:10.2307/20715596.

Marr, D., \& Hildreth, E. (1980). Theory of edge detection. Proceedings of the Royal Society of London B: Biological Sciences, 207(1167), 187-217.

Martin, D., \& Fowlkes, C. (2001). The Berkeley segmentation database and benchmark. Computer Science Department, Berkeley University. http://www. eecs. berkeley. edu/Research/Projects/CS/vision/bsds.

Martino, J. A. (2010). The immediacy of the artist's mark in shape computation. Paper presented at the ACM SIGGRAPH 2010 Art Gallery, Los Angeles, California.

Mateos-Perez, J., M., \& Pascau, J. (2013). Image Processing with ImageJ. United Kingdom: Pact Publishing Ltd.

Matisse, H., \& Flam, J. D. (1995). Matisse on art. Univ of California Press. 
McCormack, J. P., Cagan, J., \& Vogel, C. M. (2004). Speaking the Buick language: capturing, understanding, and exploring brand identity with shape grammars. Design Studies, 25(1), 1-29.

McKemmish, S. (1994). Are records ever actual? Ancora Press.

Merrill, E. B. (1987). Art styles as reflections of sociopolitical complexity. Ethnology, 26(3), 221-230.

Mitchell, W. J. (1991). Functional grammars: an introduction. Reality and virtual reality, Assoc. for CAD in Arch. New Jersey Inst. of Tech., Newark, 167-176.

Moszynska, A. "Abstract art" Grove Art Online. Oxford Art Online. Retrieved from http://www.oxfordartonline.com/subscriber/article/grove/art/T000238

Munsterberg, M. (2009). Writing about art. www. writingaboutart. org.

Nash, B. (1937). Product Development. The Journal of Marketing, 1(3), 254-262.

Neisser, U. (2014). Cognitive Psychology: Classic Edition: Psychology Press.

Netemeyer, R. G., Bearden, W. O., \& Sharma, S. (2003). Scaling Procedures Issues and Application. Thousand Oaks, California: SAGE Publications, Inc.

Nixon, M. S., \& Aguado, A. S. (2012). Feature extraction \& image processing for computer vision: Academic Press.

O'Hare, D. (1980). An Introduction to the Concepts and Methods of Multidimensional Scaling. British Educational Research Journal, 6(1), 29-42. doi:10.2307/1500819

O'Hare, D.P.A., \& Gordon, I. (1977). Dimensions of the perception of art: Verbal scales and similarity judgements. Scandinavian Journal of Psychology, 18(1), 66-70.

Osgood, C. E. (1952). The nature and measurement of meaning. Psychological bulletin, 49(3), 197.

Ozkar, M., \& Stiny, G. (2009). Shape grammars. Paper presented at the ACM SIGGRAPH 2009 Courses, New Orleans, Louisiana.

Pal, N. R., \& Pal, S. K. (1993). A review on image segmentation techniques. Pattern Recognition, 26(9), 1277-1294. doi:http://dx.doi.org/10.1016/0031-3203(93)90135-J. 
Palmer, S. E. (1977). Hierarchical structure in perceptual representation. Cognitive psychology, 9(4), 441-474.

Parker, J. R. (1988). Extracting vectors from raster images. Computers \& Graphics, 12(1), 7579.

Person, O., Schoormans, J., Snelders, D., \& Karjalainen, T. M. (2008). Should new products look similar or different? The influence of the market environment on strategic product styling. Design Studies, 29(1), 30-48.

Person, O., \& Snelders, D. (2010). Brand styles in commercial design. Design Issues, 26(1), $82-94$.

Person, O., Snelders, D., \& Schoormans, J. (2016). Assessing the performance of styling activities: An interview study with industry professionals in style-sensitive companies. Design Studies, 42, 33-22. doi:10.1016/j.destud.2015.10.001.

Podsakoff, P. M., MacKenzie, S. B., Lee, J. Y., \& Podsakoff, N. P. (2003). Common method biases in behavioral research: a critical review of the literature and recommended remedies. Journal of applied psychology, 88(5), 879.

Pugliese, M. J., \& Cagan, J. (2002). Capturing a rebel: modeling the Harley-Davidson brand through a motorcycle shape grammar. Research in Engineering Design, 13(3), 139156.

Qi, H., \& Hughes, S. (2011, 22-27 May 2011). A new method for visual stylometry on impressionist paintings. Paper presented at the Acoustics, Speech and Signal Processing (ICASSP), 2011 IEEE International Conference on.

Rand, P. (2014). Thoughts on design: Chronicle Books.

Rao, A. R. (2012). A Taxonomy for Texture Description and Identification: Springer Publishing Company, Incorporated.

Rao, A. R., \& Lohse, G. L. (1993). Identifying High Level Features of Texture Perception. CVGIP: Graphical Models and Image Processing, 55(3), 218-233. doi:http://dx.doi.org/10.1006/cgip.1993.1016.

Rood, O. N. (1881). Students' Text-book of Color: Or, Modern Chromatics, with Applications to Art and Industry (Vol. 26): D. Appleton. 
Rosenberg, S., \& Park Kim, M. (1975). The method of sorting as a data-gathering procedure in multivariate research. Multivariate Behavioral Research, 10(4), 489-502.

Rosenfeld, A. (1984). Image analysis: Problems, progress and prospects. Pattern Recognition, 17(1), 3-12. doi:http://dx.doi.org/10.1016/0031-3203(84)90031-1.

Ross, W. D. (1904). http://publicdomainreview.org/collections/a-theory-of-pure-design-harmonybalance-rhythm-1907/.

Rubin, J. H. "Realism" Grove Art Online. Oxford Art Online. Retrieved from http://www.oxfordartonline.com/subscriber/article/grove/art/T070996.

Rugg, G., \& McGeorge, P. (2005). The sorting techniques: a tutorial paper on card sorts, picture sorts and item sorts. Expert Systems, 22(3), 94-107. doi:10.1111/j.14680394.2005.00300.x

Ruskin, J. (1907). The Elements of Drawing The Elements of Perspective (E. Rhys Ed.). London: J.M. Dent \& Sons LTD.

Saffran, E. M., Coslett, H. B., \& Keener, M. T. (2003). Differences in word associations to pictures and words. Neuropsychologia, 41(11), 1541-1546. doi:http://dx.doi.org/10.1016/S0028-3932(03)00080-0

Sahoo, P. K., Soltani, S., \& Wong, A. K. (1988). A survey of thresholding techniques. Computer Vision, Graphics, and Image Processing, 41(2), 233-260.

Salisbury, M. P., Anderson, S. E., Barzel, R., \& Salesin, D. H. (1994). Interactive pen-andink illustration. Paper presented at the Proceedings of the 21st annual conference on Computer graphics and interactive techniques.

Sandoval-Mejia, A. A. L. L., \& Wang, Y. E. (2016). Multinomial Logistic Regression. Schatz, S. L., \& Bowers, C. A. (2005). 10 Questions on Room Color: Answers for Workplace Designers. Ergonomics in Design: The Quarterly of Human Factors Applications, 13(4), 21-27.

Schiffman, S. S., Reynolds, L. M., \& Young, F. W. (1981). Introduction to Multidimensional Scaling: Theory, Methods, and Applications. New York, New York: Academic Press, Inc. 
Schloss, K. B., Poggesi, R. M., \& Palmer, S. E. (2011). Effects of university affiliation and “school spirit" on color preferences: Berkeley versus Stanford. Psychonomic Bulletin \& Review, 18(3), 498-504. doi:10.3758/s13423-011-0073-1

Schunn, C. D., Paulus, P. B., Cagan, J., \& Wood, K. (2006). Final report from the NSF innovation and discovery workshop: The scientific basis of individual and team innovation and discovery. Washington (DC): National Science Foundation.

Schwab, J. A. (2002). Multinomial logistic regression: Basic relationships and complete problems: Op.

Seeley, W. (2013). Art, meaning, and perception: a question of methods for a cognitive neuroscience of art. The British Journal of Aesthetics, 53(4), 443-460.

Sethi, R. J. (2016). WAIVS. Retrieved from http://www.waivs.org/

Sezgin, M. (2004). Survey over image thresholding techniques and quantitative performance evaluation. Journal of Electronic imaging, 13(1), 146-168.

Shanken, E. A. (2006). Artists in industry and the academy: collaborative research, interdisciplinary scholarship, and the interpretation of hybrid forms Artists-in-Labs Processes of Inquiry (pp. 8-14): Springer.

Sillitoe, P. J. (2014). Diplomatic analysis of technical drawings: developing new theory for practical application. Archival Science, 14(2), 125-168.

Silver, C. A., Landis, D., \& Messick, S. (1966). Multidimensional Analysis of Visual Form: An Analysis of Individual Differences. The American Journal of Psychology, 79(1), 6272. doi: $10.2307 / 1420708$

Smith, P. (2011). Pictorial Grammar: Chomsky, John Willats, and the Rules of Representation. Art History, 34(3), 562-593. doi:10.1111/j.1467-8365.2011.00835.x Sosa, R., \& Gero, J. S. (2012). " Critical Mass of Ideas": A Model of Incubation in Brainstorming. Paper presented at the DS 73-1 Proceedings of the 2nd International Conference on Design Creativity Volume 1.

Sosa, R., Rojas, N., Gero, J. S., \& Qinqi, X. (2016). Visual divergence in humans and computers. Design Studies, 42, 56-85. doi:10.1016/j.destud.2015.10.002 
Starkweather, J., \& Moske, A. K. (2011). Multinomial logistic regression. Consulted page at September 10th: http:// www. unt. edu/ rss/ class/ Jon/ Benchmarks/ MLR_JDS_ Aug2011.pdf.

Stewart, J. B. (1959). Planned obsolescence. Harvard Business Review, 37(5), 14-174.

Stiny, G. (1980a). Introduction to shape and shape grammars. Environment and planning B, 7(3), 343-351.

Stiny, G. (1980b). Kindergarten grammars: designing with Froebel's building gifts. Environment and planning B, 7(4), 409-462.

Stiny, G. (2008). Shape: talking about seeing and doing: The MIT Press.

Stiny, G., \& Gips, J. (1971). Shape Grammars and the Generative Specification of Painting and Sculpture. Paper presented at the IFIP Congress (2).

Stiny, G., \& Mitchell, W. J. (1978). The palladian grammar. Environment and planning B: Planning and design, 5(1), 5-18.

Stone, N. J. (2001). Designing effective study environments. Journal of Environmental Psychology, 21(2), 179-190.

Stone, N. J. (2003). Environmental view and color for a simulated telemarketing task. Journal of Environmental Psychology, 23(1), 63-78.

Stone, N. J., \& English, A. J. (1998). Task type, posters, and workspace color on mood, satisfaction, and performance. Journal of Environmental Psychology, 18(2), 175-185.

Strauss, W. L., \& Dürer, A. (1974). The complete drawings of Albrecht Dürer (Vol. 1): Abaris Books.

Swanson, G. (1994). Graphic Design Education as a Liberal Art: Design and Knowledge in the University and the "Real World". Design Issues, 10(1), 53-63. doi:10.2307/1511656

Syeda-Mahmood, T. F. (1999). Detecting Perceptually Salient Texture Regions in Images. Computer Vision and Image Understanding, 76(1), 93-108. doi:http://dx.doi.org/10.1006/cviu.1999.0784

Taboada, J. A. F. (2015). From Goethes's Theory of Colours To Albers' Interaction of Colour. Revista de EGA, (25). 
Takane, Y. (1978). A maximum likelihood method for nonmetric multidimensional scaling: I. The case in which all empirical pairwise orderings are independent-Theory. Japanese Psychological Research, 20(7), 17.

Takane, Y., \& De Leeuw, J. (1987). On the relationship between item response theory and factor analysis of discretized variables. Psychometrika, 52(3), 393-408.

Tamura, H., Mori, S., \& Yamawaki, T. (1978). Textural Features Corresponding to Visual Perception. Systems, Man and Cybernetics, IEEE Transactions on, 8(6), 460-473. doi:10.1109/TSMC.1978.4309999

Tavin, K., Kushins, J., \& Elniski, J. (2007). Shaking the foundations of postsecondary art (ist) education in visual culture. Art Education, 60(5), 13-19.

Taylor, D. W., Berry, P. C., \& Block, C. H. (1958). Does group participation when using brainstorming facilitate or inhibit creative thinking? Administrative Science Quarterly, $23-47$.

Thurstone, L. L. (1927). A law of comparative judgment. Psychological review, 34(4), 273.

Verhoeff, F. (1928). An optical illusion due to chromatic aberration. American Journal of Ophthalmology, 11(11), 898-900.

Walton, K. L. (1970). Categories of Art. The Philosophical Review, 79(3), 334-367. doi: $10.2307 / 2183933$

Wan, X., Woods, A. T., Seoul, K. H., Butcher, N., \& Spence, C. (2015). When the shape of the glass influences the flavour associated with a coloured beverage: Evidence from consumers in three countries. Food Quality and Preference, 39, 109-116. doi:http://dx.doi.org/10.1016/j.foodqual.2014.07.004

Ward, G. (2008). The Grove Encyclopedia of Materials and Techniques in Art (G. W. R. Ed.): Oxford University Press.

Watson, E. W. (1985). The art of pencil drawing: Watson-Guptill Publications.

Wertheimer, M. (1938). Laws of organization in perceptual forms.

Whaley, A. L., \& Longoria, R. A. (2009). Preparing Card Sort Data for Multidimensional Scaling Analysis in Social Psychological Research: A Methodological Approach. The Journal of Social Psychology, $149(1), 105-115$. 
White, J. (1957). The birth and rebirth of pictorial space. Cambridge, MA.

Wiegersma, S., \& Van Loon, A. (1989). Some variables in the blue (red) phenomenon. The Journal of general psychology, 116(3), 259-269.

Wiggins, G. A. (2001). Towards a more precise characterisation of creativity in AI. Paper presented at the Case-based reasoning: Papers from the workshop programme at ICCBR.

Willats, J. (1997). Art and Representation: New Principles in the Analysis of Pictures. Princeton, New Jersey: Princeton University Press.

Winkenbach, G., \& Salesin, D. H. (1994). Computer-generated pen-and-ink illustration. Paper presented at the Proceedings of the 21 st annual conference on Computer graphics and interactive techniques.

Winkenbach, G., \& Salesin, D. H. (1996). Rendering parametric surfaces in pen and ink. Paper presented at the Proceedings of the 23rd annual conference on Computer graphics and interactive techniques.

Winn, W., \& Everett, R. J. (1979). Affective rating of color and black-and-white pictures. ECTJ, 27(2), 148-156.

Xiu Wu, H., Dudek, C. K., Sharman, L., \& Szabo, F. E. (2005, 6-8 July 2005). From form to content: using shape grammars for image visualization. Paper presented at the Information Visualisation, 2005. Proceedings. Ninth International Conference on.

Yang, M. C. (2009). Observations on concept generation and sketching in engineering design. Research in Engineering Design, 20(1), 1-11.

Yantis, S., \& Jones, E. (1991). Mechanisms of attentional selection: Temporally modulated priority tags. Perception \& Psychophysics, 50(2), 166-178.

Yelizaveta, M., Chua, T. S., Irina, A., \& Jain, R. (2004, 30-30 June 2004). Representation and retrieval of paintings based on art history concepts. Paper presented at the Multimedia and Expo, 2004. ICME '04. 2004 IEEE International Conference on.

Yue, K., Krishnamurti, R., \& Grobler, F. (2011). Estimating the interior layout of buildings using a shape grammar to capture building style. Journal of Computing in Civil Engineering, 26(1), 113-130. 
Zao, J., Hong, Z., Jiren, L., \& Junan, H. (1998, 16-20 Aug 1998). A new approach for intelligent object picking in line drawing images. Paper presented at the Pattern Recognition, 1998. Proceedings. Fourteenth International Conference on.

Zimmermann, H. J. (1996). Fuzzy Control Fuzzy Set Theory-and Its Applications (pp. 203240): Springer. 


\title{
Appendix A
}

\section{Ethics Information}

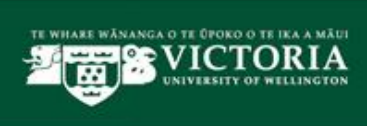

SCHOOL OF DESIGN Te Kura Hoahoa FACULTY OF ARCHITECTURE \&. DESIGN Te Wähanga Waihanga-Hoahoa VCTORIA UNIVERSITY OF WELUNGTON, PO BOX 600 , Wellington 6140, New Zesland

Phone +64-4-463 6200 Fax +64-4-4636204 Email design Q

\section{Participant Information Sheet}

\author{
Name of Procedure: \\ Multidimensional Scaling (MDS) Card Sort Activity
}

Title of Research:

Mark Making to Art: A Process for Measuring Line Traits \& Defining Styles of Art in Line Drawings

\section{Researcher:}

Jennie Sweo, School of Design, Victoria University of Wellington

\section{Imtiond vintionom}

I am a Ph.D. student in Design at Victoria University of Wellington. As part of this degree I am undertaking a research project leading to a thesis.

This research project compares the visual processing of pictures between people and computers. More specifically comparing how a person would categorize a picture based on the characteristics of lines within a drawing to computer categorization of the same pictures based on machine measures of the same lines. This research hopes to answer the following questions:

- What traits of line are used in human perception to differentiate drawings?

- Are there measurable similarities between machine vision and human perception of line traits that define an art style? And if so, what are they?

This research project has received approval from the Victoria University Human Ethics Committee. 


\section{Participation Process}

I am inviting any consenting adult to participate in this study. Participants can be university students of a consenting age but solicitation for participants is not limited to students. Professionals who would fit into either category of art expert or non-art expert will be emailed via publicly accessible email addresses and asked to participate.

The only criteria for participants is to be divided into one of two groups:

Group One: Participants who are non-art experts (individuals that do not work in visual arts, have had very little visual art education, and do not have a visual arts background).

Group Two: Participants are art experts (individuals that work in visual arts, have a visual arts background, have a visual arts education, and or have earned a college or university degree in visual arts).

\section{Participation Procedure: Card Sort Activities}

There will be 2 card sorting activities involving 120 cards with a unique drawing on each card containing people, inanimate objects, animals, and natural scenes.

\section{Card Sort Activity One}

The first card sort activity will involve 40 of the 120 cards and each participant will be instructed to categorize or sort by creating mutually exclusive piles comprised of visually similar traits of line. This card sort will use a free format: there will be no restrictions on the number of piles or groups that can be generated. The number of piles created is up to the participant.

\section{Card Sort Activity Two}

The second card sort activity will involve the remaining 80 cards and instruction to sort by creating mutually exclusive piles comprised of similarity on art style. This card sort will use a fixed format: there will be a restriction of 5 piles or groups that can be generated corresponding to 5 different art styles used based on the general categories of realism, abstraction and abstract art. The number of piles is limited to 5 piles and the participants will have to choose the best fit for each image. 


\section{Participant Time Commitment \& Compensation}

It is envisaged that the card sorting activities will take a maximum of $11 / 2$ hours to complete.

Should any participants feel the need to withdraw from the project, they may do so without question at any time including during the card sort activities.

Because of the commitment of time, those who participate and finish both card sorting activities will receive for their volunteered time a choice of $\$ 40.00$ or a $\$ 50.00$ culture vulture token.

No remittance of any kind will be given for partial participation.

Once a participant has finished the card sort activities and has received payment for their time, they can no longer withdraw their information from the study.

The card sorting activity will be done on an individual basis. A time and suitable location for each card sort will be pre-arranged on an individual basis with each participant.

\section{Research Submission Information}

Responses will form the basis of my research project and will be put into a written report on a confidential basis. It will not be possible for any participant to be identified personally. Only grouped responses will be presented in this report. All material collected will be kept confidential. No other person besides me and my supervisor Dr. Sydney Shep will see the data.

The thesis will be submitted for marking to the School of Design and deposited in the University Library. It is intended that one or more articles will be submitted for publication in scholarly journals. All card sort data will be destroyed two years after the end of the project.

If you have any further questions or would like to receive further information about the project, please contact me at VUW email: or my supervisor,

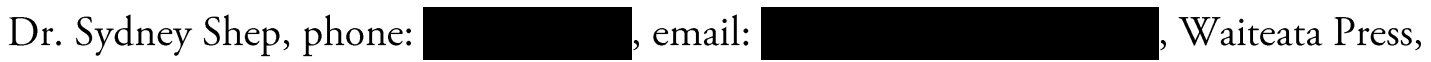
Kelburn Campus, Victoria University. 


\section{Ethics Solicitation}

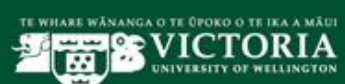

SCHOOL OF DESIGN Te Kura Hoahoa

FACULTY OF ARCHITECTURE \& DESIGN Te Wäh anga Waihanga-Hoahoa

VCTORIA UNIVERSITY OF WELLINGTON, PO BOX 600, Wellington 6140, New Zesland

Phone +64-4-463 6200 Fax +64-4-4636204 Email design Qviw. ac $n z$ Web www victoria acnz ldesign

Hello,

The reason I am contacting you is that I am conducting a study that compares the visual processing of pictures between people and computers. I am currently seeking volunteers as participants in this study, who have a background in, have advanced degrees in, or work in visual arts.

This research project has received approval from the Victoria University Human Ethics Committee.

The thesis will be submitted for marking to the School of Design and deposited in the University Library. It is intended that one or more articles will be submitted for publication in scholarly journals. All card sort data will be destroyed at the completion of the thesis publication.

If you have any further questions or would like to receive further information about the project, please contact me at and VUW email: or my supervisor Dr. Sydney Shep, phone: _, email:

, Waiteata Press, Kelburn Campus, Victoria University.

The Victoria University, Wellington School of Design is located at the Te Aro Campus: 139 Vivian St, Te Aro, Wellington 6011.

Thank you for your time in reviewing this email.

Jennie Sweo 


\section{$\circlearrowleft$ Research Participation $O$}

\section{Participants needed for a study that compares the visual processing of pictures between people and computers}

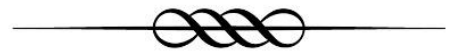

Participation in this study involves coming into a quiet classroom space that has been reserved for this study at

Victoria University Wellington School of Design is located at the Te Aro Campus: 139 Vivian St, Te Aro, Wellington 6011.

Time to be arranged with each participant.

If you would like to participate or receive

further information about the project, please contact me at

\section{VUW email:}

There will be 2 card sorting activities involving 120 cards with a unique drawing containing people, inanimate objects, animals, and natural scenes on each card.

I will explain the process when we meet.

You may withdraw from participating at anytime, including during the activities themselves, no reason is necessary. Just let me know at the time.

Both activities will take no more than $1 \frac{1}{2}$ hours.

Those who participate and finish both card sorting activities will receive for their volunteered time $\$ \mathbf{4 0 . 0 0}$

or

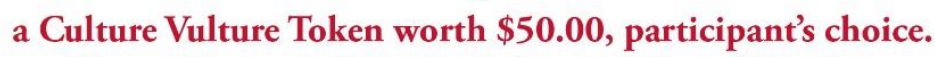
No remittance will be given for partial participation.

This research project has received approval from the Victoria University Human Ethics Committee. 


\section{Ethics: Script for Introduction}

Thank you for participating in this study. My name is Jennie Sweo and I am a Ph.D. student in Design at Victoria. I am conducting a study that compares human perception with computer vision of lines within different types of drawings.

There will be two card sort activities involving 120 cards with a unique drawing on each card containing people, inanimate objects, animals, and natural scenes. A full explanation for the first card sort will be given shortly. After the first card sort is concluded an explanation for the second card sort will be given. You can ask any questions you have about each activity before they begin.

Because of the amount of time involved (approximately $1 \frac{1}{2}$ hours) at the end of the second card sort and filling out a small questionnaire you will have the opportunity to select a remittance of either $\$ 40$ or a $\$ 50$ culture vulture token.

You can withdraw from the activities at any time for any reason and any data collected will be destroyed but there is no remittance for partial participation.

The data collected will form the basis of my research project and will be put into a written report on a confidential basis. It will not be possible for any participant to be identified personally. Only group responses will be presented in this report. All material collected will be kept confidential. No person persons besides me and my supervisor Dr.

Sydney Shep will see the data. All data collected will be destroyed 2 years after the end of this project. If you have any questions or would like to receive further information about the project my contact information is provided on the Participant Information Sheet.

Any questions?

Let us continue with the first card sort activity.

Each sheet of paper before you has a unique drawing on it containing people, inanimate objects, animals, and natural scenes. Please group the images into as many piles as you 
feel necessary based on the visual similarity of the way the lines look to you. So for example if you think two drawings have the same, kind of fat lines you would put them in the same group.

Please be aware there are no right or wrong answers and please take your time.

Do you have any questions?

Once you are happy with your groups, let me know you can then relax for a moment before starting the second card sort.

Ready to move on to the second card sort?

Each sheet of paper before you has a unique drawing on it again containing people, inanimate objects, animals, and natural scenes. This time you will be deciding which of 5 categories each image fits best. I will now review the categories and a sheet of paper with the description for each category will always be present for you to refer back to. The categories are on a sliding scale from realism through abstraction to abstract. Neo-Classicism: Imagery looks very real but on close inspection, it seems better than real—striving for perfection or idealistic.

Renaissance: Imagery looks very much like it appears in real life. From a little distance everything looks real but up-close you'll see it's an illusion. Post-Impressionist: Imagery is moving away from how it actually appears in real life. There is a noticeable reduction of realism moving into abstraction.

Expressionist: Imagery is still recognizable but far less realistic. A sense of how something feels rather than how something looks is more important.

Abstract: Imagery is non-representational. 
Again, please be aware there are no right or wrong answers and please take your time.

Do you have any questions?

Once you are happy with your groups, let me know.

You will have a moment to relax before completing the exit questionnaire and then selecting your choice of remittance. 


\section{Ethics Participant Consent Form}

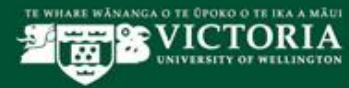

\section{CONSENT TO PARTICIPATE IN RESEARCH}

Name of Procedure: Multidimensional Scaling Card Sort Activity

Title of Project: Mark Making to Art: A Process for Measuring Line Traits \& Defining Styles of Art in Line Drawings

I have been given and have understood an explanation of this research project. I have had an opportunity to ask questions and have them answered to my satisfaction. I understand that I may withdraw myself (or any information I have provided) from this project up to and including the card sort activities without having to give reasons.

I understand that any information I provide will be kept confidential to the researcher, and the supervisor.

I understand the published results will not use my name, and that no opinions will be attributed to me in any way that will identify me.

I understand that the data I provide will not be used for any other purpose or released to others without my written consent.

I would like to receive a summary of the results of the research when it is completed. Below is my contact information.

Contact information:

I agree to take part in this research.

Signed:

Name of participant:

Date:

Researchers Contact Details: Jennie Sweo 


\section{Appendix B}

\section{Teaching Syllabus One}

\section{Model Syllabus 1 - The College Board AP Studio Arts: Drawing Syllabus 1058813v1}

\begin{tabular}{|c|c|}
\hline \multicolumn{2}{|c|}{ Scoring Components } \\
\hline SC1 & $\begin{array}{l}\text { The course promotes a sustained investigation of all three aspects of } \\
\text { portfolio development- quality, concentration, and breadth—as outlined } \\
\text { in the Course Description and Poster throughout the duration of the course. }\end{array}$ \\
\hline SC3 & $\begin{array}{l}\text { The course enables students to develop a cohesive body of work } \\
\text { investigating a strong underlying visual idea in drawing that grows out of a } \\
\text { coherent plan of action or investigation (i.e., a "concentration"). }\end{array}$ \\
\hline SC4 & $\begin{array}{l}\text { The course teaches students a variety of concepts and approaches in drawing } \\
\text { so that the student is able to demonstrate a range of abilities and versatility } \\
\text { with technique. Such conceptual variety can be demonstrated through either } \\
\text { the use of one or the use of several media. }\end{array}$ \\
\hline SC5 & $\begin{array}{l}\text { The course teaches students a variety of concepts and approaches in } \\
\text { drawing so that the student is able to demonstrate a range of abilities and } \\
\text { versatility with problem-solving. Such conceptual variety can be } \\
\text { demonstrated through either the use of one or the use of several media. }\end{array}$ \\
\hline SC6 & $\begin{array}{l}\text { The course teaches students a variety of concepts and approaches so that the } \\
\text { student is able to demonstrate a range of abilities and versatility with } \\
\text { ideation (i.e. "breadth"). Such conceptual variety can be demonstrated } \\
\text { through either the use of one or the use of several media. }\end{array}$ \\
\hline SC7 & $\begin{array}{l}\text { The course emphasizes making art as an ongoing process that involves the } \\
\text { student in informed and critical decision making. }\end{array}$ \\
\hline SC8 & $\begin{array}{l}\text { The course includes group critiques, with the teacher, enabling students to } \\
\text { learn to analyze and discuss their own artworks as well as artworks of their } \\
\text { peers. }\end{array}$ \\
\hline SC9 & $\begin{array}{l}\text { The course includes individual student critiques and or instructional } \\
\text { conversations with the teacher, enabling students to learn to analyze and } \\
\text { discuss their own artworks and better critique artworks of their peers. }\end{array}$ \\
\hline SC10 & $\begin{array}{l}\text { The course teaches students to understand artistic integrity as well as what } \\
\text { constitutes plagiarism. If students produce work that makes use of } \\
\text { photographs, published images, and/or other artists' works, the course } \\
\text { teaches students how to develop their own work so that it moves beyond } \\
\text { duplication. }\end{array}$ \\
\hline
\end{tabular}




\section{Overview}

Studio 1, Studio 2, and AP Studio Art: Drawing students meet within the same class period this academic year. All levels work toward the development of a comprehensive portfolio that may meet requirements for entry into college-level classes. Students will investigate all three portfolio components - quality, concentration, and breadth. [SC1]

In constructing the portfolio, students will explore critical characteristics of creative thinking. Students learn how to seek out creative problems that are interesting and challenging and use goal setting, informed decision making, and problem-solving skills to pursue their own artistic interest in an informed way with homework and journals. [SC7] Students are responsible for demonstrating mastery in concept, composition, and execution as they use the elements of art and principles of design to organize their works. [SC2]

Students enrolled in all levels of this course must research their ideas for their independent projects and document this in the sketchbook journal. Through goal setting, students are guided in setting challenging but attainable creative goals for projects. Students utilize a set of standards set for the class to gauge their progress and work toward their goals. These standards are based on the state course expectations and indicators and the standards for the AP Studio Art: Drawing Portfolio Exam.

Students must demonstrate the ability to come in on a daily basis and immediately engage in teacher-directed class activity and also independently work toward creatively solving problems they have developed. All levels of studio art require that due dates be met. When questions arise, it is the responsibility of the student to meet with the instructor.

Students in all levels of this studio must complete all in-class assignments, which include the artistic ideation process, in-class and out-of-class projects, reading, and research. All students are expected to have sketchbooks at all times and to develop these sketchbooks as ongoing journals. Both directed and non-directed work should become a part of the contents of the sketchbook journal. Sketchbook journals will be used to document the mandatory ideation process for in-class and out-of-class projects. [SC7]

Students are responsible for the upkeep and management of the collected body of formal drawings. A drawer in the teacher's office is assigned so that all projects can be secured.

All studio levels will be asked to write a paper on a specific arthistorical period and/ or a specific area of interest. Critique

SC1-The course promotes a sustained investigation of all three aspects of portfolio development- quality, concentration, and breadthas outlined in the Course Description and Poster throughout the duration of the course.

SC2-The course enables students to develop mastery (i.e., "quality") in concept, composition, and execution of 3-D design.

SC3-The course enables students to develop a cohesive body of work investigating a strong underlying visual idea in drawing that grows out of a coherent plan of action or investigation (i.e., a "concentration").

SC4-The course course teaches students a variety of concepts and approaches in drawing so that the student is able to demonstrate a range of abilities and versatility with technique. Such conceptual variety can be demonstrated through either the use of one or the use of several media.

SC5-The course teaches students a variety of concepts and approaches in drawing so that the student is able to demonstrate a range of abilities and versatility with problem-solving. Such conceptual variety can be demonstrated through either the use of one or the use of several media.

SC6-The course teaches students a variety of concepts and approaches so that the student is able to demonstrate a range of abilities and versatility with ideation (i.e. "breadth"). Such conceptual variety can be demonstrated 
guidelines will be provided for writing a paper that includes the cultural, social, political, and contemporaneous art movements.

Individual critiques, conferences, and discussions with the teacher, as well as group critiques with teacher and peers, will be ongoing and are a required component of the course. Each student will participate in individual student critiques with the teacher, which will provide one-on-one dialogue and help the student learn to analyze and discuss his or her individual artwork. Students are also expected to engage in verbal and written critiques of their own work, as well as the work of their peers and other artists. During critiques, the vocabulary of art will be used to discuss the work on display.

[SC8 \& SC9]

Students will have ongoing individual instructional conversations with their teacher while actively engaged in the creation their drawings to assess the strengths and weaknesses in their work and provide positive encouragement. [SC8]

Students enrolled in AP Studio Art: Drawing must complete all inclass and out-of-class assignments. Students enrolled in AP Studio Art: Drawing work toward the completion of one of three portfolios. This section will focus this year on the drawing portfolio, but the other two exams, AP Studio Art: 2-D Design and AP Studio Art: 3$\mathrm{D}$ Design, may be considered upon request. In-class assignments in the first semester assist the student in meeting the breadth requirements for section 3 of the AP Exam Portfolio. In the breadth section, the student will explore a variety of concepts and demonstrate versatility with respect to the use of media, techniques, problem solving, and ideation.

In addition, the student has to research, plan, prepare, and present to the teacher his or her concentration proposal, which will include the concentration topic, idea, concept, theme, and/or focus as well as a specific, coherent plan of action for the development of the student's focused investigation, including possible specific art mediums and specific techniques, by the conclusion of first semester. The concentration must contain a body of work that is developed from a sustained plan of action or investigation of a visual idea in drawing. Students develop a thematic or stylistic body of work that is concentrated toward their "visual idea." [SC3] Second year AP students should arrange to meet with the instructor the first week of school. These students may opt to begin their concentrations outside of class earlier in the year in place of certain assignments.

Permission to do this is given to students who can show substantial development of all three sections of the exam, particularly the breadth section, at the beginning of the fall semester. Once approval through either the use of one or the use of several media.

SC7-The course emphasizes making art as an ongoing process that involves the student in informed and critical decision making.

SC8-The course includes group critiques, with the teacher, enabling students to learn to analyze and discuss their own artworks as well as artworks of their peers.

SC9-The course includes individual student critiques and or instructional conversations with the teacher, enabling students to learn to analyze and discuss their own artworks and better critique artworks of their peers. 
for this is granted, a proposal and journal research must be completed.

\section{Units of Study}

The units of study for AP Studio Art: Drawing include:

\begin{tabular}{|l|l|}
\hline Unit & Summary Statement \\
\hline $\begin{array}{l}\text { Launching the } \\
\text { Application of } \\
\text { Creative Problem- } \\
\text { Solving Process }\end{array}$ & $\begin{array}{l}\text { Goal setting, applying creative problem solving, Sketchbook cover design } \\
\text { Altered book, journal, Expressive line drawing, Wash drawing, } \\
\text { Prismacolor color-stick drawing } \\
\text { Choose an enclosed space - a kitchen cabinet, a television, an oven, a } \\
\text { refrigerator, inside a drawer or closet. What human qualities do the objects } \\
\text { in the enclosed space assume when no one is watching? Do the mustard } \\
\text { bottles dance? Do the socks play cards? Be sure and show the interior of } \\
\text { the space as well as the objects. } \\
\text { Choose one or more sounds and translate this auditory experience into } \\
\text { visual terms; that is, portray the sounds pictorially. Your illustration can be } \\
\text { abstract or representational. Let your brain expand on the idea and } \\
\text { explore. } \\
\text { Media for exploration of conceptual drawing concerns include pen and } \\
\text { ink drawings and charcoal, Conté crayon and graphite pencils, } \\
\text { Prismacolor color sticks. You will need to use specific elements of art and } \\
\text { specific principles of design to assist with your explorations. [SC4, SC5 \& } \\
\text { SC6] } \\
\text { Inquiry into college programs } \\
* \text { Minimum of four at-home projects to be given }\end{array}$ \\
\hline
\end{tabular}




\begin{tabular}{|c|c|}
\hline $\begin{array}{l}\text { The View from } \\
\text { Here: Observational } \\
\text { Drawing }\end{array}$ & $\begin{array}{l}\text { Brookside Gardens nature botanical study } \\
\text { Still-life, wrapped objects } \\
\text { Choose an issue you care deeply about and would want to try to do } \\
\text { something about. This issue should be something that is a general issue } \\
\text { or concern in society. Some ideas you might be concerned with depicting } \\
\text { might be pollution, environmental concerns, abortion rights, racism, } \\
\text { homelessness, SIDS, religious war, religious discrimination, poverty, } \\
\text { verbal abuse, bullying, depression, teenage suicide, and discrimination. } \\
\text { What do you care about? Has anyone in your family been affected by any } \\
\text { of these? How? Why? How did it affect them? Positive and negative } \\
\text { space and the human figure in motion } \\
\text { Your car, truck, tractor from inside, outside, the sky, underneath, unusual } \\
\text { perspective } \\
\text { Media open and can include charcoal, Conté, oil sticks/oil pastels, oil } \\
\text { paint, pen and ink, complementary color scheme, analogous color } \\
\text { scheme, perspective, contrast of value and emphasis, variety, balance, } \\
\text { rhythm, repetition, proportion/scale, figure/ground relationships; can be } \\
\text { articulated through the mass, volume, color/light, form, plane, line, } \\
\text { texture. [SC4, sc5 \& sc6] } \\
\text { Group critique guidelines will be used to gauge growth, discovery, and } \\
\text { Investigation. }\end{array}$ \\
\hline $\begin{array}{l}\text { The Power of Color: } \\
\text { The Transformative } \\
\text { Effects of Value }\end{array}$ & $\begin{array}{l}\text { Develop nine drawings that demonstrate versatility in handling of color } \\
\text { media, technique, and conceptual invention. Use the elements of art and } \\
\text { principles of design to assist with your compositional considerations and } \\
\text { decisions. } \\
\text { Content: unusual landscape. From photographs you take of real } \\
\text { landscapes, cityscapes, and/or your immediate environment, use color } \\
\text { other than local color to render a finished product. Medium should be } \\
\text { one of the following: oil painting, acrylic painting, watercolor painting, } \\
\text { silkscreen multiple-layer print. No smaller than 9" x 9". Do not use local } \\
\text { color but rather use color for expression. [SC4, SC5 \& SC6] }\end{array}$ \\
\hline $\begin{array}{l}\text { Constructing } \\
\text { Meaning: Conceptual } \\
\text { Invention and } \\
\text { Compositional } \\
\text { Strength }\end{array}$ & $\begin{array}{l}\text { Review of drawing concepts, PowerPoint of AP Studio Art: Drawing } \\
\text { proposal } \\
\text { Development of self-assignment } \\
\text { Sample work for concentration }\end{array}$ \\
\hline
\end{tabular}




\section{Grading Procedures}

Grades will reflect individual achievement of the state standards for a specific marking period. They will be reported and calculated using percentages within weighted categories.

Along with the statement that grades are based on individual achievement, they also include:

- Information regarding categories and their corresponding weights

- Information about how completion homework (no more than 10 percent of the grade) and homework evaluated for learning will be included

\section{Types of Weights of Assignments}

Class group critiques with peers and teacher -40 percent [SC8] Studio class assignments - 40 percent

Class studio problems assigned for outside of class - 10 percent Homework completion - 10 percent

\section{Copyright Issues}

Throughout the course, ongoing discussions and critiques will take place to help students gain an understanding of ethical practices in making art. Students are not allowed to work from published photographs or other copyrighted work except as a reference. Students will understand they should work from their own individual life events, activities, dreams, fantasies, and still-life compositions, and they can work from photographs they take of these events and activities.

They are not to work from the Internet or works created by others, whether published or unpublished. When doing this, students must move beyond mere duplication in their work. The work must be significantly altered in the service of the individual student's own voice and expression. Misuse of copyrighted materials is plagiarism and a legal issue and can be pursued as such. [SC10]

\section{Reteaching}

We are committed to students and their learning. Reteaching occurs when teachers or students determine that students are not meeting learning goals. Teachers will determine the method and schedule to provide extra help. 


\section{Reassessment}

Assessed tasks (e.g., homework, sketchbook) may be revised to receive a higher grade until the end of a lesson unit. [SC7]

- If an assignment is determined to be reassessable, all students will be eligible for reassessment regardless of the grade on the original assignment, provided they have met these requirements:

1) Completed the original task and any required assignments;

2) Completed a tutoring session with the teacher during step or a mutually agreed upon time; and

3) Submitted the original student work, along with the original teacher comments.

- The reassessment may differ from the original to ensure that student learning has taken place.

- Scores earned on the reassessment will replace the original score.

- Assessments that indicate a final measure of learning may not be reassessed (e.g., end-of-unit assessments, final papers, final projects, culminating performances, final exams).

\section{Studio Maintenance}

All students will be responsible for maintaining personal workspaces as well as actively participating in specific classroom maintenance tasks for the good of the studio environment.

\section{Bibliography}

Chaet, Bernard. The Art of Drawing, 3rd ed. Wadsworth Thomson Learning, 1983.

Enstice, Wayne, and Melody Peters. Drawing: Space, Form, and Expression, $4^{\text {th }}$ ed. Pearson Prentice Hall, 2011.

Kaupelis, Robert. Experimental Drawing. New York: Watson-Guptill, 1992.

Lauer, David A., and Stephen Pentak. Design Basics, 7th ed. Boston: Thomson Wadsworth, 2008.

Mittler, Gene A., and James Howze. Creating and Understanding Drawings, $4^{\text {th }}$ ed. Glencoe/McGraw-Hill, 2005.

St. Aubyn, Jacklyn. Drawing Basics, 2nd ed. Belmont, Cal.: Thomson Wadsworth, 2007.

Periodicals: Art in America, Art News, Lenswork References: Master Prints; Slide Collection; AP Studio Art: Drawing Poster; Art Cards; AP Scoring Guidelines; College and University Books 


\section{Teaching Syllabus Two}

\section{Model Syllabus 2 - Cat Normoyle-Memphis College of Art Syllabus}

Foundations

Basic Drawing 1

FD100E

Memphis College of Art

Fall 2012

T/TH 1:00pm - 3:35pm

Butler Hall West

Contact Information

Cat Normoyle, Instructor

Department of Design

Office hours

T/TH 11am-12:30pm or by appointment

Gibson Hall, Room 122

Course Blog

\section{Course Description}

Seeing/drawing skills are developed and sensitivity toward the aesthetics of form and space including linear perspective, mark making, value, line and line quality is explored. Students work in black and white media on a variety of papers from still-life, landscape and self-portrait.

This is an introductory class which will expose the student to a number of traditional skills and ideas that have occupied artists throughout history. The class involves drawing from direct observation with an emphasis on space, volume, linear and free hand perspective, and other basic techniques and concepts. In Basic Drawing One there is an emphasis on line as the principle conveyor of form. The student is expected to develop disciplined work habits and an understanding of the visual artist's formal language. There will be regular class critiques and a required sketchbook. Upon successful completion of the course, student's work will demonstrate 
1. The ability to draw from observation

2. The ability to use line as the principle conveyor of form

3. The ability to use line to represent volume and space

4. The ability to use linear perspective in the creation of volume and space

5. Disciplined work habits

\section{QEP Professional Practices Outcomes:}

1. Students will demonstrate the ability to write an artist statement

2. Student will demonstrate the ability to digitally document their class work

3. Students will demonstrate the ability to research in order to stay current in their field.

\section{Class Methodologies \& Policies}

In the interest of developing an appreciation of quality materials and maximizing the life span of your work, all major drawings should be executed on good quality artist papers. Using lesser types of paper for a finished drawing will result in a lower grade.

All work must be kept in a portfolio. Respect and protect your work if you expect anyone else to do so.

All work that is handed in for grading must have your name printed unobtrusively on the back.

All finished work must be fixed. Make sure you have fixative and bring it with you to class.

Do not spray fixative in the classroom. It is bad stuff, take it outside.

The cost of materials is not an excuse for incomplete assignments.

Disruptive behavior will result in your being asked to leave class. This will be counted as an absence.

I will only discuss individual grades outside of class privately. 
I will explain all assignments and due dates in class. It is your responsibility to take notes and remember information given.

You will not be excused from this class to do work for another.

No cell phones or texting during class.

\section{EPA/OSHA Regulations}

Memphis College of Art students and faculty are required to follow the standards detailed in the "EPA (Environmental Protection Agency) Materials Handling Protocols September 2007."

All EPA/OSHA regulations that apply will be observed in this class. This is required of all students.

\section{Course Topics}

One-Point, Two-Point, Three-Point Linear Perspective

Planar Analysis \& Line Variation

Controlled Contour, Cross Contour, Blind Contour, Gesture Drawing

Free-Hand Perspective \& Urban Sketching

Line into Value

Class Outline \& Assignments

\section{Portfolio Work (60\%)}

This will make up the majority of your work in this class. We will work primarily in black dry media such as charcoal, pencil, conte on paper. The freedom you will earn as you get into more advanced classes is not as evident in Drawing I, as many of the drawings we will do are geared for a particular learning experience. Your focus, attitude and participation are critical to your success in this class.

\section{Critiques}

We will conduct critiques throughout the semester where students are expected to participate in discussion. These critiques are very important days, in which you will get direct feedback from your instructor and your classmates. Learn to take criticism without 
being defensive. Learn to listen and you'll improve. Learn to talk about your work and others. "I like it" is not permitted without some type of reason why "you like it." Learn to fail as much as succeed. Drawing is not what you might expect it to be.

\section{Classroom \& HW Exercises (20\%)}

\section{Homework}

You will be responsible for completing homework each week that will vary depending on the discussion topics and exercises happening in the classroom during that time. You can expect to have around 4 hours of homework each week. These home assignments will vary between sketchbook exercises, portfolio drawings, reading and writing assignments, artist research, etc and will most likely take the shape of portfolio work, blog assignments, and/or sketchbook assignments.

\section{Sketchbook}

You will be responsible for keeping a sketchbook throughout the semester. This sketchbook/journal should be composed of a combination of drawings, sketches, observations, ephemera, and ideas related to the course curriculum. Think of this as a part of your practice as an artist, a think pad, a place to work out drawing problems and a place to experiment. Carry it around with you. Personalize it. Use it every day. It should always be with you. I will check sketchbooks periodically during the semester. Bring it with you to class every day!

\section{Class blog \& Personal Blog}

You will be responsible for checking this blog at least once per week. The blog will be your digital classroom where critique photographs, drawing resources, artist resources, and other important information will be stored. The blog also acts as an archive of class activities as I photograph and post the work you are doing in class. I think you'll be surprised just how much you grow as an artist after the class is finished and you can look back through your work. You will need to create a blog specifically for this class where you will document and upload portfolio work for review. Each personal blog will be linked to the class blog as you will share your experiences. You will also be required to post writings / musings / inspirations to blog as assigned.

\section{Participation (20\%)}

This includes general participation in regards to Lectures and Discussions throughout the semester. You will be expected to participate with your peers and give constructive feedback during class time activities, demos, discussions. General effort and a professional attitude will be expected. 


\section{Materials List}

- Paper

- 18 x 24 Heavyweight bond

- 18 x 24 2-ply Bristol

- Stonehenge white, fawn, grey (22" x 30")

- Arches white (22" x 30")

- Rives BFK white (22” x 30”)

- Drawing Tools

- Sketchbook (8.5”x11")

- Graphite Pencils: A variety (hard - soft)

- Ebony pencil

- Graphite stick

- Black and white conte

- Vine charcoal (variety of hard - soft)

- Compressed charcoal (variety of hard - soft)

- 1 Charcoal Pencil

- Workable fixative

- Black India ink - permanent

- Fine tip pen - Faber-Castell Pitt Artist Pen (F and M)

- Watercolor brush (flat) - half-inch wide or larger

- Bamboo ink brush

- Kneaded rubber erasers (a few)

- Hard eraser

- Chamois

- Paper stump

- Fine sandpaper (several sheets)

- Metal yardstick (You may also want a smaller one)

- Pencil sharpener

- Utility knife, $x$-acto or other cutting instrument

- Masking tape

- Tool box or compartment to carry drawing tools and materials

- Portfolio case for care of drawings and drawing papers

- Drawing board (minimum size22"x30”), Alligator clips 


\section{Attendance Policy}

"On-time class attendance and participation are both critical aspects of the educational process. As the professor has the responsibility for presenting and directing the main body of day-to-day class content, so too it is each student's responsibility to engage in the critical/intellectual discourse that evolves from that presentation. Knowledge is gained not merely by accumulating information through lecture or demonstration, but by examination, question, and assimilation."

-Memphis College of Art Student Handbook

This is an experience-based studio class. You will learn from me and from your peers, so it is very important to be in class. Lectures, demonstrations, and project descriptions will not be repeated for absent or tardy students. Leaving class early without permission or arriving in excess of fifteen minutes late will be considered as one [01.0] full absence.

Four [04] tardy arrivals will be considered one [01.0] full absence.

Tardy is defined as including and in excess of five minutes late.

If you arrive after roll, come see me immediately to determine whether your arrival time will be considered a late arrival or whether you will be considered absent for the day.

Three [03] absences will decrease final grade by one-half [0.50] letter

Four [04] absences will decrease final grade by one [01] full letter

Five [05] absences will result in an " $F$ "

There are no excused absences in this class. Missed class-time cannot be "made-up". There will be no exceptions. The reasons behind the absences are not important. It would be wise to save your 2 allowable absences in anticipation of emergencies. An extended student illness requires a doctor's documentation and the consultation and assistance of Student Affairs and Academic Affairs respectively, and is the responsibility of the student. Extenuating circumstances are at the discretion of the professor.

The last day to withdraw and still receive a "W" for the course is Oct 26.

If you have a documented disability and wish to discuss academic accommodations, please contact me within the first week of classes to discuss terms. 


\section{Evaluation and Grading}

The final evaluation and assignment of grades for each assignment are based on elements such as:

1. Completion of all assignments

2. Perception and accuracy

3. Development of skills in seeing and thinking

4. Professional presentation and craftsmanship

5. Participation in critiques and discussions

6. General attitude and effort in the classroom

Each one of these areas of evaluation will result in an alphabetic grade and its accompanying numeric equivalent. The assignment of a grade is final. Projects may not be reworked for an elevated grade.

Students will receive grades for each project, exercise, test, et al, as well as midterm and final grades. Mid-semester and final grade assignments will also incorporate the attendance, application, working habits, and participation of the student and thus may not concretely be based on alphabetic grades. The faculty reserve the right to raise or lower your grade based on an improvement or degradation of commitment.

Participation in the totality of the course is expected. Provided studio time is reserved for the development of assigned learning only. Outside interruptions while in residenceacademic, artistic, or personal will not be tolerated. Lack of ongoing development, preparation, or engagement will be noted and subsequently reflected in each final project assessment. Any student who disrupts the course and/or interferes with the ability of his or her classmates to learn will be asked to leave - with the possibility of further disciplinary actions being levied. Assignments will require students to work extensively outside of scheduled class meetings. Project deadlines and critiques will be announced in relation to the current projects.

Attendance, presentation, and full participation at meetings and critiques, et al, are mandatory. Critiques, meetings, presentations, et al, begin promptly as noted for each project. Tardiness as it relates to these matters will be considered: as once the respective activity commences in relation to the known deadline. Formats must be presented as mandated prior to this time. No project or developmental material[s] will be accepted once a critique, meeting, presentation, et al, has commenced for any circumstances, thus resulting in a grade of " $F$ " - with a numeric equivalent of zero [0]. 
Absent students are unable to have their work delivered by a peer, delivered to a faculty office, or a faculty mailbox, et al, as no late work will be accepted for any circumstances, thus resulting in a grade of "F"- with a numeric equivalent of zero [0].

If you are absent the day a project or exercise is assigned, it is your responsibility to find out about missed assignments and complete all work by the due date. In some cases, there will be exercises assigned and due on the same date. These exercises cannot be "made-up".

\section{Undergraduate Grade Designations}

Note Bene; While the below descriptions note course, individual assignments, projects, tests, et al, could be applied equally. The designation of pluses and minus will be incorporated.

\section{Letter Grade of A}

The person earning this grade is as close as humanly possible to perfection in the fulfillment of the objectives of this course. It implies great effort and great success in all aspects of the class. It is rare that this grade is awarded.

\section{Letter Grade of B}

The person earning this grade has worked very hard, has pushed him/herself beyond the strict fulfillment of the objective of each problem, has shown strong advances in technical and conceptual skills and is involved and articulate in critiques and discussions.

\section{Letter Grade of C}

The student earning a "C" completed all assignments, had a positive attitude, worked hard, showed growth in skills and thinking, participated in critiques and discussions, and successfully fulfilled the requirements of the course, in general. This is the average level of achievement for all studio courses.

\section{Letter Grade of D}

The student has made the minimum effort to understand and master the skills and concepts covered in the course, or has obvious difficulties with basic skills and concepts and/or trouble in fulfilling the requirements of the class because of excess lateness, absence, poor attitude, or some other reason. 


\section{Letter Grade of F}

This grade indicates a severe problem in one or more of the following categories: lack of interest and/or seriousness of purpose, ineptitude in basic skills, and lack of understanding of concepts, terrible craftsmanship, and failure to complete assignments, bad attitude, excess lateness or absence.

\section{Alpha and Numeric Point Values}
Alpha
100-point
100.00-point
GPA-point

\begin{tabular}{|c|c|c|c|}
\hline A & $94-100$ & $93.34-100.00$ & 4.0 \\
\hline A- & $90-93$ & $90.00-93.33$ & 3.67 \\
\hline $\mathrm{B}+$ & $87-89$ & $86.67-89.99$ & 3.33 \\
\hline B & $84-86$ & $83.34-86.66$ & 3.0 \\
\hline B- & $80-83$ & $80.00-83.33$ & 2.67 \\
\hline $\mathrm{C}_{+}$ & $77-79$ & $76.67-79.99$ & 2.33 \\
\hline $\mathrm{C}$ & $74-76$ & 73.34-76.66 & 2.0 \\
\hline C- & $70-73$ & $70.00-73.33$ & 1.67 \\
\hline $\mathrm{D}$ & $60-69$ & $60.00-69.99$ & 1.0 \\
\hline $\mathrm{F}$ & $0-59$ & $00.00-59.99$ & 0.0 \\
\hline
\end{tabular}

Recognized manners of style sheets and citation are required. Students should consult sources including: The Chicago Manual of Style, University of Chicago Press; 15th edition; ISBN: 0226104036. Each available at the Memphis College of Art library, public libraries, and online at www.amazon.com.

Office hours are presented within this syllabus. Prior appointments and secure meeting times are welcomed. Regrettably, on occasion faculty service to the College will require amended hours, at which time, revisions will be posted.

Syllabus and coursework subject to change. 


\section{Academic Honesty Agreement}

The Shortest and surest way to live with honor in the world is to be, in reality, what we would appear to be; all human virtues increase and strengthen themselves by the practice and experience of them.

—Socrates [Ancient Greek Philosopher, 470 BCE_399 CE]

The acknowledgement of and adherence to a code of ethics is vital as members of society and participants within the College's academic community. To this end - the creation and presentation of all academic formats must be of the student's independent hand. Examinations will be presided by each student's honor. It is understood that the process of education - and that of a creative nature - is collective, and one should not confuse the development acquired from a peer or professorial reflections as a violation of this code. It is the blatant disregard for honesty with the knowing presentation of work other than your own - in a restricted manner, or receipt of assistance within a testing environment - which violates the prescribed ethics of our society.

Therefore, each format as requested will bear the student's signature and inscription:

\section{Ex Toto Opus Proprium Meum}

Upon independent academic review, violations will result in immediate dismissal from the course and an automatic grade of "F." 
have received the Drawing 1 | Fall 2012 course syllabus and have read it as obtained. I recognize I must be fully engaged in this course and am obliged to fully meet all of the requirements, expectations, and deadlines as detailed in their totality.

In particular, I am wholly aware of the honor, attendance, and grading policies. I understand and acknowledge the consequences of not realizing these expectations will drastically decrease my independent assigned grades and thus their culmination as a final grade. These actions may also alter my academic standing and progression within the sequence of the course of study.

Student Signature

Cat Normoyle

Date: 


\section{Schedule Overview}

* Schedule subject to change.

WEEK ONE: Introduction / Linear Perspective

- Meet \& greet

- Review of syllabus and materials

- "drawing what you see"

- Introduction to linear Perspective

- Demonstration/discussion of 1,2, and 3 point perspective, planes, ellipses

- One point perspective: work from still life of cubes, spheres, cones (planes and ellipses)

- Draw from eye-level, below eye-level, and above eye level

Materials: 4B and 6B drawing pencils, eraser, yardstick, 5 sheets of white bond paper $(18 ”$ x 24”)

Outside Assignments: One sheet of line exercises: Neatly draw a .5" border on your page. Divide the paper into at least eight horizontal bands which fill the page. Fill each band with vertical lines which explore different line weights and methods of drawing lines. Don't try to draw objects or things. Simply design the lines for strong positive/negative relationships. Lines can touch but not cross.

WEEK TWO: One-Point Linear Perspective

- Still life: cubes, cones, spheres (planes and ellipses)

- Above and below the horizon line

- Work to edge of page, push line variation

Materials: pencils, yardstick, and bond paper (18” x 24”)

Outside Assignments: Interior: One-Point Perspective (line only)

Materials: pencils, yardstick, and bond paper (18” x 24”)

WEEK THREE: Two-Point Linear Perspective

- Still life: cubes, cones, spheres (planes and ellipses)

- Above and below the horizon line

- Work to edge of page, push line variation 
- Work on wall or floor

Materials: Pencils, metal yardstick, and bond paper (18" x 24")

Outside Assignments: Interior (same one as last homework): Two-Point Perspective (line only)

Materials: Pencils, metal yardstick, and bond paper (18" x 24")

WEEK FOUR: Two-Point Linear Perspective

- Review Sketchbooks and Grades

- Still life: cubes, cones, spheres (planes and ellipses)

- Multiple Points of View

Materials: Pencils, metal yardstick, and bond paper (18" x 24")

Outside Assignments: Interior/ Free-hand Perspective (line only)

Materials: Pencils, metal yardstick, and bond paper (18" x 24")

WEEK FIVE: Ruler drawings: Planar Analysis and Line Variation

- Drapery and Objects

Materials: Pencils, metal yardstick, and bond paper (18" x 24")

Outside Assignments: Drapery: use a sheet or other non-patterned material; include the full space (line only)

Materials: charcoal pencil, metal yardstick, eraser and good paper (22" x 30")

WEEK SIX: Ruler drawings: Planar Analysis and Line Variation

- Still life objects

Materials: Pencils, metal edge ruler, and bond paper (18" x 24")

Outside Assignments: Ruler drawing: portrait head in planes (line only); work from observation with a sitter; reduce the head to a series of planes which clearly define the volume of the head as well as major features such as eyes, nose, mouth, ears, hair Materials: Charcoal pencil, metal yardstick, eraser and good paper (22" x 30")

WEEK SEVEN: Ruler drawings: Planar Analysis and Line Variation

- Midterm Sketchbooks Due 
- Still-Life Objects

Materials: conte or charcoal pencil, metal yardstick, and good paper (22" x 30")

Outside Assignments: bananas and pears

Materials: conte or charcoal pencil, metal yardstick, and good paper (22” x 30")

WEEK EIGHT: Blind and Controlled Contour/ Gesture Drawing

- Line quality: weight, width, value, space - thick/thin, dark/light, fast/slow, push/pull

- Materials: black conte, charcoal pencil, sharpened stick and ink, bond paper and Bristol

- Gesture Drawing: line and mass gesture and combination

- Materials: black conte, charcoal pencil, sharpened stick and ink, bond paper and Bristol

- Outside Assignments: Blind contour self (line only) - full page - include background

- Working from a mirror, draw four self-portraits in blind contour as we did in class. (One drawing in conte, one in pencil, one in stick and ink, one in brush and ink.) Materials: black conte, pencil, sharpened stick and ink, bamboo brush, bond paper (18" x 24”)

WEEK NINE: Cross Contour \& Wireframe

- Still-life

Materials: TBD

Outside Assignments: TBD

WEEK TEN: Free-Hand Perspective/Blocking In/ Line Quality/ Loosening Up/ Loose to Tight

- Still life

- Draw through objects

Materials: black conte or charcoal pencil, rubber eraser, bond paper (18” x 24")

Outside Assignments: Paper loops and curls: Cut out a strip of drawing paper approximately 2" x 24 ", attach the strip to a clean wall and light it, draw the paper strip four times from different angles using line only, use line variation to heighten the illusion of three-dimensionality. 
Sketchbook: Urban Sketching

WEEK ELEVEN: Free-Hand Perspective/Blocking In/ Line Quality/ Loosening Up/ Loose to Tight

- Still life with complex objects

- Draw through objects

Materials: black conte or charcoal pencil, rubber eraser, and bond paper (18" x 24")

Outside Assignments: TBA

Sketchbook: Urban Sketching

WEEK TWELVE: Free-Hand Perspective/Blocking In/ Line Quality/ Loosening Up/ Loose to Tight

- Still life with complex objects

- Draw through objects

Materials: black conte or charcoal pencil, rubber eraser, and bond paper (18” x 24")

Outside Assignments: plant or flowers

Sketchbook: Urban Sketching

Materials: black conte or charcoal pencil, rubber eraser, and bond paper (18” x 24")

WEEK THIRTEEN: Line: Controlled Contour/ Finished to Unfinished/ Limited Value/ Placement

- Skeleton Still Life

Materials: black conte, rubber eraser, and good paper (22” x $30 ")$

Outside Assignments: Self-portrait: controlled contour, work from mirror Materials: black conte, eraser, and good paper (22" x 30")

WEEK FOURTEEN: Line into Value/ Cross-Hatching/ Pen and Ink

- Still life

Materials: ink pen, metal edged ruler, pencil, 3-ply Bristol or Multimedia (18" x 24" or larger)

Outside Assignments: Attic or bathroom interior 
WEEK FIFTEEN: Line into Value/ Cross-Hatching/Still Life

Still life

Materials: ink pen, 3-ply Bristol or Multimedia (18" x 24" or larger)

Materials: ink pen, 3-ply Bristol or Multimedia (18" x 24" or larger)

PORTFOLIO AND SKETCHBOOKS TURNED IN

\section{Artists to Consider}

Luca Cambiaso

Bill Waterson

Edmund Dulac

Janet Fish

Vincent Van Gogh

Jim Dine

Dominique Ingres

Georges Seurat

Henry O. Tanner

Romare Bearden

Jennifer Bartlett

Franz Kline

Henri de Toulouse-Lautrec

Datsushika Hokusai

Giambattista Piranesi
Auguste Rodin

Winsor McKay

Alberto Giacometti

Gwen John

Martin Puryear

Edgar Degas

Kathe Kollwitz

Egon Schiele

Paula Modersohn-Becker

Mary Cassatt

Jack Beal

Pablo Picasso

Henri Matisse

Utagawa Hiroshige
Christopher Wilmarth

George Harriman

Richard Diebenkorn

Paul Cezanne

William Beckmann

Jean Auguste

Rembrandt Van Rijn

Susan Rothenberg

Horst Janssen

Jacques Villon

Maurice Sendak

Wayne Thiebaud

Sylvia Plimack-Mangold

Giorgi Morani

\section{Books for Further Study}

- A Guide to Drawing, Daniel Mendelowitz, Harcourt Brace

- Creative Drawing, Howard Smagula, Brown and Benchmark

- Design Principles and Problems, Paul Selanski, Mary Pat Fisher, Harcourt Brace

- Drawing A Contemporary Approach, Claudi Betti / Teel Sale, Harourt Brace Jovanovich

- Drawing Dimensions, Cynthia Dantzic, Prentice Hall

- Finding Water, Julia Cameron

- On Drawing, Roger Winter, Collegiate Press

- Shaping Space, Paul Zelanski, Mary Pat Fisher, Harcourt Brace

- The Art of Drawing, Bernard Chaet, Holt, Rinehart and Winston

- The Art Spirit, Robert Henri

- The Artist Way, Julia Cameron

- The New Drawing on the Right Side of the Brain, Betty Edwards 


\title{
Teaching Syllabus Three
}

\author{
Model Syllabus 3 - Alaiyo Bradshaw-Parsons School of Design
}

First Year Drawing/Imaging: People

Course Code: PUFY 1030

CRN: 5646 Section: B01

Instructor: Alaiyo Bradshaw

Email:

Blog:

Office Hours: by appointment

Semester: Fall/ 2014

Session: 12:10pm - 5:50pm / Wednesdays

Location: 2 W. 13 Street, Room 701

\section{Course Description:}

This course is an introduction to the way that meaning is constructed and communicated through visual images. Students use a variety of tools, skills, methods and media, to explore the creative process: to translate observations, analyze relationships, communicate visually, organize form, and foster the exploratory process of developing ideas.

Of primary importance is understanding how we respond to the visual world and how we use our unique and personal perceptual, physical and analytical abilities to bring twodimensional works into being. Students explore visual organization and composition, and develop sensitivity to both representational and abstract form.

Projects emphasize perceptual engagement through drawing, photography, digital image creation, and the integration of different forms of media. A sketchbook is used as an integral tool to explore the relationships between these different kinds of investigations.

Discussion, critique and written responses offer opportunities for students to communicate ideas about their projects and those of their classmates and to understand their work in historical and cultural context. The tools and methods in Drawing/Imaging form an introductory platform that Parsons students will build upon in their upper level disciplinary courses. 


\section{Class Description - People:}

The notion of people will be explored through body, objects and space. This will include study of self, each other and those around us. We will delve into meaning and culture through observing, analyzing, conceptualizing, researching and critiquing.

How do our bodies define us? What is the relationship to historical reference? Can people be examined beyond figure studies and anatomy? When are the environment and representational belongings an extension? These and more questions will be addressed by this section, which looks to investigate the notion of people through drawing, painting, photography, Photoshop and Illustrator.

\section{Learning Outcomes}

By the successful completion of this course, students will be able, at an introductory level, to:

1. Demonstrate perceptual and visual awareness through drawing from observation (figures, objects and environments)

2. Demonstrate the application of elements of art and principles of design related to two-dimensional form and their implications on content

3. Demonstrate an engagement with visual and perceptual literacy related to aesthetic phenomena, such as principles of gestalt and color theory

4. Demonstrate an understanding that perception is conditioned by an understanding of context as well as culture as a dynamic system in which meaning is constructed

5. Demonstrate the appropriate and exploratory application of analog and digital tools, media and processes to convey observations and ideas. Tools include raster and vector software applications, wet and dry media and various substrates

6. Demonstrate comprehension of skills and techniques across media with a synthesis of the two; as well as an understanding of the value of craftsmanship and its impact on form and meaning

7. Demonstrate reflection on creative skills learned, choices made, and connections fostered, through the ongoing documentation and archiving of assignments in an online learning portfolio. Students will use the portfolio and a sketchbook to demonstrate an engagement with the idea of making as a form of thinking

8. Course Outline (short outline excerpt from full syllabus. See full syllabus for more details) 


\section{Week Date Activity Homework Due}

Perception and Representation

Week 1 8/27 -Intro/Syllabus/Computer

(Figure Drawing) Gesture, Blind Contour, Memory, Opposite Hand,

Contour Drawing and more

\#1-The Body and Line

1. 5 gesture drawings of friends in sketchbook. Review next assignment and references.

2. Collect 4 objects that tell a story about your personal history. The objects should be three-dimensional and contain complex shapes

3. Bring in digital camera

Due $9 / 3$

Week 2 9/3 (Trip to the Metropolitan Museum)

Museum assignment

Photography techniques

\#2-Self Exploration Through Cultural and Personal Objects (3 part assignment)

1. Use drawing started in class from sketchbook to do most of your Museum

Contour Drawing. Bring in all personal objects, materials and computer to start composition for the next part of the assignment.

2. Photograph and import

3. Due $9 / 10$

Week 3

9/10 Intro to Illustrator Positive/Negative/digital

Museum assignment.

Work from a completely different composition of the same objects used on Contour Drawing. Work with your best Pos/Neg sketchbook drawing photographed and placed in computer.

1. 5 contour drawings of in sketchbook. Review next assignment and Illustrator references.

2. Use Illustrator drawing started in class and complete most of your Museum Pos/Neg Drawing. Bring in all personal objects and computer to start composition for the next part of the assignment. Photo/Import.

3. Due $9 / 17$ 
Week 4 9/17 Illustrator-Value drawing/digital Museum assignment. Work with a completely different composition of same obj. hand drawn, photographed and placed in computer to create the digital part of Value

Drawing.

1. 5 pos/neg drawings of in sketchbook. Review next assignment and Illustrator references.

2. Use illustrator and hand drawing started in class to complete the collaged Value Drawing. Have all three drawings completed for critique.

3. Due $9 / 24$

Week 5 9/24 Desk and formal critique of -Self Exploration through Cultural and Personal Objects (3 part project).

1. Research patterns in black and white from different cultures. Review next assignment and references.

2. Bring in computer.

3. Due $10 / 1$

Week 6 10/1 (Figure Drawing)

Illustrator Complete contour figure drawing of man and costume.

Create patterns in illustrator based on sketchbook finds.

\#3 Pattern Man

1. Finalize Pattern Man drawing combining hand drawn and Illustrator tech.

Review next assignment and references, bring materials.

2. Due $10 / 8$

Analysis of Structure and Representation

Week 7 10/08 (Figure Drawing)

\#4 Structural Head

\#5 Torso anatomy/rendering

1. Anatomy, mass, rendering, chiaroscuro

2. Practice structural figures in your sketchbook.

3. Complete the geometric head study.

4. Due $10 / 15$

Week 8 10/15 (Trip to the NYPL or WSP)

\#6 Perspective Drawing

Make large sized drawings and sketches. Photograph.

1. Sketchbook thumbnails

2. Complete the contour drawing for review.

3. Due $10 / 22$ 


\section{Course Structure of Drawing/Imaging: People}

There is a three-part structure to this class over the course of a fifteen week semester. PLEASE NOTE: ANYTHING IN THE ABOVE OUTLINE AND THE OVERALL SYLLABUS IS SUBJECT TO CHANGE.

You will be notified via the blog, in class and by email.

Week 9 10/22

1 and 2 point perspective exercises.

1. Sketchbook-1pt and $2 \mathrm{pt}$, and foreshortened figure.

2. Complete line or rendered perspective drawing

3. Due $10 / 29$

Week 10 10/29 Desk and formal critique of Perspective project (Foreshortened figure study)

2. Five sketchbook drawings

Due $11 / 5$

Week 11 11/5 (Still-Life Drawing/Painting) Intro to Photoshop

\#7 Edible Object - color (painting/drawing)

1. Sketchbook compositions

2. Complete color drawings and Photoshop portions not completed in class.

3. Form groups for next project trip to Natural History and Proposal Due 11/12

4. Context and Representation

Week 12 (outside)

$11 / 12$ (Trip-Natural History Museum on your own)

\#8 Instructional Booklet-(Draw and Photograph) from trip. Photoshop/Illustrator

Working in class,

1. Sketchbook thumbnails. Bring to class for submission.

2. Proposal

3. Meet with group to start.

Gather all materials for class.

Due $11 / 19$

Week 13 11/19 Work in groups

Bookmaking and mixed media. ... Continue Natural History informational booklet.

Turn in sketchbooks for competition

1. Meet with group to finalize project. Gather all materials for class to finalize and present project

(No homework over the break) 
Due $12 / 3$

Week 14 12/3 Completion, desk and formal critique of Information booklet project

2. Work from images in sketchbook to create a small self-portrait combining any materials.

3. Due $12 / 10$

Week 15 12/10 Formal Critique and Party!

\#9 Self-Portrait

Enjoy your break!!!

(Part 1) Perception and Representation (Weeks 1-6)

Visualizing three-dimensional reality into a two dimensional form

During the first part of the semester students explore the elements and principles of art and design in the context of visual perception and representation. Focusing on the cognitive process as it pertains to image making, students consider awareness, perception, reasoning, and judgment. The concept of visualizing three-dimensional reality into a two dimensional form is discussed, demonstrated and practiced.

Week 1 (August 27)

Assignment 1 (The Body and Line: Gesture and Contour from the model)

Basic Gestalt Elements of Design and Composition

a. Gesture drawing

(Opposite hand, skeletal, memory, group, continual line)

Capturing the action of the subject (Class warm up exercises)

Grasping "the whole" movement by scribbling

Attention to the use of the page; Composition, ${ }^{* *}$ ORIENTATION/DIRECTION,

PROXIMITY

b. Blind Contour Drawing

c. Contour

Materials: Newsprint, graphite, charcoal pencils

Weeks 2-5 (September 3-September 24)

Assignment $2-(3$ weeks $)$

(Trip to the Metropolitan Museum - Self-Exploration Through Cultural and Personal Objects)

(Contour, Positive Negative, Tonal Value)

Record a three-dimensional object or figurative sculpture in sketchbook from the area of the Museum relating most closely to personal cultural background. Combine Museum object with four personal objects brought from home into three different compositions considering and solving each design problem. All objects should tell a personal story. 
Week 2 -Assignment 2 (September 2)

a. Line and shapes in two-dimensional space incorporate precise contour, line weight and play with scale, proportion and repetition (complete the first of three images) Seeing Organizing, **SCALE, NUMBER, ALTERATION, REPETITION, PROPORTION, AXIS, FOCAL POINT, CLOSURE

Drawing with Accuracy

Digital Tools: Digital Photography: image quality, size, image formats

Week 3 -Assignment 2 (September 10)

b. Intro to Adobe Illustrator Relationships between Positive and Negative Shapes (use same objects in a different composition)

- Void and Mass

- Space and Volume

- Empty and Full

- Black and White, ** DIRECTION, RHYTHM, CONTRAST, BALANCE, SYMMETRY, CONTINUOUS

Week 4 -Assignment 2 (September 17)

c. Introduction to Value (complete the last image of the triptych for presentation)

- Value as Space, ** DOMINANCE, FOCAL POINT, CONTRAST, RHYTHM

- Simplifying Shape

- Value Reduction

- Figure Ground Relationships

- Photography

Materials: Ink, Bristol board, collage, charcoal, Adobe Illustrator

Week 5-Assignment 2 (September 24)

Fine tune three-part assignment. Desk and formal critique.

Photography technique for archiving work and reference

Materials: Sharpies, ink, collage, Bristol board, drawing paper, Adobe Illustrator, digital camera

Week 6 -Assignment 3 (October 1)

(Mark Making and Pattern Man - Model in Costume)

Mark making; expressive possibilities of line and shape. Employ unique mark making techniques chosen from cultural backgrounds, half hand drawn in ink / half digitally rendered in Illustrator applied to figure drawing of model in costume completed in class. 
Examples shown in class:

a. Expressive and Calligraphic-DeKooning and Chinese calligraphy

b. Visual Texture-Roussel

c. Value-Kollwitz

d. Decorative Strokes-Matisse

e. Turbulent, Swirling-Van Gogh

f. Scanning work for digital usage

Materials: Sharpies, Bristol board, collage, Adobe Illustrator

Digital Tools (weeks 3-6): Printing and Scanning Guidelines, Illustrator

Fundamentals Tutorial: preferences, new document, page set-up, menus, shape tools, selection tools, rotation, reflect, cut, copy, paste and transform again, grid, guides and snap to guides, using the shift key to constrain, selections, selecting multiple objects, align palette, fill and stroke, pathfinder palette, navigation: hand tool and navigation palette, zoom: zoom tool and other options. Placing images as templates, drawing with the pen tool, clicking and dragging technique, anchor points and Bezier handles, open and closed paths, ellipse and polygon tools, creating, duplicating, moving, deleting and merging layers. Placing images (as template), pen tool, rotate and scale tools, blend tool, layers palette, pathfinder palette, brush tool.

(Part 2) Analysis of Structure and Representation (Weeks 7-12)

\section{Conventions of Imaging}

In this section, students' build upon their perceptual skills and understanding of gestalt theory, engaging the mind in the process of understanding structure and representation. Students utilize different analytical methods to explore conventions of representation and imaging including the use of drawing systems and geometry, cultural conventions of spatial representation, color perception, framing of images and point of view.

Week 7-Assignment 4 (October 8)

(Geometric Drawing Conventions and the Head)

a. The head is inscribed into simple geometric forms or "blocks"

b. Actual form is achieved by a subtractive "carving" of the block, or additive construction

c. Drawing of block formation

Assignment 5

(Study of the pelvis and ribcage)

a. Introduction to Anatomy: Foundations of the human structure

b. Description the major masses of the figure, rib cage, and pelvis 
c. Discover underlying compositional structures both from observation and from examples within the art of diverse world cultures.

d. Conventions of the Human Figure, in art history, and in design

e. Drawing from figurative sculpture

(Chiaroscuro and the Figure)

a. Conveying light

b. Rendering Shade and Shadow

c. Tonal Range

d. Drapery mapping

Materials: White or color paper, charcoal or single hue chalk, mid-toned paper, white chalk

Weeks 8-10 (October 15-October 29)

Assignment 6-(2 weeks)

(Trip to NYPL or WSP) - Conventions \& Variation in Cultural Perspective

Representation

Week 8-Assignment 6 (October 15)

a. Introduction to 1 and 2 point perspective (viewer based)

b. Construction of planes and volumes in relation to horizon line and vanishing points Construction of ellipses

Week 9 -Assignment 6 (October 22)

c. Complex Interior; Interfacing the knowledge and experience of visual perception and the figure in perspective (foreshortening).

Week10-Assignment 6 (October 29)

Fine tune assignment. Desk and formal critique.

Materials: Graphite, ink, collage, Bristol board, drawing paper

Weeks 11 (November 11)

Assignment 7

(Edible Object-Relationship to the Body)

(Perception, Analysis and Critical Thinking)

Students choose their own type of fruit or vegetable from a variety and recreate it in color pencil. Students paint a hand in watercolor. Students draw/paint the objects through visual perception, analytical construction, and interpretation of color mixing and theory. Observe the differences in personal interpretation. Each of the senses is experienced, questioned and discussed. 
Students take color images in three dimensional form and use scans and Photoshop tools and techniques to create an image based people, places and things narrative formed around the painted and drawn objects.

a. Still-life Observational Drawing

b. Single Frame Narrative Interpretations

c. Limited Color Studies (Triad/primaries)

d. Perceptual Observation through Sight, Touch, Smell and Taste

Materials: color pencil, watercolor, scanner, Adobe Photoshop

Digital Tools: Photoshop Fundamentals Tutorial: scanning, image mode, size and resolution, crop and transformation tools, file formats, selection tools, image adjustment layers: brightness/contrast, transparency, layers, masks and more.

Use of high res internet searches and image capture.

(Part 3) Context and Representation (Weeks 12-15)

Meaning and Culture

Students further explore representation and meaning in relationship to context and cultural influences, responding thoughtfully and creatively through the application and transformation of the tools of drawing and imaging. Contextual examples for students to explore may include: Personal / Interpersonal, Cultural, Economic, Historical, Philosophical, Religious, Scientific, Political, Social, etc.

Weeks 12-14

Assignment 8-(3 weeks November 12-December 3)

(Trip to the Natural History Museum (on your own) - Instructional Booklet)

Choose group members. Pull from drawings, photos and other reference of the Natural History Museum.

Use research to investigate the cultural background and other meaning of your chosen section of the museum. Complete and submit the required proposal. Project objectives: Target a specific audience, (children, your piers, visitor to the Museum, etc.) and produce an eight-page booklet. Consider audience, instruction, format, and equal participation from the group. Meet with your group outside of class.

Week 12 -Assignment 8 (November 12)

a. Working in Groups

b. Digital Output 
c. Digital Photography

d. Researching

e. Writing a Proposal

f. Time Management

g. Book Layout

h. Text and Image

i. Mixed Media

j. Adobe Photoshop

k. Adobe Illustrator

1. Adobe InDesign

Week 13-Assignment 8 (November 19)

\section{Book Making Workshop}

Materials: book making and chosen mixed media, Adobe Photoshop, Illustrator, InDesign, camera

Digital Tools: Photoshop-Selecting: marquee tool, quick selection tool, pen tool, editing paths, saving paths, loading paths as selections, saving and loading selections, select all, select none, inverse, expand and contract, cropping, flipping and rotating selections; selecting an entire layer; feathering, adding, subtracting, transforming and modifying selections; layer masks; quick mask to edit selections. Layers: creating and deleting a layer; duplicate, hide or show layer; turning a layer into a selection; creating a background and converting a background into a layer; restacking layers.

Illustrator and Photoshop cross platform techniques.) What works best in each program. Introduction to type.

Week 14 -Assignment 8 (December 3)

Fine tune assignment. Desk and formal critique.

Week 15 (December 10)

Assignment 9

(Self-Portrait through Dream or Imagination)

Research Historical, Philosophical, Religious, Scientific, Political or Social concepts. Exploring the inner and outer self. Use your journal sketchbook images. Define them. Use any chosen medium. 


\section{THE SKETCHBOOK:}

The sketchbook will be reviewed weekly, so value its importance. It is a place to develop a way of working. Think about the intended appearance. There should be richness in the overall book. Use it to record notes and within the notes incorporate visual notes such as doodles and diagrams. It is a place to develop ideas such as thumbnails, gather research, draw from observation, record thoughts and inspirations, keep notes, handouts, vocabulary from classes and develop your voice. The sketchbook will also be an important part of presentations for critiques. (see blog for more)

There will be a sketchbook competition and exhibition nearer to the end of November until the first week in December.

\section{Grading and Evaluation}

Students' ability to meet the course's learning outcomes will be evaluated based on the following criteria:

- Evidence of the ability to solve problems, both creative and technical;

- Evidence of the understanding of the project assignments and course material;

- The correct use of materials and formats specified;

- Quality of work as evidenced in in-class exercises, final projects, sketchbook exploration and the learning portfolio;

- Participation in class and online;

- Improvement in technical, creative, and problem solving abilities;

- Attendance in class and the timely completion of projects.

\section{Final Grade Calculation}

10\% Sketchbook/Learning Portfolio

$10 \%$ Improvement/Participation

10\% Quality/Presentation

$10 \%$ Preparedness/Process Work/Digital Storage

$25 \%$ In-Class Projects

$15 \%$ Long-term projects

$15 \%$ Final

5\% Attendance

$100 \%$ TOTAL

\section{Reduced Project Grades for:}

- Not handing in projects on time (before midnight on the same day will be accepted)

- Not coming prepared to class with materials, handouts, review of the blog

- Incomplete projects at required level 
- Sleeping or texting during class

- MISSING TWO CLASSES

- Not participating in group projects, discussions and critiques

- ABSENT ON THE DAY OF A CRITIQUE

See more descriptive Grading Criteria on blog:

Log on Canvas to find the Course Blog

\section{Grading Standards}

A $[4.0 ; 96-100 \%]$

Work of exceptional quality, which often goes beyond the stated goals of the course

A- [3.7; $91-95 \%]$

Work of very high quality

$\mathrm{B}+[3.3 ; 86-90 \%]$

Work of high quality that indicates substantially higher than average abilities

B $[3.0 ; 81-85 \%]$

Very good work that satisfies the goals of the course

B- $[2.7 ; 76-80 \%]$

Good work

$\mathrm{C}+[2.3 ; 71-75 \%]$

Above-average work

C $[2.0 ; 66-70 \%]$

Average work that indicates an understanding of the course material; passable

Satisfactory completion of a course is considered to be a grade of $\mathrm{C}$ or higher.

C- $[1.7 ; 61-65 \%]$ Passing work but below good academic standing

$\mathrm{D}[1.0 ; 46-60 \%]$

Below-average work that indicates a student does not fully understand the assignments;

Probation level though passing for credit

F $[0.0 ; 0-45 \%]$

Failure, no credit

Grade of W

The grade of W may be issued by the Office of the Registrar to a student who officially withdraws from a course within the applicable deadline. There is no academic penalty, but the grade will appear on the student transcript. A grade of W may also be issued by an instructor to a graduate student (except at Parsons and Mannes) who has not completed course requirements nor arranged for an Incomplete. 


\section{Grade of WF}

The grade of WF is issued by an instructor to a student (all undergraduates and all graduate students) who has not attended or not completed all required work in a course but did not officially withdraw before the withdrawal deadline.

It differs from an "F," which would indicate that the student technically completed requirements but that the level of work did not qualify for a passing grade. The WF is equivalent to an $\mathrm{F}$ in calculating the grade point average (zero grade points), and no credit is awarded.

\section{Grades of Incomplete}

The grade of I, or temporary incomplete, may be granted to a student under unusual and extenuating circumstances, such as when the student's academic life is interrupted by a medical or personal emergency. This mark is not given automatically but only upon the student's request and at the discretion of the instructor. A Request for Incomplete form must be completed and signed by student and instructor. The time allowed for completion of the work and removal of the "I" mark will be set by the instructor with the following limitations:

Undergraduate students: Work must be completed no later than the seventh week of the following fall semester for spring or summer term incompletes and no later than the seventh week of the following spring semester for fall term incompletes. Grades of "I" not revised in the prescribed time will be recorded as a final grade of "WF" by the Office of the Registrar.

\section{Divisional, Program and Class Policies}

- Responsibility

Students are responsible for all assignments, even if they are absent. Late assignments, failure to complete the assignments for class discussion and/or critique, and lack of preparedness for in-class discussions, presentations and/or critiques will jeopardize your successful completion of this course.

\section{- Participation}

Class participation is an essential part of class and includes: keeping up with reading, assignments, projects, contributing meaningfully to class discussions, active participation in group work, and coming to class regularly and on time. 
- Attendance

Faculty members may fail any student who is absent for a significant portion of class time. A significant portion of class time is defined as three absences for classes that meet once per week and four absences for classes that meet two or more times per week. During intensive summer sessions a significant portion of class time is defined as two absences. Lateness or early departure from class may also translate into one full absence.

\section{- Canvas}

Use of Canvas is an important resource for this class. Students should check it for the course blog, grades and announcements before coming to class each week.

\section{- Delays}

In rare instances, I may be delayed arriving to class. If I have not arrived by the time class is scheduled to start, you must wait a minimum of thirty minutes for my arrival. In the event that I will miss class entirely, a sign will be posted at the classroom indicating your assignment for the next class meeting

\section{- Academic Integrity}

This is the university's Statement on Academic Integrity: "Plagiarism and cheating of any kind in the course of academic work will not be tolerated. Academic honesty includes accurate use of quotations, as well as appropriate and explicit citation of sources in instances of paraphrasing and describing ideas, or reporting on research findings or any aspect of the work of others (including that of instructors and other students). These standards of academic honesty and citation of sources apply to all forms of academic work (examinations, essays, theses, computer work, art and design work, oral presentations, and other projects)."

It is the responsibility of students to learn the procedures specific to their discipline for correctly and appropriately differentiating their own work from that of others. Compromising your academic integrity may lead to serious consequences, including (but not limited to) one or more of the following: failure of the assignment, failure of the course, academic warning, disciplinary probation, suspension from the university, or dismissal from the university.

Every student at Parsons signs an Academic Integrity Statement as a part of the registration process. Thus, you are held responsible for being familiar with, understanding, adhering to and upholding the spirit and standards of academic integrity as set forth by the Parsons Student Handbook. 


\section{Guidelines for Written Assignments}

Plagiarism is the use of another person's words or ideas in any academic work using books, journals, internet postings, or other student papers without proper acknowledgment. For further information on proper acknowledgment and plagiarism, including expectations for paraphrasing source material and proper forms of citation in research and writing, students should consult the Chicago Manual of Style (cf. Turabian, 6th edition). The University Writing Center also provides useful on-line resources to help students understand and avoid plagiarism.

Students must receive prior permission from instructors to submit the same or substantially overlapping material for two different assignments. Submission of the same work for two assignments without the prior permission of instructors is plagiarism.

\section{Guidelines for Studio Assignments}

Work from other visual sources may be imitated or incorporated into studio work if the fact of imitation or incorporation and the identity of the original source are properly acknowledged. There must be no intent to deceive; the work must make clear that it emulates or comments on the source as a source. Referencing a style or concept in otherwise original work does not constitute plagiarism. The originality of studio work that presents itself as "in the manner of" or as playing with "variations on" a particular source should be evaluated by the individual faculty member in the context of a critique. Incorporating ready-made materials into studio work as in a collage, synthesized photograph or paste-up is not plagiarism in the educational context. In the commercial world, however, such appropriation is prohibited by copyright laws and may result in legal consequences.

- Student Disability Services

In keeping with the University's policy of providing equal access for students with disabilities, any student with a disability who needs academic accommodations is welcome to meet with me privately. All conversations will be kept confidential.

Students requesting any accommodations will also need to meet with Jason Luchs in the office of Student Disability Services, who will conduct an intake, and if appropriate, provide an academic accommodation notification letter to you to bring to me. At that point I will review the letter with you and discuss these accommodations in relation to this course. 


\section{Books}

- Fill in the Blank by ViiZ and Doggie Horner (Quirk Productions Inc., 2012)

- Charles Bargue Drawing Course by Gerald M. Ackerman (ARC Edition International, 2003)

- Keys to Drawing by Bert Dodson (North Light Books, 1985)

- Drawing for Graphic Design by Timothy Samara (Rockport Publishers, 2012)

- Design Drawing by Francis D.K. Ching (John Wiley \& Sons, 1998)

- Perspective Drawing Handbook by Joseph D’Amelio (Dover, 1964)

- Constructive Anatomy by George B. Bridgman (Digireads, 2009)

- The Natural Way to Draw by Kimon Nicolaides (Mariner Books, 1990

- Graphic Design Manual by Armin Hofmann (Reinhold, 1965)

- The Visual Display of Quantitative Information by Edward Tufte

- (Graphics Press, 1983)

- Envisioning Information by Edward Tufte (Graphics Press, 1990)

- Color Basics by Stephen Pentak and Richard Roth (Wadsworth, 2004)

- The Art of Color by Johannes Itten (Van Nostrand Reinhold, 1961)

- Color and Meaning by John Cage (University of Californis Press 2000)

- Interaction of Color by Josef Albers (Yale University Press, 1963) (now an app for the iPad: see

- www.wired.com/design/2013/08/josef-albers- classic-interaction-of-color-gets-a-21stcentury-upgrade

- Drawing Distinctions by Patrick Maynard (Cornell University Press, 2005)

\section{Art supply stores}

- (Remember to take you New school ID for student discount.)

- Utrecht/Blick Art \& Drafting Supplies, 21 East 13th St. (just east of Fifth Ave.), 650 Sixth Ave. (btw 19th and 20th Sts.),1

- Bond St. (east of Broadway)

- Da Vinci, 137 East 23rd and 132 West 21st St.

- NY Central Art Supply, 62 Third Ave near 11th St. (great paper supply!)

- Downtown Stationers (close by in a pinch), Sixth Ave. btw. 12th \& 13th Sts.

- East Side Copy Shop, 15 East 13th St.

- Village Copier (opposite East Side Copy on 13th St.)

- M\&J Trimming, 1000 Sixth Ave. (btw. 37th \& 38th Sts.)

- A.I. Friedman, 44 West 18th St. (graphic arts supplies)

- Paper Presentation, 23 West 18th St. (specialty papers, envelopes) 
- Tekserve, 119 West 23rd St. (btw. Sixth \& Seventh Aves. - good technical resource for hard drive crashes, etc.)

Required Materials (First-Year Materials List)

- Pencils, Pens and Erasers

- Prismacolor Kneaded Rubber Erasers 13/4" × 11/4" × 1/4"

- Staedtler Mars Plastic Eraser

- Helix Hand-Held Pencil Sharpener Sharpener with 2 holes

- General's Kimberly Drawing Pencils Black 6B

- General's Kimberly Drawing Pencils Black 2B

- General's Kimberly Drawing Pencils Black HB

- General's Kimberly Drawing Pencils Black F

- General's Kimberly Drawing Pencils Black 2H

- General's Kimberly Drawing Pencils Black $4 \mathrm{H}$

- Conté Crayons Sanguine Medici, package of 2

- Cretacolor Monolith Woodless Pencil Graphite pencil 9B

- Winsor \& Newton Vine Charcoal Packs Medium, package of 12 sticks

- General's compressed charcoal 4 sticks

- Sharpie Ultra-Fine Point Marker Black, $0.3 \mathrm{~mm}$

- Sharpie Fine Point Marker Black, 0.5mm

- Super Sharpie Marker Black

- Sharpie Chisel Tip Marker Black

- Prismacolor Ebony Pencil Package of 2

Paper and Pads

- 4 Crescent No. 99 University Grade Cold Press Illustration Board White, 15" × $20 "$, 14-ply (\$2.04 each)

- Canson 180 Degree Hardbound Sketchbooks 80 sheets, 65lb, 8.3" × 11.7"

- Strathmore 400 Series Bristol Board Pads 15 sheets, 11" $\times 14$ ", 2-ply vellum

- Strathmore 300 Series Drawing pad 25 sheets, 18" × 24"

- Strathmore 300 Series Newsprint Pads Off white, 120 sheets, 18 " $\times 24$ ", rough

- Speedball Tracing Paper In Rolls White, 8lb, 18" × 20yd

- Assorted Supplies

- Alumicutter Ruler Black, 18"

- Blick Acrylic Edge T-Square 24"

- Blick Triangles $30^{\circ} / 60^{\circ}, 10^{\prime \prime}$

- Alvin Cutting Mats Green/Black, 12" × 18" 
- Fiskars Recycled Scissors 8" straight

- Olfa Snap-Off Blade Utility Knife

- Olfa SNAPit 'N' TRAPit Pro Heavy-Duty Snap-Off Blades $18 \mathrm{~mm}$, package of 5

- Elmer's Glue Sticks 0.21 oz glue stick

- 2 Acco Binder Clips (2) Large, 2"

- Alvin Semicircular Protractor 6"

- ArtBin Tote Folios Black/Charcoal, 23" × 27"

- Laptop

- Adobe Cloud installed

- $\mathrm{GHz}$ quad-core processor

- 64-bit operating system: Mac OS X 10.7 or Microsoft Windows 7 Professional

- 8 GB RAM

- $500 \mathrm{~GB}$ hard drive or flash storage

- Graphics: GPU card with 1 GB of VRAM

- Ethernet, wireless, and Bluetooth connectivity

- Integrated HD webcam

- Media card reader

- Digital Storage for Backup of Files

- External Hard Drive - Suggested: LaCie 500GB Rugged Triple Interface 


\section{Appendix C}

\section{Developing a Multi-Modular Design Exercise Based on the Identification of Visual Features}

The following exercise shows how the identification of visual features can assist in solutions to a specific visual design problem while also meeting teaching goals and objectives:

- The demonstration of application of elements of art and principles of design related to two-dimensional form;

- The demonstration of skills and techniques; and

- The demonstration of perceptual and visual awareness.

The exercise illustrates a flexible system of visual tasks that the student could develop as a part of their own design practice. It supports a practice of design ideation based on visual tasks that can systematically guide human studies (Stiny, 2008; Taylor, Berry, \& Block, 1958). Another important learning outcome and objective of this exercise is the articulation of a set of strategies the student could use beyond the scope of this particular project.

The exercise because of its many expectations and facets of different types of inquiry and actions needed will be built in modules. Each module builds upon the past module with a flexible amount of idea generation, evaluation and visual tasks. It will not be necessary to divulge all the information involving all the modules to the student at one time and overwhelm them but rather go in a step-by-step fashion and upon full completion they will be able to discuss and perceive the entire process, and how each piece fits into that process. 


\section{Module One: Line \& Word Pairings}

The first module is a very simple exercise that needs a little preparation and is a word game of sorts. The idea is select ten words, preferably words that elicit quick spontaneous responses without much thought; there is a variety of psychology literature to help with this if needed (Bradley \& Lang, 1994; Osgood, 1952; Saffran et al., 2003). For this example, I will use these ten words: tree, crowd, alone, happy, sad, angry, mountain, sunny, man, and woman.

At the beginning of class hand out 10 small sheets of paper no larger than 4 inches by 4 inches to every student. Instruct them to write one of the preselected words on one side of each paper and then ask them to flip the paper over. They will then be given 10 seconds to draw whatever comes into their mind that they associate with that word. No more than 10 seconds—you want quick spontaneous responses.

So for example if the word is angry. Tell them the word and have them write it on one side of the piece of paper. Instruct them to turn the small square of paper over. They now have ten seconds to draw what they feel are angry marks or make an

very fast angry drawing. When the ten second limit is reached tell them to stop. You do not want any evaluation of marks made at this stage. There is no right or wrong way to draw.

Repeat this process until all ten words and all ten pieces of paper are used. Afterwards you can discuss students' perceptions of each word and students themselves can evaluate what types of marks they made. They can share their small drawings with each other so they can see different perceptions.

\section{Module Two: Line \& Word Pairings}

Each student then needs to research and find one artist's drawing that they think represents each of the words and examine the types of marks made in each drawing. Determinations need to be made as to what types of visual features are 
present and their interactions within the picture plane. Ask them to create studies based on small sections of the images that capture various feature interactions. They are to keep everything--the ten quick drawings, copies of the ten artists' drawings found, and their own studies in their sketchbooks for later reference.

\section{Module Three: The Creation of 30 Analogs}

This module involves each student closely examining and evaluating the ten quick drawings or doodles created in the first step to find design possibilities that can be built upon. They can also reference the studies they made from their examinations of the artists' drawings for possible solutions. They are to create three different possible design solutions for each of the initial ten quick doodles. These small designs are to be done on illustration board or Bristol board—a drawing surface of quality. They are to be done on a grid in squares again no larger than 3 inches by three inches. They can use ink, pencil, crayon—no color just black, white and grey tones. Encourage experimentation within each set of solutions—-positive/negative space, thick lines, thin lines, cross hatching, stippling, etc. Even though every student is working from the same initial ten words the diversity of solutions will be built upon each student's own perceptions (Figure 1). 


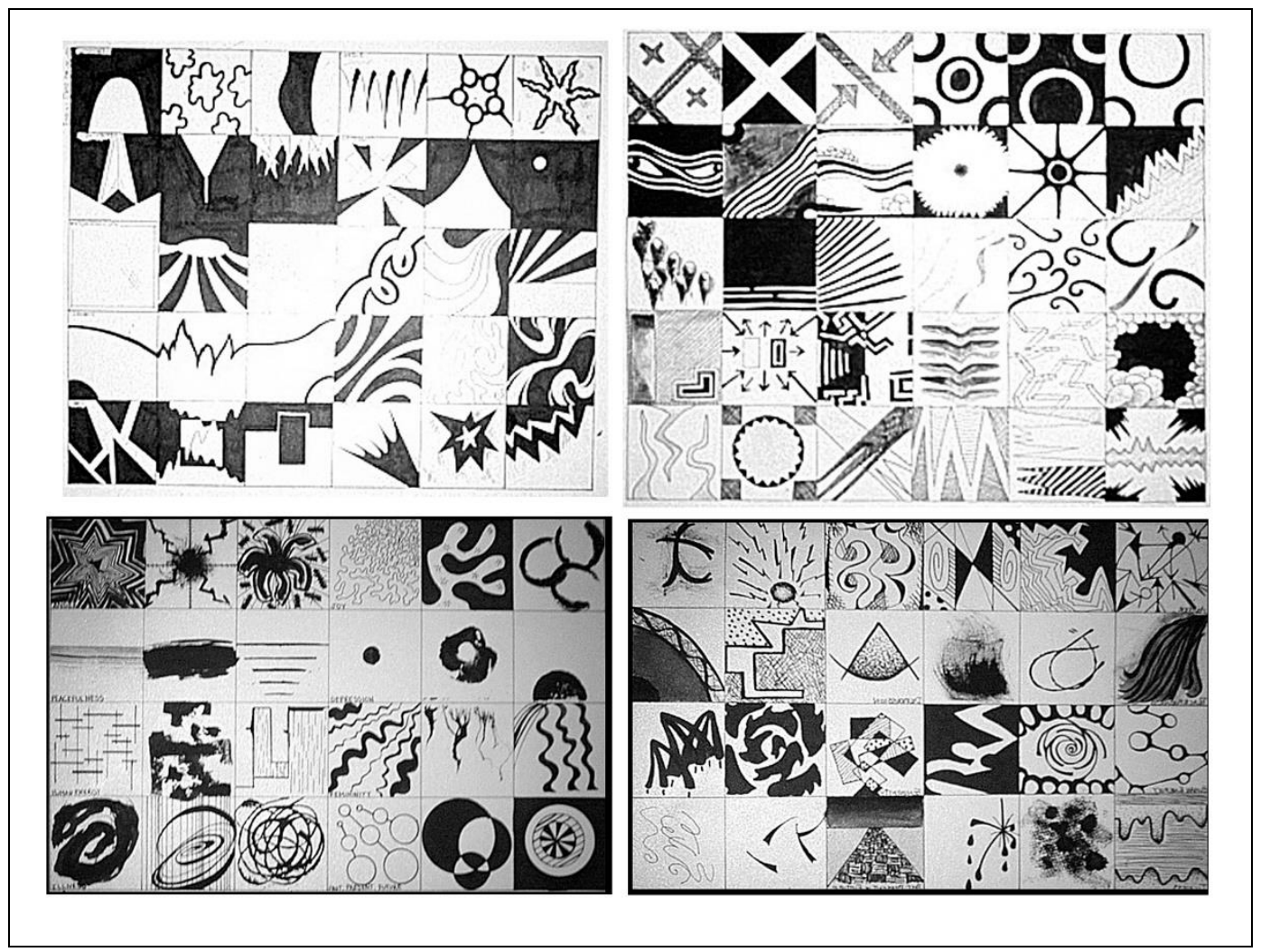

Figure 1: Visual samples of analogs created from step three of the design exercise.

When students present their final analogs a discussion of different perceptions and attitudes expressed is encouraged. Evaluations can be made as to which types of marks evoke particular feelings. Which images seem balanced? Which images seem pleasant? What types of marks promote anxiety? What types of marks are calming?

\section{Module Four: The Selection of Characters}

The next module again involves examination and a selection process of five designs from the thirty analogs that will be refined and turned into characters. These refined designed characters can be done in the students' sketchbooks. Each character will have a part to play in the next step of the design project. For ease of explanation, let us name each character A, B, C, D and E. The part each character plays involves a 
design concept: transformation, scale, line/implied line and pattern based on a rhythmic repetition.

The identification of specific visual features will assist students with the task of determining how each character might display each of the design concepts and how that display links back to a visual feature or combinations of visual features. From the list of words used in the first module we have the word "woman" and a drawing was to be researched from an image data base and chosen by the student that they perceived as the perfect union between the word and imagery.

Examining the image for visual definitions of the design concepts, they can select specimen areas from which they can borrow for the purpose of developing a visual display of the concepts as outlined in this part of the exercise-transformation, scale, line/implied line and pattern based on a rhythmic repetition (Figure 2). Once an area of interest is extracted, other types of examination can be done. Some of these examinations can be based on purely visual comparisons. Others can include comparisons of measures for each specimen collected to specimens created by the student. 


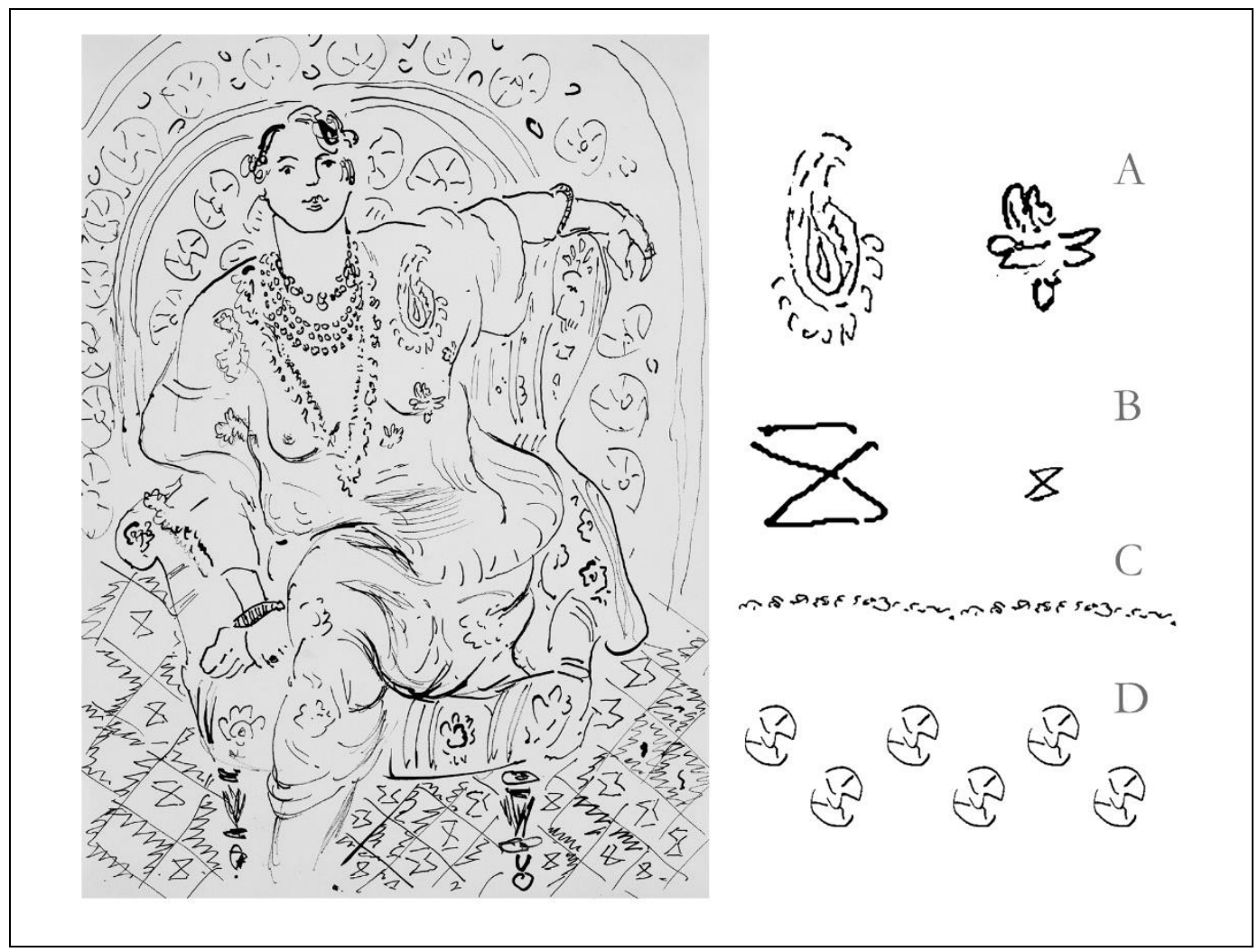

Figure 2: Initial visual sampling taken from the image for each concept-A. Transformation, B. Scale, C \& D. Linelimplied line, and Pattern.

Henri Matisse. (1925-26), Odalisque with Flowery Background, (pen and India ink on paper). Private Collection, Photo (C) Christie's Images, Bridgeman Images.

\section{Module Five: The Storyboard}

The overview of this step takes the most basic elements in design, line and shape and experiments with several of the principles by which we tend to organize them: variables of length, width, placement, plus repetition, rhythm, motif, texture, figure/ground, positive/negative relationships, concepts of transformation, and even narrative. The five characters developed from module four will be repeated and will interact throughout the creation of 6 panels, $6 \times 6$ inches each, which will connect in sequence 36 inches long, with continuity from one square to the next, and with some variation within specified arrangements and transformations. 


\section{Character Concepts:}

Transformation — one character will mutate and be significantly transformed by the

final panel, perhaps evolving into its opposite-parts may expand, parts may be repeated, overlap or be turned inside out.

Scale-one character will maintain its identity but change size/scale

Motif One: Line/Implied Line_-one character will maintain its identity and remain the same size, can be repeated more than once per panel, but moves in and out of the narrative panel format

Motif Two: Texture/Pattern Rhythm—one character is introduced and multiplies in a rhythmic repetition, used once in panel 3, twice in panel 4, four times in panel five, and either two or four times in panel 6 (the repetition can vary with each individual storyboard)

\section{Overall Transformation \& Narrative Concepts:}

In general, there is continuity, the image flows from one panel to the next. The characters move and or rotate. All the characters should overlap or exit the edge of the panel at least once. Students should be encouraged to experiment with making one or more panels become negative.

\section{Panel One:}

Introduce character A, B and C. One or two characters are fully contained in the format; one or two are cropped to the next panel or off one of the edges. Experiment with how the characters interact with edges. 


\section{Panel Two:}

Character A begins to mutate in character E. Character B becomes larger by at least $50 \%$ and will continue to change scale by $50 \%$ with each progressive panel. Character C moves and continues to move throughout the rest of the panels.

\section{Panel Three:}

Character A continues to mutate in character E. Character B continues to expand possibly taking up $1 / 3$ of panel 3 and $1 / 3$ of panel 4 . Character $C$ continues to move throughout the rest of the panels. Introduction of character D.

\section{Panel Four:}

Character A continues to mutate in character E. Character B can slide out of view and or reverse scale change. Character $\mathrm{C}$ continues to move throughout the rest of the panels. Character D begins to repeat-twice in this panel.

\section{Panel Five:}

Character A continues to mutate in character E, nearing completion of transformation. Character B continues scale change. Character $\mathrm{C}$ continues to move throughout the rest of the panels. Character D repeats_-four times in this panel.

\section{Panel Six:}

Character A completes transformation into character E. Character B finished scaling. Character C continues to move throughout the panel. Character D repeats-either twice or eight times in this panel.

Each storyboard will be unique to each student, based on the choices they made throughout the process from the marks they made, the artists' works they chose to examine for borrowing to the refined characters they developed and how they interpreted the instructions for each panel (Figure 3). 


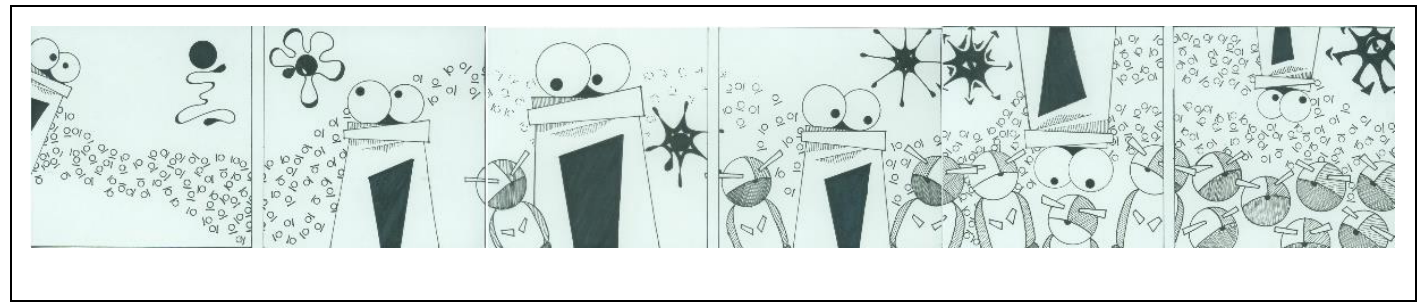

Figure 3: Sample storyboard interpretation.

\section{Module Six Analysis and Evaluation}

There are different types of analysis, examination and evaluation that can occur at this phase of the project. The first type of analysis and evaluation deals with visual tasks which each student should address. This can be done with specific examination of each panel of the storyboard and can include comparing one visual feature to another as well as interactions between features. Students need to be able to link the visual tasks which should be broken down systematically so that direct links are made qualitatively. These can be used to make further stylistic changes to a second version of the storyboard. The visual tasks should relate to the underlying design principles, which can be clearly discussed at this point for each panel:

- Panel One-Deals with asymmetrical balance, unity by placement, and open form vs. closed form

- Panel Two-Deals with scale change, transformation, and directional movement

- Panel Three-Deals with unity and variety, spatial considerations of positive/negative space, figure/ground activation, focal point

- Panel Four-Deals with scale change, transformation, and directional movement

- Panel Five-Deals with continuity

- Panel Six-Deals with resolution 


\section{Learning Outcomes of the Storyboard Project}

The many steps of this project illustrates the need for a broad overview to fully grasp an appreciation of what is involved in a creative ideation process. Reviewing all the tasks and processes involved students should have a clearer idea of what a creative ideation process should look like, as well as an appreciation for time management.

Students would not necessarily use every step of this project in a real world scenario but it presents a flow that is easily repeatable and capable of modification to almost any creative ideation process through to a finished project. The project illustrates where divergent reasoning process could be applied with successful outcomes. It also demonstrates points where evaluation should be held to a minimum to allow for exploration to develop ideas. The full project illustrates the importance of a spectrum of formats for communication that directly assisted with visual reasoning in the overall design process. 


\section{Appendix D}

\section{Correspondence Bridgeman Images}

Dear Jennie,

My sincere apology for the delay in replying to your email.

Please go ahead and use all of these 20 images in your dissertation. The usage is fine and covered by your subscription to Bridgeman Education.

Let me know if you have any further questions.

All the best,

Kerstin

Hello Kerstin,

As promised below is a list of the images (image IDs) I am requesting permission to us in my dissertation.

MAA388942, CH99237, LEF221009, CH401798, XIR56652, LEF221005, XIR242720, STM620885, JKL66605, GHA62377, CH398597, CH995409, CH990542, CH986911, LSR383118, CH497515, CH990726, NUL117816, SD873784, CH656467

If there are any issues using any of these images please let me know. Again, thank you so much for your help.

Best Regards,

Jennie Sweo :)

From: Kerstin Anschuetz

Sent: Thursday, May 12, 2016 11:08 PM

To: Jennie Sweo

Subject: Re: A Couple of Questions and Assistance

Dear Jennie,

We have received your payment for the renewal of you subscription, many thanks.

Your new subscription will expire on the 30th of May 2017.

Best regards,

Kerstin 


\section{Appendix E}

\section{Additional MDS Plots Card Sort One}

A1.1 Goodness of Fit of the data for analysis in the MDS Free Card Sort, the Art Expert Group, a 45degree angle indicates the linearity of the data and visually supports the Goodness of Fit.

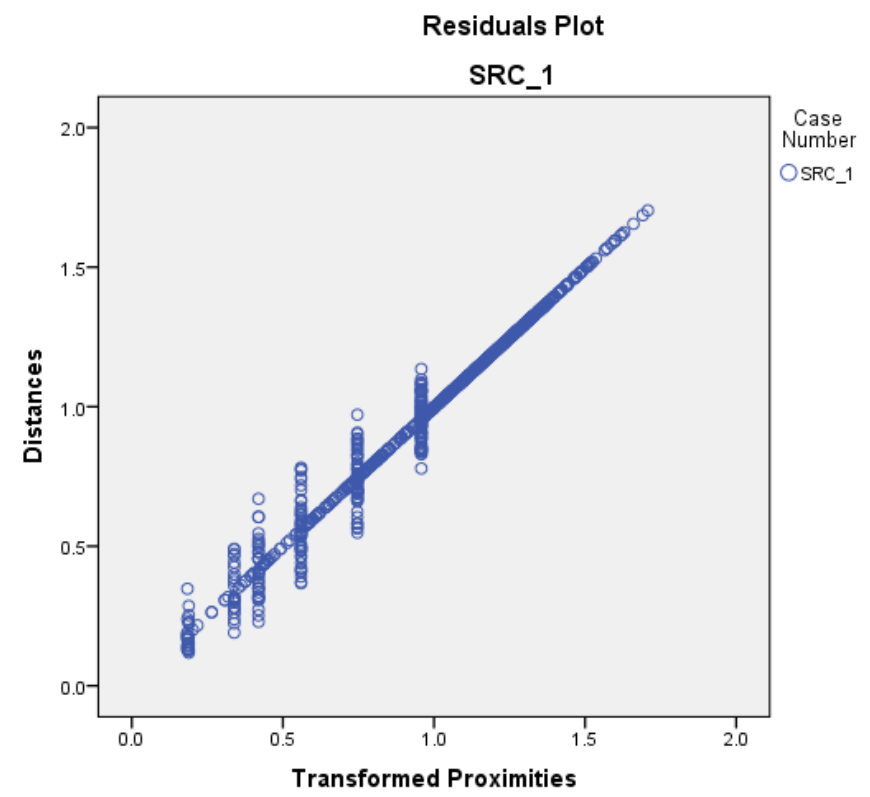


A1.2 Goodness of Fit of the data for analysis in the MDS Free Card Sort, the Art Novice Group, a 45-degree angle indicates the linearity of the data and visually supports the Goodness of Fit.

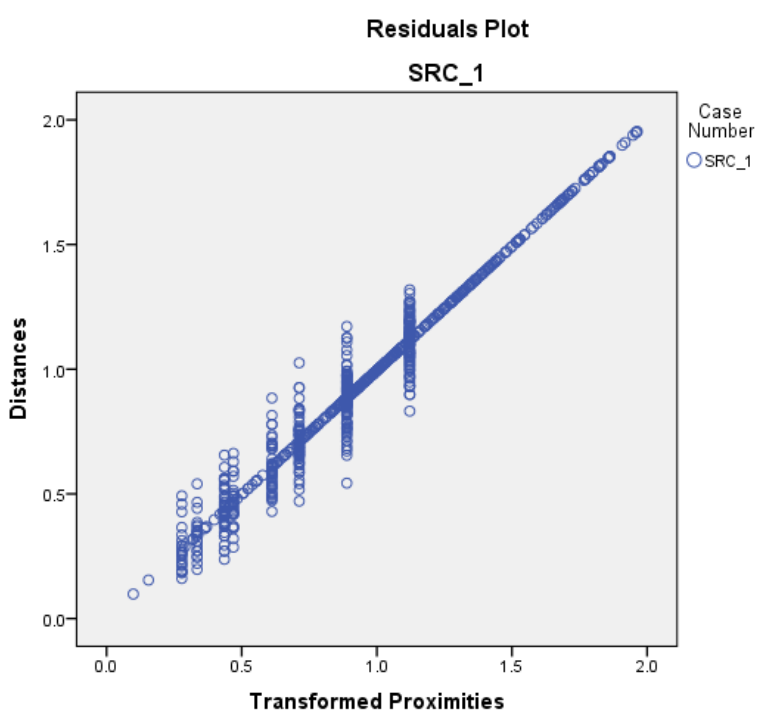

A1.3 Goodness of Fit of the data for analysis in the MDS Free Card Sort, the Combined Groups: Art Experts \& Art Novice Group, a 45-degree angle indicates the linearity of the data and visually supports the Goodness of Fit.

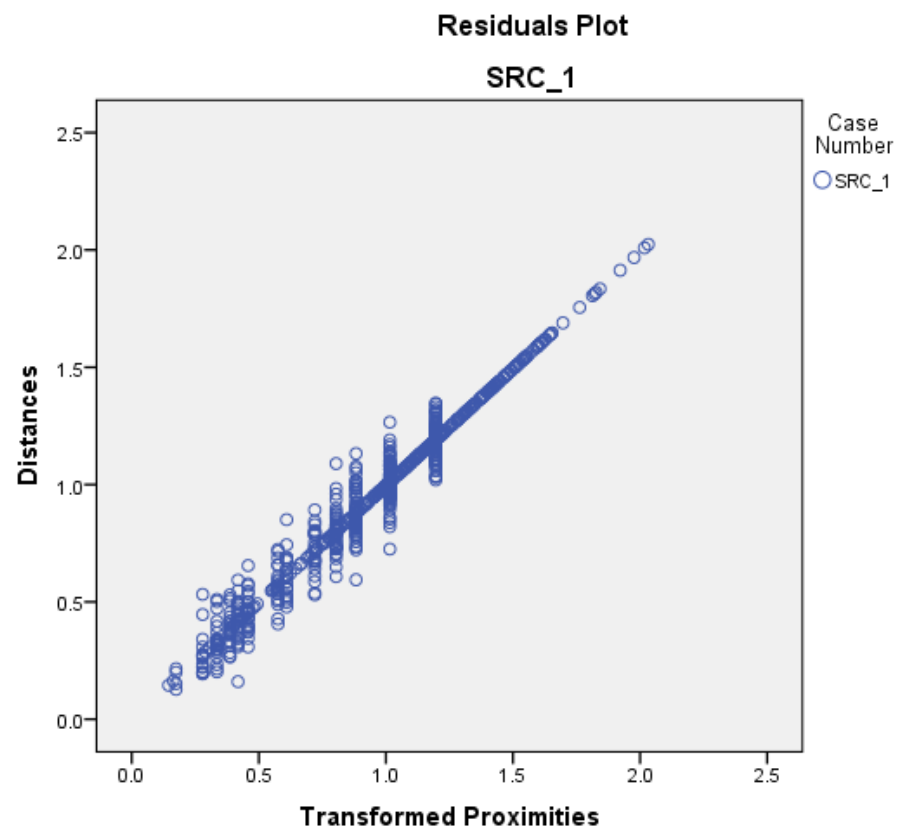




\section{Appendix F}

\section{MDS Card Sort One Results \& Dimensions}

\begin{tabular}{|c|c|c|c|c|}
\hline \multicolumn{5}{|c|}{ B1.1 Dimension One for MDS Free Card Sort with Image \& Artists' Names } \\
\hline Dimension 1 & Image No. & Image Title, Date & Artist's Name & Bridgeman ID \\
\hline .697 & 40 & The Artist in Society, 1922 & Max Beckmann & $\mathrm{CH} 990542$ \\
\hline .631 & 25 & $\begin{array}{l}\text { Man Lying Face Down, back } \\
\text { view, } 1910\end{array}$ & Egon Schiele & JKL66605 \\
\hline .620 & 39 & Untitled, 1967 & Al Held & CH986911 \\
\hline .617 & 18 & Untitled, 1944 & Arshile Gorky & $\mathrm{CH} 990726$ \\
\hline .613 & 17 & Abstract Composition, 1916 & Wassily Kandinsky & MAM713834 \\
\hline .584 & 36 & $\begin{array}{l}\text { Apparatus from the consulting } \\
\text { room of Dr. Ph., } 1922\end{array}$ & Paul Klee & NUL1 17816 \\
\hline .581 & 1 & Untitled, 1985 & Frank Günzel & STM620885 \\
\hline .576 & 16 & Death Throes, 1896 & Edvard Munch & CH659495 \\
\hline .553 & 5 & Belly, 1976 & Venturino Venturi & SBL868214 \\
\hline .542 & 32 & Fox, 1912 & Georges Braque & PHL740458 \\
\hline .524 & 30 & Studies of sculptures & Alberto Giacometti & AAG860865 \\
\hline .458 & 22 & $\begin{array}{l}\text { The Two Girls and the } \\
\text { Skeleton }\end{array}$ & Edvard Munch & CH659479 \\
\hline .422 & 21 & $\begin{array}{l}\text { Work No. } 517 \text { (triptych), } \\
2006\end{array}$ & Martin Creed & CH497515 \\
\hline .358 & 8 & $\begin{array}{l}\text { Illustration from Miserable } \\
\text { Miracle, } 1956\end{array}$ & Henri Michaux & LSR383118 \\
\hline .352 & 6 & The Pont des Arts, 1924 & Paul Signac & XIR243742 \\
\hline .283 & 35 & $\begin{array}{l}\text { Kneider weiblicher halbakt, } \\
1917\end{array}$ & Egon Schiele & CH398597 \\
\hline .184 & 28 & $\begin{array}{l}\text { Christchurch, Spitalfields, } \\
\text { No.2, } 1990\end{array}$ & Leon Kossoff & XYC162474 \\
\hline .170 & 7 & The Lezardrieux Bridge, 1922 & Paul Signac & $\mathrm{CH} 401798$ \\
\hline .141 & 27 & After the Bath, 1924 & Pierre Bonnard & SD873784 \\
\hline-.102 & 31 & $\begin{array}{l}\text { Head of an apostle, study for } \\
\text { the fresco, 1520-25 }\end{array}$ & Andrea del Sarto & AII80160 \\
\hline-.161 & 26 & Garden of Flowers, 1888 & Vincent van Gogh & $\mathrm{CH} 99237$ \\
\hline-.181 & 15 & The Olive Trees & Vincent van Gogh & XIR56652 \\
\hline-.266 & 23 & $\begin{array}{l}\text { Boy reading, from the The } \\
\text { Vallardi Album }\end{array}$ & Antonio Pisanello & XIR242720 \\
\hline
\end{tabular}




\begin{tabular}{|c|c|c|c|c|}
\hline-.326 & 10 & Study of a male head & Andrea del Sarto & AII80158 \\
\hline-.339 & 19 & Study of an Angel & Sandro Botticelli, & BEN44325 \\
\hline-.342 & 2 & $\begin{array}{l}\text { Maurice Appert Seated, 1886- } \\
88\end{array}$ & $\begin{array}{l}\text { Georges Pierre } \\
\text { Seurat }\end{array}$ & LEF221009 \\
\hline-.342 & 9 & Cradle & Vincent van Gogh & XTD68232 \\
\hline-.401 & 37 & Man with a Pick, 1883 & $\begin{array}{l}\text { Georges Pierre } \\
\text { Seurat }\end{array}$ & LEF221005 \\
\hline-.407 & 11 & Study of a Woman Weeping & $\begin{array}{l}\text { Jean Baptiste } \\
\text { Carpeaux }\end{array}$ & AGN95361 \\
\hline-.413 & 3 & $\begin{array}{l}\text { Portrait Study of a Young } \\
\text { Man }\end{array}$ & Sir William Allan & FAS201497 \\
\hline-.432 & 14 & Portrait of Euterpe Ionides & $\begin{array}{l}\text { Joseph Benwell } \\
\text { Clark }\end{array}$ & BAL25928 \\
\hline-.438 & 4 & Portrait of Mantegna & Aubrey Beardsley & KDC397351 \\
\hline-.503 & 29 & Young Monk Reading & Raphael & CND202006 \\
\hline-.526 & 34 & Henri of Orleans & $\begin{array}{l}\text { Emile Jean Horace } \\
\text { Vernet }\end{array}$ & CND248192 \\
\hline-.549 & 12 & Soren Aabye Kierkegaard & $\begin{array}{l}\text { Johan Vilhelm } \\
\text { Gertner }\end{array}$ & XIR267137 \\
\hline-.590 & 24 & Study for Laus Veneria, 1875 & $\begin{array}{l}\text { Sir Edward Coley } \\
\text { Burne Jones }\end{array}$ & MAA388942 \\
\hline-.618 & 20 & $\begin{array}{l}\text { Jossine de Pisseleu, dame } \\
\text { Lenoncourt, } 1535\end{array}$ & Clouet & CND233182 \\
\hline-.651 & 33 & $\begin{array}{l}\text { Portrait of Humphrey of } \\
\text { England }\end{array}$ & Flemish School & XIR166075 \\
\hline-.654 & 38 & Nymphs and satyrs, 1510 & Luca Signorelli & MEB857641 \\
\hline-.666 & 13 & Study of Michaelangelo & Frederic Leighton & LGH2506 \\
\hline
\end{tabular}

\begin{tabular}{|l|l|l|l|l|}
\hline \multicolumn{3}{|c|}{ B1.2 Dimension Two for MDS Free Card Sort with Image \& Artists' Names } \\
\hline Dimension 2 & $\begin{array}{l}\text { Image } \\
\text { No. }\end{array}$ & Image Title, Date & Artist's Name & Bridgeman ID \\
\hline .692 & 21 & $\begin{array}{l}\text { Work No. 517 (triptych), } \\
2006\end{array}$ & Martin Creed & CH497515 \\
\hline .482 & 36 & $\begin{array}{l}\text { Apparatus from the consulting } \\
\text { room of Dr. Ph.,1922 }\end{array}$ & Paul Klee & NUL117816 \\
\hline .449 & 24 & Study for Laus Veneria,1875 & $\begin{array}{l}\text { Sir Edward Coley } \\
\text { Burne Jones }\end{array}$ & MAA388942 \\
\hline .432 & 34 & Henri of Orleans & $\begin{array}{l}\text { Emile Jean Horace } \\
\text { Vernet }\end{array}$ & CND248192 \\
\hline 429 & 14 & Portrait of Euterpe Ionides & $\begin{array}{l}\text { Joseph Benwell } \\
\text { Clark }\end{array}$ & BAL25928 \\
\hline
\end{tabular}




\begin{tabular}{|c|c|c|c|c|}
\hline .404 & 32 & Fox, 1912 & Georges Braque & PHL740458 \\
\hline .340 & 10 & Study of a male head & Frank Günzel & AII 80158 \\
\hline .338 & 39 & Untitled, 1967 & Al Held & $\mathrm{CH} 986911$ \\
\hline .318 & 3 & $\begin{array}{l}\text { Portrait Study of a Young } \\
\text { Man }\end{array}$ & Sir William Allan & FAS201497 \\
\hline .288 & 12 & Soren Aabye Kierkegaard & $\begin{array}{l}\text { Johan Vilhelm } \\
\text { Gertner }\end{array}$ & XIR267137v \\
\hline .285 & 29 & Young Monk Reading & Raphael & CND202006 \\
\hline .284 & 38 & Nymphs and satyrs, 1510 & Luca Signorelli & MEB857641 \\
\hline .263 & 5 & Belly, 1976 & Venturino Venturi & SBL868214 \\
\hline .249 & 40 & The Artist in Society, 1922 & Max Beckmann & $\mathrm{CH} 990542$ \\
\hline .195 & 31 & $\begin{array}{l}\text { Head of an apostle, study for } \\
\text { the fresco, } 1520-25\end{array}$ & Andrea del Sarto & AII80160 \\
\hline .133 & 17 & Abstract Composition, 1916 & Wassily Kandinsky & MAM713834 \\
\hline .110 & 28 & $\begin{array}{l}\text { Christchurch, Spitalfields, } \\
\text { No.2, } 1990\end{array}$ & Leon Kossoff & XYC162474 \\
\hline .092 & 8 & $\begin{array}{l}\text { Illustration from Miserable } \\
\text { Miracle, } 1956\end{array}$ & Henri Michaux & LSR383118 \\
\hline .059 & 13 & Study of Michaelangelo & Frederic Leighton & LGH2506 \\
\hline .030 & 23 & $\begin{array}{l}\text { Boy reading, from the The } \\
\text { Vallardi Album }\end{array}$ & Antonio Pisanello & XIR242720 \\
\hline .028 & 30 & Studies of sculptures & Alberto Giacometti & AAG86086 \\
\hline .008 & 33 & $\begin{array}{l}\text { Portrait of Humphrey of } \\
\text { England }\end{array}$ & Flemish School & XIR166075 \\
\hline-.027 & 1 & Untitled, 1985 & Frank Günzel & STM620885 \\
\hline-.060 & 27 & After the Bath, 1924 & Pierre Bonnard & SD873784 \\
\hline-.065 & 4 & Portrait of Mantegna & Aubrey Beardsley & KDC397351 \\
\hline-.106 & 20 & $\begin{array}{l}\text { Jossine de Pisseleu, dame } \\
\text { Lenoncourt, } 1535\end{array}$ & Clouet & CND233182 \\
\hline-.137 & 25 & $\begin{array}{l}\text { Man Lying Face Down, back } \\
\text { view, } 1910\end{array}$ & Egon Schiele & JKL66605 \\
\hline-.140 & 19 & Study of an Angel & Sandro Botticelli & BEN44325 \\
\hline-.140 & 35 & $\begin{array}{l}\text { Kneider weiblicher halbakt, } \\
1917\end{array}$ & Egon Schiele & CH398597 \\
\hline-.146 & 18 & Untitled, 1944 & Arshile Gorky & $\mathrm{CH} 990726$ \\
\hline-.238 & 37 & Man with a Pick, 1883 & $\begin{array}{l}\text { Georges Pierre } \\
\text { Seurat }\end{array}$ & LEF221005 \\
\hline-.240 & 22 & $\begin{array}{l}\text { The Two Girls and the } \\
\text { Skeleton }\end{array}$ & Edvard Munch & CH659479 \\
\hline
\end{tabular}




\begin{tabular}{|l|l|l|l|l|}
\hline-.332 & 2 & $\begin{array}{l}\text { Maurice Appert Seated, 1886- } \\
88\end{array}$ & $\begin{array}{l}\text { Georges Pierre } \\
\text { Seurat }\end{array}$ & LEF221009 \\
\hline-.405 & 9 & Cradle & Vincent van Gogh & XTD68232 \\
\hline-.405 & 16 & Death Throes, 1896 & Edvard Munch & CH659495 \\
\hline-.469 & 11 & Study of a Woman Weeping & $\begin{array}{l}\text { Jean Baptiste } \\
\text { Carpeaux }\end{array}$ & AGN95361 \\
\hline-.666 & 6 & The Pont des Arts, 1924 & Paul Signac & XIR243742 \\
\hline-.735 & 7 & The Lezardrieux Bridge, 1922 & Paul Signac & CH401798 \\
\hline-.768 & 15 & The Olive Trees & Vincent van Gogh & XIR56652 \\
\hline-.829 & 26 & Garden of Flowers, 1888 & Vincent van Gogh & CH99237 \\
\hline
\end{tabular}

\begin{tabular}{|l|l|l|l|l|}
\hline \multicolumn{3}{|c|}{ B1.3 Dimension Three for MDS Free Card Sort with Image \& Artists' Names } \\
\hline Dimension 3 & $\begin{array}{l}\text { Image } \\
\text { No. }\end{array}$ & Image Title, Date & Artist's Name & $\begin{array}{l}\text { Bridgeman } \\
\text { ID }\end{array}$ \\
\hline .746 & 37 & Man with a Pick, 1883 & $\begin{array}{l}\text { Georges Pierre } \\
\text { Seurat }\end{array}$ & LEF221005 \\
\hline .604 & 2 & $\begin{array}{l}\text { Maurice Appert Seated, } \\
\text { 1886-88 }\end{array}$ & $\begin{array}{l}\text { Georges Pierre } \\
\text { Seurat }\end{array}$ & LEF221009 \\
\hline .509 & 27 & After the Bath, 1924 & Pierre Bonnard & SD873784 \\
\hline .436 & 28 & $\begin{array}{l}\text { Christchurch, Spitalfields, } \\
\text { No.2, 1990 }\end{array}$ & Leon Kossoff & XYC162474 \\
\hline .388 & 11 & $\begin{array}{l}\text { Study of a Woman } \\
\text { Weeping }\end{array}$ & $\begin{array}{l}\text { Jean Baptiste } \\
\text { Carpeaux }\end{array}$ & AGN95361 \\
\hline .325 & 31 & $\begin{array}{l}\text { Head of an apostle, study } \\
\text { for the fresco, 1520-25 }\end{array}$ & $\begin{array}{l}\text { Andrea del } \\
\text { Sarto }\end{array}$ & AII80160 \\
\hline .307 & 9 & Cradle & $\begin{array}{l}\text { Vincent van } \\
\text { Gogh }\end{array}$ & XTD68232 \\
\hline .240 & 38 & Nymphs and satyrs, 1510 & Luca Signorelli & MEB857641 \\
\hline .136 & 30 & Studies of sculptures & $\begin{array}{l}\text { Alberto } \\
\text { Giacometti }\end{array}$ & AAG860865 \\
\hline .133 & 19 & Study of an Angel & Sandro Botticelli & BEN44325 \\
\hline .112 & 30 & The Artist in Society, 1922 & Max Beckmann & CH990542 \\
\hline .084 & 32 & Fox, 1912 & Georges Braque & PHL740458 \\
\hline .073 & 10 & Study of a male head & $\begin{array}{l}\text { Andrea del } \\
\text { Sarto }\end{array}$ & AII80158 \\
\hline .064 & 19 & Paul Klee & NUL117816 \\
\hline .031 & 362006 \\
\hline
\end{tabular}




\begin{tabular}{|c|c|c|c|c|}
\hline .030 & 25 & $\begin{array}{l}\text { Man Lying Face Down, } \\
\text { back view, } 1910\end{array}$ & Egon Schiele & JKL66605 \\
\hline .026 & 18 & Untitled, 1944 & Arshile Gorky & $\mathrm{CH} 990726$ \\
\hline .021 & 1 & Untitled, 1985 & Frank Günzel & STM620885 \\
\hline .018 & 5 & Belly, 1976 & $\begin{array}{l}\text { Venturino } \\
\text { Venturi }\end{array}$ & SBL868214 \\
\hline .003 & 17 & $\begin{array}{l}\text { Abstract Composition, } \\
1916\end{array}$ & $\begin{array}{l}\text { Wassily } \\
\text { Kandinsky }\end{array}$ & MAM713834 \\
\hline-.044 & 13 & Study of Michaelangelo & $\begin{array}{l}\text { Frederic } \\
\text { Leighton }\end{array}$ & LGH2506 \\
\hline-.050 & 20 & $\begin{array}{l}\text { Jossine de Pisseleu, dame } \\
\text { Lenoncourt, } 1535\end{array}$ & Clouet & CND233182 \\
\hline-.053 & 15 & The Olive Trees & $\begin{array}{l}\text { Vincent van } \\
\text { Gogh }\end{array}$ & XIR56652 \\
\hline-.059 & 21 & $\begin{array}{l}\text { Work No. } 517 \text { (triptych), } \\
2006\end{array}$ & Martin Creed & $\mathrm{CH} 497515$ \\
\hline-.100 & 8 & $\begin{array}{l}\text { Illustration from Miserable } \\
\text { Miracle, } 1956\end{array}$ & Henri Michaux & LSR383118 \\
\hline-.128 & 39 & Untitled, 1967 & $\mathrm{Al} \mathrm{Held}$ & $\mathrm{CH} 986911$ \\
\hline-.171 & 35 & $\begin{array}{l}\text { Kneider weiblicher } \\
\text { halbakt, } 1917\end{array}$ & Egon Schiele & $\mathrm{CH} 398597$ \\
\hline-.192 & 22 & $\begin{array}{l}\text { The Two Girls and the } \\
\text { Skeleton }\end{array}$ & Edvard Munch & CH659479 \\
\hline-.203 & 34 & Henri of Orleans & $\begin{array}{l}\text { Emile Jean } \\
\text { Horace Vernet }\end{array}$ & CND248192 \\
\hline-.210 & 12 & Soren Aabye Kierkegaard & $\begin{array}{l}\text { Johan Vilhelm } \\
\text { Gertner }\end{array}$ & XIR267137 \\
\hline-.250 & 3 & $\begin{array}{l}\text { Portrait Study of a Young } \\
\text { Man }\end{array}$ & $\begin{array}{l}\text { Sir William } \\
\text { Allan }\end{array}$ & FAS201497 \\
\hline-.256 & 6 & The Pont des Arts, 1924 & Edvard Munch & XIR243742 \\
\hline-.264 & 16 & Death Throes, 1896 & Edvard Munch & CH659495 \\
\hline-.273 & 4 & Portrait of Mantegna & Aubrey Beardsley & KDC397351 \\
\hline-.275 & 33 & $\begin{array}{l}\text { Portrait of Humphrey of } \\
\text { England }\end{array}$ & Flemish School & XIR166075 \\
\hline-.288 & 24 & $\begin{array}{l}\text { Study for Laus Veneria, } \\
1875\end{array}$ & $\begin{array}{l}\text { Sir Edward } \\
\text { Coley Burne } \\
\text { Jones }\end{array}$ & MAA388942 \\
\hline-.291 & 14 & Portrait of Euterpe Ionides & $\begin{array}{l}\text { Joseph Benwell } \\
\text { Clark }\end{array}$ & BAL25928 \\
\hline-.352 & 7 & $\begin{array}{l}\text { The Lezardrieux Bridge, } \\
1922\end{array}$ & Paul Signac & CH401798 \\
\hline
\end{tabular}




\begin{tabular}{|l|l|l|l|l|}
\hline-.394 & 26 & Garden of Flowers, 1888 & $\begin{array}{l}\text { Vincent van } \\
\text { Gogh }\end{array}$ & CH99237 \\
\hline-.432 & 23 & $\begin{array}{l}\text { Boy reading, from the The } \\
\text { Vallardi Album }\end{array}$ & $\begin{array}{l}\text { Antonio } \\
\text { Pisanello }\end{array}$ & XIR242720 \\
\hline
\end{tabular}

\begin{tabular}{|c|c|c|c|c|}
\hline \multicolumn{5}{|c|}{ B1.4 Dimension Four for MDS Free Card Sort with Image \& Artists' Names } \\
\hline Dimension 4 & $\begin{array}{l}\text { Image } \\
\text { No. }\end{array}$ & Image Title, Date & Artist's Name & $\begin{array}{l}\text { Bridgeman } \\
\text { ID }\end{array}$ \\
\hline .363 & 18 & Untitled, 1944 & Arshile Gorky & $\mathrm{CH} 990726$ \\
\hline .354 & 8 & $\begin{array}{l}\text { Illustration from Miserable } \\
\text { Miracle, } 1956\end{array}$ & Henri Michaux & LSR383118 \\
\hline .327 & 1 & Untitled, 1985 & Frank Günzel & STM620885 \\
\hline .324 & 30 & Studies of sculptures & $\begin{array}{l}\text { Alberto } \\
\text { Giacometti }\end{array}$ & AAG860865 \\
\hline .236 & 5 & Belly, 1976 & $\begin{array}{l}\text { Venturino } \\
\text { Venturi } \\
\end{array}$ & SBL868214 \\
\hline .211 & 17 & $\begin{array}{l}\text { Abstract Composition, } \\
1916\end{array}$ & $\begin{array}{l}\text { Wassily } \\
\text { Kandinsky }\end{array}$ & MAM713834 \\
\hline .149 & 14 & Portrait of Euterpe Ionides & $\begin{array}{l}\text { Joseph Benwell } \\
\text { Clark }\end{array}$ & BAL25928 \\
\hline .140 & 10 & Study of a male head & $\begin{array}{l}\text { Andrea del } \\
\text { Sarto }\end{array}$ & AII80158 \\
\hline .134 & 28 & $\begin{array}{l}\text { Christchurch, Spitalfields, } \\
\text { No. } 2,1990\end{array}$ & Leon Kossoff & XYC162474 \\
\hline .125 & 27 & After the Bath, 1924 & Pierre Bonnard & SD873784 \\
\hline .122 & 31 & $\begin{array}{l}\text { Head of an apostle, study } \\
\text { for the fresco, } 1520-25\end{array}$ & $\begin{array}{l}\text { Andrea del } \\
\text { Sarto }\end{array}$ & AII80160 \\
\hline .119 & 23 & $\begin{array}{l}\text { Boy reading, from the The } \\
\text { Vallardi Album }\end{array}$ & $\begin{array}{l}\text { Antonio } \\
\text { Pisanello }\end{array}$ & XIR242720 \\
\hline .105 & 6 & The Pont des Arts, 1924 & Paul Signac & XIR243742 \\
\hline .098 & 3 & $\begin{array}{l}\text { Portrait Study of a Young } \\
\text { Man }\end{array}$ & $\begin{array}{l}\text { Sir William } \\
\text { Allan }\end{array}$ & FAS201497 \\
\hline .095 & 24 & $\begin{array}{l}\text { Study for Laus Veneria, } \\
1875\end{array}$ & $\begin{array}{l}\text { Sir Edward } \\
\text { Coley Burne } \\
\text { Jones }\end{array}$ & MAA388942 \\
\hline .048 & 40 & The Artist in Society, 1922 & Max Beckmann & $\mathrm{CH} 990542$ \\
\hline .045 & 34 & Henri of Orleans & $\begin{array}{l}\text { Emile Jean } \\
\text { Horace Vernet }\end{array}$ & CND248192 \\
\hline .044 & 12 & Soren Aabye Kierkegaard & $\begin{array}{l}\text { Johan Vilhelm } \\
\text { Gertner }\end{array}$ & XIR267137 \\
\hline
\end{tabular}




\begin{tabular}{|c|c|c|c|c|}
\hline .031 & 29 & Young Monk Reading & Raphael & CND202006 \\
\hline .016 & 4 & Portrait of Mantegna & $\begin{array}{l}\text { Aubrey } \\
\text { Beardsley }\end{array}$ & KDC397351 \\
\hline .010 & 19 & Study of an Angel & Sandro Botticelli & BEN44325 \\
\hline .005 & 7 & $\begin{array}{l}\text { The Lezardrieux Bridge, } \\
1922\end{array}$ & Paul Signac & CH401798 \\
\hline-.011 & 25 & $\begin{array}{l}\text { Man Lying Face Down, } \\
\text { back view, } 1910\end{array}$ & Egon Schiele & JKL66605 \\
\hline.-027 & 26 & Garden of Flowers, 1888 & $\begin{array}{l}\text { Vincent van } \\
\text { Gogh }\end{array}$ & CH99237 \\
\hline-.029 & 33 & $\begin{array}{l}\text { Portrait of Humphrey of } \\
\text { England }\end{array}$ & Flemish School & XIR166075 \\
\hline-.044 & 15 & The Olive Trees & $\begin{array}{l}\text { Vincent van } \\
\text { Gogh }\end{array}$ & XIR56652 \\
\hline-.048 & 13 & Study of Michaelangelo & $\begin{array}{l}\text { Frederic } \\
\text { Leighton }\end{array}$ & LGH2506 \\
\hline-.078 & 36 & $\begin{array}{l}\text { Apparatus from the } \\
\text { consulting room of Dr. } \\
\text { Ph., } 1922\end{array}$ & Paul Klee & NUL1 17816 \\
\hline-.087 & 20 & $\begin{array}{l}\text { Jossine de Pisseleu, dame } \\
\text { Lenoncourt, } 1535\end{array}$ & Clouet & CND233182 \\
\hline-.089 & 38 & Nymphs and satyrs, 1510 & Luca Signorelli & MEB857641 \\
\hline-.105 & 22 & $\begin{array}{l}\text { The Two Girls and the } \\
\text { Skeleton }\end{array}$ & Edvard Munch & $\mathrm{CH} 659479$ \\
\hline-.124 & 2 & $\begin{array}{l}\text { Maurice Appert Seated, } \\
1886-88\end{array}$ & $\begin{array}{l}\text { Georges Pierre } \\
\text { Seurat }\end{array}$ & LEF221009 \\
\hline-.130 & 11 & $\begin{array}{l}\text { Study of a Woman } \\
\text { Weeping }\end{array}$ & $\begin{array}{l}\text { Jean Baptiste } \\
\text { Carpeaux }\end{array}$ & AGN95361 \\
\hline-.134 & 32 & Fox, 1912 & Georges Braque & PHL740458 \\
\hline-.146 & 37 & Man with a Pick, 1883 & $\begin{array}{l}\text { Georges Pierre } \\
\text { Seurat }\end{array}$ & LEF221005 \\
\hline-.158 & 9 & Cradle & $\begin{array}{l}\text { Vincent van } \\
\text { Gogh }\end{array}$ & XTD68232 \\
\hline-.236 & 16 & Death Throes, 1896 & Edvard Munch & CH659495 \\
\hline-.337 & 35 & $\begin{array}{l}\text { Kneider weiblicher halbakt, } \\
1917\end{array}$ & Egon Schiele & $\mathrm{CH} 398597$ \\
\hline-394 & 21 & $\begin{array}{l}\text { Work No. } 517 \text { (triptych), } \\
2006\end{array}$ & Martin Creed & CH497515 \\
\hline-.922 & 39 & Untitled, 1967 & Al Held & CH986911 \\
\hline
\end{tabular}




\section{Appendix G}

\section{Image Usage Logistic Regressions}

\begin{tabular}{|c|c|}
\hline \multicolumn{2}{|c|}{ List of Works Used in Both Multinomial and Bivariate Logistic Regression } \\
\hline \multicolumn{2}{|c|}{ Egon Schiele Drawings } \\
\hline Image Title, Date & Bridgeman ID \\
\hline Portrait of Man, 1907 & CH653354 \\
\hline Reclining Woman, 1918 & CH1768467 \\
\hline Female Nude, 1911 & $\mathrm{CH} 1768306$ \\
\hline Female Nude, 1911 & $\mathrm{CH} 1768307$ \\
\hline Nude Girl, 1912 & $\mathrm{CH} 826143$ \\
\hline Seated Nude with Shoes and Stockings, 1918 & $\mathrm{CH} 826186$ \\
\hline Kneeling Nude from the front, 1914 & $\mathrm{CH} 652633$ \\
\hline Seated Girl with a Bow in her Hair, 1909 & $\mathrm{CH} 988714$ \\
\hline $\begin{array}{l}\text { Young Man Reclining with his Head Resting on His } \\
\text { Crossed Leg }\end{array}$ & $\mathrm{CH} 652733$ \\
\hline Young woman with hat, 1909 & CH1126872 \\
\hline Female nude, 1918 & CH1121486 \\
\hline Running woman & $\mathrm{CH} 995690$ \\
\hline Erich Lederer in profile, hand to head & CH1126869 \\
\hline Hand study, Dr. Viktor Ritter von Bauer, 1917 & CH1123562 \\
\hline August Lederer, 1918 & CH1123559 \\
\hline Serena Lederer, 1917 & CH1126866 \\
\hline Portrait of August Lederer, 1918 & CH1126873 \\
\hline Kneeling female nude, 1917 & $\mathrm{CH} 992649$ \\
\hline Standing nude, 1918 & $\mathrm{CH} 993712$ \\
\hline Prostrate female nude, 1913 & $\mathrm{CH} 995693$ \\
\hline Mother and child, 1917 & CH1121479 \\
\hline $\begin{array}{l}\text { A Portrait of the Artist's Father-in-Law, Johann Harms, } \\
1915\end{array}$ & JKL104849 \\
\hline Reclining nude, 1918 & CH1126877 \\
\hline Boy Lying on His Stomach, 1918 & CH1196585 \\
\hline
\end{tabular}




\begin{tabular}{|l|l|}
\hline \multicolumn{2}{|c|}{ List of Works Used in Both Multinomial and Bivariate Logistic Regressions } \\
\hline \multicolumn{2}{|c|}{ Egon Schiele Drawings (continued) } \\
\hline Image Title, Date & Bridgeman ID \\
\hline $\begin{array}{l}\text { Female nude kneeling and bending forward to the left, } \\
1918\end{array}$ & CH993649 \\
\hline Portrait of a Girl, 1917 & ONT996116 \\
\hline Portrait of Arthur Roessler, 1910 & CH995698 \\
\hline Reclining female nude, 1914 & CH1121476 \\
\hline Hands, studies for a portrait of Dr. Hugo Koller, no date & CH1121483 \\
\hline listed & CH995700 \\
\hline Nude Girl, 1912 & DMA1070872 \\
\hline Portrait of Guido Arnot, 1918 & CH992650 \\
\hline Seated female nude with hand on chin, 1914 & CH993709 \\
\hline Seated female nude with open blouse, 1913 & CH993710 \\
\hline Female nude bent forward, both hands on the left thigh, \\
1913 & CH1196255 \\
\hline Reclining Nude, 1914 & CH1196045 \\
\hline Seated Child, 1916 & CH988447 \\
\hline & CH987516 \\
\hline Potato Gatherer, 1885 & CH825461 \\
\hline Head of a Peasant Woman, Facing Right, 1884 & CH825563 \\
\hline Sitting Man with Little Girl, 1882 & XTD68232 \\
\hline Working the Fields at Arles, 1888 & CH259617 \\
\hline Cradle, no date given & CH376683 \\
\hline The Artist's House in Arles, no date given & XTD68234 \\
\hline The Flower Garden, 1888 & HGM81104 \\
\hline Peasant Woman Gleaming, 1885 & XIR56652 \\
\hline The street cleaner, no date given & HGM81105 \\
\hline The Olive Trees, no date given & JKL66607 \\
\hline The Bakery in de Geest, 1882 & NUL115930 \\
\hline Man with a Spade Resting, 1882 & CH27364 \\
\hline The Corner of the Park, 1888 & \\
\hline In the Orchard, 1883 & \\
\hline The Young Blacksmith, 1882 & \\
\hline
\end{tabular}




\begin{tabular}{|l|l|}
\hline \multicolumn{2}{|c|}{ List of Works Used in Both Multinomial and Bivariate Logistic Regressions } \\
\hline \multicolumn{2}{|c|}{ Vincent van Gogh Drawings (continued) } \\
\hline Café Terrace at Night, 1888 & DMA1069554 \\
\hline Fishing Boats at Saintes-Maries-de-la-Mer, 1888 & STM620338 \\
\hline Figure on a Road, 1884 & CH100807 \\
\hline Cypresses, 1889 & TBM157669 \\
\hline Rocky Ground at Montmajour, 1888 & LEF221094 \\
\hline Haystacks, 1888 & PHL434430 \\
\hline Six Pines Near the Enclosure Wall, 1899 & CH1195952 \\
\hline & CH 1767882 \\
\hline The Promenade, 1882 & XOS1766137 \\
\hline Madame Seurat, the Artist's Mother, 1882 Drawings \\
\hline The Painter and His Palette, 1881 & CH1767884 \\
\hline Haymaker or Stone Breaker, 1883 & CH1767883 \\
\hline Une Couseuse, 1881 & WHT430649 \\
\hline The Lighthouse at Honfleur & XOS1127604 \\
\hline Echo, Study for the Bathers at Asnieres, 1883 & XOS954830 \\
\hline Walking, 1882 & CH376578 \\
\hline A Woman Fishing, 1884 & XOS1127594 \\
\hline Carriage and Dog, 1882 & XMV2962740 \\
\hline The Walker with a Muff, 1884 & CH376579 \\
\hline Maurice Appert Seated, 1886 & LEF221009 \\
\hline Study for Sunday Afternoon on the Island of La Grande & XIR326117 \\
\hline ette, 1884 & XOS1766138 \\
\hline An Indian Man, 1878 & XOS1766125 \\
\hline Poplars, 1883 & XCF274351 \\
\hline Study for Sunday Afternoon on the Island of La Grande \\
Jette, 1884 & UEA419956 \\
\hline Woman on a Bench, 1880 & LEF221005 \\
\hline Man with a Pick, 1883 & XOS1766136 \\
\hline Une Elegante, Woman strolling, 1884 & INC2968553 \\
\hline Seated Woman with a Parasol, 1884 & \\
\hline
\end{tabular}

